\title{
CALCULATIONS WITH SPECTROSCOPIC ACCURACY: ENERGIES AND TRANSITION RATES IN THE NITROGEN ISOELECTRONIC SEQUENCE FROM Ar XII TO Zn XXIV
}

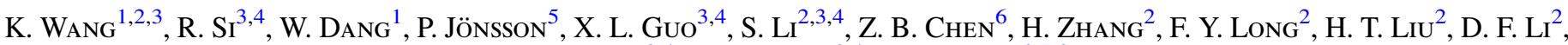 \\ R. Hutton ${ }^{3,4}$, C. Y. Chen ${ }^{3,4}$, AND J. YAN ${ }^{2,7,8}$ \\ ${ }^{1}$ Hebei Key Lab of Optic-electronic Information and Materials, The College of Physics Science and Technology, Hebei University, Baoding 071002, China \\ ${ }^{2}$ Institute of Applied Physics and Computational Mathematics, Beijing 100088, China; yan_jun@iapcm.ac.cn \\ ${ }^{3}$ Applied Ion Beam Physics Laboratory, Fudan University, Key Laboratory of the Ministry of Education, China; chychen@fudan.edu.cn \\ ${ }^{4}$ Shanghai EBIT Lab, Institute of Modern Physics, Department of Nuclear Science and Technology, Fudan University, Shanghai 200433, China \\ ${ }^{5}$ Group for Materials Science and Applied Mathematics, Malmö University, SE-20506, Malmö, Sweden \\ ${ }^{6}$ College of Science, National University of Defense Technology, Changsha 410073, China \\ ${ }^{7}$ Center for Applied Physics and Technology, Peking University, Beijing 100871, China \\ ${ }^{8}$ Collaborative Innovation Center of IFSA (CICIFSA), Shanghai Jiao Tong University, Shanghai 200240, China \\ Received 2015 November 3; accepted 2016 January 15; published 2016 March 9
}

\begin{abstract}
Combined relativistic configuration interaction and many-body perturbation calculations are performed for the 359 fine-structure levels of the $2 s^{2} 2 p^{3}, 2 s 2 p^{4}, 2 p^{5}, 2 s^{2} 2 p^{2} 31,2 s 2 p^{3} 31,2 p^{4} 31$, and $2 s^{2} 2 p^{2} 4 l$ configurations in N-like ions from Ar XII to Zn XXIV. Complete and consistent data sets of energies, wavelengths, radiative rates, oscillator strengths, and line strengths for all possible electric dipole, magnetic dipole, electric quadrupole, and magnetic quadrupole transitions among the 359 levels are given for each ion. The present work significantly increases the amount of accurate data for ions in the nitrogen-like sequence, and the accuracy of the energy levels is high enough to enable the identification and interpretation of observed spectra involving the $n=3$, 4 levels, for which experimental values are largely scarce. Meanwhile, the results should be of great help for modeling and diagnosing astrophysical and fusion plasmas.
\end{abstract}

Key words: atomic data - atomic processes

Supporting material: machine-readable tables

\section{INTRODUCTION}

Spectra from L-shell ions, in a wide wavelength range from the X-ray to the ultraviolet, have been obtained from the solar atmosphere, stars, and other astronomical objects by many astrophysical missions, such as the Solar and Heliospheric Observatory, Hinode, Chandra, and the Solar Dynamics Observatory (Brinkman et al. 2000; Landi et al. 2002; Raassen et al. 2002; Curdt et al. 2004; Ishibashi et al. 2006; Brown et al. 2008; Del Zanna 2008, 2012; Warren et al. 2008; Del Zanna \& Andretta 2011; Del Zanna \& Woods 2013; Beiersdorfer et al. 2014; Träbert et al. 2014a, 2014b). Analysis of the observed spectra provides information on the structure, chemical abundances, evolution, and physical conditions of the astrophysical objects. Such an analysis requires a wide range of atomic parameters, such as energy levels and radiative transition properties (Kallman \& Palmeri 2007; Massacrier \& Artru 2012; Del Zanna \& Woods 2013; Beiersdorfer et al. 2014; Nave et al. 2015). In view of this, we have already reported the systematic and highly accurate calculations for the beryllium and carbon isoelectronic sequences (Wang et al. 2014, 2015). This work presents our studies on the nitrogen isoelectronic sequence from Ar XII to Zn XXIV. Numerous lines of the above N-like ions have been observed in astrophysical plasmas, as well as in laboratory plasmas (Feldman et al. 1980, 1997, 2000, 2004; McKenzie et al. 1980b; Doschek et al. 1981; Eidelsberg et al. 1981; Phillips et al. 1982, 1983; Doschek \& Cowan 1984; Lawson \& Peacock 1984; Acton et al. 1985; Seely et al. 1986; Doyle 1987; Fawcett et al. 1987; Lippmann et al. 1987; Brosius et al. 1998; Behar et al. 2001; Curdt et al. 2001, 2004; Mewe et al. 2001; Brown et al. 2002; Kaastra et al. 2002; Ko et al. 2002; Lepson et al. 2003; Mohan et al. 2003; Ness et al. 2003; Landi \& Phillips 2005, 2006; Parenti et al. 2005; Chen et al. 2007; Del Zanna 2008, 2012; Gu et al. 2007; Shestov et al. 2008; Beiersdorfer et al. 2014; Träbert et al. 2014a, 2014b).

Many theoretical efforts have been devoted to studying energy levels and transition characteristics in $\mathrm{N}$-like ions. Most of the systematic calculations, such as Godefroid \& Fischer (1984), Becker et al. (1989), Merkelis et al. (1997, 1999), Gu (2005a), and Rynkun et al. (2014), were limited to a few transitions among the 15 fine-structure levels of the $\left(1 s^{2}\right) 2 s^{2} 2 p^{3}, \quad 2 s 2 p^{4}$, and $2 p^{5}$ configurations (the $n=2$ complex).

To our knowledge, there were no systematic calculations beyond the $n=2$ states along the isoelectronic sequence, except for one calculation preformed by Tachiev \& Froese Fischer (2002). Using the multi-configuration Hartree-Fock method with relativistic corrections in the Breit-Pauli approximation (MCHF-BP), they computed energies and transition data for the levels up to $2 s^{2} 2 p^{2} 3 d$ in N-like ions with $Z=7-17$. However, a few calculations have been carried out for selected individual ions. Bhatia et al. (1989), Eissner et al. (2005), and Landi \& Bhatia (2005) reported both the $n=2$ and $n=3$ results of Ar XII, Ca XIV, Ti XVI, Fe xx, Zn xxIv, and $\mathrm{Kr}$ xxx using the SUPERSTRUCTURE (SS) code (Eissner et al. 1974). The energy levels and radiative decay rates for the transitions involving the $n \geqslant 3$ levels in Fexx were calculated using various methods. The calculations include the BreitPauli R-matrix (BPRM) calculations and the configuration interaction calculations using the SS code by Nahar (2004), the multiconfiguration Dirac-Hartree-Fock (MCDHF) calculations by Jonauskas et al. (2005), and the results of Witthoeft et al. (2007) using the AUTOSTRUCTURE (AS) code (Badnell 1986). 
Dong et al. (2012) employed the MCDHF method in the GRASP package (Dyall et al. 1989) to calculate level energies and radiative rates among the transitions for the 272 levels of the $n=2,3$ levels in Ca XIV. Energy levels and radiative data for the transitions up to the $n=10$ levels in ScXV were provided by Massacrier \& Artru (2012) using the FAC code (Gu 2003, 2008). A combined relativistic configuration interaction (RCI) and many-body perturbation theory (MBPT) approach was used by $\mathrm{Gu}$ (2005b) to obtain the level energies for the $2 l^{5}$ and $2 l^{4} 3 l^{\prime}$ configurations in Fe XX and Ni XXII with high accuracy.

Among the above calculations for $\mathrm{N}$-like ions, the results for the $n=2$ states reported by Rynkun et al. (2014) and Gu (2005a), and the data for the $n=2,3$ levels obtained by $\mathrm{Gu}$ (2005b) in Fe Xx and Ni XXII are the most accurate so far. In contrast with the accurate values (Gu 2005a, 2005b; Rynkun et al. 2014), all the other mentioned calculations involving the $n \geqslant 3$ complexes for highly charged N-like ions from Ar XII to $\mathrm{Zn}$ XXIV are quite inaccurate due to the limited configuration interaction effects included in their works. For instance, the energies of the SS calculations (Bhatia et al. 1989; Eissner et al. 2005; Landi \& Bhatia 2005) for five ions from Ar XII to Zn XXIV deviate from the corresponding observations by up to $5 \%$, which may be outdated for line identification and plasma diagnostics. In terms of theoretical works, Fe xx is currently the most studied ion in the nitrogen isoelectronic sequence so far. The deviations from the observed energies are up to $3.4 \%$ for the BPRM calculations (Nahar 2004), 2.2\% for the MCDHF values (Jonauskas et al. 2005), and $4.3 \%$ for the AS results (Witthoeft et al. 2007), which are far from spectroscopic accuracy. Therefore, high-quality systematic calculations involving states beyond the $n=2$ configurations are greatly desired, because of their importance in modeling and diagnosing of astrophysical plasmas (Phillips et al. 1982; Acton et al. 1985; Del Zanna 2008; Beiersdorfer et al. 2014) and laboratory plasmas (Fawcett \& Hayes 1975). Databases such as CHIANTI (Dere et al. 1997; Landi et al. 2013) also demand complete and consistent data sets of high accuracy, with the aim of offering the astrophysical community tools and data to carry out accurate plasma diagnostics.

Recently, Radžiūtè et al. (2015) reported calculated energies and radiative transition properties for the 272 states of the $2 s^{2} 2 p^{3}, 2 s 2 p^{4}, 2 p^{5}, 2 s^{2} 2 p^{2} 3 l, 2 s 2 p^{3} 3 l$, and $2 p^{4} 3 l(l=0,1,2)$ configurations in N-like ions CrXVIII, Fexx, NixxII, and Zn XxIV, using the MCDHF and RCI method implemented in the GRASP2K code (Jönsson et al. 2007, 2013). Comparing with the calculations of Rynkun et al. (2014), who used the same method but only reported the results for the $n=2$ complex, Radžiūtė et al. (2015) adopted much larger configuration state function expansions and considered the electron correlation effects elaborately for both the $n=2$ and $n=3$ levels. Therefore, high accuracy was achieved in their calculations, which was in general at the same level as the accuracy of the calculations performed by Rynkun et al. (2014) and $\mathrm{Gu}$ (2005a, 2005b), and the data can be used to identify observed spectral lines.

In the present work, we report energy levels and transition properties for all possible electric dipole (E1), magnetic dipole (M1), electric quadrupole (E2), and magnetic quadrupole (M2) transitions among the 359 levels of the $2 s^{2} 2 p^{3}, 2 s 2 p^{4}, 2 p^{5}$, $2 s^{2} 2 p^{2} 3 l, 2 s 2 p^{3} 3 l, 2 p^{4} 3 l$, and $2 s^{2} 2 p^{2} 4 l$ configurations in the $\mathrm{N}$-like ions with $18 \leqslant Z \leqslant 30$, in an effort to offer complete and consistent data sets of high accuracy. A combined RCI and MBPT approach implemented in the FAC code (Gu 2003, 2005a, 2005b; Gu et al. 2006) is used, in which both dynamic and nondynamic electron correlation effects can be well accounted for. For the purpose of assessing the present MBPT results, extensive MCDHF and RCI calculations (hereafter referred to as $\mathrm{MCDHF} / \mathrm{RCI}$ ) for $\mathrm{Fe} \mathrm{xx}$ have been carried out using the latest version of the GRASP2K code (Jönsson et al. 2013). Comparisons are made between the present MCDHF/RCI and MBPT results, as well as with available observed data and theoretical values. The MBPT calculated energies agree well with the observed values from the Atomic Spectra Database (ASD) of the National Institute of Standards and Technology (NIST; Kramida et al. 2014), i.e., there is a difference within $0.2 \%$ for all levels. The present calculations are generally more accurate than existing systematic calculations, and stand for a significant extension of the MBPT work reported by $\mathrm{Gu}$ (2005b) and the MCDHF/RCI results performed by Radžiūtè et al. (2015) to include data for the other nine ions in the range of Ar XII to $\mathrm{Zn}$ XXIV. We hope that the present data will be of great help in analyzing older experiments and planning new ones. Meanwhile, complete data sets will be useful for the identification of observed spectra, as well as for modeling and diagnosing astrophysical and fusion plasmas.

\section{CALCULATIONS AND RESULTS}

A combined RCI and MBPT approach (Lindgren 1974; Safronova et al. 1996; Vilkas et al. 1999) was implemented within the FAC code by $\mathrm{Gu}$ (2005a, 2005b). In the present work, we employ the improved implementation by $\mathrm{Gu}$ et al. (2006), in which the Hamiltonian is taken to be the no-pair Dirac-Coulomb-Breit Hamiltonian $H_{\mathrm{DCB}}$. The key feature of the RCI and MBPT approach is the partitioning of the Hilbert space of the system into two subspaces, i.e., a model space $M$ and an orthogonal space $N$. The true eigenvalues of $H_{\mathrm{DCB}}$ can be obtained through solving the eigenvalue problem of a nonHermitian effective Hamiltonian in the model space $M$. The first-order perturbation expansion of the effective Hamiltonian within the Rayleigh-Schrödinger scheme consists of two parts: one is the exact $H_{\mathrm{DCB}}$ matrix in the model space $M$, and the other includes perturbations from the configurations in the $N$ space up to the second order for the level energies of interest. In the present calculations, the model space $M$ contains all of the configurations $2 l^{4} n l^{\prime} \quad\left(2 \leqslant n \leqslant 3\right.$ and $\left.l^{\prime} \leqslant n-1\right)$ and $2 s^{2} 2 p^{2} 4 l^{\prime}\left(l^{\prime}=0-3\right)$. The $N$ space contains all configurations formed by single and double virtual excitations of the $M$ space. For single excitations, configurations with $n \leqslant 200$ and $l \leqslant \min (n-1,25)$ are included. For double excitations, configurations with an inner electron promotion up to $n=65$ and a promotion of the outer electron up to $n^{\prime}=200$ are considered.

We start the energy structure calculations for N-like ions using an optimized local central potential, which is derived from a Dirac-Fock-Slater self-consistent field calculation with the $(2 s, 2 p)^{5}$ configurations. We then perform the MBPT calculations to obtain level energies and radiative transition properties, such as transition wavelengths, line strengths, oscillator strengths, and radiative rates of all E1, M1, E2, and M2 transitions among the states in the $M$ space using the length form. In addition to the Hamiltonian $H_{\mathrm{DCB}}$, several high-order corrections, such as the finite nuclear size, nuclear recoil, 
Table 1

Level Energies (in eV) of the States in N-like Ions with $Z=18-30$, as well as Level Designations in Both the LSJ-and $j j$ Coupling Schemes, and the Dominant Mixing Coefficients of the $L S J$ Basis

\begin{tabular}{|c|c|c|c|c|c|c|c|c|}
\hline \multirow[t]{2}{*}{$Z$} & \multirow[t]{2}{*}{ Key } & \multirow[t]{2}{*}{ Conf } & \multirow[t]{2}{*}{$L S J$} & \multirow[t]{2}{*}{$j j^{\mathrm{a}, \mathrm{b}, \mathrm{c}}$} & \multirow[t]{2}{*}{$J^{\pi}$} & \multicolumn{2}{|c|}{ Energy } & \multirow{2}{*}{$\begin{array}{l}\text { Mixing coefficients } \\
\qquad L S J^{\mathrm{f}}\end{array}$} \\
\hline & & & & & & $\mathrm{NIST}^{\mathrm{d}}$ & $\mathrm{MBPT}^{\mathrm{e}}$ & \\
\hline 26 & 1 & $2 s^{2} 2 p^{3}$ & ${ }^{4} S_{3 / 2}$ & $2 p+1(3) 3$ & $3 / 2^{\circ}$ & $0.00000 \mathrm{E}+00$ & $0.00000 \mathrm{E}+00$ & $-0.94(1)$ \\
\hline 26 & 2 & $2 s^{2} 2 p^{3}$ & ${ }^{2} \mathrm{D}_{3 / 2}$ & $2 p-1(1) 12 p+2(4) 3$ & $3 / 2^{\circ}$ & $1.71867 \mathrm{E}+01$ & $1.71795 \mathrm{E}+01$ & $0.86(2)-0.42(5)$ \\
\hline 26 & 3 & $2 s^{2} 2 p^{3}$ & ${ }^{2} D_{5 / 2}$ & $2 p-1(1) 12 p+2(4) 5$ & $5 / 2^{\circ}$ & $2.18373 \mathrm{E}+01$ & $2.18329 \mathrm{E}+01$ & $1.00(3)$ \\
\hline 26 & 4 & $2 s^{2} 2 p^{3}$ & ${ }^{2} P_{1 / 2}$ & $2 p-1(1) 12 p+2(0) 1$ & $1 / 2^{o}$ & $3.22694 \mathrm{E}+01$ & $3.22817 \mathrm{E}+01$ & $0.99(4)$ \\
\hline 26 & 5 & $2 s^{2} 2 p^{3}$ & ${ }^{2} P_{3 / 2}$ & $2 p+3(3) 3$ & $3 / 2^{o}$ & $4.00890 \mathrm{E}+01$ & $4.01007 \mathrm{E}+01$ & $-0.84(5)-0.48(2)$ \\
\hline 26 & 6 & $2 s^{1} 2 p^{4}$ & ${ }^{4} P_{5 / 2}$ & $2 s+1(1) 12 p+2(4) 5$ & $5 / 2^{e}$ & $9.33266 \mathrm{E}+01$ & $9.33152 \mathrm{E}+01$ & $-0.99(6)$ \\
\hline 26 & 7 & $2 s 2 p^{4}$ & ${ }^{4} P_{3 / 2}$ & $2 s+1(1) 12 p-1(1) 02 p+3(3) 3$ & $3 / 2^{e}$ & $1.01745 \mathrm{E}+02$ & $1.01741 \mathrm{E}+02$ & $-0.99(7)$ \\
\hline 26 & 8 & $2 s 2 p^{4}$ & ${ }^{4} P_{1 / 2}$ & $2 s+1(1) 12 p+2(0) 1$ & $1 / 2^{e}$ & $1.04454 \mathrm{E}+02$ & $1.04450 \mathrm{E}+02$ & $-0.97(8)$ \\
\hline 26 & 9 & $2 s 2 p^{4}$ & ${ }^{2} D_{3 / 2}$ & $2 s+1(1) 12 p+2(4) 3$ & $3 / 2^{e}$ & $1.29262 \mathrm{E}+02$ & $1.29225 \mathrm{E}+02$ & $-0.97(9)$ \\
\hline 26 & 10 & $2 s 2 p^{4}$ & ${ }^{2} D_{5 / 2}$ & $2 s+1(1) 12 p-1(1) 22 p+3(3) 5$ & $5 / 2^{e}$ & $1.31220 \mathrm{E}+02$ & $1.31187 \mathrm{E}+02$ & $-0.98(10)$ \\
\hline 26 & 11 & $2 s 2 p^{4}$ & ${ }^{2} S_{1 / 2}$ & $2 s+1(1) 12 p+2(0) 1$ & $1 / 2^{e}$ & $1.48193 \mathrm{E}+02$ & $1.48170 \mathrm{E}+02$ & $0.85(11) 0.49(13)$ \\
\hline 26 & 12 & $2 s 2 p^{4}$ & ${ }^{2} P_{3 / 2}$ & $2 s+1(1) 12 p-1(1) 22 p+3(3) 3$ & $3 / 2^{e}$ & $1.54042 \mathrm{E}+02$ & $1.54031 \mathrm{E}+02$ & $0.97(12)$ \\
\hline 26 & 13 & $2 s 2 p^{4}$ & ${ }^{2} P_{1 / 2}$ & $2 s+1(1) 1$ & $1 / 2^{e}$ & $1.66144 \mathrm{E}+02$ & $1.66140 \mathrm{E}+02$ & $-0.87(13) 0.48(11)$ \\
\hline 26 & 14 & $2 p^{5}$ & ${ }^{2} P_{3 / 2}$ & $2 p+3(3) 3$ & $3 / 2^{\circ}$ & $2.42304 \mathrm{E}+02$ & $2.42209 \mathrm{E}+02$ & $-0.99(14)$ \\
\hline 26 & 15 & $2 p^{5}$ & ${ }^{2} P_{1 / 2}$ & $2 p-1(1) 1$ & $1 / 2^{o}$ & $2.55654 \mathrm{E}+02$ & $2.55574 \mathrm{E}+02$ & $-0.99(15)$ \\
\hline 26 & 16 & $2 s^{2} 2 p^{2}\left({ }^{3} P\right) 3 s$ & ${ }^{4} P_{1 / 2}$ & $3 s+1(1) 1$ & $1 / 2^{e}$ & $\ldots$ & $8.87256 \mathrm{E}+02$ & $0.88(16)$ \\
\hline 26 & 17 & $2 s^{2} 2 p^{2}\left({ }^{3} P\right) 3 s$ & ${ }^{4} P_{3 / 2}$ & $2 p-1(1) 12 p+1(3) 23 s+1(1) 3$ & $3 / 2^{e}$ & $\ldots$ & $8.95508 \mathrm{E}+02$ & $0.97(17)$ \\
\hline 26 & 18 & $2 s^{2} 2 p^{2}\left({ }^{3} P\right) 3 s$ & ${ }^{2} P_{1 / 2}$ & $2 p-1(1) 12 p+1(3) 23 s+1(1) 1$ & $1 / 2^{e}$ & $\cdots$ & $8.99163 \mathrm{E}+02$ & $-0.91(18)-0.40(16)$ \\
\hline 26 & 19 & $2 s^{2} 2 p^{2}\left({ }^{3} P\right) 3 s$ & ${ }^{4} P_{5 / 2}$ & $2 p-1(1) 12 p+1(3) 43 s+1(1) 5$ & $5 / 2^{e}$ & $\ldots$ & $9.00731 \mathrm{E}+02$ & $-0.89(19) 0.44(22)$ \\
\hline 26 & 20 & $2 s^{2} 2 p^{2}\left({ }^{3} P\right) 3 s$ & ${ }^{2} P_{3 / 2}$ & $2 p-1(1) 12 p+1(3) 43 s+1(1) 3$ & $3 / 2^{e}$ & $\ldots$ & $9.04521 \mathrm{E}+02$ & $-0.81(20) 0.56(24)$ \\
\hline 26 & 21 & $2 s^{2} 2 p^{2}\left({ }^{3} P\right) 3 p$ & ${ }^{4} D_{1 / 2}$ & $3 p-1(1) 1$ & $1 / 2^{\circ}$ & $\cdots$ & $9.12215 \mathrm{E}+02$ & $0.76(21) 0.45(25)$ \\
\hline 26 & 22 & $2 s^{2} 2 p^{2}\left({ }^{1} D\right) 3 s$ & ${ }^{2} D_{5 / 2}$ & $2 p+2(4) 43 s+1(1) 5$ & $5 / 2^{e}$ & $\ldots$ & $9.17442 \mathrm{E}+02$ & $0.89(22) 0.44(19)$ \\
\hline 26 & 23 & $2 s^{2} 2 p^{2}\left({ }^{3} P\right) 3 p$ & ${ }^{4} D_{3 / 2}$ & $3 p+1(3) 3$ & $3 / 2^{\circ}$ & $\cdots$ & $9.17687 \mathrm{E}+02$ & $-0.80(23)-0.48(26)$ \\
\hline 26 & 24 & $2 s^{2} 2 p^{2}\left({ }^{1} D\right) 3 s$ & ${ }^{2} D_{3 / 2}$ & $2 p+2(4) 43 s+1(1) 3$ & $3 / 2^{e}$ & $\cdots$ & $9.18679 \mathrm{E}+02$ & $-0.82(24)-0.53(20)$ \\
\hline 26 & 25 & $2 s^{2} 2 p^{2}\left({ }^{3} P\right) 3 p$ & ${ }^{2} S_{1 / 2}$ & $2 p-1(1) 12 p+1(3) 23 p-1(1) 1$ & $1 / 2^{\circ}$ & $\ldots$ & $9.20003 \mathrm{E}+02$ & $0.66(25)-0.60(21) 0.44(28)$ \\
\hline 26 & 26 & $2 s^{2} 2 p^{2}\left({ }^{3} P\right) 3 p$ & ${ }^{4} P_{3 / 2}$ & $2 p-1(1) 12 p+1(3) 23 p-1(1) 3$ & $3 / 2^{\circ}$ & $\cdots$ & $9.23572 \mathrm{E}+02$ & $-0.59(23) 0.56(26)-0.48(30)$ \\
\hline 26 & 27 & $2 s^{2} 2 p^{2}\left({ }^{3} P\right) 3 p$ & ${ }^{4} D_{5 / 2}$ & $2 p-1(1) 12 p+1(3) 23 p+1(3) 5$ & $5 / 2^{\circ}$ & $\cdots$ & $9.24893 \mathrm{E}+02$ & $0.93(27)$ \\
\hline 26 & 28 & $2 s^{2} 2 p^{2}\left({ }^{3} P\right) 3 p$ & ${ }^{4} P_{1 / 2}$ & $2 p-1(1) 12 p+1(3) 23 p+1(3) 1$ & $1 / 2^{o}$ & $\cdots$ & $9.26421 \mathrm{E}+02$ & $-0.82(28) 0.45(25)$ \\
\hline 26 & 29 & $2 s^{2} 2 p^{2}\left({ }^{3} P\right) 3 p$ & ${ }^{4} P_{5 / 2}$ & $2 p-1(1) 12 p+1(3) 43 p-1(1) 5$ & $5 / 2^{\circ}$ & $\cdots$ & $9.27206 \mathrm{E}+02$ & $0.69(29)-0.48(35)-0.45(43)$ \\
\hline 26 & 30 & $2 s^{2} 2 p^{2}\left({ }^{3} P\right) 3 p$ & ${ }^{2} D_{3 / 2}$ & $2 p-1(1) 12 p+1(3) 23 p+1(3) 3$ & $3 / 2^{o}$ & $\cdots$ & $9.28803 \mathrm{E}+02$ & $0.70(30) 0.52(26)$ \\
\hline 26 & 31 & $2 s^{2} 2 p^{2}\left({ }^{3} P\right) 3 p$ & ${ }^{4} D_{7 / 2}$ & $2 p-1(1) 12 p+1(3) 43 p+1(3) 7$ & $7 / 2^{\circ}$ & $\cdots$ & $9.30078 \mathrm{E}+02$ & $0.90(31)-0.42(40)$ \\
\hline 26 & 32 & $2 s^{2} 2 p^{2}\left({ }^{3} P\right) 3 p$ & ${ }^{4} S_{3 / 2}$ & $2 p-1(1) 12 p+1(3) 43 p+1(3) 3$ & $3 / 2^{\circ}$ & $\cdots$ & $9.33058 \mathrm{E}+02$ & $0.79(32)-0.46(49)$ \\
\hline 26 & 33 & $2 s^{2} 2 p^{2}\left({ }^{1} S\right) 3 s$ & ${ }^{2} S_{1 / 2}$ & $2 p+2(0) 03 s+1(1) 1$ & $1 / 2^{e}$ & $\cdots$ & $9.33892 \mathrm{E}+02$ & $0.94(33)$ \\
\hline 26 & 34 & $2 s^{2} 2 p^{2}\left({ }^{3} P\right) 3 p$ & ${ }^{2} P_{3 / 2}$ & $2 p-1(1) 12 p+1(3) 43 p+1(3) 3$ & $3 / 2^{o}$ & $\cdots$ & $9.35816 \mathrm{E}+02$ & $-0.82(34)$ \\
\hline 26 & 35 & $2 s^{2} 2 p^{2}\left({ }^{3} P\right) 3 p$ & ${ }^{2} D_{5 / 2}$ & $2 p-1(1) 12 p+1(3) 43 p+1(3) 5$ & $5 / 2^{\circ}$ & $\cdots$ & $9.36508 \mathrm{E}+02$ & $-0.58(35)-0.56(29) 0.53(37)$ \\
\hline 26 & 36 & $2 s^{2} 2 p^{2}\left({ }^{3} P\right) 3 p$ & ${ }^{2} P_{1 / 2}$ & $2 p+2(4) 43 p+1(3) 1$ & $1 / 2^{o}$ & $\ldots$ & $9.39099 \mathrm{E}+02$ & $0.83(36)-0.40(25)$ \\
\hline 26 & 37 & $2 s^{2} 2 p^{2}\left({ }^{1} D\right) 3 p$ & ${ }^{2} F_{5 / 2}$ & $2 p+2(4) 43 p+1(3) 5$ & $5 / 2^{\circ}$ & $\cdots$ & $9.45675 \mathrm{E}+02$ & $0.73(37) 0.52(43)$ \\
\hline 26 & 38 & $2 s^{2} 2 p^{2}\left({ }^{3} P\right) 3 d$ & ${ }^{4} F_{3 / 2}$ & $3 d-1(3) 3$ & $3 / 2^{e}$ & $\cdots$ & $9.46845 \mathrm{E}+02$ & $-0.82(38)$ \\
\hline 26 & 39 & $2 s 2 p^{3}\left({ }^{5} S\right) 3 s$ & ${ }^{6} S_{5 / 2}$ & $2 s+1(1) 12 p+1(3) 43 s+1(1) 5$ & $5 / 2^{\circ}$ & $\cdots$ & $9.47222 \mathrm{E}+02$ & $0.97(39)$ \\
\hline 26 & 40 & $2 s^{2} 2 p^{2}\left({ }^{1} D\right) 3 p$ & ${ }^{2} F_{7 / 2}$ & $2 p+2(4) 43 p+1(3) 7$ & $7 / 2^{\circ}$ & $\cdots$ & $9.47512 \mathrm{E}+02$ & $-0.90(40)-0.41(31)$ \\
\hline 26 & 41 & $2 s^{2} 2 p^{2}\left({ }^{1} D\right) 3 p$ & ${ }^{2} D_{3 / 2}$ & $2 p+2(4) 43 p-1(1) 3$ & $3 / 2^{\circ}$ & $\ldots$ & $9.48346 \mathrm{E}+02$ & $0.73(41)-0.52(49)$ \\
\hline
\end{tabular}


Table 1

(Continued)

$J^{\pi}$

Energ

nergy

MBPT $^{\mathrm{e}}$

Mixing coefficients

$9.49663 \mathrm{E}+02$

$9.50483 \mathrm{E}+02$

$2 s^{2} 2 p^{2}\left({ }^{1} D\right) 3 p$

\section{$3 d+1(5) 5$}

$5 / 2^{e}$

$2 s^{2} 2 p^{2}\left({ }^{1} D\right) 3 p$

$2 p-1(1) 12 p+1(3) 43 p+1(3) 1$

$2 s^{2} 2 p^{2}\left({ }^{3} P\right) 3 d$

$2 p-1(1) 12 p+1(3) 23 d-1(3) 3$

$2 s^{2} 2 p^{2}\left({ }^{3} P\right) 3 d$

$2 s^{2} 2 p^{2}\left({ }^{3} P\right) 3 d$

$2 p-1(1) 12 p+1(3) 23 d+1(5) 7$

$2 p-1(1) 12 p+1(3) 23 d-1(3) 5$

$2 s^{2} 2 p^{2}\left({ }^{3} P\right) 3 d$

$2 s^{2} 2 p^{2}\left({ }^{1} D\right) 3 p$

$2 s^{2} 2 p^{2}\left({ }^{3} P\right) 3 d$

$2 p-1(1) 12 p+1(3) 23 d-1(3) 1$

$2 p+2(4) 43 p+1(3) 3$

$2 p-1(1) 12 p+1(3) 23 d+1(5) 3$

$2 p-1(1) 12 p+1(3) 43 d-1(3) 7$

$2 p-1(1) 12 p+1(3) 23 d+1(5) 5$

$2 s^{2} 2 p^{2}\left({ }^{3} P\right) 3 d$

$2 s^{2} 2 p^{2}\left({ }^{3} P\right) 3 d$

$2 s 2 p^{3}\left({ }^{5} S\right) 3 s$

$2 s^{2} 2 p^{2}\left({ }^{1} S\right) 3 p$

$2 s^{2} 2 p^{2}\left({ }^{3} P\right) 3 d$

$2 s^{2} 2 p^{2}\left({ }^{1} S\right) 3 p$

$2 s^{2} 2 p^{2}\left({ }^{3} P\right) 3 d$

$2 s^{2} 2 p^{2}\left({ }^{3} P\right) 3 d$

$2 s^{2} 2 p^{2}\left({ }^{3} P\right) 3 d$

$2 s^{2} 2 p^{2}\left({ }^{3} P\right) 3 d$

$2 s^{2} 2 p^{2}\left({ }^{3} P\right) 3 d$

$2 s^{2} 2 p^{2}\left({ }^{3} P\right) 3 d$

$2 s 2 p^{3}\left({ }^{5} S\right) 3 p$

$2 s 2 p^{3}\left({ }^{5} S\right) 3 p$

$2 s^{2} 2 p^{2}\left({ }^{1} D\right) 3 d$

$2 s 2 p^{3}\left({ }^{5} S\right) 3 p$

$2 s^{2} 2 p^{2}\left({ }^{1} D\right) 3 d$

$2 s^{2} 2 p^{2}\left({ }^{1} D\right) 3 d$

$2 s^{2} 2 p^{2}\left({ }^{1} D\right) 3 d$

$2 s^{2} 2 p^{2}\left({ }^{1} D\right) 3 d$

$2 s^{2} 2 p^{2}\left({ }^{1} D\right) 3 d$

$2 s 2 p^{3}\left({ }^{3} D\right) 3 s$

$2 s 2 p^{3}\left({ }^{5} S\right) 3 p$

$2 s 2 p^{3}\left({ }^{5} S\right) 3 p$

$2 s 2 p^{3}\left({ }^{3} D\right) 3 s$

$2 s 2 p^{3}\left({ }^{3} D\right) 3 s$

$2 s 2 p^{3}\left({ }^{5} S\right) 3 p$

$2 s^{2} 2 p^{2}\left({ }^{1} D\right) 3 d$

$2 s^{2} 2 p^{2}\left({ }^{1} D\right) 3 d$

$2 s^{2} 2 p^{2}\left({ }^{1} D\right) 3 d$

$2 s 2 p^{3}\left({ }^{3} D\right) 3 s$

${ }^{4} F_{9 / 2} \quad 2 p-1(1) 12 p+1(3) 43 d+1(5) 9$

${ }^{4} S_{3 / 2} \quad 2 s+1(1) 12 p+1(3) 43 s+1(1) 3$

$2 p+2(0) 03 p-1(1) 1$

$2 p-1(1) 12 p+1(3) 43 d+1(5) 5$

$2 p+2(0) 03 p+1(3) 3$

$2 p-1(1) 12 p+1(3) 43 d-1(3) 3$

$2 p-1(1) 12 p+1(3) 43 d+1(5) 1$

$2 p-1(1) 12 p+1(3) 43 d-1(3) 1$

$2 p+2(4) 43 d+1(5) 7$

$2 p-1(1) 12 p+1(3) 43 d+1(5) 3$

$2 p-1(1) 12 p+1(3) 43 d+1(5) 5$

$2 s+1(1) 12 p+1(3) 43 p-1(1) 3$

$2 s+1(1) 12 p+1(3) 43 p-1(1) 5$

$2 p+2(4) 43 d+1(5) 7$

$2 s+1(1) 12 p+1(3) 43 p+1(3) 7$

$2 p+2(4) 43 d+1(5) 9$

$2 p+2(4) 43 d-1(3) 3$

$2 p+2(4) 43 d-1(3) 5$

$2 p-1(1) 12 p+1(3) 43 d+1(5) 1$

$2 p+2(4) 43 d-1(3) 7$

$2 s+1(1) 12 p+1(3) 23 s+1(1) 3$

$2 s+1(1) 12 p+1(3) 43 p+1(3) 3$

$2 s+1(1) 12 p-1(1) 22 p+2(4) 43 p+1(3) 5$

$2 s+1(1) 12 p+1(3) 23 s+1(1) 1$

$2 s+1(1) 12 p-1(1) 02 p+2(4) 43 s+1(1) 5$

$2 s+1(1) 12 p+1(3) 43 p+1(3) 1$

$2 p+2(4) 43 d-1(3) 1$

$2 p+2(4) 43 d+1(5) 5$

$2 p+2(4) 43 d+1(5) 3$

$2 s+1(1) 12 p-1(1) 22 p+2(4) 63 s+1(1) 7$

$5 / 2^{\circ}$

$1 / 2^{\circ}$

$3 / 2^{e}$

$7 / 2^{e}$

$5 / 2^{e}$

$1 / 2^{e}$

$3 / 2^{\circ}$

$3 / 2^{e}$

$7 / 2^{e}$

$9 / 2^{e}$

$3 / 2^{\circ}$

$1 / 2^{\circ}$

$5 / 2^{e}$

$3 / 2^{\circ}$

$3 / 2^{e}$

$1 / 2^{e}$

$1 / 2^{e}$

$7 / 2^{e}$

$3 / 2^{e}$

$5 / 2^{e}$

$3 / 2^{e}$

$5 / 2^{e}$

$7 / 2^{e}$

$7 / 2^{e}$

$9 / 2^{e}$

$3 / 2^{e}$

$5 / 2^{e}$

$1 / 2^{e}$

$7 / 2^{e}$

$3 / 2^{\circ}$

$3 / 2^{e}$

$5 / 2^{e}$

$1 / 2^{\circ}$

$5 / 2^{\circ}$

$1 / 2^{e}$

$1 / 2^{e}$

$5 / 2^{e}$

$3 / 2^{e}$

$7 / 2^{\circ}$

9.49

$9.50483 \mathrm{E}+02$
$9.51568 \mathrm{E}+02$

$9.55961 \mathrm{E}+02$

$9.56098 \mathrm{E}+02$

$9.57029 \mathrm{E}+02$

$9.57031 \mathrm{E}+02$

$9.58815 \mathrm{E}+02$

$9.60139 \mathrm{E}+02$

$9.60413 \mathrm{E}+02$

$9.60594 \mathrm{E}+02$

$9.60748 \mathrm{E}+02$

$9.61962 \mathrm{E}+02$

$9.64255 \mathrm{E}+02$

$9.67320 \mathrm{E}+02$

$67320 \mathrm{E}+02$

...

$9.69600 \mathrm{E}+02$

$9.74390 \mathrm{E}+02$

$9.72410 \mathrm{E}+02$

...

$\cdots$

$\ldots$

$\ldots$

$9.81830 \mathrm{E}+02$

$9.81090 \mathrm{E}+02$

$9.83810 \mathrm{E}+02$

...

$\cdots$

$\ldots$

$\cdots$

$9.89770 \mathrm{E}+02$

$9.87780 \mathrm{E}+02$
$9.64894 \mathrm{E}+02$

$9.66050 \mathrm{E}+02$

$9.66340 \mathrm{E}+02$

$9.66610 \mathrm{E}+02$

$9.67502 \mathrm{E}+02$

$9.68982 \mathrm{E}+02$

$9.71784 \mathrm{E}+02$

$9.71812 \mathrm{E}+02$

$9.74484 \mathrm{E}+02$

$9.75301 \mathrm{E}+02$

$9.76874 \mathrm{E}+02$

$9.77608 \mathrm{E}+02$

$9.78936 \mathrm{E}+02$

$9.80739 \mathrm{E}+02$

$9.81172 \mathrm{E}+02$

$9.83193 \mathrm{E}+02$

$9.83605 \mathrm{E}+02$

$9.85101 \mathrm{E}+02$

$9.85218 \mathrm{E}+02$

$9.85272 \mathrm{E}+02$

$9.85295 \mathrm{E}+02$

$9.85360 \mathrm{E}+02$

$9.86208 \mathrm{E}+02$

$9.87258 \mathrm{E}+02$

$9.87413 \mathrm{E}+02$

$9.87692 \mathrm{E}+02$

$9.88095 \mathrm{E}+02$
$L S J^{\mathrm{f}}$

$-0.73(47)-0.54(42)$

$-0.74(43) 0.57(35)$

$0.96(44)$

(45) $-0.55(38) 0.45(50)$

$-0.85(46)-0.49(51)$

$-0.68(47)-0.49(52)-0.41(80)$

$0.91(48)$

$-0.61(49)-0.53(34)-0.46(54)$

$0.74(50)-0.56(45)$

$0.64(51)-0.49(72)-0.44(46)$

$-0.64(52)-0.53(56)$

$-0.91(53) 0.40(68)$

$-0.84(54)$

$0.90(55)$

$0.66(56)-0.61(42)-0.40(70)$

$0.93(57)$

$0.85(58)$

$-0.75(59) 0.52(60)$

$-0.76(60)-0.51(59)$

$0.67(61) 0.51(51)-0.49(66)$

$-0.87(62)$

$0.81(63)-0.40(80)$

$-0.97(64)$

$-0.95(65)$

$-0.67(66)-0.64(72)$

$0.96(67)$

$0.91(68)$

$0.92(69)$

$0.75(70)-0.52(80)$

$-0.95(71)$

$0.60(61)-0.60(72) 0.49(66)$

$-0.93(73)$

$-0.95(74)$

$0.93(75)$

$0.95(76)$

$0.91(77)$

$0.97(78)$

$-0.91(79)$

$-0.59(63)-0.54(80)-0.49(70)$

$-0.87(81)$

$0.99(82)$ 
Table 1

(Continued)

Z

$J^{\pi}$

Energ

Energy

$\mathrm{MBPT}^{\mathrm{e}}$

Mixing coefficients

$9.93651 \mathrm{E}+02$

$9.95696 \mathrm{E}+02$

$9.97849 \mathrm{E}+02$

$9.99148 \mathrm{E}+02$

$1.00253 \mathrm{E}+03$

$1.00387 \mathrm{E}+03$

$1.00616 \mathrm{E}+03$

$1.00619 \mathrm{E}+03$

$1.00620 \mathrm{E}+03$

$1.00630 \mathrm{E}+03$

$1.00633 \mathrm{E}+03$

$1.00660 \mathrm{E}+03$

$1.00969 \mathrm{E}+03$

$1.00997 \mathrm{E}+03$

$1.01075 \mathrm{E}+03$

$1.01162 \mathrm{E}+03$

$1.01182 \mathrm{E}+03$

$1.01243 \mathrm{E}+03$

$1.01411 \mathrm{E}+03$

$1.01475 \mathrm{E}+03$

$1.01599 \mathrm{E}+03$

$1.01625 \mathrm{E}+03$

$1.01715 \mathrm{E}+03$

$1.01763 \mathrm{E}+03$

$1.01802 \mathrm{E}+03$

$1.01907 \mathrm{E}+03$

$1.01928 \mathrm{E}+03$

$1.01963 \mathrm{E}+03$

$1.02008 \mathrm{E}+03$

$1.02020 \mathrm{E}+03$

$1.02243 \mathrm{E}+03$

$1.02314 \mathrm{E}+03$

$1.02468 \mathrm{E}+03$

$1.02487 \mathrm{E}+03$

$1.02545 \mathrm{E}+03$

$1.02819 \mathrm{E}+03$

$1.02892 \mathrm{E}+03$

$1.02935 \mathrm{E}+03$

$1.03004 \mathrm{E}+03$

$1.03091 \mathrm{E}+03$

$1.03093 \mathrm{E}+03$

$L S J^{\mathrm{f}}$

$0.90(83)$

$0.91(84)$

$-0.94(85)$

$0.90(86)$

$-0.97(87)$

$-0.90(88)$

0.98(89)

$-0.98(90)$

$-0.80(91)-0.51(92)$

$-0.67(92) 0.62(91)$

$0.98(93)$

$0.98(94)$

$-0.85(95)-0.40(105)$

$-0.79(96)-0.45(103)$

$-0.95(97)$

$0.74(98)-0.56(102)$

$0.84(99) 0.40(103)$

$-0.86(100)$

$0.82(101)-0.49(104)$

$0.80(102) 0.54(98)$

$0.62(96)-0.62(103) 0.42(99)$

$0.78(104) 0.44(101)$

$0.88(105)-0.40(95)$

$-0.92(106)$

$1.00(107)$

$0.88(108) 0.41(104)$

$0.95(109)$

$-0.96(110)$

$0.96(111)$

$0.96(112)$

$0.77(113)-0.53(125)$

$-0.89(114)-0.42(128)$

$-0.90(115)$

$-0.90(116)$

$0.80(117)-0.43(103)$

$0.88(118)$

$-0.86(119)-0.45(144)$

$-0.83(120)-0.50(127)$

$-0.96(121)$

$-0.91(122)$

0.93(123) 
Table 1

(Continued)

Z

$J^{\pi}$

$\mathrm{NIST}^{\mathrm{d}}$

Energy

$2 s+1(1) 12 p-1(1) 22 p+2(0) 23 p+1(3) 5$

$2 s+1(1) 12 p-1(1) 02 p+2(0) 03 p+1(3) 3$

$2 s+1(1) 12 p+3(3) 43 p+1(3) 7$

$2 s+1(1) 12 p-1(1) 22 p+2(0) 23 p+1(3) 1$

$2 s+1(1) 12 p-1(1) 22 p+2(0) 23 p-1(1) 1$

$2 s+1(1) 12 p-1(1) 02 p+2(0) 03 p+1(3) 3$

$2 s+1(1) 12 p-1(1) 22 p+2(0) 23 p+1(3) 5$

$2 s+1(1) 12 p-1(1) 22 p+2(0) 23 p+1(3) 3$

$2 s+1(1) 12 p+3(3) 43 p+1(3) 3$

$2 s+1(1) 12 p+1(3) 23 d-1(3) 3$

$2 s+1(1) 12 p+3(3) 43 p+1(3) 5$

$2 s+1(1) 12 p-1(1) 02 p+2(4) 43 d-1(3) 5$

$2 s+1(1) 12 p-1(1) 22 p+2(4) 63 d-1(3) 7$

$2 s+1(1) 12 p+1(3) 23 d-1(3) 5$

$2 s+1(1) 12 p-1(1) 02 p+2(4) 43 d+1(5) 9$

$2 s+1(1) 12 p+1(3) 23 d+1(5) 7$

$2 s+1(1) 12 p-1(1) 22 p+2(0) 23 p+1(3) 1$

$2 s+1(1) 12 p-1(1) 22 p+2(4) 63 d+1(5) 9$

$2 s+1(1) 12 p-1(1) 02 p+2(4) 43 d-1(3) 1$

$2 s+1(1) 12 p+3(3) 23 s+1(1) 3$

$2 s+1(1) 12 p+3(3) 23 s+1(1) 1$

$2 s+1(1) 12 p-1(1) 22 p+2(4) 63 d+1(5) 11$

$2 s+1(1) 12 p+1(3) 43 d-1(3) 3$

$2 s+1(1) 12 p-1(1) 02 p+2(4) 43 d+1(5) 5$

$2 s+1(1) 12 p+1(3) 23 d-1(3) 1$

$2 s+1(1) 12 p-1(1) 22 p+2(4) 63 d-1(3) 7$

$2 s+1(1) 12 p-1(1) 22 p+2(4) 63 d+1(5) 7$

$2 s+1(1) 12 p-1(1) 22 p+2(4) 23 p-1(1) 3$

$2 s+1(1) 12 p-1(1) 22 p+2(4) 63 d-1(3) 9$

$2 s+1(1) 12 p-1(1) 22 p+2(4) 23 p-1(1) 1$

$2 s+1(1) 12 p-1(1) 22 p+2(4) 63 d-1(3) 5$

$2 s+1(1) 12 p+1(3) 23 d+1(5) 3$

$2 s+1(1) 12 p-1(1) 22 p+2(4) 63 d+1(5) 1$

$2 s+1(1) 12 p-1(1) 22 p+2(4) 63 d-1(3) 3$

$2 s+1(1) 12 p+1(3) 43 d+1(5) 5$

$2 s+1(1) 12 p-1(1) 22 p+2(4) 23 p+1(3) 5$

$2 s+1(1) 12 p-1(1) 22 p+2(4) 63 d+1(5) 3$

$2 s+1(1) 12 p-1(1) 22 p+2(4) 63 d+1(5) 1$

$2 s+1(1) 12 p-1(1) 22 p+2(4) 23 p+1(3) 3$

$2 s+1(1) 12 p-1(1) 22 p+2(4) 23 p+1(3) 1$

$2 s+1(1) 12 p-1(1) 22 p+2(4) 43 p-1(1) 5$

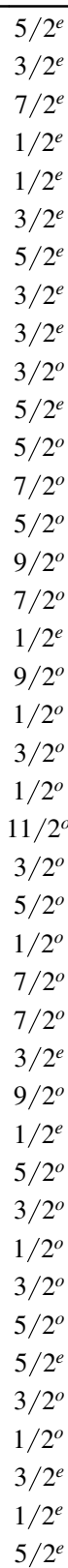

$3 / 2^{e}$
$7 / 2^{e}$

$1 / 2^{e}$

$1 / 2^{e}$

$5 / 2^{e}$

$3 / 2^{e}$

$3 / 2^{e}$

$3 / 2^{\circ}$

$5 / 2^{e}$

$5 / 2^{\circ}$

$7 / 2^{\circ}$

$5 / 2^{\circ}$

$9 / 2^{\circ}$

$1 / 2^{e}$

$9 / 2^{\circ}$

$1 / 2^{\circ}$

$3 / 2^{\circ}$
$1 / 2^{\circ}$

$11 / 2^{\circ}$

$3 / 2^{\circ}$

$1 / 2^{\circ}$
$7 / 2^{\circ}$

$7 / 2^{\circ}$

$3 / 2^{e}$

$9 / 2^{\circ}$

$1 / 2^{e}$

$3 / 2^{\circ}$

$1 / 2^{\circ}$

$3 / 2^{\circ}$

$5 / 2^{\circ}$

$3 / 2^{\circ}$

$1 / 2^{\circ}$

$3 / 2^{e}$
$1 / 2^{e}$

$5 / 2^{e}$
Energy

1.032
1.033
1.034
1.035
1.035
1.036
1.037
1.037
1.040
1.040
1.040
1.041

$1.03242 \mathrm{E}+03$

$1.03361 \mathrm{E}+03$

$1.03492 \mathrm{E}+03$

$1.03502 \mathrm{E}+03$

$1.03583 \mathrm{E}+03$

$1.03676 \mathrm{E}+03$

$1.03712 \mathrm{E}+03$

$1.03793 \mathrm{E}+03$

$1.04059 \mathrm{E}+03$

$1.04070 \mathrm{E}+03$

$1.04085 \mathrm{E}+03$

$1.04163 \mathrm{E}+03$

$1.04285 \mathrm{E}+03$

$1.04430 \mathrm{E}+03$

$1.04458 \mathrm{E}+03$

$1.04472 \mathrm{E}+03$

$1.04598 \mathrm{E}+03$

$1.04624 \mathrm{E}+03$

$1.04659 \mathrm{E}+03$

$1.04667 \mathrm{E}+03$

$1.04716 \mathrm{E}+03$

$1.04724 \mathrm{E}+03$

$1.04725 \mathrm{E}+03$

$1.04863 \mathrm{E}+03$

$1.04872 \mathrm{E}+03$

$1.04956 \mathrm{E}+03$

$1.05077 \mathrm{E}+03$

$1.05102 \mathrm{E}+03$

$1.05129 \mathrm{E}+03$

$1.05137 \mathrm{E}+03$

$1.05217 \mathrm{E}+03$

$1.05275 \mathrm{E}+03$

$1.05299 \mathrm{E}+03$

$1.05341 \mathrm{E}+03$

$1.05347 \mathrm{E}+03$

$1.05387 \mathrm{E}+03$

$1.05544 \mathrm{E}+03$

$1.05584 \mathrm{E}+03$

$1.05597 \mathrm{E}+03$

$1.05601 \mathrm{E}+03$

$1.05683 \mathrm{E}+03$
Mixing coefficients

$L S J^{\mathrm{f}}$

$0.90(124)$

$0.79(125) 0.52(113)$

-0.87 (126)

$-0.75(127) 0.45(120) 0.40(128)$

$0.76(128) 0.46(127)$

$-0.74(129) 0.54(131)$

$0.81(130)-0.41(134)$

$0.73(131) 0.57(129)$

$0.75(132) 0.52(117)$

$0.91(133)$

$-0.75(134)-0.51(130)$

$0.83(135)$

$-0.70(136) 0.59(139)$

$-0.88(137)-0.42(135)$

$-0.89(138)$

$-0.73(139)-0.64(136)$

$0.81(140)$

$0.97(141)$

$-0.90(142)$

$0.91(143)$

$0.87(144)-0.44(119)$

$-1.00(145)$

$-0.87(146)$

$-0.78(147)-0.43(154)$

$0.81(148) 0.42(156)$

$0.69(149) 0.64(150)$

$-0.71(150) 0.65(149)$

$-0.77(151)-0.46(178)$

$-0.93(152)$

$0.66(153) 0.51(163)-0.42(197)$

$0.78(154)-0.55(147)$

$-0.68(155)-0.48(160)-0.42(177)$

$-0.82(156) 0.50(148)$

$-0.65(155)-0.60(157) 0.41(146)$

$0.64(158)-0.58(187) 0.47(168)$

$-0.90(159)$

$-0.76(160)-0.51(157)$

$-0.94(161)$

$-0.63(162) 0.58(151)-0.47(178)$

$-0.64(153) 0.57(163) 0.41(140)$

$-0.92(164)$ 
Table 1

(Continued)

Z

$J^{\pi}$

Energ

Energy

$\mathrm{MBPT}^{\mathrm{e}}$

Mixing coefficients

$1.05883 \mathrm{E}+03$

$1.05943 \mathrm{E}+03$

$1.06026 \mathrm{E}+03$

$1.06066 \mathrm{E}+03$

$1.06201 \mathrm{E}+03$

$1.06259 \mathrm{E}+03$

$1.06265 \mathrm{E}+03$

$1.06278 \mathrm{E}+03$

$1.06289 \mathrm{E}+03$

$1.06431 \mathrm{E}+03$

$1.06534 \mathrm{E}+03$

$1.06574 \mathrm{E}+03$

$1.06582 \mathrm{E}+03$

$1.06682 \mathrm{E}+03$

$1.06724 \mathrm{E}+03$

$1.06748 \mathrm{E}+03$

$1.06811 \mathrm{E}+03$

$1.06814 \mathrm{E}+03$

$1.06838 \mathrm{E}+03$

$1.06874 \mathrm{E}+03$

$1.07111 \mathrm{E}+03$

$1.07325 \mathrm{E}+03$

$1.07513 \mathrm{E}+03$

$1.07592 \mathrm{E}+03$

$1.07675 \mathrm{E}+03$

$1.07696 \mathrm{E}+03$

$1.07716 \mathrm{E}+03$

$1.07721 \mathrm{E}+03$

$1.08051 \mathrm{E}+03$

$1.08363 \mathrm{E}+03$

$1.08402 \mathrm{E}+03$

$1.08436 \mathrm{E}+03$

$1.08441 \mathrm{E}+03$

$1.08510 \mathrm{E}+03$

$1.08712 \mathrm{E}+03$

$1.08840 \mathrm{E}+03$

$1.08888 \mathrm{E}+03$

$1.08933 \mathrm{E}+03$

$1.09140 \mathrm{E}+03$

$1.09179 \mathrm{E}+03$

$1.09440 \mathrm{E}+03$

$0.96(165)$

$L S J$

$0.93(166)$

$0.91(167)$

$-0.78(168) 0.57(158)$

$0.93(169)$

$-0.89(170)$

$-0.86(171)$

$-0.92(172)$

$0.83(173) 0.41(182)$

$0.85(174)$

$-0.82(175)-0.40(183)$

$-0.75(176)-0.47(179)$

$0.69(177) 0.55(184)$

$0.64(192)-0.62(162) 0.43(178)$

$-0.77(179) 0.48(176)$

$0.75(180) 0.46(177)$

$-0.80(181)-0.41(197)$

$-0.83(182)$

$-0.82(183)$

$0.70(184) 0.53(180)$

$0.93(185)$

$0.85(186)$

$0.75(187) 0.49(158)$

$0.93(188)$

$-0.87(189)$

$-0.86(190)$

$-0.69(191) 0.62(197)$

$-0.63(192) 0.55(178)-0.44(190)$

$-0.88(193)$

$-0.88(194)$

$0.73(195)-0.43(219) 0.42(199)$

$-0.90(196)$

$0.56(163) 0.56(191) 0.55(197)$

$0.89(198)$

$-0.67(199) 0.58(195)$

$-0.69(200)-0.57(208)$

$0.97(201)$

$0.86(202)$

$-0.90(203)$

$2 s+1(1) 12 p-1(1) 22 p+2(4) 43 d+1(5) 7$
$2 s+1(1) 12 p-1(1) 22 p+2(4) 43 d-1(3) 5$

$2 s+1(1) 12 p-1(1) 22 p+2(4) 43 d-1(3) 3$

$3 / 2^{\circ}$

$-0.90(204)$ 
Table 1

(Continued)

$L S J$

$J^{\pi}$

Energ

nergy

Mixing coefficients

MBPT $^{\mathrm{e}}$

$L S J^{\mathrm{f}}$

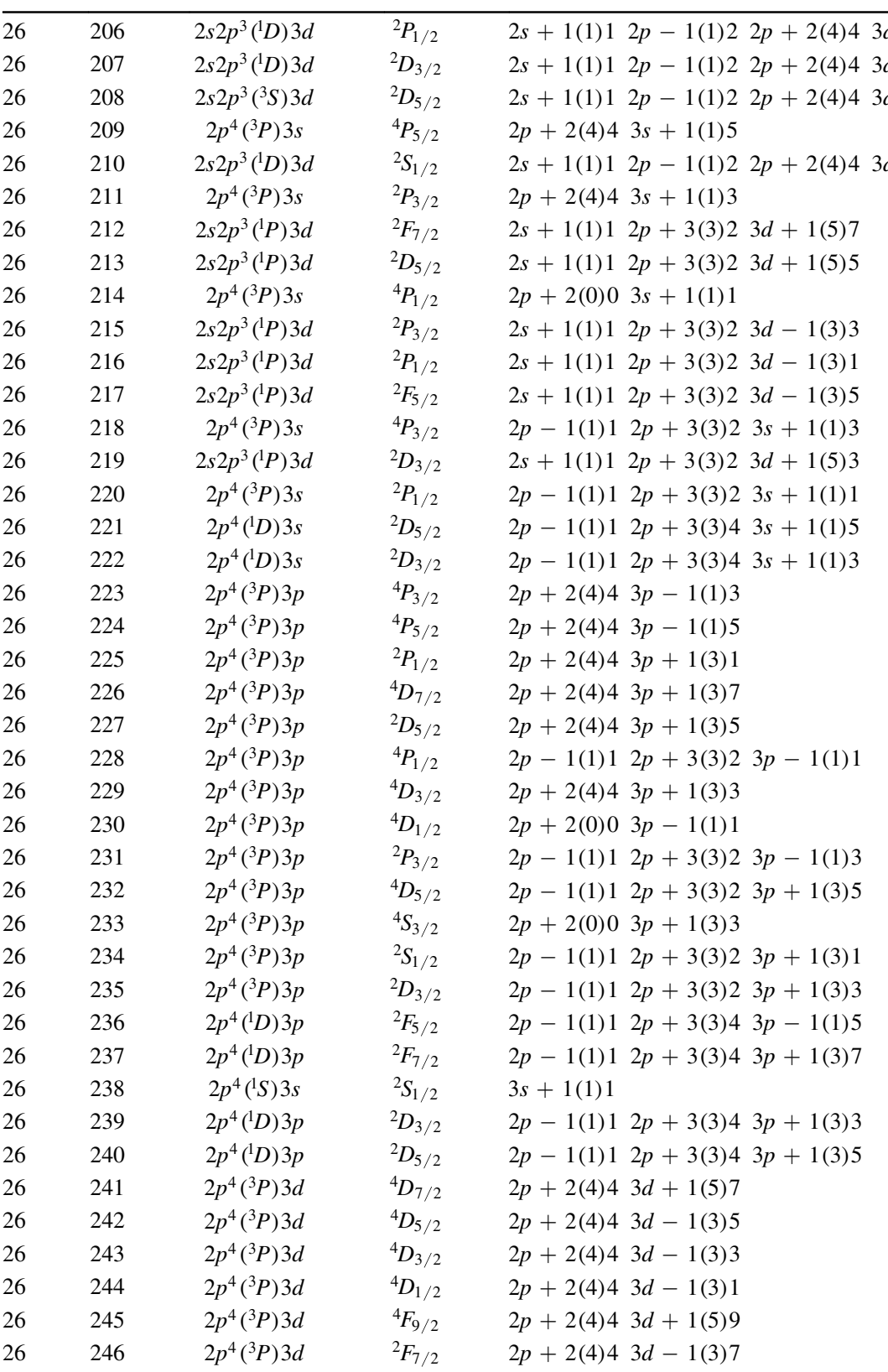

$1 / 2^{o}$

..

1.09

$1.09538 \mathrm{E}+03$

$0.75(206)-0.62(210)$

$09699 \mathrm{E}+03-0.75(207)-0.48(205)$

$1.09713 \mathrm{E}+03$

$1.09773 \mathrm{E}+03$

$1.09878 \mathrm{E}+03$

$1.10202 \mathrm{E}+03$

$1.10646 \mathrm{E}+03$

$1.10688 \mathrm{E}+03$

$1.10873 \mathrm{E}+03$

$1.10889 \mathrm{E}+03$

$1.10905 \mathrm{E}+03$

$1.10953 \mathrm{E}+03$

$1.11071 \mathrm{E}+03$

$1.11418 \mathrm{E}+03$

$1.11555 \mathrm{E}+03$

$1.12037 \mathrm{E}+03$

$1.12101 \mathrm{E}+03$

$1.12142 \mathrm{E}+03$

$1.12193 \mathrm{E}+03$

$1.12570 \mathrm{E}+03$

$1.12605 \mathrm{E}+03$

$1.12621 \mathrm{E}+03$

$1.13295 \mathrm{E}+03$

$1.13307 \mathrm{E}+03$

$1.13410 \mathrm{E}+03$

$1.13550 \mathrm{E}+03$

$1.13740 \mathrm{E}+03$

$1.13846 \mathrm{E}+03$

$1.14019 \mathrm{E}+03$

$1.14081 \mathrm{E}+03$

$1.14377 \mathrm{E}+03$

$1.14674 \mathrm{E}+03$

$1.14848 \mathrm{E}+03$

$1.14914 \mathrm{E}+03$

$1.15077 \mathrm{E}+03$

$1.15207 \mathrm{E}+03$

$1.15211 \mathrm{E}+03$

$1.15292 \mathrm{E}+03$

$1.15417 \mathrm{E}+03$

$1.15484 \mathrm{E}+03$

$1.15627 \mathrm{E}+03$

$0.62(200)-0.55(208)-0.52(217)$

$0.94(209)$

$0.75(210) 0.52(206)$

$0.68(211) 0.64(218)$

$-0.92(212)$

$-0.71(213)-0.55(217)$

$-0.95(214)$

$0.82(215)-0.46(219)$

$0.92(216)$

$-0.65(213) 0.59(217)$

$-0.77(218) 0.59(211)$

$-0.71(219)-0.57(199)$

$0.96(220)$

$-0.94(221)$

$-0.91(222)$

$-0.82(223)$

$-0.82(224) 0.51(232)$

$-0.65(228)-0.47(225) 0.46(249)$ $0.93(226)$

$-0.77(227)-0.42(224)$

$0.73(228)-0.41(230)$

$-0.72(229)-0.47(235) 0.41(233)$

$-0.82(230)$

$-0.63(231)-0.62(229)$

$-0.76(232) 0.50(227)$

$0.67(233) 0.57(223)$

$0.77(234) 0.44(225)$

$0.83(235) 0.49(233)$

$0.90(236)$

$-0.93(237)$

$-0.91(238)$

$-0.91(239)$

$-0.92(240)$

$0.87(241)-0.42(255)$

$0.88(242)$

$-0.84(243) 0.42(250)$

$-0.71(244) 0.42(252) 0.41(248)$

$0.93(245)$

$-0.76(246)-0.51(255)$ 
Table 1

(Continued)

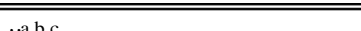

$J^{\pi}$

Energ

nergy

Mixing coefficients

\begin{tabular}{|c|c|c|}
\hline \multicolumn{2}{|c|}{ Energy } & Mixing coef \\
\hline NIST $^{\mathrm{d}}$ & MBPT $^{\mathrm{e}}$ & $L S J^{\mathrm{f}}$ \\
\hline & $15671 \mathrm{E}+03$ & $065(231)$ \\
\hline
\end{tabular}

\begin{tabular}{|c|c|c|c|c|}
\hline 26 & 247 & $2 p^{4}\left({ }^{1} D\right) 3 p$ & ${ }^{2} P_{3 / 2}$ & $2 p-1(1) 12 p+3(3) 43 p-1(1) 3$ \\
\hline 26 & 248 & $2 p^{4}\left({ }^{3} P\right) 3 d$ & ${ }^{4} P_{1 / 2}$ & $2 p+2(4) 43 d+1(5) 1$ \\
\hline 26 & 249 & $2 p^{4}\left({ }^{1} D\right) 3 p$ & ${ }^{2} P_{1 / 2}$ & $2 p-1(1) 12 p+3(3) 43 p+1(3) 1$ \\
\hline 26 & 250 & $2 p^{4}\left({ }^{3} P\right) 3 d$ & ${ }^{4} P_{3 / 2}$ & $2 p+2(4) 43 d+1(5) 3$ \\
\hline 26 & 251 & $2 p^{4}\left({ }^{3} P\right) 3 d$ & ${ }^{2} F_{5 / 2}$ & $2 p+2(4) 43 d+1(5) 5$ \\
\hline 26 & 252 & $2 p^{4}\left({ }^{3} P\right) 3 d$ & ${ }^{2} P_{1 / 2}$ & $2 p-1(1) 12 p+3(3) 23 d-1(3) 1$ \\
\hline 26 & 253 & $2 p^{4}\left({ }^{3} P\right) 3 d$ & ${ }^{4} F_{3 / 2}$ & $2 p+2(0) 03 d-1(3) 3$ \\
\hline 26 & 254 & $2 p^{4}\left({ }^{3} P\right) 3 d$ & ${ }^{4} F_{5 / 2}$ & $2 p+2(0) 03 d+1(5) 5$ \\
\hline 26 & 255 & $2 p^{4}\left({ }^{3} P\right) 3 d$ & ${ }^{4} F_{7 / 2}$ & $2 p-1(1) 12 p+3(3) 23 d+1(5) 7$ \\
\hline 26 & 256 & $2 p^{4}\left({ }^{3} P\right) 3 d$ & ${ }^{2} D_{3 / 2}$ & $2 p-1(1) 12 p+3(3) 23 d-1(3) 3$ \\
\hline 26 & 257 & $2 p^{4}\left({ }^{3} P\right) 3 d$ & ${ }^{4} P_{5 / 2}$ & $2 p-1(1) 12 p+3(3) 23 d+1(5) 5$ \\
\hline 26 & 258 & $2 p^{4}\left({ }^{3} P\right) 3 d$ & ${ }^{2} P_{3 / 2}$ & $2 p-1(1) 12 p+3(3) 23 d+1(5) 3$ \\
\hline 26 & 259 & $2 p^{4}\left({ }^{3} P\right) 3 d$ & ${ }^{2} D_{5 / 2}$ & $2 p-1(1) 12 p+3(3) 23 d-1(3) 5$ \\
\hline 26 & 260 & $2 p^{4}\left({ }^{1} D\right) 3 d$ & ${ }^{2} G_{7 / 2}$ & $2 p-1(1) 12 p+3(3) 43 d-1(3) 7$ \\
\hline 26 & 261 & $2 p^{4}\left({ }^{1} D\right) 3 d$ & ${ }^{2} G_{9 / 2}$ & $2 p-1(1) 12 p+3(3) 43 d+1(5) 9$ \\
\hline 26 & 262 & $2 p^{4}\left({ }^{1} S\right) 3 p$ & ${ }^{2} P_{1 / 2}$ & $3 p-1(1) 1$ \\
\hline 26 & 263 & $2 p^{4}\left({ }^{1} S\right) 3 p$ & ${ }^{2} P_{3 / 2}$ & $3 p+1(3) 3$ \\
\hline 26 & 264 & $2 p^{4}\left({ }^{1} D\right) 3 d$ & ${ }^{2} F_{5 / 2}$ & $2 p-1(1) 12 p+3(3) 43 d+1(5) 5$ \\
\hline 26 & 265 & $2 p^{4}\left({ }^{1} D\right) 3 d$ & ${ }^{2} S_{1 / 2}$ & $2 p-1(1) 12 p+3(3) 43 d-1(3) 1$ \\
\hline 26 & 266 & $2 p^{4}\left({ }^{1} D\right) 3 d$ & ${ }^{2} F_{7 / 2}$ & $2 p-1(1) 12 p+3(3) 43 d+1(5) 7$ \\
\hline 26 & 267 & $2 p^{4}\left({ }^{1} D\right) 3 d$ & ${ }^{2} D_{5 / 2}$ & $2 p-1(1) 12 p+3(3) 43 d-1(3) 5$ \\
\hline 26 & 268 & $2 p^{4}\left({ }^{1} D\right) 3 d$ & ${ }^{2} P_{3 / 2}$ & $2 p-1(1) 12 p+3(3) 43 d-1(3) 3$ \\
\hline 26 & 269 & $2 p^{4}\left({ }^{1} D\right) 3 d$ & ${ }^{2} D_{3 / 2}$ & $2 p-1(1) 12 p+3(3) 43 d+1(5) 3$ \\
\hline 26 & 270 & $2 p^{4}\left({ }^{1} D\right) 3 d$ & ${ }^{2} P_{1 / 2}$ & $2 p-1(1) 12 p+3(3) 43 d+1(5) 1$ \\
\hline 26 & 271 & $2 s^{2} 2 p^{2}\left({ }^{3} P\right) 4 s$ & ${ }^{4} P_{1 / 2}$ & $4 s+1(1) 1$ \\
\hline 26 & 272 & $2 p^{4}\left({ }^{1} S\right) 3 d$ & ${ }^{2} D_{5 / 2}$ & $3 d+1(5) 5$ \\
\hline 26 & 273 & $2 p^{4}\left({ }^{1} S\right) 3 d$ & ${ }^{2} D_{3 / 2}$ & $3 d-1(3) 3$ \\
\hline 26 & 274 & $2 s^{2} 2 p^{2}\left({ }^{3} P\right) 4 s$ & ${ }^{4} P_{3 / 2}$ & $2 p-1(1) 12 p+1(3) 24 s+1(1) 3$ \\
\hline 26 & 275 & $2 s^{2} 2 p^{2}\left({ }^{3} P\right) 4 s$ & ${ }^{2} P_{1 / 2}$ & $2 p-1(1) 12 p+1(3) 24 s+1(1) 1$ \\
\hline 26 & 276 & $2 s^{2} 2 p^{2}\left({ }^{3} P\right) 4 p$ & ${ }^{4} D_{1 / 2}$ & $4 p-1(1) 1$ \\
\hline 26 & 277 & $2 s^{2} 2 p^{2}\left({ }^{3} P\right) 4 p$ & ${ }^{4} P_{3 / 2}$ & $4 p+1(3) 3$ \\
\hline 26 & 278 & $2 s^{2} 2 p^{2}\left({ }^{3} P\right) 4 s$ & ${ }^{4} P_{5 / 2}$ & $2 p-1(1) 12 p+1(3) 44 s+1(1) 5$ \\
\hline 26 & 279 & $2 s^{2} 2 p^{2}\left({ }^{3} P\right) 4 s$ & ${ }^{2} P_{3 / 2}$ & $2 p-1(1) 12 p+1(3) 44 s+1(1) 3$ \\
\hline 26 & 280 & $2 s^{2} 2 p^{2}\left({ }^{3} P\right) 4 p$ & ${ }^{2} S_{1 / 2}$ & $2 p-1(1) 12 p+1(3) 24 p-1(1) 1$ \\
\hline 26 & 281 & $2 s^{2} 2 p^{2}\left({ }^{3} P\right) 4 p$ & ${ }^{4} D_{3 / 2}$ & $2 p-1(1) 12 p+1(3) 24 p-1(1) 3$ \\
\hline 26 & 282 & $2 s^{2} 2 p^{2}\left({ }^{3} P\right) 4 p$ & ${ }^{4} D_{5 / 2}$ & $2 p-1(1) 12 p+1(3) 24 p+1(3) 5$ \\
\hline 26 & 283 & $2 s^{2} 2 p^{2}\left({ }^{3} P\right) 4 p$ & ${ }^{4} P_{1 / 2}$ & $2 p-1(1) 12 p+1(3) 24 p+1(3) 1$ \\
\hline 26 & 284 & $2 s^{2} 2 p^{2}\left({ }^{3} P\right) 4 p$ & ${ }^{2} D_{3 / 2}$ & $2 p-1(1) 12 p+1(3) 24 p+1(3) 3$ \\
\hline 26 & 285 & $2 s^{2} 2 p^{2}\left({ }^{3} P\right) 4 d$ & ${ }^{4} F_{3 / 2}$ & $4 d-1(3) 3$ \\
\hline 26 & 286 & $2 s^{2} 2 p^{2}\left({ }^{3} P\right) 4 p$ & ${ }^{4} P_{5 / 2}$ & $2 p-1(1) 12 p+1(3) 44 p-1(1) 5$ \\
\hline 26 & 287 & $2 s^{2} 2 p^{2}\left({ }^{3} P\right) 4 d$ & ${ }^{4} P_{5 / 2}$ & $4 d+1(5) 5$ \\
\hline
\end{tabular}

$3 / 2^{\circ}$

$1.15671 \mathrm{E}+03$

$-0.71(247)-0.65(231)$

$1.15952 \mathrm{E}+03 \quad-0.83(248) 0.44(252)$

$1.16135 \mathrm{E}+03 \quad 0.75(249) 0.56(225)$

$\begin{array}{llll}1 / 2^{e} & \ldots & 1.15952 \mathrm{E}+03 & -0.83(248) 0.46(252) \\ 1 / 2^{o} & \ldots & 1.16135 \mathrm{E}+03 & 0.75(249) 0.56(225) \\ 3 / 2^{e} & \ldots & 1.16172 \mathrm{E}+03 & 0.74(250) 0.53(256)\end{array}$

$3 / 2^{e}$

$5 / 2^{e}$

$1 / 2^{e}$

$3 / 2^{e}$
$5 / 2^{e}$

$7 / 2^{e}$

$3 / 2^{e}$

$5 / 2^{e}$

$3 / 2^{e}$

$5 / 2^{e}$

$7 / 2^{e}$

$9 / 2^{e}$

$1 / 2^{\circ}$

$3 / 2^{\circ}$

$5 / 2^{e}$

$1 / 2^{e}$

$7 / 2^{e}$

$5 / 2^{e}$

$3 / 2^{e}$

$3 / 2^{e}$

$1 / 2^{e}$

$1 / 2^{e}$

$5 / 2^{e}$
$3 / 2^{e}$

$3 / 2^{e}$
$3 / 2^{e}$

$1 / 2^{e}$

$1 / 2^{\circ}$

$3 / 2^{\circ}$

$5 / 2^{e}$

$3 / 2^{e}$

$1 / 2^{\circ}$

$3 / 2^{\circ}$

$5 / 2^{\circ}$

$1 / 2^{\circ}$

$3 / 2^{\circ}$

$3 / 2^{e}$

$5 / 2^{\circ}$

$5 / 2^{e}$

$1.16223 \mathrm{E}+03$

$1.16436 \mathrm{E}+03$

$1.16547 \mathrm{E}+03$

$1.16603 \mathrm{E}+03$

$1.16611 \mathrm{E}+03$

$1.16705 \mathrm{E}+03$

$1.16929 \mathrm{E}+03$

$1.17106 \mathrm{E}+03$

$1.17228 \mathrm{E}+03$

$1.17424 \mathrm{E}+03$

$1.17470 \mathrm{E}+03$

$1.17681 \mathrm{E}+03$

$1.17691 \mathrm{E}+03$

$1.17878 \mathrm{E}+03$

$1.18009 \mathrm{E}+03$

$1.18015 \mathrm{E}+03$

$1.18382 \mathrm{E}+03$

$1.18397 \mathrm{E}+03$

$1.18731 \mathrm{E}+03$

$1.18862 \mathrm{E}+03$

$1.20056 \mathrm{E}+03$

$1.20623 \mathrm{E}+03$

$1.20825 \mathrm{E}+03$

$1.20938 \mathrm{E}+03$

$1.21039 \mathrm{E}+03$

$1.21098 \mathrm{E}+03$

$1.21351 \mathrm{E}+03$

$1.21463 \mathrm{E}+03$

$1.21583 \mathrm{E}+03$

$1.21955 \mathrm{E}+03$

$1.22105 \mathrm{E}+03$

$1.22167 \mathrm{E}+03$

$1.22266 \mathrm{E}+03$

$1.22338 \mathrm{E}+03$

$1.22408 \mathrm{E}+03$

$1.22548 \mathrm{E}+03$

$0.60(254) 0.53(251)-0.42(259)-0.42(257)$

$0.69(244) 0.53(252)-0.41(270)$

$0.91(253)$

$-0.73(254)-0.51(257)$

$0.72(255)-0.51(246) 0.45(241)$

$0.59(243) 0.49(250)-0.48(256) 0.43(269)$

$-0.70(257)-0.62(251)$

$-0.72(258) 0.52(268)$

$0.65(259) 0.54(251)-0.42(267)$

$-0.91(260)$

$-0.93(261)$

$-0.86(262) 0.42(225)$

$0.94(263)$

$-0.82(264)-0.54(267)$

$0.92(265)$

$0.95(266)$

$-0.70(267)-0.56(259) 0.40(264)$

$-0.80(268)-0.53(258)$

$0.79(269) 0.58(256)$

$0.77(270) 0.59(252)$

$0.82(271)-0.48(275)$

$-0.95(272)$

$-0.90(273)$

$0.94(274)$

$0.86(275) 0.51(271)$

$0.77(276)$

$0.64(281) 0.56(277)-0.44(284)$

$0.88(278)-0.47(293)$

$-0.82(279) 0.51(294)$

$-0.61(280) 0.58(276)-0.54(283)$

$-0.78(281)$

$0.82(282) 0.50(286)$

$-0.74(283) 0.48(292) 0.43(280)$

$-0.76(284)-0.49(277)$

$-0.76(285)-0.41(301)$

$-0.60(286) 0.51(282) 0.47(291) 0.40(320)$

$-0.58(300)-0.56(305) 0.42(302)-0.42(287)$ 
Table 1

(Continued)

\begin{tabular}{|c|c|c|c|c|c|c|c|c|}
\hline \multirow[t]{2}{*}{$Z$} & \multirow[t]{2}{*}{ Key } & \multirow[t]{2}{*}{ Conf } & \multirow[t]{2}{*}{$L S J$} & \multirow[t]{2}{*}{$j j^{\mathrm{a}, \mathrm{b}, \mathrm{c}}$} & \multirow[t]{2}{*}{$J^{\pi}$} & \multicolumn{2}{|c|}{ Energy } & \multirow{2}{*}{$\begin{array}{c}\text { Mixing coefficients } \\
\qquad L S J^{\mathrm{f}}\end{array}$} \\
\hline & & & & & & $\mathrm{NIST}^{\mathrm{d}}$ & MBPT $^{\mathrm{e}}$ & \\
\hline 26 & 288 & $2 s^{2} 2 p^{2}\left({ }^{3} P\right) 4 p$ & ${ }^{4} D_{7 / 2}$ & $2 p-1(1) 12 p+1(3) 44 p+1(3) 7$ & $7 / 2^{\circ}$ & $\cdots$ & $1.22673 \mathrm{E}+03$ & $-0.89(288) 0.46(321)$ \\
\hline 26 & 289 & $2 s^{2} 2 p^{2}\left({ }^{3} P\right) 4 p$ & ${ }^{4} S_{3 / 2}$ & $2 p-1(1) 12 p+1(3) 44 p-1(1) 3$ & $3 / 2^{\circ}$ & $\cdots$ & $1.22763 \mathrm{E}+03$ & $0.72(289)-0.53(277)-0.40(334)$ \\
\hline 26 & 290 & $2 s^{2} 2 p^{2}\left({ }^{3} P\right) 4 p$ & ${ }^{2} P_{3 / 2}$ & $2 p-1(1) 12 p+1(3) 44 p+1(3) 3$ & $3 / 2^{\circ}$ & $\cdots$ & $1.22845 \mathrm{E}+03$ & $-0.80(290) 0.48(319)$ \\
\hline 26 & 291 & $2 s^{2} 2 p^{2}\left({ }^{3} P\right) 4 p$ & ${ }^{2} D_{5 / 2}$ & $2 p-1(1) 12 p+1(3) 44 p+1(3) 5$ & $5 / 2^{\circ}$ & $\cdots$ & $1.22950 \mathrm{E}+03$ & $0.70(291) 0.53(286)-0.41(318)$ \\
\hline 26 & 292 & $2 s^{2} 2 p^{2}\left({ }^{3} P\right) 4 p$ & ${ }^{2} P_{1 / 2}$ & $2 p-1(1) 12 p+1(3) 44 p+1(3) 1$ & $1 / 2^{o}$ & $\cdots$ & $1.22980 \mathrm{E}+03$ & $-0.77(292) 0.48(280)$ \\
\hline 26 & 293 & $2 s^{2} 2 p^{2}\left({ }^{1} D\right) 4 s$ & ${ }^{2} D_{5 / 2}$ & $2 p+2(4) 44 s+1(1) 5$ & $5 / 2^{e}$ & $\cdots$ & $1.23061 \mathrm{E}+03$ & $-0.88(293)-0.47(278)$ \\
\hline 26 & 294 & $2 s^{2} 2 p^{2}\left({ }^{1} D\right) 4 s$ & ${ }^{2} D_{3 / 2}$ & $2 p+2(4) 44 s+1(1) 3$ & $3 / 2^{e}$ & $\cdots$ & $1.23102 \mathrm{E}+03$ & $-0.86(294)-0.47(279)$ \\
\hline 26 & 295 & $2 s^{2} 2 p^{2}\left({ }^{3} P\right) 4 f$ & ${ }^{4} G_{5 / 2}$ & $4 f-1(5) 5$ & $5 / 2^{\circ}$ & $\cdots$ & $1.23166 \mathrm{E}+03$ & $0.70(295) 0.45(308) 0.42(329)$ \\
\hline 26 & 296 & $2 s^{2} 2 p^{2}\left({ }^{3} P\right) 4 f$ & ${ }^{4} G_{7 / 2}$ & $4 f+1(7) 7$ & $7 / 2^{\circ}$ & $\cdots$ & $1.23186 \mathrm{E}+03$ & $-0.52(311) 0.52(309) 0.50(327) 0.46(296)$ \\
\hline 26 & 297 & $2 s^{2} 2 p^{2}\left({ }^{3} P\right) 4 d$ & ${ }^{2} P_{3 / 2}$ & $2 p-1(1) 12 p+1(3) 24 d-1(3) 3$ & $3 / 2^{e}$ & $\cdots$ & $1.23307 \mathrm{E}+03$ & $-0.63(285) 0.60(297) 0.40(301)$ \\
\hline 26 & 298 & $2 s^{2} 2 p^{2}\left({ }^{3} P\right) 4 d$ & ${ }^{4} F_{7 / 2}$ & $2 p-1(1) 12 p+1(3) 24 d+1(5) 7$ & $7 / 2^{e}$ & $\cdots$ & $1.23335 \mathrm{E}+03$ & $0.77(298) 0.58(303)$ \\
\hline 26 & 299 & $2 s^{2} 2 p^{2}\left({ }^{3} P\right) 4 d$ & ${ }^{4} D_{1 / 2}$ & $2 p-1(1) 12 p+1(3) 24 d-1(3) 1$ & $1 / 2^{e}$ & $\ldots$ & $1.23345 \mathrm{E}+03$ & $-0.89(299)$ \\
\hline 26 & 300 & $2 s^{2} 2 p^{2}\left({ }^{3} P\right) 4 d$ & ${ }^{4} F_{5 / 2}$ & $2 p-1(1) 12 p+1(3) 24 d-1(3) 5$ & $5 / 2^{e}$ & $1.23265 \mathrm{E}+03$ & $1.23382 \mathrm{E}+03$ & $-0.79(300) 0.50(287)$ \\
\hline 26 & 301 & $2 s^{2} 2 p^{2}\left({ }^{3} P\right) 4 d$ & ${ }^{4} D_{3 / 2}$ & $2 p-1(1) 12 p+1(3) 24 d+1(5) 3$ & $3 / 2^{e}$ & $\cdots$ & $1.23531 \mathrm{E}+03$ & $0.63(301)-0.51(297)-0.43(316)$ \\
\hline 26 & 302 & $2 s^{2} 2 p^{2}\left({ }^{3} P\right) 4 d$ & ${ }^{2} F_{5 / 2}$ & $2 p-1(1) 12 p+1(3) 24 d+1(5) 5$ & $5 / 2^{e}$ & $1.23538 \mathrm{E}+03$ & $1.23546 \mathrm{E}+03$ & $-0.82(302)-0.45(287)$ \\
\hline 26 & 303 & $2 s^{2} 2 p^{2}\left({ }^{3} P\right) 4 d$ & ${ }^{4} D_{7 / 2}$ & $2 p-1(1) 12 p+1(3) 44 d-1(3) 7$ & $7 / 2^{e}$ & $\ldots$ & $1.23809 \mathrm{E}+03$ & $-0.60(303) 0.58(298) 0.42(335)$ \\
\hline 26 & 304 & $2 s^{2} 2 p^{2}\left({ }^{3} P\right) 4 d$ & ${ }^{4} F_{9 / 2}$ & $2 p-1(1) 12 p+1(3) 44 d+1(5) 9$ & $9 / 2^{e}$ & $\ldots$ & $1.23827 \mathrm{E}+03$ & $0.89(304)-0.46(336)$ \\
\hline 26 & 305 & $2 s^{2} 2 p^{2}\left({ }^{3} P\right) 4 d$ & ${ }^{4} D_{5 / 2}$ & $2 p-1(1) 12 p+1(3) 44 d-1(3) 5$ & $5 / 2^{e}$ & $1.23885 \mathrm{E}+03$ & $1.23940 \mathrm{E}+03$ & $-0.72(305) 0.51(287)$ \\
\hline 26 & 306 & $2 s^{2} 2 p^{2}\left({ }^{3} P\right) 4 d$ & ${ }^{4} P_{3 / 2}$ & $2 p-1(1) 12 p+1(3) 44 d-1(3) 3$ & $3 / 2^{e}$ & $1.24096 \mathrm{E}+03$ & $1.24002 \mathrm{E}+03$ & $-0.77(306) 0.45(301)$ \\
\hline 26 & 307 & $2 s^{2} 2 p^{2}\left({ }^{3} P\right) 4 d$ & ${ }^{4} P_{1 / 2}$ & $2 p-1(1) 12 p+1(3) 44 d-1(3) 1$ & $1 / 2^{e}$ & $1.24096 \mathrm{E}+03$ & $1.24033 \mathrm{E}+03$ & $-0.85(307) 0.41(342)$ \\
\hline 26 & 308 & $2 s^{2} 2 p^{2}\left({ }^{3} P\right) 4 f$ & ${ }^{2} D_{5 / 2}$ & $2 p-1(1) 12 p+1(3) 24 f-1(5) 5$ & $5 / 2^{\circ}$ & $\cdots$ & $1.24050 \mathrm{E}+03$ & $0.68(295)-0.60(308)$ \\
\hline 26 & 309 & $2 s^{2} 2 p^{2}\left({ }^{3} P\right) 4 f$ & ${ }^{4} D_{7 / 2}$ & $2 p-1(1) 12 p+1(3) 24 f+1(7) 7$ & $7 / 2^{\circ}$ & $\cdots$ & $1.24066 \mathrm{E}+03$ & $0.67(309)-0.63(296)$ \\
\hline 26 & 310 & $2 s^{2} 2 p^{2}\left({ }^{3} P\right) 4 d$ & ${ }^{2} P_{1 / 2}$ & $2 p-1(1) 12 p+1(3) 44 d+1(5) 1$ & $1 / 2^{e}$ & $\cdots$ & $1.24085 \mathrm{E}+03$ & $-0.82(310)$ \\
\hline 26 & 311 & $2 s^{2} 2 p^{2}\left({ }^{3} P\right) 4 f$ & ${ }^{2} G_{7 / 2}$ & $2 p-1(1) 12 p+1(3) 24 f-1(5) 7$ & $7 / 2^{\circ}$ & $\cdots$ & $1.24094 \mathrm{E}+03$ & $-0.71(311)-0.47(296)-0.42(332)$ \\
\hline 26 & 312 & $2 s^{2} 2 p^{2}\left({ }^{3} P\right) 4 f$ & ${ }^{4} G_{9 / 2}$ & $2 p-1(1) 12 p+1(3) 24 f+1(7) 9$ & $9 / 2^{\circ}$ & $\cdots$ & $1.24095 \mathrm{E}+03$ & $-0.72(312)-0.56(330) 0.41(323)$ \\
\hline 26 & 313 & $2 s^{2} 2 p^{2}\left({ }^{3} P\right) 4 f$ & ${ }^{4} F_{3 / 2}$ & $2 p-1(1) 12 p+1(3) 24 f-1(5) 3$ & $3 / 2^{\circ}$ & $\cdots$ & $1.24114 \mathrm{E}+03$ & $-0.77(313)-0.45(328)-0.45(331)$ \\
\hline 26 & 314 & $2 s^{2} 2 p^{2}\left({ }^{3} P\right) 4 f$ & ${ }^{4} D_{5 / 2}$ & $2 p-1(1) 12 p+1(3) 24 f+1(7) 5$ & $5 / 2^{\circ}$ & $\ldots$ & $1.24140 \mathrm{E}+03$ & $0.57(333)-0.54(314)-0.50(329)$ \\
\hline 26 & 315 & $2 s^{2} 2 p^{2}\left({ }^{3} P\right) 4 d$ & ${ }^{2} D_{5 / 2}$ & $2 p-1(1) 12 p+1(3) 44 d+1(5) 5$ & $5 / 2^{e}$ & $1.24220 \mathrm{E}+03$ & $1.24152 \mathrm{E}+03$ & $0.80(315)-0.46(341)$ \\
\hline 26 & 316 & $2 s^{2} 2 p^{2}\left({ }^{3} P\right) 4 d$ & ${ }^{2} D_{3 / 2}$ & $2 p-1(1) 12 p+1(3) 44 d+1(5) 3$ & $3 / 2^{e}$ & $1.24517 \mathrm{E}+03$ & $1.24159 \mathrm{E}+03$ & $0.79(316)$ \\
\hline 26 & 317 & $2 s^{2} 2 p^{2}\left({ }^{3} P\right) 4 d$ & ${ }^{2} F_{7 / 2}$ & $2 p-1(1) 12 p+1(3) 44 d+1(5) 7$ & $7 / 2^{e}$ & $1.24220 \mathrm{E}+03$ & $1.24180 \mathrm{E}+03$ & $0.76(317)-0.44(339) 0.43(303)$ \\
\hline 26 & 318 & $2 s^{2} 2 p^{2}\left({ }^{1} D\right) 4 p$ & ${ }^{2} F_{5 / 2}$ & $2 p+2(4) 44 p+1(3) 5$ & $5 / 2^{\circ}$ & $\cdots$ & $1.24233 \mathrm{E}+03$ & $0.73(318) 0.48(320) 0.41(291)$ \\
\hline 26 & 319 & $2 s^{2} 2 p^{2}\left({ }^{1} D\right) 4 p$ & ${ }^{2} D_{3 / 2}$ & $2 p+2(4) 44 p-1(1) 3$ & $3 / 2^{\circ}$ & $\cdots$ & $1.24264 \mathrm{E}+03$ & $0.71(319)-0.59(334)$ \\
\hline 26 & 320 & $2 s^{2} 2 p^{2}\left({ }^{1} D\right) 4 p$ & ${ }^{2} D_{5 / 2}$ & $2 p+2(4) 44 p-1(1) 5$ & $5 / 2^{\circ}$ & $\cdots$ & $1.24298 \mathrm{E}+03$ & $0.79(320)-0.44(318)$ \\
\hline 26 & 321 & $2 s^{2} 2 p^{2}\left({ }^{1} D\right) 4 p$ & ${ }^{2} F_{7 / 2}$ & $2 p+2(4) 44 p+1(3) 7$ & $7 / 2^{\circ}$ & $\cdots$ & $1.24299 \mathrm{E}+03$ & $0.89(321) 0.46(288)$ \\
\hline 26 & 322 & $2 s^{2} 2 p^{2}\left({ }^{1} D\right) 4 p$ & ${ }^{2} P_{1 / 2}$ & $2 p+2(4) 44 p+1(3) 1$ & $1 / 2^{o}$ & $\cdots$ & $1.24370 \mathrm{E}+03$ & $0.93(322)$ \\
\hline 26 & 323 & $2 s^{2} 2 p^{2}\left({ }^{3} P\right) 4 f$ & ${ }^{2} G_{9 / 2}$ & $2 p-1(1) 12 p+1(3) 44 f-1(5) 9$ & $9 / 2^{\circ}$ & $\cdots$ & $1.24603 \mathrm{E}+03$ & $0.65(323) 0.56(312)-0.45(350)$ \\
\hline 26 & 324 & $2 s^{2} 2 p^{2}\left({ }^{3} P\right) 4 f$ & ${ }^{4} G_{11 / 2}$ & $2 p-1(1) 12 p+1(3) 44 f+1(7) 11$ & $11 / 2^{o}$ & $\cdots$ & $1.24607 \mathrm{E}+03$ & $0.88(324)-0.47(351)$ \\
\hline 26 & 325 & $2 s^{2} 2 p^{2}\left({ }^{1} S\right) 4 s$ & ${ }^{2} S_{1 / 2}$ & $2 p+2(0) 04 s+1(1) 1$ & $1 / 2^{e}$ & $\cdots$ & $1.24621 \mathrm{E}+03$ & $-0.94(325)$ \\
\hline 26 & 326 & $2 s^{2} 2 p^{2}\left({ }^{3} P\right) 4 f$ & ${ }^{4} D_{1 / 2}$ & $2 p-1(1) 12 p+1(3) 44 f-1(5) 1$ & $1 / 2^{o}$ & $\cdots$ & $1.24630 \mathrm{E}+03$ & $-0.90(326) 0.44(354)$ \\
\hline 26 & 327 & $2 s^{2} 2 p^{2}\left({ }^{3} P\right) 4 f$ & ${ }^{4} F_{7 / 2}$ & $2 p-1(1) 12 p+1(3) 44 f-1(5) 7$ & $7 / 2^{\circ}$ & $\cdots$ & $1.24633 \mathrm{E}+03$ & $0.67(327)-0.48(346)-0.40(296)$ \\
\hline 26 & 328 & $2 s^{2} 2 p^{2}\left({ }^{3} P\right) 4 f$ & ${ }^{4} D_{3 / 2}$ & $2 p-1(1) 12 p+1(3) 44 f-1(5) 3$ & $3 / 2^{\circ}$ & $\cdots$ & $1.24635 \mathrm{E}+03$ & $0.80(328)$ \\
\hline
\end{tabular}


Table 1

(Continued)

\begin{tabular}{|c|c|c|c|c|c|c|c|c|}
\hline \multirow[t]{2}{*}{$Z$} & \multirow[t]{2}{*}{ Key } & \multirow[t]{2}{*}{ Conf } & \multirow[t]{2}{*}{$L S J$} & \multirow[t]{2}{*}{$j j^{\mathrm{a}, \mathrm{b}, \mathrm{c}}$} & \multirow[t]{2}{*}{$J^{\pi}$} & \multicolumn{2}{|c|}{ Energy } & \multirow{2}{*}{$\begin{array}{l}\text { Mixing coefficients } \\
\qquad L S J^{\mathrm{f}}\end{array}$} \\
\hline & & & & & & $\mathrm{NIST}^{\mathrm{d}}$ & $\mathrm{MBPT}^{\mathrm{e}}$ & \\
\hline 26 & 329 & $2 s^{2} 2 p^{2}\left({ }^{3} P\right) 4 f$ & ${ }^{4} F_{5 / 2}$ & $2 p-1(1) 12 p+1(3) 44 f-1(5) 5$ & $5 / 2^{\circ}$ & $\ldots$ & $1.24640 \mathrm{E}+03$ & $0.67(329)-0.54(314) 0.41(348)$ \\
\hline 26 & 330 & $2 s^{2} 2 p^{2}\left({ }^{3} P\right) 4 f$ & ${ }^{4} F_{9 / 2}$ & $2 p-1(1) 12 p+1(3) 44 f+1(7) 9$ & $9 / 2^{\circ}$ & $\cdots$ & $1.24651 \mathrm{E}+03$ & $0.68(330) 0.49(323)-0.49(347)$ \\
\hline 26 & 331 & $2 s^{2} 2 p^{2}\left({ }^{3} P\right) 4 f$ & ${ }^{2} D_{3 / 2}$ & $2 p-1(1) 12 p+1(3) 44 f+1(7) 3$ & $3 / 2^{\circ}$ & $\ldots$ & $1.24654 \mathrm{E}+03$ & $-0.77(331) 0.41(313)$ \\
\hline 26 & 332 & $2 s^{2} 2 p^{2}\left({ }^{3} P\right) 4 f$ & ${ }^{2} F_{7 / 2}$ & $2 p-1(1) 12 p+1(3) 44 f+1(7) 7$ & $7 / 2^{\circ}$ & $\cdots$ & $1.24662 \mathrm{E}+03$ & $-0.69(332) 0.48(349)$ \\
\hline 26 & 333 & $2 s^{2} 2 p^{2}\left({ }^{3} P\right) 4 f$ & ${ }^{2} F_{5 / 2}$ & $2 p-1(1) 12 p+1(3) 44 f+1(7) 5$ & $5 / 2^{\circ}$ & $\cdots$ & $1.24666 \mathrm{E}+03$ & $-0.69(333) 0.49(308)-0.40(353)$ \\
\hline 26 & 334 & $2 s^{2} 2 p^{2}\left({ }^{1} D\right) 4 p$ & ${ }^{2} P_{3 / 2}$ & $2 p+2(4) 44 p+1(3) 3$ & $3 / 2^{\circ}$ & $\cdots$ & $1.24677 \mathrm{E}+03$ & $-0.64(334)-0.49(319)-0.44(290)$ \\
\hline 26 & 335 & $2 s^{2} 2 p^{2}\left({ }^{1} D\right) 4 d$ & ${ }^{2} F_{7 / 2}$ & $2 p+2(4) 44 d+1(5) 7$ & $7 / 2^{e}$ & $\cdots$ & $1.25394 \mathrm{E}+03$ & $-0.75(335)-0.48(339)$ \\
\hline 26 & 336 & $2 s^{2} 2 p^{2}\left({ }^{1} D\right) 4 d$ & ${ }^{2} G_{9 / 2}$ & $2 p+2(4) 44 d+1(5) 9$ & $9 / 2^{e}$ & $\ldots$ & $1.25480 \mathrm{E}+03$ & $-0.89(336)-0.45(304)$ \\
\hline 26 & 337 & $2 s^{2} 2 p^{2}\left({ }^{1} D\right) 4 d$ & ${ }^{2} D_{5 / 2}$ & $2 p+2(4) 44 d-1(3) 5$ & $5 / 2^{e}$ & $1.25745 \mathrm{E}+03$ & $1.25537 \mathrm{E}+03$ & $-0.71(337) 0.57(341)$ \\
\hline 26 & 338 & $2 s^{2} 2 p^{2}\left({ }^{1} D\right) 4 d$ & ${ }^{2} D_{3 / 2}$ & $2 p+2(4) 44 d-1(3) 3$ & $3 / 2^{e}$ & $1.25600 \mathrm{E}+03$ & $1.25546 \mathrm{E}+03$ & $0.89(338)$ \\
\hline 26 & 339 & $2 s^{2} 2 p^{2}\left({ }^{1} D\right) 4 d$ & ${ }^{2} G_{7 / 2}$ & $2 p+2(4) 44 d-1(3) 7$ & $7 / 2^{e}$ & $1.25745 \mathrm{E}+03$ & $1.25577 \mathrm{E}+03$ & $-0.71(339) 0.49(335)-0.41(317)$ \\
\hline 26 & 340 & $2 s^{2} 2 p^{2}\left({ }^{1} D\right) 4 d$ & ${ }^{2} P_{1 / 2}$ & $2 p+2(4) 44 d+1(5) 1$ & $1 / 2^{e}$ & $\ldots$ & $1.25585 \mathrm{E}+03$ & $-0.92(340)$ \\
\hline 26 & 341 & $2 s^{2} 2 p^{2}\left({ }^{1} D\right) 4 d$ & ${ }^{2} F_{5 / 2}$ & $2 p+2(4) 44 d+1(5) 5$ & $5 / 2^{e}$ & $1.25832 \mathrm{E}+03$ & $1.25743 \mathrm{E}+03$ & $0.62(341) 0.55(337) 0.48(315)$ \\
\hline 26 & 342 & $2 s^{2} 2 p^{2}\left({ }^{1} D\right) 4 d$ & ${ }^{2} S_{1 / 2}$ & $2 p+2(4) 44 d-1(3) 1$ & $1 / 2^{e}$ & $\ldots$ & $1.25770 \mathrm{E}+03$ & $0.89(342)$ \\
\hline 26 & 343 & $2 s^{2} 2 p^{2}\left({ }^{1} D\right) 4 d$ & ${ }^{2} P_{3 / 2}$ & $2 p+2(4) 44 d+1(5) 3$ & $3 / 2^{e}$ & $1.25832 \mathrm{E}+03$ & $1.25787 \mathrm{E}+03$ & $-0.86(343)$ \\
\hline 26 & 344 & $2 s^{2} 2 p^{2}\left({ }^{1} S\right) 4 p$ & ${ }^{2} P_{1 / 2}$ & $2 p+2(0) 04 p-1(1) 1$ & $1 / 2^{o}$ & $\ldots$ & $1.25812 \mathrm{E}+03$ & $0.95(344)$ \\
\hline 26 & 345 & $2 s^{2} 2 p^{2}\left({ }^{1} S\right) 4 p$ & ${ }^{2} P_{3 / 2}$ & $2 p+2(0) 04 p+1(3) 3$ & $3 / 2^{\circ}$ & $\cdots$ & $1.25903 \mathrm{E}+03$ & $-0.95(345)$ \\
\hline 26 & 346 & $2 s^{2} 2 p^{2}\left({ }^{1} D\right) 4 f$ & ${ }^{2} G_{7 / 2}$ & $2 p+2(4) 44 f-1(5) 7$ & $7 / 2^{\circ}$ & $\cdots$ & $1.26157 \mathrm{E}+03$ & $-0.84(346)$ \\
\hline 26 & 347 & $2 s^{2} 2 p^{2}\left({ }^{1} D\right) 4 f$ & ${ }^{2} G_{9 / 2}$ & $2 p+2(4) 44 f+1(7) 9$ & $9 / 2^{\circ}$ & $\cdots$ & $1.26158 \mathrm{E}+03$ & $-0.86(347)-0.41(330)$ \\
\hline 26 & 348 & $2 s^{2} 2 p^{2}\left({ }^{1} D\right) 4 f$ & ${ }^{2} F_{5 / 2}$ & $2 p+2(4) 44 f-1(5) 5$ & $5 / 2^{\circ}$ & $\cdots$ & $1.26174 \mathrm{E}+03$ & $0.89(348)$ \\
\hline 26 & 349 & $2 s^{2} 2 p^{2}\left({ }^{1} D\right) 4 f$ & ${ }^{2} F_{7 / 2}$ & $2 p+2(4) 44 f+1(7) 7$ & $7 / 2^{\circ}$ & $\cdots$ & $1.26192 \mathrm{E}+03$ & $-0.85(349)$ \\
\hline 26 & 350 & $2 s^{2} 2 p^{2}\left({ }^{1} D\right) 4 f$ & ${ }^{2} H_{9 / 2}$ & $2 p+2(4) 44 f-1(5) 9$ & $9 / 2^{\circ}$ & $\cdots$ & $1.26211 \mathrm{E}+03$ & $0.88(350) 0.41(323)$ \\
\hline 26 & 351 & $2 s^{2} 2 p^{2}\left({ }^{1} D\right) 4 f$ & ${ }^{2} H_{11 / 2}$ & $2 p+2(4) 44 f+1(7) 11$ & $11 / 2^{o}$ & $\cdots$ & $1.26221 \mathrm{E}+03$ & $0.88(351) 0.47(324)$ \\
\hline 26 & 352 & $2 s^{2} 2 p^{2}\left({ }^{1} D\right) 4 f$ & ${ }^{2} D_{3 / 2}$ & $2 p+2(4) 44 f-1(5) 3$ & $3 / 2^{\circ}$ & $\cdots$ & $1.26242 \mathrm{E}+03$ & $-0.88(352)$ \\
\hline 26 & 353 & $2 s^{2} 2 p^{2}\left({ }^{1} D\right) 4 f$ & ${ }^{2} D_{5 / 2}$ & $2 p+2(4) 44 f+1(7) 5$ & $5 / 2^{\circ}$ & $\cdots$ & $1.26265 \mathrm{E}+03$ & $0.89(353)$ \\
\hline 26 & 354 & $2 s^{2} 2 p^{2}\left({ }^{1} D\right) 4 f$ & ${ }^{2} P_{1 / 2}$ & $2 p+2(4) 44 f-1(5) 1$ & $1 / 2^{o}$ & $\cdots$ & $1.26315 \mathrm{E}+03$ & $0.90(354) 0.44(326)$ \\
\hline 26 & 355 & $2 s^{2} 2 p^{2}\left({ }^{1} D\right) 4 f$ & ${ }^{2} P_{3 / 2}$ & $2 p+2(4) 44 f+1(7) 3$ & $3 / 2^{\circ}$ & $\ldots$ & $1.26328 \mathrm{E}+03$ & $-0.90(355)$ \\
\hline 26 & 356 & $2 s^{2} 2 p^{2}\left({ }^{1} S\right) 4 d$ & ${ }^{2} D_{5 / 2}$ & $2 p+2(0) 04 d+1(5) 5$ & $5 / 2^{e}$ & $1.27567 \mathrm{E}+03$ & $1.27100 \mathrm{E}+03$ & $-0.96(356)$ \\
\hline 26 & 357 & $2 s^{2} 2 p^{2}\left({ }^{1} S\right) 4 d$ & ${ }^{2} D_{3 / 2}$ & $2 p+2(0) 04 d-1(3) 3$ & $3 / 2^{e}$ & $1.27319 \mathrm{E}+03$ & $1.27126 \mathrm{E}+03$ & $-0.95(357)$ \\
\hline 26 & 358 & $2 s^{2} 2 p^{2}\left({ }^{1} S\right) 4 f$ & ${ }^{2} F_{5 / 2}$ & $2 p+2(0) 04 f-1(5) 5$ & $5 / 2^{\circ}$ & $\ldots$ & $1.27750 \mathrm{E}+03$ & $-0.96(358)$ \\
\hline 26 & 359 & $2 s^{2} 2 p^{2}\left({ }^{1} S\right) 4 f$ & ${ }^{2} F_{7 / 2}$ & $2 p+2(0) 04 f+1(7) 7$ & $7 / 2^{\circ}$ & $\cdots$ & $1.27763 \mathrm{E}+03$ & $-0.96(359)$ \\
\hline
\end{tabular}

Notes.

a The number at the end or inside of the bracket is $2 J$.

${ }^{\mathrm{b}}{ }_{s+}=s_{1 / 2}, p-=p / 1 / 2, p+=p_{3 / 2}, d-=d_{3 / 2}, d+=d_{5 / 2}, f-=f_{5 / 2}$, and $f+=f_{7 / 2}$.

${ }^{\mathrm{c}}$ The number after \pm is the occupation number of the corresponding sub-shell. For example, the $j j$ configuration of level 7 is $2 s_{1 / 2} 2 p_{1 / 2} 2 p_{3 / 2}^{3}$.

${ }^{d}$ The observed energies from the NIST ASD (Kramida et al. 2014).

e The present MBPT results.

${ }^{f}$ The mixing coefficient of the $L S J$ basis of the state indicated by the key in parenthesis.

(This table is available in its entirety in machine-readable form.) 
vacuum polarization (VP), and electron self-energy (SE), are also taken into account in the calculations.

Table 1 lists our energies (in eV) of the 359 levels for each ion, as well as the observed results from the NIST ASD (Kramida et al. 2014). Also listed in Table 1 is the symmetry $J^{\pi}$ of the state, i.e., the parity $\pi$ and total angular momentum $J$. For each state in each ion, an index number $j / i$ is assigned, which can be used in Table 2 to represent the upper $(j)$ or lower $(i)$ levels of the radiative transition. The wavelength $\left(\lambda_{j i}\right.$ in $\left.\AA\right)$, line strength $\left(S_{j i}\right.$ in atomic units, $\left.1 \mathrm{AU}=6.460 \times 10^{-36} \mathrm{~cm}^{2} \mathrm{esu}^{2}\right)$, oscillator strength $\left(f_{j i}\right.$ dimensionless), and radiative rate $\left(A_{j i}\right.$ in $\left.\mathrm{s}^{-1}\right)$ for all possible E1, M1, E2, and M2 transitions among the 359 levels, are listed in Table 2.

In a large-scale calculation, it is difficult to unambiguously label all of the states. Using the $L S J$-or $j j$ coupling schemes, the identifications and the corresponding configurations can be determined clearly for a majority of the states listed in Table 1. However, in the symmetry of $3 / 2^{\circ}$ in $2 s^{2} 2 p^{2} n p$ configurations and $3 / 2^{e}$ in $2 s^{2} 2 p^{2} n d$ configurations, the identifications of some states are not unique. The dominant components of the configuration basis for each state in both the $L S J$-and $j j$ coupling schemes are also given for each state in Table 1 to help to remove these ambiguities. The $j j$ notation is given directly by the MBPT calculations, and the $L S J$-notation is obtained using the $j j \rightarrow L S J$-transformation presented by Gaigalas et al. (2004).

For assessing the accuracy of the MBPT results, extensive MCDHF and subsequent RCI calculations are performed for Fe xx using the GRASP2K code (Jönsson et al. 2013). In the MCDHF method, the Hamiltonian is taken to be DiracCoulomb Hamiltonian $H_{\mathrm{DC}}$. The atomic state functions (ASFs) are approximated by expansions over $j j$-coupled configuration state functions (CSFs). Based on equal level weights of several states, the so-called extended optimal level (EOL) scheme (Dyall et al. 1989), both the radial parts of the Dirac orbitals and the expansion coefficients were optimized to selfconsistency in the relativistic self-consistent field procedure. In the subsequent RCI calculation (McKenzie et al. 1980a), the Breit interaction is computed in the low-frequency limit by multiplying the frequency with a scale factor of $10^{-6}$, and the other small corrections such as finite nuclear size, nuclear recoil, VP, and SE, are also included.

In the present MCDHF/RCI calculations, the configurations in the $M$ space of the above MBPT calculations are split up into the even and odd groups, and are chosen as the reference configurations. Then the multi-configuration expansions are obtained through single and double excitations of the orbitals in the reference configurations, with orbitals in an active set with principal quantum numbers $n=3, \ldots, 7$ and angular symmetries $s, p, d, f, g$, and $h$. To monitor the convergence of the calculated energies and transition parameters, the active sets were increased in a systematic way by adding layers of orbitals. For the $n=7$ expansion this resulted in 1182541 CSFs with odd parity and 1150043 CSFs with even parity. The self-consistent field calculations for each layer of orbitals are followed by the RCI calculations. A more detailed description of the calculation procedure can be found in our very recent work for $\mathrm{Mg}$-like $\mathrm{Cu}$ XVIII and $\mathrm{Kr}$ Xxv ( $\mathrm{Si}$ et al. 2015b, 2015a).

\section{COMPARISONS}

Employing the MBPT approach, we have carried out systematic and highly accurate calculations for energy levels and transition rates of the beryllium and carbon isoelectronic sequences (Wang et al. 2014, 2015). We now focus our attention on the nitrogen isoelectronic sequence, and our work greatly increases accurate results for nitrogen-like ions in quantity. The accuracy of our MBPT results will be accessed, in the following, by comparing with available observed values, as well as with other elaborate/systematic calculations.

\subsection{Energy Levels}

Our MBPT values agree well with the NIST observations for all the $182 n=2$ states of the 13 ions considered here, i.e., the differences are within $0.1 \%$ for 157 levels, and are between $0.1 \%$ and $0.2 \%$ for the remaining 25 levels. The previous theoretical results, including the MBPT calculations reported by $\mathrm{Gu}$ (2005a, hereafter referred to as MBPT2) and the MCDHF and RCI calculations performed by Rynkun et al. (2014, MCDHF/RCI2), are the most accurate in the sequence so far when compared with the observed values. The relative differences between calculations and observations are within $0.1 \%$ for 150 levels in MBPT2, and 138 levels in MCDHF/ RCI2. The deviations are larger than $0.2 \%$ for 7 levels (up to $0.3 \%$ for $2 s^{2} 2 p^{3}{ }^{2} P_{3 / 2}$ in $\mathrm{Ar}$ XII) in MBPT2, and 14 levels (up to $0.34 \%$ for $2 s^{2} 2 p^{3}{ }^{2} D_{3 / 2}$ in CaxIv) in MCDHF/RCI2. Comparing with the MBPT2 and MCDHF/RCI2 calculations, there is generally a better agreement of the NIST values and our results due to the more effective electron correlation effects included within our work because of our consideration of more configurations in both the $N$ and $M$ spaces.

Recently, using the MCDHF and RCI method Radžiūte et al. (2015) reported the energies and transition rates for the 272 states of the $(2 s, 2 p)^{5}$ and $(2 s, 2 p)^{4} 3 l(l=0,1,2)$ configurations in N-like ions $\mathrm{Cr}$ xvIII, Fe xx, NixxII, and $\mathrm{Zn}$ xxIV (MCDHF/RCI3). Since effective configuration interaction effects have been taken into account, their high-accuracy data can be used to identify the observed spectra. Comparisons of the NIST and CHIANTI experimental results, the present calculations, and the MCDHF/RCI3 values for the $n=2$ states in Fe xx show good agreement, i.e., the mean relative deviations from the NIST and CHIANTI experimental values are $0.021 \%$ and $0.021 \%$ for this work, and $0.041 \%$ and $0.046 \%$ for the MCDHF/RCI3 results; plus, the mean (with standard deviation) of the relative differences between the two sets of calculated values is $0.015 \% \pm 0.015 \%$ for all 272 states of the $n=2,3$ configurations, which, again, is highly satisfactory.

The experimental values are sparse for the $n=3,4$ levels of $\mathrm{N}$-like ions. To confirm the accuracy of the present $n \geqslant 3$ results and show the importance of the electron correlation effects, we have performed another independent calculation for Fe xx using the MCDHF and RCI method. In Table 3, energies for the 344 levels of the $n=3,4$ complexes in Fe xx from the MBPT and MCDHF/RCI calculations in this work are compared with calculated values from a previous calculation using the AS code by Witthoeft et al. (2007). Also collected in Table 3 are experimental values from the NIST and CHIANTI databases. The deviations of the MCDHF/RCI and MBPT energies are plotted in Figure 1. It can be seen that the agreement between the two calculations is better than $0.08 \%$ 
Table 2

Wavelengths ( $\lambda$, in $\AA$ ), Line Strengths ( $S$, in Atomic Units), Absorption Oscillator Strengths ( $f$, Dimensionless), and Transition Rates $\left(A\right.$, in s $\left.{ }^{-1}\right)$ for the Transitions in N-like Ions with $Z=18-30$

\begin{tabular}{|c|c|c|c|c|c|c|}
\hline$Z$ & $j-i$ & Type & $\lambda$ & $S$ & $f$ & $A$ \\
\hline 26 & $2-1$ & M1 & $7.2170 \mathrm{E}+02$ & $8.729 \mathrm{EE}-01$ & $1.223 \mathrm{EE}-06$ & $1.566 \mathrm{E}+04$ \\
\hline 26 & $2-1$ & $\mathrm{E} 2$ & $7.2170 \mathrm{E}+02$ & $5.198 \mathrm{E}-04$ & $5.804 \mathrm{EE}-11$ & 7.433EE-01 \\
\hline 26 & $3-1$ & M1 & $5.6788 \mathrm{E}+02$ & $5.106 \mathrm{E}-02$ & 9.091EE-08 & $1.254 \mathrm{E}+03$ \\
\hline 26 & $3-1$ & $\mathrm{E} 2$ & $5.6788 \mathrm{E}+02$ & $1.066 \mathrm{E}-03$ & 2.443EE-10 & $3.369 \mathrm{E}+00$ \\
\hline 26 & $3-2$ & M1 & $2.6644 \mathrm{E}+03$ & $1.780 \mathrm{E}+00$ & $6.752 \mathrm{E}-07$ & $4.230 \mathrm{E}+02$ \\
\hline 26 & $3-2$ & $\mathrm{E} 2$ & $2.6644 \mathrm{E}+03$ & $1.909 \mathrm{E}-03$ & 4.237EE-12 & 2.654EE-03 \\
\hline 26 & $4-1$ & M1 & $3.8407 \mathrm{E}+02$ & $1.316 \mathrm{E}-01$ & 3.464EE-07 & $3.133 \mathrm{E}+04$ \\
\hline 26 & $4-1$ & E2 & $3.8407 \mathrm{E}+02$ & $1.016 \mathrm{E}-04$ & 7.528EE-11 & $6.808 \mathrm{E}+00$ \\
\hline 26 & $4-2$ & M1 & $8.2097 \mathrm{E}+02$ & $2.373 \mathrm{E}-01$ & 2.922EE-07 & $5.783 \mathrm{E}+03$ \\
\hline 26 & $4-2$ & $\mathrm{E} 2$ & $8.2097 \mathrm{E}+02$ & $3.518 \mathrm{E}-03$ & $2.669 \mathrm{EE}-10$ & $5.283 \mathrm{E}+00$ \\
\hline 26 & $4-3$ & E2 & $1.1866 \mathrm{E}+03$ & $3.125 \mathrm{E}-03$ & $5.234 \mathrm{EE}-11$ & 7.439EE-01 \\
\hline 26 & $5-1$ & M1 & $3.0918 \mathrm{E}+02$ & $1.273 \mathrm{E}-01$ & 4.164EE-07 & $2.905 \mathrm{E}+04$ \\
\hline 26 & $5-1$ & E2 & $3.0918 \mathrm{E}+02$ & $3.867 \mathrm{E}-06$ & 5.492EE-12 & 3.832EE-01 \\
\hline 26 & $5-2$ & M1 & $5.4092 \mathrm{E}+02$ & $1.020 \mathrm{E}+00$ & $1.906 \mathrm{E}-06$ & $4.344 \mathrm{E}+04$ \\
\hline 26 & $5-2$ & $\mathrm{E} 2$ & $5.4092 \mathrm{E}+02$ & $1.235 \mathrm{E}-03$ & 3.275EE-10 & $7.466 \mathrm{E}+00$ \\
\hline 26 & $5-3$ & M1 & $6.7870 \mathrm{E}+02$ & $5.600 \mathrm{E}-01$ & 5.561EE-07 & $1.208 \mathrm{E}+04$ \\
\hline 26 & $5-3$ & $\mathrm{E} 2$ & $6.7870 \mathrm{E}+02$ & $7.691 \mathrm{E}-03$ & $6.884 \mathrm{EE}-10$ & $1.495 \mathrm{E}+01$ \\
\hline 26 & $5-4$ & M1 & $1.5857 \mathrm{E}+03$ & $9.556 \mathrm{E}-01$ & $1.219 \mathrm{EE}-06$ & $1.616 \mathrm{E}+03$ \\
\hline 26 & $5-4$ & $\mathrm{E} 2$ & $1.5857 \mathrm{E}+03$ & $1.005 \mathrm{E}-03$ & $2.115 \mathrm{EE}-11$ & $2.806 \mathrm{EE}-02$ \\
\hline 26 & $6-1$ & E1 & $1.3287 \mathrm{E}+02$ & $8.191 \mathrm{E}-02$ & 4.681EE-02 & $1.179 \mathrm{E}+10$ \\
\hline 26 & $6-1$ & M2 & $1.3287 \mathrm{E}+02$ & $1.586 \mathrm{E}+00$ & $3.778 \mathrm{E}-10$ & $9.517 \mathrm{E}+01$ \\
\hline 26 & $6-2$ & E1 & $1.6285 \mathrm{E}+02$ & $6.935 \mathrm{E}-03$ & 3.234EE-03 & $5.423 \mathrm{E}+08$ \\
\hline 26 & $6-2$ & M2 & $1.6285 \mathrm{E}+02$ & $4.569 \mathrm{E}-01$ & $5.912 \mathrm{EE}-11$ & $9.914 \mathrm{E}+00$ \\
\hline 26 & $6-3$ & E1 & $1.7345 \mathrm{E}+02$ & $3.624 \mathrm{E}-03$ & $1.058 \mathrm{EE}-03$ & $2.345 \mathrm{E}+08$ \\
\hline 26 & $6-3$ & M2 & $1.7345 \mathrm{E}+02$ & $3.208 \mathrm{E}-01$ & $2.291 \mathrm{EE}-11$ & $5.079 \mathrm{E}+00$ \\
\hline 26 & $6-4$ & M2 & $2.0314 \mathrm{E}+02$ & $1.613 \mathrm{E}-01$ & $2.150 \mathrm{EE}-11$ & $1.158 \mathrm{E}+00$ \\
\hline 26 & $6-5$ & E1 & $2.3299 \mathrm{E}+02$ & $8.312 \mathrm{E}-04$ & 2.709EE-04 & $2.219 \mathrm{E}+07$ \\
\hline 26 & $6-5$ & M2 & $2.3299 \mathrm{E}+02$ & $2.804 \mathrm{E}-01$ & $1.239 \mathrm{EE}-11$ & $1.015 \mathrm{E}+00$ \\
\hline 26 & $7-1$ & E1 & $1.2186 \mathrm{E}+02$ & $5.958 \mathrm{E}-02$ & 3.713EE-02 & $1.668 \mathrm{E}+10$ \\
\hline 26 & $7-1$ & M2 & $1.2186 \mathrm{E}+02$ & $1.259 \mathrm{E}-01$ & $3.888 \mathrm{EE}-11$ & $1.746 \mathrm{E}+01$ \\
\hline 26 & $7-2$ & E1 & $1.4662 \mathrm{E}+02$ & $4.934 \mathrm{E}-04$ & $2.556 \mathrm{EE}-04$ & $7.930 \mathrm{E}+07$ \\
\hline 26 & $7-2$ & M2 & $1.4662 \mathrm{E}+02$ & $8.682 \mathrm{E}-01$ & $1.539 \mathrm{EE}-10$ & $4.776 \mathrm{E}+01$ \\
\hline 26 & $7-3$ & E1 & $1.5516 \mathrm{E}+02$ & $3.537 \mathrm{E}-04$ & 1.154EE-04 & $4.797 \mathrm{E}+07$ \\
\hline 26 & $7-3$ & M2 & $1.5516 \mathrm{E}+02$ & $3.142 \mathrm{E}-01$ & 3.133EE-11 & $1.302 \mathrm{E}+01$ \\
\hline 26 & $7-4$ & E1 & $1.7850 \mathrm{E}+02$ & $3.719 \mathrm{E}-05$ & $3.165 \mathrm{EE}-05$ & $3.313 \mathrm{E}+06$ \\
\hline 26 & $7-4$ & M2 & $1.7850 \mathrm{E}+02$ & $4.655 \mathrm{E}-01$ & $9.148 \mathrm{EE}-11$ & $9.576 \mathrm{E}+00$ \\
\hline 26 & $7-5$ & E1 & $2.0114 \mathrm{E}+02$ & $2.477 \mathrm{E}-03$ & $9.350 \mathrm{EE}-04$ & $1.541 \mathrm{E}+08$ \\
\hline 26 & $7-5$ & M2 & $2.0114 \mathrm{E}+02$ & $1.879 \mathrm{E}-03$ & $1.290 \mathrm{EE}-13$ & $2.127 \mathrm{E}-02$ \\
\hline 26 & $7-6$ & M1 & $1.4715 \mathrm{E}+03$ & $3.521 \mathrm{E}+00$ & $1.613 \mathrm{E}-06$ & $7.452 \mathrm{E}+03$ \\
\hline 26 & $7-6$ & $\mathrm{E} 2$ & $1.4715 \mathrm{E}+03$ & $2.981 \mathrm{E}-03$ & $2.618 \mathrm{EE}-11$ & $1.210 \mathrm{EE}-01$ \\
\hline 26 & $8-1$ & E1 & $1.1870 \mathrm{E}+02$ & $3.080 \mathrm{E}-02$ & $1.970 \mathrm{EE}-02$ & $1.865 \mathrm{E}+10$ \\
\hline 26 & $8-1$ & M2 & $1.1870 \mathrm{E}+02$ & $9.276 \mathrm{E}-02$ & 3.099EE-11 & $2.934 \mathrm{E}+01$ \\
\hline 26 & $8-2$ & E1 & $1.4207 \mathrm{E}+02$ & $7.929 \mathrm{E}-04$ & 4.238EE-04 & $2.801 \mathrm{E}+08$ \\
\hline 26 & $8-2$ & M2 & $1.4207 \mathrm{E}+02$ & $2.760 \mathrm{E}-01$ & $5.378 \mathrm{EE}-11$ & $3.555 \mathrm{E}+01$ \\
\hline 26 & $8-3$ & M2 & $1.5007 \mathrm{E}+02$ & $6.761 \mathrm{E}-02$ & 7.453EE-12 & $6.622 \mathrm{E}+00$ \\
\hline 26 & $8-4$ & E1 & $1.7180 \mathrm{E}+02$ & $1.070 \mathrm{E}-03$ & 9.455EE-04 & $2.137 \mathrm{E}+08$ \\
\hline 26 & $8-5$ & E1 & $1.9267 \mathrm{E}+02$ & $5.282 \mathrm{E}-05$ & $2.082 \mathrm{EE}-05$ & $7.481 \mathrm{E}+06$ \\
\hline 26 & $8-5$ & M2 & $1.9267 \mathrm{E}+02$ & $2.527 \mathrm{E}-01$ & $1.974 \mathrm{EE}-11$ & $7.094 \mathrm{E}+00$ \\
\hline 26 & $8-6$ & E2 & $1.1135 \mathrm{E}+03$ & $2.452 \mathrm{E}-03$ & $4.970 \mathrm{EE}-11$ & 8.022EE-01 \\
\hline 26 & $8-7$ & M1 & $4.5763 \mathrm{E}+03$ & $3.091 \mathrm{E}+00$ & $6.829 \mathrm{E}-07$ & $4.350 \mathrm{E}+02$ \\
\hline 26 & $8-7$ & E2 & $4.5763 \mathrm{E}+03$ & $2.980 \mathrm{E}-04$ & 1.305EE-13 & $8.315 \mathrm{EE}-05$ \\
\hline 26 & $9-1$ & E1 & $9.5944 \mathrm{E}+01$ & $2.710 \mathrm{E}-03$ & $2.145 \mathrm{EE}-03$ & $1.554 \mathrm{E}+09$ \\
\hline 26 & $9-1$ & M2 & $9.5944 \mathrm{E}+01$ & $1.329 \mathrm{E}-01$ & 8.407EE-11 & $6.092 \mathrm{E}+01$ \\
\hline 26 & $9-2$ & E1 & $1.1066 \mathrm{E}+02$ & $1.023 \mathrm{E}-01$ & 7.022EE-02 & $3.825 \mathrm{E}+10$ \\
\hline 26 & $9-2$ & M2 & $1.1066 \mathrm{E}+02$ & $7.046 \mathrm{E}-02$ & $2.906 \mathrm{EE}-11$ & $1.583 \mathrm{E}+01$ \\
\hline 26 & $9-3$ & E1 & $1.1545 \mathrm{E}+02$ & $9.015 \mathrm{E}-05$ & 3.953EE-05 & $2.968 \mathrm{E}+07$ \\
\hline 26 & $9-3$ & M2 & $1.1545 \mathrm{E}+02$ & $6.343 \mathrm{E}-01$ & $1.536 \mathrm{EE}-10$ & $1.153 \mathrm{E}+02$ \\
\hline 26 & $9-4$ & E1 & $1.2789 \mathrm{E}+02$ & $1.094 \mathrm{E}-02$ & $1.300 \mathrm{EE}-02$ & $2.650 \mathrm{E}+09$ \\
\hline 26 & $9-4$ & M2 & $1.2789 \mathrm{E}+02$ & $8.441 \mathrm{E}-02$ & $4.510 \mathrm{EE}-11$ & $9.196 \mathrm{E}+00$ \\
\hline 26 & $9-5$ & E1 & $1.3911 \mathrm{E}+02$ & $2.620 \mathrm{E}-03$ & $1.430 \mathrm{EE}-03$ & $4.929 \mathrm{E}+08$ \\
\hline 26 & $9-5$ & M2 & $1.3911 \mathrm{E}+02$ & $2.916 \mathrm{E}-02$ & 6.052EE-12 & $2.086 \mathrm{E}+00$ \\
\hline 26 & $9-6$ & M1 & $3.4526 \mathrm{E}+02$ & $5.357 \mathrm{E}-04$ & $1.046 \mathrm{EE}-09$ & $8.777 \mathrm{E}+01$ \\
\hline 26 & $9-6$ & E2 & $3.4526 \mathrm{E}+02$ & $2.185 \mathrm{E}-04$ & $1.486 \mathrm{EE}-10$ & $1.247 \mathrm{E}+01$ \\
\hline 26 & $9-7$ & M1 & $4.5111 \mathrm{E}+02$ & $1.660 \mathrm{E}-01$ & $3.720 \mathrm{EE}-07$ & $1.219 \mathrm{E}+04$ \\
\hline
\end{tabular}


Table 2

(Continued)

\begin{tabular}{|c|c|c|c|c|c|c|}
\hline$Z$ & $j-i$ & Type & $\lambda$ & $S$ & $f$ & $A$ \\
\hline 26 & $9-7$ & E2 & $4.5111 \mathrm{E}+02$ & $1.326 \mathrm{E}-06$ & $6.062 \mathrm{EE}-13$ & $1.987 \mathrm{EE}-02$ \\
\hline 26 & $9-8$ & M1 & $5.0044 \mathrm{E}+02$ & $4.812 \mathrm{E}-02$ & $1.944 \mathrm{EE}-07$ & $2.589 \mathrm{E}+03$ \\
\hline 26 & $9-8$ & E2 & $5.0044 \mathrm{E}+02$ & $1.509 \mathrm{E}-04$ & $1.011 \mathrm{EE}-10$ & $1.346 \mathrm{E}+00$ \\
\hline 26 & $10-1$ & E1 & $9.4510 \mathrm{E}+01$ & $3.994 \mathrm{E}-05$ & 3.209EE-05 & $1.598 \mathrm{E}+07$ \\
\hline 26 & $10-1$ & M2 & $9.4510 \mathrm{E}+01$ & $1.781 \mathrm{E}-02$ & $1.179 \mathrm{EE}-11$ & $5.870 \mathrm{E}+00$ \\
\hline 26 & $10-2$ & E1 & $1.0875 \mathrm{E}+02$ & $5.550 \mathrm{E}-05$ & $3.876 \mathrm{EE}-05$ & $1.457 \mathrm{E}+07$ \\
\hline 26 & $10-2$ & M2 & $1.0875 \mathrm{E}+02$ & $8.255 \mathrm{E}-01$ & 3.587EE-10 & $1.349 \mathrm{E}+02$ \\
\hline 26 & $10-3$ & E1 & $1.1338 \mathrm{E}+02$ & $1.257 \mathrm{E}-01$ & $5.611 \mathrm{EE}-02$ & $2.912 \mathrm{E}+10$ \\
\hline 26 & $10-3$ & M2 & $1.1338 \mathrm{E}+02$ & $1.552 \mathrm{E}+00$ & $3.967 \mathrm{E}-10$ & $2.058 \mathrm{E}+02$ \\
\hline 26 & $10-4$ & M2 & $1.2536 \mathrm{E}+02$ & $7.344 \mathrm{E}-01$ & 4.166EE-10 & $5.895 \mathrm{E}+01$ \\
\hline 26 & $10-5$ & E1 & $1.3612 \mathrm{E}+02$ & $4.019 \mathrm{E}-02$ & 2.242EE-02 & $5.381 \mathrm{E}+09$ \\
\hline 26 & $10-5$ & M2 & $1.3612 \mathrm{E}+02$ & $1.922 \mathrm{E}-02$ & $4.259 \mathrm{EE}-12$ & $1.022 \mathrm{E}+00$ \\
\hline 26 & $10-6$ & M1 & $3.2738 \mathrm{E}+02$ & $2.362 \mathrm{E}-01$ & 4.862EE-07 & $3.026 \mathrm{E}+04$ \\
\hline 26 & $10-6$ & E2 & $3.2738 \mathrm{E}+02$ & $5.495 \mathrm{E}-04$ & $4.382 \mathrm{EE}-10$ & $2.727 \mathrm{E}+01$ \\
\hline 26 & $10-7$ & M1 & $4.2106 \mathrm{E}+02$ & $2.492 \mathrm{E}-02$ & $5.984 \mathrm{EE}-08$ & $1.501 \mathrm{E}+03$ \\
\hline 26 & $10-7$ & E2 & $4.2106 \mathrm{E}+02$ & $2.290 \mathrm{E}-04$ & $1.288 \mathrm{EE}-10$ & $3.230 \mathrm{E}+00$ \\
\hline 26 & $10-8$ & $\mathrm{E} 2$ & $4.6373 E+02$ & $9.146 \mathrm{E}-05$ & $7.700 \mathrm{EE}-11$ & 7.961EE-01 \\
\hline 26 & $10-9$ & M1 & $6.3211 \mathrm{E}+03$ & $2.284 \mathrm{E}+00$ & $3.653 \mathrm{E}-07$ & $4.066 \mathrm{E}+01$ \\
\hline 26 & $10-9$ & E2 & $6.3211 \mathrm{E}+03$ & $1.964 \mathrm{E}-03$ & $3.265 \mathrm{EE}-13$ & 3.633EE-05 \\
\hline 26 & $11-1$ & E1 & $8.3677 \mathrm{E}+01$ & $9.587 \mathrm{E}-04$ & 8.701EE-04 & $1.658 \mathrm{E}+09$ \\
\hline 26 & $11-1$ & M2 & $8.3677 \mathrm{E}+01$ & $2.016 \mathrm{E}-01$ & $1.923 \mathrm{EE}-10$ & $3.664 \mathrm{E}+02$ \\
\hline 26 & $11-2$ & E1 & $9.4651 \mathrm{E}+01$ & $3.466 \mathrm{E}-02$ & $2.781 \mathrm{EE}-02$ & $4.141 \mathrm{E}+10$ \\
\hline 26 & $11-2$ & M2 & $9.4651 \mathrm{E}+01$ & $6.441 \mathrm{E}-03$ & 4.244EE-12 & $6.320 \mathrm{E}+00$ \\
\hline 26 & $11-3$ & M2 & $9.8137 \mathrm{E}+01$ & $5.754 \mathrm{E}-02$ & $2.268 \mathrm{EE}-11$ & $4.712 \mathrm{E}+01$ \\
\hline 26 & $11-4$ & E1 & $1.0699 \mathrm{E}+02$ & $4.123 \mathrm{E}-02$ & $5.853 \mathrm{EE}-02$ & $3.411 \mathrm{E}+10$ \\
\hline 26 & $11-5$ & E1 & $1.1473 \mathrm{E}+02$ & $3.138 \mathrm{E}-03$ & $2.077 \mathrm{EE}-03$ & $2.105 E+09$ \\
\hline 26 & $11-5$ & M2 & $1.1473 \mathrm{E}+02$ & $2.480 \mathrm{E}-01$ & 9.179EE-11 & $9.303 E+01$ \\
\hline 26 & $11-6$ & E2 & $2.2602 \mathrm{E}+02$ & $9.446 \mathrm{E}-06$ & 2.289EE-11 & $8.967 \mathrm{E}+00$ \\
\hline 26 & $11-7$ & M1 & $2.6704 \mathrm{E}+02$ & $1.512 \mathrm{E}-01$ & $5.725 \mathrm{EE}-07$ & $1.071 \mathrm{E}+05$ \\
\hline 26 & $11-7$ & $\mathrm{E} 2$ & $2.6704 \mathrm{E}+02$ & $2.530 \mathrm{E}-05$ & $5.578 \mathrm{EE}-11$ & $1.043 \mathrm{E}+01$ \\
\hline 26 & $11-8$ & M1 & $2.8359 \mathrm{E}+02$ & $2.118 \mathrm{E}-02$ & $1.510 \mathrm{EE}-07$ & $1.252 \mathrm{E}+04$ \\
\hline 26 & $11-9$ & M1 & $6.5444 \mathrm{E}+02$ & $7.051 \mathrm{E}-03$ & $1.089 \mathrm{EE}-08$ & $3.393 E+02$ \\
\hline 26 & $11-9$ & E2 & $6.5444 \mathrm{E}+02$ & $3.435 \mathrm{E}-03$ & $5.144 \mathrm{EE}-10$ & $1.602 \mathrm{E}+01$ \\
\hline 26 & $11-10$ & E2 & $7.3002 \mathrm{E}+02$ & $4.756 \mathrm{E}-03$ & 3.421EE-10 & $1.285 \mathrm{E}+01$ \\
\hline 26 & $12-1$ & E1 & $8.0493 \mathrm{E}+01$ & $4.195 \mathrm{E}-03$ & 3.957EE-03 & $4.074 \mathrm{E}+09$ \\
\hline 26 & $12-1$ & M2 & $8.0493 \mathrm{E}+01$ & $4.967 \mathrm{E}-01$ & $5.322 \mathrm{EE}-10$ & $5.479 \mathrm{E}+02$ \\
\hline 26 & $12-2$ & E1 & $9.0597 \mathrm{E}+01$ & $1.984 \mathrm{E}-02$ & $1.663 \mathrm{EE}-02$ & $1.352 \mathrm{E}+10$ \\
\hline 26 & $12-2$ & M2 & $9.0597 \mathrm{E}+01$ & $9.584 \mathrm{E}-02$ & 7.202EE-11 & $5.853 \mathrm{E}+01$ \\
\hline 26 & $12-3$ & E1 & $9.3787 \mathrm{E}+01$ & $1.508 \mathrm{E}-01$ & $8.141 \mathrm{EE}-02$ & $9.260 \mathrm{E}+10$ \\
\hline 26 & $12-3$ & M2 & $9.3787 \mathrm{E}+01$ & $2.176 \mathrm{E}-01$ & $9.825 \mathrm{EE}-11$ & $1.118 \mathrm{E}+02$ \\
\hline 26 & $12-4$ & E1 & $1.0184 \mathrm{E}+02$ & $1.738 \mathrm{E}-02$ & 2.593EE-02 & $8.338 \mathrm{E}+09$ \\
\hline 26 & $12-4$ & M2 & $1.0184 \mathrm{E}+02$ & $4.189 \mathrm{E}-02$ & 4.433EE-11 & $1.426 \mathrm{E}+01$ \\
\hline 26 & $12-5$ & E1 & $1.0882 \mathrm{E}+02$ & $2.289 \mathrm{E}-02$ & $1.597 \mathrm{EE}-02$ & $8.995 \mathrm{E}+09$ \\
\hline 26 & $12-5$ & M2 & $1.0882 \mathrm{E}+02$ & $5.286 \mathrm{E}-02$ & $2.292 \mathrm{EE}-11$ & $1.291 \mathrm{E}+01$ \\
\hline 26 & $12-6$ & M1 & $2.0420 \mathrm{E}+02$ & $2.546 \mathrm{E}-02$ & 8.404EE-08 & $2.017 \mathrm{E}+04$ \\
\hline 26 & $12-6$ & E2 & $2.0420 \mathrm{E}+02$ & $3.048 \mathrm{E}-06$ & $1.002 \mathrm{EE}-11$ & $2.404 \mathrm{E}+00$ \\
\hline 26 & $12-7$ & M1 & $2.3711 \mathrm{E}+02$ & $8.340 \mathrm{E}-04$ & 3.556EE-09 & $4.219 \mathrm{E}+02$ \\
\hline 26 & $12-7$ & E2 & $2.3711 \mathrm{E}+02$ & $6.680 \mathrm{E}-05$ & 2.103EE-10 & $2.496 \mathrm{E}+01$ \\
\hline 26 & $12-8$ & M1 & $2.5006 \mathrm{E}+02$ & $7.027 \mathrm{E}-03$ & $5.682 \mathrm{EE}-08$ & $3.030 \mathrm{E}+03$ \\
\hline 26 & $12-8$ & $\mathrm{E} 2$ & $2.5006 \mathrm{E}+02$ & $2.066 \mathrm{E}-05$ & $1.109 \mathrm{EE}-10$ & $5.917 \mathrm{E}+00$ \\
\hline 26 & $12-9$ & M1 & $4.9981 \mathrm{E}+02$ & $2.248 \mathrm{E}-01$ & 4.547EE-07 & $1.214 \mathrm{E}+04$ \\
\hline 26 & $12-9$ & $\mathrm{E} 2$ & $4.9981 \mathrm{E}+02$ & $8.670 \mathrm{E}-04$ & $2.915 \mathrm{EE}-10$ & $7.782 \mathrm{E}+00$ \\
\hline 26 & $12-10$ & M1 & $5.4273 \mathrm{E}+02$ & $1.128 \mathrm{E}-01$ & $1.401 \mathrm{EE}-07$ & $4.759 \mathrm{E}+03$ \\
\hline 26 & $12-10$ & $\mathrm{E} 2$ & $5.4273 \mathrm{E}+02$ & $7.284 \mathrm{E}-05$ & $1.275 \mathrm{EE}-11$ & 4.331EE-01 \\
\hline 26 & $12-11$ & M1 & $2.1154 \mathrm{E}+03$ & $2.869 \mathrm{E}-01$ & $2.742 \mathrm{EE}-07$ & $2.044 \mathrm{E}+02$ \\
\hline 26 & $12-11$ & E2 & $2.1154 \mathrm{E}+03$ & $1.834 \mathrm{E}-04$ & $1.627 \mathrm{EE}-12$ & $1.212 \mathrm{EE}-03$ \\
\hline 26 & $13-1$ & E1 & $7.4627 \mathrm{E}+01$ & $4.883 \mathrm{E}-05$ & 4.969EE-05 & $1.190 \mathrm{E}+08$ \\
\hline 26 & $13-1$ & M2 & $7.4627 \mathrm{E}+01$ & $1.819 \mathrm{E}-01$ & $2.446 \mathrm{EE}-10$ & $5.860 \mathrm{E}+02$ \\
\hline 26 & $13-2$ & E1 & $8.3233 \mathrm{E}+01$ & $1.497 \mathrm{E}-02$ & $1.366 \mathrm{EE}-02$ & $2.630 \mathrm{E}+10$ \\
\hline 26 & $13-2$ & M2 & $8.3233 \mathrm{E}+01$ & $7.836 \mathrm{E}-02$ & 7.594EE-11 & $1.462 \mathrm{E}+02$ \\
\hline 26 & $13-3$ & M2 & $8.5917 \mathrm{E}+01$ & $8.036 \mathrm{E}-02$ & $4.720 \mathrm{EE}-11$ & $1.280 \mathrm{E}+02$ \\
\hline 26 & $13-4$ & E1 & $9.2624 \mathrm{E}+01$ & $2.873 \mathrm{E}-03$ & 4.711EE-03 & $3.663 \mathrm{E}+09$ \\
\hline 26 & $13-5$ & E1 & $9.8370 \mathrm{E}+01$ & $8.249 \mathrm{E}-02$ & $6.368 \mathrm{EE}-02$ & $8.779 \mathrm{E}+10$ \\
\hline 26 & $13-5$ & M2 & $9.8370 \mathrm{E}+01$ & $5.010 \mathrm{E}-01$ & $2.941 \mathrm{EE}-10$ & $4.054 \mathrm{E}+02$ \\
\hline
\end{tabular}


Table 2

(Continued)

\begin{tabular}{|c|c|c|c|c|c|c|}
\hline$Z$ & $j-i$ & Type & $\lambda$ & $S$ & $f$ & $A$ \\
\hline 26 & $13-6$ & E2 & $1.7025 \mathrm{E}+02$ & $7.128 \mathrm{E}-07$ & $4.042 \mathrm{EE}-12$ & $2.790 \mathrm{E}+00$ \\
\hline 26 & $13-7$ & M1 & $1.9253 \mathrm{E}+02$ & $1.713 \mathrm{E}-02$ & 8.993EE-08 & $3.237 \mathrm{E}+04$ \\
\hline 26 & $13-7$ & E2 & $1.9253 \mathrm{E}+02$ & $3.238 \mathrm{E}-06$ & $1.905 \mathrm{EE}-11$ & $6.855 \mathrm{E}+00$ \\
\hline 26 & $13-8$ & M1 & $2.0098 \mathrm{E}+02$ & $1.057 \mathrm{E}-02$ & $1.063 \mathrm{EE}-07$ & $1.755 \mathrm{E}+04$ \\
\hline 26 & $13-9$ & M1 & $3.3587 \mathrm{E}+02$ & $6.243 \mathrm{E}-02$ & 1.879EE-07 & $2.222 \mathrm{E}+04$ \\
\hline 26 & $13-9$ & E2 & $3.3587 \mathrm{E}+02$ & $4.754 \mathrm{E}-04$ & $5.267 \mathrm{EE}-10$ & $6.229 \mathrm{E}+01$ \\
\hline 26 & $13-10$ & E2 & $3.5472 \mathrm{E}+02$ & $1.369 \mathrm{E}-03$ & $8.586 \mathrm{EE}-10$ & $1.366 \mathrm{E}+02$ \\
\hline 26 & $13-11$ & M1 & $6.8998 \mathrm{E}+02$ & $5.152 \mathrm{E}-01$ & $1.510 \mathrm{EE}-06$ & $2.115 \mathrm{E}+04$ \\
\hline 26 & $13-12$ & M1 & $1.0240 \mathrm{E}+03$ & $9.664 \mathrm{E}-01$ & $9.541 \mathrm{EE}-07$ & $1.214 \mathrm{E}+04$ \\
\hline 26 & $13-12$ & E2 & $1.0240 \mathrm{E}+03$ & $2.761 \mathrm{E}-03$ & $1.079 \mathrm{EE}-10$ & $1.373 \mathrm{E}+00$ \\
\hline 26 & $14-1$ & M1 & $5.1189 \mathrm{E}+01$ & $1.023 \mathrm{E}-04$ & 2.020EE-09 & $5.142 \mathrm{E}+03$ \\
\hline 26 & $14-1$ & E2 & $5.1189 \mathrm{E}+01$ & $1.560 \mathrm{E}-05$ & 4.883EE-09 & $1.243 \mathrm{E}+04$ \\
\hline 26 & $14-2$ & M1 & $5.5097 \mathrm{E}+01$ & $1.866 \mathrm{E}-04$ & 3.424EE-09 & $7.523 \mathrm{E}+03$ \\
\hline 26 & $14-2$ & E2 & $5.5097 \mathrm{E}+01$ & $1.632 \mathrm{E}-04$ & 4.096EE-08 & $9.001 \mathrm{E}+04$ \\
\hline 26 & $14-3$ & M1 & $5.6260 \mathrm{E}+01$ & $8.306 \mathrm{E}-05$ & $9.950 \mathrm{EE}-10$ & $3.145 \mathrm{E}+03$ \\
\hline 26 & $14-3$ & E2 & $5.6260 \mathrm{E}+01$ & $2.862 \mathrm{E}-04$ & 4.498EE-08 & $1.422 \mathrm{E}+05$ \\
\hline 26 & $14-4$ & M1 & $5.9061 \mathrm{E}+01$ & $8.144 \mathrm{E}-05$ & 2.788EE-09 & $2.666 \mathrm{E}+03$ \\
\hline 26 & $14-4$ & E2 & $5.9061 \mathrm{E}+01$ & $6.797 \mathrm{E}-05$ & 2.770EE-08 & $2.648 \mathrm{E}+04$ \\
\hline 26 & $14-5$ & M1 & $6.1346 \mathrm{E}+01$ & $1.471 \mathrm{E}-05$ & 2.424EE-10 & $4.296 \mathrm{E}+02$ \\
\hline 26 & $14-5$ & E2 & $6.1346 \mathrm{E}+01$ & $2.373 \mathrm{E}-06$ & 4.315EE-10 & $7.648 \mathrm{E}+02$ \\
\hline 26 & $14-6$ & E1 & $8.3270 \mathrm{E}+01$ & $3.158 \mathrm{E}-03$ & $1.920 \mathrm{EE}-03$ & $2.770 \mathrm{E}+09$ \\
\hline 26 & $14-6$ & M2 & $8.3270 \mathrm{E}+01$ & $1.550 \mathrm{E}+00$ & $1.000 \mathrm{E}-09$ & $1.443 \mathrm{E}+03$ \\
\hline 26 & $14-7$ & E1 & $8.8265 \mathrm{E}+01$ & $2.046 \mathrm{E}-03$ & $1.761 \mathrm{EE}-03$ & $1.507 \mathrm{E}+09$ \\
\hline 26 & $14-7$ & M2 & $8.8265 \mathrm{E}+01$ & $7.668 \mathrm{E}-02$ & $6.232 \mathrm{EE}-11$ & $5.335 \mathrm{E}+01$ \\
\hline 26 & $14-8$ & E1 & $9.0001 \mathrm{E}+01$ & $6.885 \mathrm{E}-04$ & $1.162 \mathrm{EE}-03$ & $4.784 \mathrm{E}+08$ \\
\hline 26 & $14-8$ & M2 & $9.0001 \mathrm{E}+01$ & $2.121 \mathrm{E}-01$ & 3.252EE-10 & $1.339 \mathrm{E}+02$ \\
\hline 26 & $14-9$ & E1 & $1.0974 \mathrm{E}+02$ & $4.008 \mathrm{E}-02$ & 2.773EE-02 & $1.536 \mathrm{E}+10$ \\
\hline 26 & $14-9$ & M2 & $1.0974 \mathrm{E}+02$ & $1.823 \mathrm{E}-01$ & 7.708EE-11 & $4.269 \mathrm{E}+01$ \\
\hline 26 & $14-10$ & E1 & $1.1168 \mathrm{E}+02$ & $1.053 \mathrm{E}-01$ & 4.773EE-02 & $3.829 \mathrm{E}+10$ \\
\hline 26 & $14-10$ & M2 & $1.1168 \mathrm{E}+02$ & $3.159 \mathrm{E}-01$ & 8.449EE-11 & $6.778 \mathrm{E}+01$ \\
\hline 26 & $14-11$ & E1 & $1.3184 \mathrm{E}+02$ & $3.709 \mathrm{E}-02$ & 4.273EE-02 & $8.198 \mathrm{E}+09$ \\
\hline 26 & $14-11$ & M2 & $1.3184 \mathrm{E}+02$ & $4.290 \mathrm{E}-01$ & 2.092EE-10 & $4.014 \mathrm{E}+01$ \\
\hline 26 & $14-12$ & E1 & $1.4061 \mathrm{E}+02$ & $1.465 \mathrm{E}-01$ & 7.913EE-02 & $2.670 \mathrm{E}+10$ \\
\hline 26 & $14-12$ & M2 & $1.4061 \mathrm{E}+02$ & $1.403 \mathrm{E}-01$ & $2.821 \mathrm{EE}-11$ & $9.519 \mathrm{E}+00$ \\
\hline 26 & $14-13$ & E1 & $1.6299 \mathrm{E}+02$ & $1.178 \mathrm{E}-02$ & $1.098 \mathrm{EE}-02$ & $1.378 \mathrm{E}+09$ \\
\hline 26 & $14-13$ & M2 & $1.6299 \mathrm{E}+02$ & $1.230 \mathrm{E}-02$ & 3.176EE-12 & $3.987 \mathrm{E}-01$ \\
\hline 26 & $15-1$ & M1 & $4.8512 \mathrm{E}+01$ & $1.080 \mathrm{E}-05$ & $2.252 \mathrm{EE}-10$ & $1.276 \mathrm{E}+03$ \\
\hline 26 & $15-1$ & E2 & $4.8512 \mathrm{E}+01$ & $6.872 \mathrm{E}-07$ & $2.527 \mathrm{EE}-10$ & $1.432 \mathrm{E}+03$ \\
\hline 26 & $15-2$ & M1 & $5.2008 \mathrm{E}+01$ & $1.277 \mathrm{E}-07$ & $2.481 \mathrm{EE}-12$ & $1.224 \mathrm{E}+01$ \\
\hline 26 & $15-2$ & E2 & $5.2008 \mathrm{E}+01$ & $3.422 \mathrm{E}-05$ & $1.021 \mathrm{EE}-08$ & $5.036 \mathrm{E}+04$ \\
\hline 26 & $15-3$ & E2 & $5.3043 \mathrm{E}+01$ & $7.596 \mathrm{E}-05$ & 1.424EE-08 & $1.013 \mathrm{E}+05$ \\
\hline 26 & $15-4$ & M1 & $5.5525 \mathrm{E}+01$ & $1.117 \mathrm{E}-08$ & $4.068 \mathrm{EE}-13$ & $8.801 \mathrm{E}-01$ \\
\hline 26 & $15-5$ & M1 & $5.7540 \mathrm{E}+01$ & $1.536 \mathrm{E}-04$ & $2.699 \mathrm{E}-09$ & $1.088 \mathrm{E}+04$ \\
\hline 26 & $15-5$ & E2 & $5.7540 \mathrm{E}+01$ & $1.519 \mathrm{E}-04$ & $3.348 \mathrm{E}-08$ & $1.349 \mathrm{E}+05$ \\
\hline 26 & $15-6$ & M2 & $7.6411 \mathrm{E}+01$ & $2.033 \mathrm{E}-01$ & $1.697 \mathrm{E}-10$ & $5.817 \mathrm{E}+02$ \\
\hline 26 & $15-7$ & E1 & $8.0596 \mathrm{E}+01$ & $1.378 \mathrm{E}-04$ & $1.299 \mathrm{E}-04$ & $2.667 \mathrm{E}+08$ \\
\hline 26 & $15-7$ & M2 & $8.0596 \mathrm{E}+01$ & $5.794 \mathrm{E}-01$ & $6.185 \mathrm{E}-10$ & $1.270 \mathrm{E}+03$ \\
\hline 26 & $15-8$ & E1 & $8.2041 \mathrm{E}+01$ & $4.628 \mathrm{E}-04$ & $8.567 \mathrm{E}-04$ & $8.490 \mathrm{E}+08$ \\
\hline 26 & $15-9$ & E1 & $9.8128 \mathrm{E}+01$ & $3.794 \mathrm{E}-02$ & $2.936 \mathrm{E}-02$ & $4.068 \mathrm{E}+10$ \\
\hline 26 & $15-9$ & M2 & $9.8128 \mathrm{E}+01$ & $1.089 \mathrm{E}-01$ & $6.439 \mathrm{E}-11$ & $8.920 \mathrm{E}+01$ \\
\hline 26 & $15-10$ & M2 & $9.9676 \mathrm{E}+01$ & $8.885 \mathrm{E}-01$ & $3.342 \mathrm{E}-10$ & $6.732 \mathrm{E}+02$ \\
\hline 26 & $15-11$ & E1 & $1.1544 \mathrm{E}+02$ & $3.698 \mathrm{E}-03$ & $4.865 \mathrm{E}-03$ & $2.435 \mathrm{E}+09$ \\
\hline 26 & $15-12$ & E1 & $1.2210 \mathrm{E}+02$ & $5.737 \mathrm{E}-02$ & $3.568 \mathrm{E}-02$ & $3.193 \mathrm{E}+10$ \\
\hline 26 & $15-12$ & M2 & $1.2210 \mathrm{E}+02$ & $4.963 \mathrm{E}-02$ & $1.523 \mathrm{E}-11$ & $1.363 \mathrm{E}+01$ \\
\hline 26 & $15-13$ & E1 & $1.3863 \mathrm{E}+02$ & $7.299 \mathrm{E}-02$ & $7.996 \mathrm{E}-02$ & $2.775 \mathrm{E}+10$ \\
\hline 26 & $15-14$ & M1 & $9.2763 \mathrm{E}+02$ & $1.321 \mathrm{E}+00$ & $1.440 \mathrm{E}-06$ & $2.232 \mathrm{E}+04$ \\
\hline 26 & $15-14$ & E2 & $9.2763 \mathrm{E}+02$ & $2.538 \mathrm{E}-03$ & $1.335 \mathrm{E}-10$ & $2.069 \mathrm{E}+00$ \\
\hline
\end{tabular}

Note. Only transitions among the $n=2$ levels in Fe xx are shown here.

(This table is available in its entirety in machine-readable form.)

for all the 344 levels. The mean (with standard deviation) of the relative differences between the two sets of energy values is $0.023 \% \pm 0.012 \%$, which is highly satisfactory.
As shown in Table 3, experimental observations are largely missing, i.e., the NIST and CHIANTI databases list the energies for 27 and 37 out of the $344 n=3$, 4 levels in Fe xx. 
Table 3

Level Energies (in eV) for the $n=3,4$ Levels in Fe xx

\begin{tabular}{|c|c|c|c|c|c|}
\hline \multirow[b]{2}{*}{ Level } & \multicolumn{5}{|c|}{ Energy $(\mathrm{eV})$} \\
\hline & NIST $^{\mathrm{a}}$ & CHIANTI $^{\mathrm{b}}$ & $\mathrm{MBPT}^{\mathrm{c}}$ & $\mathrm{MCDHF} / \mathrm{RCI}^{\mathrm{d}}$ & $\mathrm{AS}^{\mathrm{e}}$ \\
\hline $2 s^{2} 2 p^{2}\left({ }^{3} P\right) 3 s{ }^{4} P_{1 / 2}$ & $\cdots$ & 887.355 & 887.256 & 887.403 & 889.851 \\
\hline $2 s^{2} 2 p^{2}\left({ }^{3} P\right) 3 s \quad{ }^{4} P_{3 / 2}$ & $\cdots$ & 895.581 & 895.508 & 895.656 & 897.924 \\
\hline $2 s^{2} 2 p^{2}\left({ }^{3} P\right) 3 s^{2} P_{1 / 2}$ & $\cdots$ & $\ldots$ & 899.163 & 899.367 & 901.900 \\
\hline $2 s^{2} 2 p^{2}\left({ }^{3} P\right) 3 s{ }^{4} P_{5 / 2}$ & $\cdots$ & 899.702 & 900.731 & 900.888 & 903.450 \\
\hline $2 s^{2} 2 p^{2}\left({ }^{3} P\right) 3 s^{2} P_{3 / 2}$ & $\cdots$ & $\ldots$ & 904.521 & 904.731 & 907.556 \\
\hline $2 s^{2} 2 p^{2}\left({ }^{3} P\right) 3 p{ }^{4} D_{1 / 2}$ & $\cdots$ & $\cdots$ & 912.215 & 912.364 & 914.791 \\
\hline $2 s^{2} 2 p^{2}\left({ }^{1} D\right) 3 s^{2} D_{5 / 2}$ & $\cdots$ & $\cdots$ & 917.442 & 917.635 & 920.142 \\
\hline $2 s^{2} 2 p^{2}\left({ }^{3} P\right) 3 p{ }^{4} D_{3 / 2}$ & $\cdots$ & 916.602 & 917.687 & 917.834 & 920.134 \\
\hline $2 s^{2} 2 p^{2}\left({ }^{1} D\right) 3 s^{2} D_{3 / 2}$ & $\cdots$ & $\ldots$ & 918.679 & 918.887 & 921.394 \\
\hline $2 s^{2} 2 p^{2}\left({ }^{3} P\right) 3 p{ }^{2} S_{1 / 2}$ & $\cdots$ & $\ldots$ & 920.003 & 920.158 & 922.438 \\
\hline $2 s^{2} 2 p^{2}\left({ }^{3} P\right) 3 p{ }^{4} P_{3 / 2}$ & $\cdots$ & 923.659 & 923.572 & 923.737 & 926.195 \\
\hline $2 s^{2} 2 p^{2}\left({ }^{3} P\right) 3 p{ }^{4} D_{5 / 2}$ & $\cdots$ & 924.884 & 924.893 & 925.038 & 927.226 \\
\hline $2 s^{2} 2 p^{2}\left({ }^{3} P\right) 3 p{ }^{4} P_{1 / 2}$ & $\cdots$ & $\cdots$ & 926.421 & 926.581 & 928.810 \\
\hline $2 s^{2} 2 p^{2}\left({ }^{3} P\right) 3 p{ }^{4} P_{5 / 2}$ & $\cdots$ & $\ldots$ & 927.206 & 927.372 & 929.974 \\
\hline $2 s^{2} 2 p^{2}\left({ }^{3} P\right) 3 p p^{2} D_{3 / 2}$ & $\cdots$ & $\ldots$ & 928.803 & 928.983 & 931.354 \\
\hline $2 s^{2} 2 p^{2}\left({ }^{3} P\right) 3 p{ }^{4} D_{7 / 2}$ & $\cdots$ & 930.341 & 930.078 & 930.233 & 932.688 \\
\hline $2 s^{2} 2 p^{2}\left({ }^{3} P\right) 3 p{ }^{4} S_{3 / 2}$ & $\cdots$ & 933.122 & 933.058 & 933.234 & 935.582 \\
\hline $2 s^{2} 2 p^{2}\left({ }^{1} S\right) 3 s^{2} S_{1 / 2}$ & $\ldots$ & $\ldots$ & 933.892 & 934.065 & 935.557 \\
\hline $2 s^{2} 2 p^{2}\left({ }^{3} P\right) 3 p{ }^{2} P_{3 / 2}$ & $\cdots$ & $\cdots$ & 935.816 & 936.045 & 938.679 \\
\hline $2 s^{2} 2 p^{2}\left({ }^{3} P\right) 3 p{ }^{2} D_{5 / 2}$ & $\ldots$ & $\ldots$ & 936.508 & 936.707 & 939.294 \\
\hline $2 s^{2} 2 p^{2}\left({ }^{3} P\right) 3 p{ }^{2} P_{1 / 2}$ & $\cdots$ & $\cdots$ & 939.099 & 939.320 & 941.691 \\
\hline $2 s^{2} 2 p^{2}\left({ }^{1} D\right) 3 p{ }^{2} F_{5 / 2}$ & $\ldots$ & $\ldots$ & 945.675 & 945.858 & 948.449 \\
\hline $2 s^{2} 2 p^{2}\left({ }^{3} P\right) 3 d^{4} F_{3 / 2}$ & $\cdots$ & 947.095 & 946.845 & 947.053 & 949.554 \\
\hline $2 s 2 p^{3}\left({ }^{5} S\right) 3 s{ }^{6} S_{5 / 2}$ & $\ldots$ & $\ldots$ & 947.222 & 947.223 & 947.807 \\
\hline $2 s^{2} 2 p^{2}\left({ }^{1} D\right) 3 p{ }^{2} F_{7 / 2}$ & $\cdots$ & $\cdots$ & 947.512 & 947.704 & 950.125 \\
\hline $2 s^{2} 2 p^{2}\left({ }^{1} D\right) 3 p{ }^{2} D_{3 / 2}$ & $\cdots$ & $\cdots$ & 948.346 & 948.590 & 951.169 \\
\hline $2 s^{2} 2 p^{2}\left({ }^{3} P\right) 3 d{ }^{4} D_{5 / 2}$ & $\cdots$ & 949.925 & 949.663 & 949.876 & 952.528 \\
\hline $2 s^{2} 2 p^{2}\left({ }^{1} D\right) 3 p{ }^{2} D_{5 / 2}$ & $\cdots$ & $\ldots$ & 950.483 & 950.752 & 953.573 \\
\hline $2 s^{2} 2 p^{2}\left({ }^{1} D\right) 3 p{ }^{2} P_{1 / 2}$ & $\cdots$ & $\cdots$ & 951.568 & 951.810 & 954.445 \\
\hline $2 s^{2} 2 p^{2}\left({ }^{3} P\right) 3 d^{2} P_{3 / 2}$ & $\cdots$ & 956.225 & 955.961 & 956.185 & 958.636 \\
\hline $2 s^{2} 2 p^{2}\left({ }^{3} P\right) 3 d^{4} F_{7 / 2}$ & $\cdots$ & 956.364 & 956.098 & 956.314 & 958.844 \\
\hline $2 s^{2} 2 p^{2}\left({ }^{3} P\right) 3 d{ }^{4} F_{5 / 2}$ & $\cdots$ & 957.333 & 957.029 & 957.261 & 959.879 \\
\hline $2 s^{2} 2 p^{2}\left({ }^{3} P\right) 3 d{ }^{4} D_{1 / 2}$ & $\cdots$ & $\ldots$ & 957.031 & 957.246 & 959.493 \\
\hline $2 s^{2} 2 p^{2}\left({ }^{1} D\right) 3 p{ }^{2} P_{3 / 2}$ & $\cdots$ & 959.600 & 958.815 & 959.069 & 961.314 \\
\hline $2 s^{2} 2 p^{2}\left({ }^{3} P\right) 3 d{ }^{4} D_{3 / 2}$ & $\cdots$ & $\ldots$ & 960.139 & 960.367 & 962.993 \\
\hline $2 s^{2} 2 p^{2}\left({ }^{3} P\right) 3 d{ }^{4} D_{7 / 2}$ & $\ldots$ & $\ldots$ & 960.413 & 960.644 & 963.407 \\
\hline $2 s^{2} 2 p^{2}\left({ }^{3} P\right) 3 d{ }^{2} F_{5 / 2}$ & $\cdots$ & 960.711 & 960.594 & 960.842 & 963.608 \\
\hline $2 s^{2} 2 p^{2}\left({ }^{3} P\right) 3 d{ }^{4} F_{9 / 2}$ & $\ldots$ & $\ldots$ & 960.748 & 960.978 & 963.815 \\
\hline $2 s 2 p^{3}\left({ }^{5} S\right) 3 s{ }^{4} S_{3 / 2}$ & $\cdots$ & 962.581 & 961.962 & 962.170 & 963.986 \\
\hline $2 s^{2} 2 p^{2}\left({ }^{1} S\right) 3 p{ }^{2} P_{1 / 2}$ & $\cdots$ & $\ldots$ & 964.255 & 964.474 & 966.222 \\
\hline $2 s^{2} 2 p^{2}\left({ }^{3} P\right) 3 d^{4} P_{5 / 2}$ & 967.32 & 965.205 & 964.894 & 965.127 & 967.940 \\
\hline $2 s^{2} 2 p^{2}\left({ }^{1} S\right) 3 p{ }^{2} P_{3 / 2}$ & $\ldots$ & $\ldots$ & 966.050 & 966.263 & 967.950 \\
\hline $2 s^{2} 2 p^{2}\left({ }^{3} P\right) 3 d{ }^{4} P_{3 / 2}$ & 967.32 & 966.588 & 966.340 & 966.573 & 969.375 \\
\hline $2 s^{2} 2 p^{2}\left({ }^{3} P\right) 3 d^{2} P_{1 / 2}$ & $\ldots$ & 966.801 & 966.610 & 966.856 & 969.639 \\
\hline $2 s^{2} 2 p^{2}\left({ }^{3} P\right) 3 d^{4} P_{1 / 2}$ & $\cdots$ & 967.719 & 967.502 & 967.741 & 970.474 \\
\hline $2 s^{2} 2 p^{2}\left({ }^{3} P\right) 3 d^{2} F_{7 / 2}$ & 969.6 & 968.928 & 968.982 & 969.263 & 972.189 \\
\hline $2 s^{2} 2 p^{2}\left({ }^{3} P\right) 3 d^{2} D_{3 / 2}$ & 974.39 & $\ldots$ & 971.784 & 972.089 & 975.183 \\
\hline $2 s^{2} 2 p^{2}\left({ }^{3} P\right) 3 d^{2} D_{5 / 2}$ & 972.41 & 972.230 & 971.812 & 972.133 & 975.394 \\
\hline $2 s 2 p^{3}\left({ }^{5} S\right) 3 p{ }^{6} P_{3 / 2}$ & $\ldots$ & $\ldots$ & 974.484 & 974.453 & 975.024 \\
\hline $2 s 2 p^{3}\left({ }^{5} S\right) 3 p{ }^{6} P_{5 / 2}$ & $\cdots$ & 973.408 & 975.301 & 975.275 & 976.016 \\
\hline $2 s^{2} 2 p^{2}\left({ }^{1} D\right) 3 d^{2} G_{7 / 2}$ & $\cdots$ & $\ldots$ & 976.874 & 977.113 & 979.996 \\
\hline $2 s 2 p^{3}\left({ }^{5} S\right) 3 p{ }^{6} P_{7 / 2}$ & $\cdots$ & $\cdots$ & 977.608 & 977.603 & 978.090 \\
\hline $2 s^{2} 2 p^{2}\left({ }^{1} D\right) 3 d^{2} G_{9 / 2}$ & $\cdots$ & $\cdots$ & 978.936 & 979.216 & 982.038 \\
\hline $2 s^{2} 2 p^{2}\left({ }^{1} D\right) 3 d{ }^{2} D_{3 / 2}$ & 981.83 & $\cdots$ & 980.739 & 981.006 & 983.687 \\
\hline $2 s^{2} 2 p^{2}\left({ }^{1} D\right) 3 d{ }^{2} D_{5 / 2}$ & 981.09 & $\ldots$ & 981.172 & 981.448 & 984.323 \\
\hline
\end{tabular}


Table 3

(Continued)

\begin{tabular}{|c|c|c|c|c|c|}
\hline \multirow[b]{2}{*}{ Level } & \multicolumn{5}{|c|}{ Energy $(\mathrm{eV})$} \\
\hline & NIST $^{\mathrm{a}}$ & CHIANTI $^{\mathrm{b}}$ & $\mathrm{MBPT}^{\mathrm{c}}$ & $\mathrm{MCDHF} / \mathrm{RCI}^{\mathrm{d}}$ & $\mathrm{AS}^{\mathrm{e}}$ \\
\hline $2 s^{2} 2 p^{2}\left({ }^{1} D\right) 3 d^{2} P_{1 / 2}$ & $\ldots$ & $\ldots$ & 983.193 & 983.450 & 986.182 \\
\hline $2 s^{2} 2 p^{2}\left({ }^{1} D\right) 3 d^{2} F_{7 / 2}$ & 983.81 & $\ldots$ & 983.605 & 983.933 & 987.124 \\
\hline $2 s 2 p^{3}\left({ }^{3} D\right) 3 s{ }^{4} D_{3 / 2}$ & $\ldots$ & $\cdots$ & 985.101 & 985.226 & 987.295 \\
\hline $2 s 2 p^{3}\left({ }^{5} S\right) 3 p{ }^{4} P_{3 / 2}$ & $\ldots$ & 985.488 & 985.218 & 985.294 & 986.373 \\
\hline $2 s 2 p^{3}\left({ }^{5} S\right) 3 p{ }^{4} P_{5 / 2}$ & $\cdots$ & 985.488 & 985.272 & 985.357 & 986.458 \\
\hline $2 s 2 p^{3}\left({ }^{3} D\right) 3 s{ }^{4} D_{1 / 2}$ & $\ldots$ & $\ldots$ & 985.295 & 985.426 & 987.492 \\
\hline $2 s 2 p^{3}\left({ }^{3} D\right) 3 s{ }^{4} D_{5 / 2}$ & $\cdots$ & $\cdots$ & 985.360 & 985.481 & 987.617 \\
\hline $2 s 2 p^{3}\left({ }^{5} S\right) 3 p{ }^{4} P_{1 / 2}$ & $\ldots$ & 986.664 & 986.208 & 986.290 & 987.327 \\
\hline $2 s^{2} 2 p^{2}\left({ }^{1} D\right) 3 d^{2} S_{1 / 2}$ & $\cdots$ & $\ldots$ & 987.258 & 987.553 & 990.464 \\
\hline $2 s^{2} 2 p^{2}\left({ }^{1} D\right) 3 d^{2} F_{5 / 2}$ & 989.77 & $\ldots$ & 987.413 & 987.728 & 990.671 \\
\hline $2 s^{2} 2 p^{2}\left({ }^{1} D\right) 3 d^{2} P_{3 / 2}$ & 987.78 & $\ldots$ & 987.692 & 987.956 & 990.609 \\
\hline $2 s 2 p^{3}\left({ }^{3} D\right) 3 s{ }^{4} D_{7 / 2}$ & $\ldots$ & $\cdots$ & 988.095 & 988.222 & 990.744 \\
\hline $2 s 2 p^{3}\left({ }^{3} D\right) 3 s^{2} D_{3 / 2}$ & $\cdots$ & $\cdots$ & 993.651 & 993.870 & 996.273 \\
\hline $2 s 2 p^{3}\left({ }^{3} D\right) 3 s^{2} D_{5 / 2}$ & $\ldots$ & $\ldots$ & 995.696 & 995.903 & 998.604 \\
\hline $2 s^{2} 2 p^{2}\left({ }^{1} S\right) 3 d^{2} D_{5 / 2}$ & 997.70 & $\cdots$ & 997.849 & 998.085 & 1000.112 \\
\hline $2 s^{2} 2 p^{2}\left({ }^{1} S\right) 3 d^{2} D_{3 / 2}$ & $\ldots$ & $\cdots$ & 999.148 & 999.399 & 1001.402 \\
\hline $2 s 2 p^{3}\left({ }^{3} P\right) 3 s{ }^{4} P_{1 / 2}$ & $\cdots$ & $\cdots$ & 1002.53 & 1002.64 & 1004.31 \\
\hline $2 s 2 p^{3}\left({ }^{3} P\right) 3 s{ }^{4} P_{3 / 2}$ & $\cdots$ & $\cdots$ & 1003.87 & 1003.99 & 1005.86 \\
\hline $2 s 2 p^{3}\left({ }^{5} S\right) 3 d^{6} D_{1 / 2}$ & $\cdots$ & $\cdots$ & 1006.16 & 1006.18 & 1006.59 \\
\hline $2 s 2 p^{3}\left({ }^{5} S\right) 3 d^{6} D_{3 / 2}$ & $\cdots$ & $\cdots$ & 1006.19 & 1006.21 & 1006.70 \\
\hline $2 s 2 p^{3}\left({ }^{5} S\right) 3 d{ }^{6} D_{5 / 2}$ & $\cdots$ & $\cdots$ & 1006.20 & 1006.25 & 1006.86 \\
\hline $2 s 2 p^{3}\left({ }^{3} P\right) 3 s{ }^{4} P_{5 / 2}$ & $\cdots$ & $\cdots$ & 1006.30 & 1006.41 & 1008.45 \\
\hline $2 s 2 p^{3}\left({ }^{5} S\right) 3 d^{6} D_{7 / 2}$ & $\cdots$ & $\cdots$ & 1006.33 & 1006.35 & 1007.10 \\
\hline $2 s 2 p^{3}\left({ }^{5} S\right) 3 d^{6} D_{9 / 2}$ & $\ldots$ & $\cdots$ & 1006.60 & 1006.62 & 1007.50 \\
\hline $2 s 2 p^{3}\left({ }^{3} D\right) 3 p{ }^{4} D_{1 / 2}$ & $\cdots$ & $\cdots$ & 1009.69 & 1009.78 & 1011.64 \\
\hline $2 s 2 p^{3}\left({ }^{3} D\right) 3 p{ }^{4} D_{3 / 2}$ & $\ldots$ & $\cdots$ & 1009.97 & 1010.06 & 1011.98 \\
\hline $2 s 2 p^{3}\left({ }^{3} P\right) 3 s^{2} P_{1 / 2}$ & $\cdots$ & $\cdots$ & 1010.75 & 1010.96 & 1013.03 \\
\hline $2 s 2 p^{3}\left({ }^{3} D\right) 3 p{ }^{4} F_{5 / 2}$ & $\ldots$ & $\ldots$ & 1011.62 & 1011.71 & 1013.82 \\
\hline $2 s 2 p^{3}\left({ }^{3} D\right) 3 p{ }^{4} F_{3 / 2}$ & $\cdots$ & $\cdots$ & 1011.82 & 1011.94 & 1014.03 \\
\hline $2 s 2 p^{3}\left({ }^{3} P\right) 3 s^{2} P_{3 / 2}$ & $\cdots$ & $\cdots$ & 1012.43 & 1012.64 & 1014.97 \\
\hline $2 s 2 p^{3}\left({ }^{3} D\right) 3 p{ }^{4} F_{7 / 2}$ & $\ldots$ & $\ldots$ & 1014.11 & 1014.21 & 1016.53 \\
\hline $2 s 2 p^{3}\left({ }^{3} D\right) 3 p{ }^{4} D_{5 / 2}$ & $\cdots$ & $\cdots$ & 1014.75 & 1014.84 & 1016.84 \\
\hline $2 s 2 p^{3}\left({ }^{3} D\right) 3 p{ }^{2} P_{3 / 2}$ & $\ldots$ & $\cdots$ & 1015.99 & 1016.10 & 1018.12 \\
\hline $2 s 2 p^{3}\left({ }^{3} D\right) 3 p{ }^{4} D_{7 / 2}$ & $\cdots$ & $\cdots$ & 1016.25 & 1016.35 & 1018.46 \\
\hline $2 s 2 p^{3}\left({ }^{3} D\right) 3 p{ }^{2} P_{1 / 2}$ & $\ldots$ & $\cdots$ & 1017.15 & 1017.28 & 1019.36 \\
\hline $2 s 2 p^{3}\left({ }^{3} D\right) 3 p{ }^{2} F_{5 / 2}$ & $\cdots$ & $\cdots$ & 1017.63 & 1017.77 & 1019.90 \\
\hline $2 s 2 p^{3}\left({ }^{3} D\right) 3 p{ }^{4} F_{9 / 2}$ & $\ldots$ & $\cdots$ & 1018.02 & 1018.13 & 1020.57 \\
\hline $2 s 2 p^{3}\left({ }^{3} D\right) 3 p{ }^{2} F_{7 / 2}$ & $\cdots$ & $\ldots$ & 1019.07 & 1019.20 & 1021.71 \\
\hline $2 s 2 p^{3}\left({ }^{5} S\right) 3 d{ }^{4} D_{5 / 2}$ & $\ldots$ & 1019.03 & 1019.28 & 1019.43 & 1020.93 \\
\hline $2 s 2 p^{3}\left({ }^{5} S\right) 3 d{ }^{4} D_{3 / 2}$ & $\cdots$ & 1019.82 & 1019.63 & 1019.77 & 1021.21 \\
\hline $2 s 2 p^{3}\left({ }^{5} S\right) 3 d^{4} D_{7 / 2}$ & $\ldots$ & 1018.24 & 1020.08 & 1020.23 & 1021.76 \\
\hline $2 s 2 p^{3}\left({ }^{5} S\right) 3 d^{4} D_{1 / 2}$ & $\cdots$ & $\ldots$ & 1020.20 & 1020.34 & 1021.72 \\
\hline $2 s 2 p^{3}\left({ }^{3} D\right) 3 p{ }^{4} P_{3 / 2}$ & $\ldots$ & $\ldots$ & 1022.43 & 1022.57 & 1024.67 \\
\hline $2 s 2 p^{3}\left({ }^{3} D\right) 3 p{ }^{4} P_{1 / 2}$ & $\cdots$ & $\cdots$ & 1023.14 & 1023.31 & 1025.48 \\
\hline $2 s 2 p^{3}\left({ }^{3} D\right) 3 p{ }^{4} P_{5 / 2}$ & $\cdots$ & $\cdots$ & 1024.68 & 1024.88 & 1027.44 \\
\hline $2 s 2 p^{3}\left({ }^{3} S\right) 3 s{ }^{4} S_{3 / 2}$ & $\cdots$ & $\cdots$ & 1024.87 & 1025.03 & 1027.88 \\
\hline $2 s 2 p^{3}\left({ }^{3} D\right) 3 p^{2} D_{3 / 2}$ & $\cdots$ & $\cdots$ & 1025.45 & 1025.64 & 1028.17 \\
\hline $2 s 2 p^{3}\left({ }^{3} D\right) 3 p^{2} D_{5 / 2}$ & $\ldots$ & $\ldots$ & 1028.19 & 1028.38 & 1031.02 \\
\hline $2 s 2 p^{3}\left({ }^{3} S\right) 3 s{ }^{2} S_{1 / 2}$ & $\cdots$ & $\cdots$ & 1028.92 & 1029.11 & 1032.08 \\
\hline $2 s 2 p^{3}\left({ }^{3} P\right) 3 p{ }^{4} D_{1 / 2}$ & $\cdots$ & $\cdots$ & 1029.35 & 1029.45 & 1031.22 \\
\hline $2 s 2 p^{3}\left({ }^{1} D\right) 3 s^{2} D_{5 / 2}$ & $\ldots$ & $\cdots$ & 1030.04 & 1030.22 & 1033.53 \\
\hline $2 s 2 p^{3}\left({ }^{3} P\right) 3 p{ }^{4} D_{3 / 2}$ & $\ldots$ & $\cdots$ & 1030.91 & 1031.01 & 1032.90 \\
\hline $2 s 2 p^{3}\left({ }^{1} D\right) 3 s^{2} D_{3 / 2}$ & $\cdots$ & $\cdots$ & 1030.93 & 1031.12 & 1034.31 \\
\hline $2 s 2 p^{3}\left({ }^{3} P\right) 3 p{ }^{4} D_{5 / 2}$ & $\cdots$ & $\cdots$ & 1032.42 & 1032.52 & 1034.46 \\
\hline $2 s 2 p^{3}\left({ }^{3} P\right) 3 p{ }^{4} S_{3 / 2}$ & $\ldots$ & $\ldots$ & 1033.61 & 1033.72 & 1035.45 \\
\hline
\end{tabular}


Table 3

(Continued)

\begin{tabular}{|c|c|c|c|c|c|}
\hline \multirow[b]{2}{*}{ Level } & \multicolumn{5}{|c|}{ Energy $(\mathrm{eV})$} \\
\hline & NIST $^{\mathrm{a}}$ & CHIANTI $^{\mathrm{b}}$ & $\mathrm{MBPT}^{\mathrm{c}}$ & $\mathrm{MCDHF} / \mathrm{RCI}^{\mathrm{d}}$ & $\mathrm{AS}^{\mathrm{e}}$ \\
\hline $2 s 2 p^{3}\left({ }^{3} P\right) 3 p{ }^{4} D_{7 / 2}$ & $\ldots$ & $\ldots$ & 1034.92 & 1035.02 & 1036.92 \\
\hline $2 s 2 p^{3}\left({ }^{3} P\right) 3 p{ }^{2} P_{1 / 2}$ & $\ldots$ & $\ldots$ & 1035.02 & 1035.14 & 1037.05 \\
\hline $2 s 2 p^{3}\left({ }^{3} P\right) 3 p{ }^{4} P_{1 / 2}$ & $\cdots$ & $\cdots$ & 1035.83 & 1035.99 & 1038.05 \\
\hline $2 s 2 p^{3}\left({ }^{3} P\right) 3 p{ }^{4} P_{3 / 2}$ & $\ldots$ & $\ldots$ & 1036.76 & 1036.91 & 1038.91 \\
\hline $2 s 2 p^{3}\left({ }^{3} P\right) 3 p{ }^{4} P_{5 / 2}$ & $\cdots$ & $\cdots$ & 1037.12 & 1037.27 & 1039.45 \\
\hline $2 s 2 p^{3}\left({ }^{3} P\right) 3 p{ }^{2} D_{3 / 2}$ & $\ldots$ & $\ldots$ & 1037.93 & 1038.08 & 1040.01 \\
\hline $2 s 2 p^{3}\left({ }^{3} P\right) 3 p{ }^{2} P_{3 / 2}$ & $\cdots$ & $\cdots$ & 1040.59 & 1040.75 & 1042.86 \\
\hline $2 s 2 p^{3}\left({ }^{3} D\right) 3 d d^{4} F_{3 / 2}$ & $\cdots$ & $\cdots$ & 1040.70 & 1040.84 & 1042.75 \\
\hline $2 s 2 p^{3}\left({ }^{3} P\right) 3 p{ }^{2} D_{5 / 2}$ & $\cdots$ & $\cdots$ & 1040.85 & 1041.01 & 1043.16 \\
\hline $2 s 2 p^{3}\left({ }^{3} D\right) 3 d{ }^{4} F_{5 / 2}$ & $\cdots$ & $\cdots$ & 1041.63 & 1041.77 & 1043.79 \\
\hline $2 s 2 p^{3}\left({ }^{3} D\right) 3 d d^{4} F_{7 / 2}$ & $\ldots$ & $\cdots$ & 1042.85 & 1043.00 & 1045.21 \\
\hline $2 s 2 p^{3}\left({ }^{3} D\right) 3 d{ }^{4} G_{5 / 2}$ & $\cdots$ & $\cdots$ & 1044.30 & 1044.48 & 1046.48 \\
\hline $2 s 2 p^{3}\left({ }^{3} D\right) 3 d^{4} G_{9 / 2}$ & $\cdots$ & $\cdots$ & 1044.58 & 1044.75 & 1047.10 \\
\hline $2 s 2 p^{3}\left({ }^{3} D\right) 3 d^{4} G_{7 / 2}$ & $\cdots$ & $\cdots$ & 1044.72 & 1044.89 & 1047.07 \\
\hline $2 s 2 p^{3}\left({ }^{3} P\right) 3 p{ }^{2} S_{1 / 2}$ & $\cdots$ & $\cdots$ & 1045.98 & 1046.21 & 1048.59 \\
\hline $2 s 2 p^{3}\left({ }^{3} D\right) 3 d{ }^{4} F_{9 / 2}$ & $\cdots$ & $\cdots$ & 1046.24 & 1046.38 & 1048.87 \\
\hline $2 s 2 p^{3}\left({ }^{3} D\right) 3 d^{4} D_{1 / 2}$ & $\cdots$ & $\cdots$ & 1046.59 & 1046.74 & 1048.76 \\
\hline $2 s 2 p^{3}\left({ }^{1} P\right) 3 s{ }^{2} P_{3 / 2}$ & $\cdots$ & $\cdots$ & 1046.67 & 1046.88 & 1049.77 \\
\hline $2 s 2 p^{3}\left({ }^{1} P\right) 3 s^{2} P_{1 / 2}$ & $\cdots$ & $\cdots$ & 1047.16 & 1047.37 & 1050.15 \\
\hline $2 s 2 p^{3}\left({ }^{3} D\right) 3 d{ }^{4} G_{11 / 2}$ & $\cdots$ & $\cdots$ & 1047.24 & 1047.41 & 1050.12 \\
\hline $2 s 2 p^{3}\left({ }^{3} D\right) 3 d^{4} D_{3 / 2}$ & $\cdots$ & $\cdots$ & 1047.25 & 1047.40 & 1049.42 \\
\hline $2 s 2 p^{3}\left({ }^{3} D\right) 3 d^{4} D_{5 / 2}$ & $\cdots$ & 1048.85 & 1048.63 & 1048.78 & 1050.94 \\
\hline $2 s 2 p^{3}\left({ }^{3} D\right) 3 d^{2} S_{1 / 2}$ & $\cdots$ & $\ldots$ & 1048.72 & 1048.89 & 1051.09 \\
\hline $2 s 2 p^{3}\left({ }^{3} D\right) 3 d{ }^{4} D_{7 / 2}$ & $\ldots$ & 1049.56 & 1049.56 & 1049.75 & 1052.37 \\
\hline $2 s 2 p^{3}\left({ }^{3} D\right) 3 d^{2} G_{7 / 2}$ & $\cdots$ & $\ldots$ & 1050.77 & 1050.97 & 1053.62 \\
\hline $2 s 2 p^{3}\left({ }^{3} S\right) 3 p{ }^{4} P_{3 / 2}$ & $\ldots$ & $\cdots$ & 1051.02 & 1051.17 & 1054.08 \\
\hline $2 s 2 p^{3}\left({ }^{3} D\right) 3 d^{2} G_{9 / 2}$ & $\ldots$ & $\cdots$ & 1051.29 & 1051.52 & 1054.31 \\
\hline $2 s 2 p^{3}\left({ }^{3} S\right) 3 p{ }^{4} P_{1 / 2}$ & $\ldots$ & $\ldots$ & 1051.37 & 1051.53 & 1058.97 \\
\hline $2 s 2 p^{3}\left({ }^{3} D\right) 3 d{ }^{4} P_{5 / 2}$ & $\ldots$ & $\cdots$ & 1052.17 & 1052.32 & 1054.76 \\
\hline $2 s 2 p^{3}\left({ }^{3} D\right) 3 d{ }^{4} P_{3 / 2}$ & $\cdots$ & $\cdots$ & 1052.75 & 1052.94 & 1055.28 \\
\hline $2 s 2 p^{3}\left({ }^{3} D\right) 3 d{ }^{4} P_{1 / 2}$ & $\ldots$ & $\ldots$ & 1052.99 & 1053.16 & 1055.54 \\
\hline $2 s 2 p^{3}\left({ }^{3} D\right) 3 d^{2} P_{3 / 2}$ & $\cdots$ & $\cdots$ & 1053.41 & 1053.59 & 1068.07 \\
\hline $2 s 2 p^{3}\left({ }^{3} D\right) 3 d^{2} D_{5 / 2}$ & $\ldots$ & $\cdots$ & 1053.47 & 1053.67 & 1056.06 \\
\hline $2 s 2 p^{3}\left({ }^{3} S\right) 3 p{ }^{4} P_{5 / 2}$ & $\cdots$ & 1056.17 & 1053.87 & 1054.01 & 1056.80 \\
\hline $2 s 2 p^{3}\left({ }^{3} D\right) 3 d d^{4} S_{3 / 2}$ & $\ldots$ & $\ldots$ & 1055.44 & 1055.65 & 1058.46 \\
\hline $2 s 2 p^{3}\left({ }^{3} D\right) 3 d{ }^{2} P_{1 / 2}$ & $\cdots$ & $\cdots$ & 1055.84 & 1056.07 & 1058.85 \\
\hline $2 s 2 p^{3}\left({ }^{1} D\right) 3 p{ }^{2} P_{3 / 2}$ & $\ldots$ & $\cdots$ & 1055.97 & 1056.11 & 1079.98 \\
\hline $2 s 2 p^{3}\left({ }^{3} S\right) 3 p{ }^{2} P_{1 / 2}$ & $\cdots$ & $\cdots$ & 1056.01 & 1056.18 & 1054.35 \\
\hline $2 s 2 p^{3}\left({ }^{1} D\right) 3 p^{2} F_{5 / 2}$ & $\ldots$ & $\ldots$ & 1056.83 & 1056.99 & 1060.23 \\
\hline $2 s 2 p^{3}\left({ }^{1} D\right) 3 p{ }^{2} F_{7 / 2}$ & $\cdots$ & $\cdots$ & 1058.83 & 1058.99 & 1062.22 \\
\hline $2 s 2 p^{3}\left({ }^{3} D\right) 3 d^{2} D_{3 / 2}$ & $\ldots$ & $\ldots$ & 1059.43 & 1059.65 & 1062.26 \\
\hline $2 s 2 p^{3}\left({ }^{3} D\right) 3 d^{2} F_{7 / 2}$ & $\cdots$ & $\cdots$ & 1060.26 & 1060.51 & 1063.44 \\
\hline $2 s 2 p^{3}\left({ }^{3} D\right) 3 d{ }^{2} F_{5 / 2}$ & $\ldots$ & $\ldots$ & 1060.66 & 1060.91 & 1063.87 \\
\hline $2 s 2 p^{3}\left({ }^{1} D\right) 3 p^{2} D_{3 / 2}$ & $\cdots$ & $\cdots$ & 1062.01 & 1062.25 & 1065.76 \\
\hline $2 s 2 p^{3}\left({ }^{3} P\right) 3 d{ }^{4} F_{3 / 2}$ & $\cdots$ & $\cdots$ & 1062.59 & 1062.75 & 1064.45 \\
\hline $2 s 2 p^{3}\left({ }^{3} P\right) 3 d d^{4} F_{5 / 2}$ & $\cdots$ & $\cdots$ & 1062.65 & 1062.81 & 1064.65 \\
\hline $2 s 2 p^{3}\left({ }^{1} D\right) 3 p^{2} D_{5 / 2}$ & $\cdots$ & $\cdots$ & 1062.78 & 1063.01 & 1066.54 \\
\hline $2 s 2 p^{3}\left({ }^{3} P\right) 3 d d^{4} F_{7 / 2}$ & $\ldots$ & $\ldots$ & 1062.89 & 1063.05 & 1065.13 \\
\hline $2 s 2 p^{3}\left({ }^{3} P\right) 3 d d^{4} F_{9 / 2}$ & $\cdots$ & $\cdots$ & 1064.31 & 1064.47 & 1066.68 \\
\hline $2 s 2 p^{3}\left({ }^{3} P\right) 3 d{ }^{4} P_{5 / 2}$ & $\cdots$ & $\cdots$ & 1065.34 & 1065.50 & 1067.47 \\
\hline $2 s 2 p^{3}\left({ }^{3} P\right) 3 d{ }^{4} P_{1 / 2}$ & $\ldots$ & $\cdots$ & 1065.74 & 1065.89 & 1067.71 \\
\hline $2 s 2 p^{3}\left({ }^{3} P\right) 3 d{ }^{4} P_{3 / 2}$ & $\ldots$ & $\cdots$ & 1065.82 & 1065.99 & $\ldots$ \\
\hline $2 s 2 p^{3}\left({ }^{3} S\right) 3 p{ }^{2} P_{3 / 2}$ & $\cdots$ & $\cdots$ & 1066.82 & 1067.06 & 1059.06 \\
\hline $2 s 2 p^{3}\left({ }^{3} P\right) 3 d^{4} D_{1 / 2}$ & $\cdots$ & $\cdots$ & 1067.24 & 1067.42 & 1069.61 \\
\hline $2 s 2 p^{3}\left({ }^{3} P\right) 3 d^{2} D_{3 / 2}$ & $\ldots$ & $\ldots$ & 1067.48 & 1067.66 & 1071.35 \\
\hline
\end{tabular}


Table 3

(Continued)

\begin{tabular}{|c|c|c|c|c|c|}
\hline \multirow[b]{2}{*}{ Level } & \multicolumn{5}{|c|}{ Energy (eV) } \\
\hline & NIST $^{\mathrm{a}}$ & CHIANTI $^{\mathrm{b}}$ & $\mathrm{MBPT}^{\mathrm{c}}$ & $\mathrm{MCDHF} / \mathrm{RCI}^{\mathrm{d}}$ & $\mathrm{AS}^{\mathrm{e}}$ \\
\hline $2 s 2 p^{3}\left({ }^{1} D\right) 3 p^{2} P_{1 / 2}$ & $\ldots$ & $\ldots$ & 1068.11 & 1068.33 & 1071.59 \\
\hline $2 s 2 p^{3}\left({ }^{3} P\right) 3 d^{4} D_{7 / 2}$ & $\cdots$ & $\cdots$ & 1068.14 & 1068.32 & 1070.69 \\
\hline $2 s 2 p^{3}\left({ }^{3} P\right) 3 d^{4} D_{5 / 2}$ & $\cdots$ & $\cdots$ & 1068.38 & 1068.57 & 1070.87 \\
\hline $2 s 2 p^{3}\left({ }^{3} P\right) 3 d^{4} D_{3 / 2}$ & $\cdots$ & $\cdots$ & 1068.74 & 1068.94 & 1069.90 \\
\hline $2 s 2 p^{3}\left({ }^{3} P\right) 3 d^{2} F_{5 / 2}$ & $\cdots$ & $\cdots$ & 1071.11 & 1071.34 & 1073.68 \\
\hline $2 s 2 p^{3}\left({ }^{3} P\right) 3 d^{2} F_{7 / 2}$ & $\cdots$ & $\cdots$ & 1073.25 & 1073.50 & 1076.20 \\
\hline $2 s 2 p^{3}\left({ }^{3} P\right) 3 d^{2} D_{5 / 2}$ & $\cdots$ & $\cdots$ & 1075.13 & 1075.38 & 1078.14 \\
\hline $2 s 2 p^{3}\left({ }^{1} P\right) 3 p{ }^{2} D_{5 / 2}$ & $\cdots$ & $\cdots$ & 1075.92 & 1076.12 & 1078.99 \\
\hline $2 s 2 p^{3}\left({ }^{3} P\right) 3 d{ }^{2} P_{1 / 2}$ & $\cdots$ & $\cdots$ & 1076.75 & 1076.98 & 1079.64 \\
\hline $2 s 2 p^{3}\left({ }^{1} P\right) 3 p{ }^{2} P_{3 / 2}$ & $\cdots$ & $\cdots$ & 1076.96 & 1077.17 & 1080.70 \\
\hline $2 s 2 p^{3}\left({ }^{1} P\right) 3 p{ }^{2} S_{1 / 2}$ & $\cdots$ & $\cdots$ & 1077.16 & 1077.42 & 1080.59 \\
\hline $2 s 2 p^{3}\left({ }^{1} P\right) 3 p{ }^{2} D_{3 / 2}$ & $\cdots$ & $\cdots$ & 1077.21 & 1077.44 & 1070.44 \\
\hline $2 s 2 p^{3}\left({ }^{3} P\right) 3 d d^{2} P_{3 / 2}$ & $\cdots$ & $\ldots$ & 1080.51 & 1080.78 & 1083.60 \\
\hline $2 s 2 p^{3}\left({ }^{3} S\right) 3 d{ }^{4} D_{5 / 2}$ & $\cdots$ & 1085.76 & 1083.63 & 1083.84 & 1086.97 \\
\hline $2 s 2 p^{3}\left({ }^{3} S\right) 3 d^{4} D_{3 / 2}$ & $\ldots$ & 1085.76 & 1084.02 & 1084.23 & 1087.24 \\
\hline $2 s 2 p^{3}\left({ }^{3} S\right) 3 d^{4} D_{7 / 2}$ & $\cdots$ & $\ldots$ & 1084.36 & 1084.56 & 1087.81 \\
\hline $2 s 2 p^{3}\left({ }^{1} P\right) 3 p{ }^{2} P_{1 / 2}$ & $\cdots$ & $\ldots$ & 1084.41 & 1084.70 & 1088.06 \\
\hline $2 s 2 p^{3}\left({ }^{3} S\right) 3 d^{4} D_{1 / 2}$ & $\cdots$ & $\cdots$ & 1085.10 & 1085.31 & 1088.29 \\
\hline $2 s 2 p^{3}\left({ }^{3} S\right) 3 d^{2} D_{3 / 2}$ & $\ldots$ & $\cdots$ & 1087.12 & 1087.34 & 1090.57 \\
\hline $2 s 2 p^{3}\left({ }^{1} D\right) 3 d^{2} D_{5 / 2}$ & $\cdots$ & $\cdots$ & 1088.40 & 1088.62 & 1101.54 \\
\hline $2 s 2 p^{3}\left({ }^{1} D\right) 3 d^{2} G_{9 / 2}$ & $\ldots$ & $\ldots$ & 1088.88 & 1089.12 & 1092.78 \\
\hline $2 s 2 p^{3}\left({ }^{1} D\right) 3 d^{2} G_{7 / 2}$ & $\cdots$ & $\cdots$ & 1089.33 & 1089.57 & 1092.95 \\
\hline $2 s 2 p^{3}\left({ }^{1} D\right) 3 d^{2} F_{7 / 2}$ & $\ldots$ & $\ldots$ & 1091.40 & 1091.68 & 1095.47 \\
\hline $2 s 2 p^{3}\left({ }^{1} D\right) 3 d^{2} F_{5 / 2}$ & $\cdots$ & $\cdots$ & 1091.79 & 1092.06 & 1095.73 \\
\hline $2 s 2 p^{3}\left({ }^{1} D\right) 3 d^{2} P_{3 / 2}$ & $\ldots$ & $\cdots$ & 1094.40 & 1094.65 & 1098.28 \\
\hline $2 s 2 p^{3}\left({ }^{1} D\right) 3 d^{2} P_{1 / 2}$ & $\cdots$ & $\cdots$ & 1095.38 & 1095.60 & 1099.07 \\
\hline $2 s 2 p^{3}\left({ }^{1} D\right) 3 d^{2} D_{3 / 2}$ & $\cdots$ & $\cdots$ & 1096.99 & 1097.28 & 1101.12 \\
\hline $2 s 2 p^{3}\left({ }^{3} S\right) 3 d^{2} D_{5 / 2}$ & $\cdots$ & $\cdots$ & 1097.13 & 1097.46 & 1092.06 \\
\hline $2 p^{4}\left({ }^{3} P\right) 3 s{ }^{4} P_{5 / 2}$ & $\cdots$ & $\cdots$ & 1097.73 & 1097.86 & $\ldots$ \\
\hline $2 s 2 p^{3}\left({ }^{1} D\right) 3 d^{2} S_{1 / 2}$ & $\cdots$ & $\cdots$ & 1098.78 & 1099.00 & 1102.40 \\
\hline $2 p^{4}\left({ }^{3} P\right) 3 s^{2} P_{3 / 2}$ & $\cdots$ & $\cdots$ & 1102.02 & 1102.21 & $\ldots$ \\
\hline $2 s 2 p^{3}\left({ }^{1} P\right) 3 d^{2} F_{7 / 2}$ & $\cdots$ & $\cdots$ & 1106.46 & 1106.73 & 1110.01 \\
\hline $2 s 2 p^{3}\left({ }^{1} P\right) 3 d^{2} D_{5 / 2}$ & $\cdots$ & $\cdots$ & 1106.88 & 1107.14 & 1110.40 \\
\hline $2 p^{4}\left({ }^{3} P\right) 3 s{ }^{4} P_{1 / 2}$ & $\cdots$ & $\cdots$ & 1108.73 & 1108.71 & $\ldots$ \\
\hline $2 s 2 p^{3}\left({ }^{1} P\right) 3 d^{2} P_{3 / 2}$ & $\cdots$ & $\cdots$ & 1108.89 & 1109.16 & 1112.47 \\
\hline $2 s 2 p^{3}\left({ }^{1} P\right) 3 d^{2} P_{1 / 2}$ & $\cdots$ & $\cdots$ & 1109.05 & 1109.34 & 1112.70 \\
\hline $2 s 2 p^{3}\left({ }^{1} P\right) 3 d^{2} F_{5 / 2}$ & $\cdots$ & $\cdots$ & 1109.53 & 1109.83 & 1113.38 \\
\hline $2 p^{4}\left({ }^{3} P\right) 3 s{ }^{4} P_{3 / 2}$ & $\cdots$ & $\cdots$ & 1110.71 & 1110.88 & $\ldots$ \\
\hline $2 s 2 p^{3}\left({ }^{1} P\right) 3 d^{2} D_{3 / 2}$ & $\cdots$ & $\cdots$ & 1114.18 & 1114.50 & 1118.31 \\
\hline $2 p^{4}\left({ }^{3} P\right) 3 s^{2} P_{1 / 2}$ & $\cdots$ & $\cdots$ & 1115.55 & 1115.75 & $\ldots$ \\
\hline $2 p^{4}\left({ }^{1} D\right) 3 s^{2} D_{5 / 2}$ & $\cdots$ & $\cdots$ & 1120.37 & 1120.58 & $\cdots$ \\
\hline $2 p^{4}\left({ }^{1} D\right) 3 s^{2} D_{3 / 2}$ & $\cdots$ & $\cdots$ & 1121.01 & 1121.23 & $\cdots$ \\
\hline $2 p^{4}\left({ }^{3} P\right) 3 p{ }^{4} P_{3 / 2}$ & $\cdots$ & $\cdots$ & 1121.42 & 1121.53 & $\cdots$ \\
\hline $2 p^{4}\left({ }^{3} P\right) 3 p{ }^{4} P_{5 / 2}$ & $\cdots$ & $\cdots$ & 1121.93 & 1122.04 & $\cdots$ \\
\hline $2 p^{4}\left({ }^{3} P\right) 3 p{ }^{2} P_{1 / 2}$ & $\cdots$ & $\cdots$ & 1125.70 & 1125.81 & $\cdots$ \\
\hline $2 p^{4}\left({ }^{3} P\right) 3 p{ }^{4} D_{7 / 2}$ & $\cdots$ & $\cdots$ & 1126.05 & 1126.19 & $\cdots$ \\
\hline $2 p^{4}\left({ }^{3} P\right) 3 p{ }^{2} D_{5 / 2}$ & $\cdots$ & $\cdots$ & 1126.21 & 1126.37 & $\cdots$ \\
\hline $2 p^{4}\left({ }^{3} P\right) 3 p{ }^{4} P_{1 / 2}$ & $\cdots$ & $\cdots$ & 1132.95 & 1133.07 & $\ldots$ \\
\hline $2 p^{4}\left({ }^{3} P\right) 3 p{ }^{4} D_{3 / 2}$ & $\cdots$ & $\cdots$ & 1133.07 & 1133.23 & $\cdots$ \\
\hline $2 p^{4}\left({ }^{3} P\right) 3 p{ }^{4} D_{1 / 2}$ & $\cdots$ & $\cdots$ & 1134.10 & 1134.07 & $\ldots$ \\
\hline $2 p^{4}\left({ }^{3} P\right) 3 p{ }^{2} P_{3 / 2}$ & $\cdots$ & $\cdots$ & 1135.50 & 1135.65 & $\ldots$ \\
\hline $2 p^{4}\left({ }^{3} P\right) 3 p{ }^{4} D_{5 / 2}$ & $\cdots$ & $\cdots$ & 1137.40 & 1137.53 & $\cdots$ \\
\hline $2 p^{4}\left({ }^{3} P\right) 3 p{ }^{4} S_{3 / 2}$ & $\cdots$ & $\ldots$ & 1138.46 & 1138.49 & $\cdots$ \\
\hline $2 p^{4}\left({ }^{3} P\right) 3 p{ }^{2} S_{1 / 2}$ & $\ldots$ & $\cdots$ & 1140.19 & 1140.36 & $\ldots$ \\
\hline $2 p^{4}\left({ }^{3} P\right) 3 p{ }^{2} D_{3 / 2}$ & $\cdots$ & $\cdots$ & 1140.81 & 1140.96 & $\cdots$ \\
\hline
\end{tabular}


Table 3

(Continued)

\begin{tabular}{|c|c|c|c|c|c|}
\hline \multirow[b]{2}{*}{ Level } & \multicolumn{5}{|c|}{ Energy $(\mathrm{eV})$} \\
\hline & NIST $^{\mathrm{a}}$ & CHIANTI $^{\mathrm{b}}$ & $\mathrm{MBPT}^{\mathrm{c}}$ & $\mathrm{MCDHF} / \mathrm{RCI}^{\mathrm{d}}$ & $\mathrm{AS}^{\mathrm{e}}$ \\
\hline $2 p^{4}\left({ }^{1} D\right) 3 p{ }^{2} F_{5 / 2}$ & $\cdots$ & $\cdots$ & 1143.77 & 1143.97 & $\cdots$ \\
\hline $2 p^{4}\left({ }^{1} D\right) 3 p{ }^{2} F_{7 / 2}$ & $\cdots$ & $\ldots$ & 1146.74 & 1146.94 & $\cdots$ \\
\hline $2 p^{4}\left({ }^{1} S\right) 3 s^{2} S_{1 / 2}$ & $\cdots$ & $\ldots$ & 1148.48 & 1148.90 & $\cdots$ \\
\hline $2 p^{4}\left({ }^{1} D\right) 3 p{ }^{2} D_{3 / 2}$ & $\ldots$ & $\ldots$ & 1149.14 & 1149.38 & $\cdots$ \\
\hline $2 p^{4}\left({ }^{1} D\right) 3 p{ }^{2} D_{5 / 2}$ & $\cdots$ & $\cdots$ & 1150.77 & 1151.02 & $\cdots$ \\
\hline $2 p^{4}\left({ }^{3} P\right) 3 d^{4} D_{7 / 2}$ & $\cdots$ & $\cdots$ & 1152.07 & 1152.20 & $\cdots$ \\
\hline $2 p^{4}\left({ }^{3} P\right) 3 d^{4} D_{5 / 2}$ & $\cdots$ & $\cdots$ & 1152.11 & 1152.23 & $\cdots$ \\
\hline $2 p^{4}\left({ }^{3} P\right) 3 d{ }^{4} D_{3 / 2}$ & $\cdots$ & $\cdots$ & 1152.92 & 1153.05 & $\cdots$ \\
\hline $2 p^{4}\left({ }^{3} P\right) 3 d^{4} D_{1 / 2}$ & $\cdots$ & $\cdots$ & 1154.17 & 1154.30 & $\cdots$ \\
\hline $2 p^{4}\left({ }^{3} P\right) 3 d^{4} F_{9 / 2}$ & $\cdots$ & $\cdots$ & 1154.84 & 1155.03 & $\cdots$ \\
\hline $2 p^{4}\left({ }^{3} P\right) 3 d^{2} F_{7 / 2}$ & $\cdots$ & $\cdots$ & 1156.27 & 1156.50 & $\cdots$ \\
\hline $2 p^{4}\left({ }^{1} D\right) 3 p{ }^{2} P_{3 / 2}$ & $\cdots$ & $\cdots$ & 1156.71 & 1157.16 & $\cdots$ \\
\hline $2 p^{4}\left({ }^{3} P\right) 3 d{ }^{4} P_{1 / 2}$ & $\cdots$ & $\cdots$ & 1159.52 & 1159.68 & $\cdots$ \\
\hline $2 p^{4}\left({ }^{1} D\right) 3 p^{2} P_{1 / 2}$ & $\cdots$ & $\cdots$ & 1161.35 & 1161.78 & $\cdots$ \\
\hline $2 p^{4}\left({ }^{3} P\right) 3 d{ }^{4} P_{3 / 2}$ & $\cdots$ & $\cdots$ & 1161.72 & 1161.90 & $\cdots$ \\
\hline $2 p^{4}\left({ }^{3} P\right) 3 d d^{2} F_{5 / 2}$ & $\cdots$ & $\cdots$ & 1162.23 & 1162.45 & $\cdots$ \\
\hline $2 p^{4}\left({ }^{3} P\right) 3 d{ }^{2} P_{1 / 2}$ & $\cdots$ & $\cdots$ & 1164.36 & 1164.50 & $\cdots$ \\
\hline $2 p^{4}\left({ }^{3} P\right) 3 d{ }^{4} F_{3 / 2}$ & $\cdots$ & $\cdots$ & 1165.47 & 1165.50 & $\cdots$ \\
\hline $2 p^{4}\left({ }^{3} P\right) 3 d d^{4} F_{5 / 2}$ & $\cdots$ & $\cdots$ & 1166.03 & 1166.08 & $\cdots$ \\
\hline $2 p^{4}\left({ }^{3} P\right) 3 d^{4} F_{7 / 2}$ & $\cdots$ & $\cdots$ & 1166.11 & 1166.30 & $\cdots$ \\
\hline $2 p^{4}\left({ }^{3} P\right) 3 d^{2} D_{3 / 2}$ & $\cdots$ & $\cdots$ & 1167.05 & 1167.21 & $\cdots$ \\
\hline $2 p^{4}\left({ }^{3} P\right) 3 d{ }^{4} P_{5 / 2}$ & $\cdots$ & $\cdots$ & 1169.29 & 1169.48 & $\cdots$ \\
\hline $2 p^{4}\left({ }^{3} P\right) 3 d{ }^{2} P_{3 / 2}$ & $\cdots$ & $\cdots$ & 1171.06 & 1171.24 & $\cdots$ \\
\hline $2 p^{4}\left({ }^{3} P\right) 3 d^{2} D_{5 / 2}$ & $\cdots$ & $\cdots$ & 1172.28 & 1172.45 & $\cdots$ \\
\hline $2 p^{4}\left({ }^{1} D\right) 3 d^{2} G_{7 / 2}$ & $\cdots$ & $\cdots$ & 1174.24 & 1174.52 & $\cdots$ \\
\hline $2 p^{4}\left({ }^{1} D\right) 3 d^{2} G_{9 / 2}$ & $\cdots$ & $\cdots$ & 1174.70 & 1174.98 & $\cdots$ \\
\hline $2 p^{4}\left({ }^{1} S\right) 3 p{ }^{2} P_{1 / 2}$ & $\cdots$ & $\cdots$ & 1176.81 & 1177.29 & $\cdots$ \\
\hline $2 p^{4}\left({ }^{1} S\right) 3 p{ }^{2} P_{3 / 2}$ & $\cdots$ & $\cdots$ & 1176.91 & 1177.35 & $\cdots$ \\
\hline $2 p^{4}\left({ }^{1} D\right) 3 d^{2} F_{5 / 2}$ & $\cdots$ & $\ldots$ & 1178.78 & 1179.06 & $\cdots$ \\
\hline $2 p^{4}\left({ }^{1} D\right) 3 d^{2} S_{1 / 2}$ & $\cdots$ & $\cdots$ & 1180.09 & 1180.28 & $\cdots$ \\
\hline $2 p^{4}\left({ }^{1} D\right) 3 d^{2} F_{7 / 2}$ & $\cdots$ & $\cdots$ & 1180.15 & 1180.45 & $\cdots$ \\
\hline $2 p^{4}\left({ }^{1} D\right) 3 d^{2} D_{5 / 2}$ & $\cdots$ & $\cdots$ & 1183.82 & 1184.16 & $\cdots$ \\
\hline $2 p^{4}\left({ }^{1} D\right) 3 d^{2} P_{3 / 2}$ & $\cdots$ & $\cdots$ & 1183.97 & 1184.31 & $\cdots$ \\
\hline $2 p^{4}\left({ }^{1} D\right) 3 d^{2} D_{3 / 2}$ & $\cdots$ & $\cdots$ & 1187.31 & 1187.66 & $\cdots$ \\
\hline $2 p^{4}\left({ }^{1} D\right) 3 d^{2} P_{1 / 2}$ & $\cdots$ & $\cdots$ & 1188.62 & 1188.98 & $\cdots$ \\
\hline $2 s^{2} 2 p^{2}\left({ }^{3} P\right) 4 s{ }^{4} P_{1 / 2}$ & $\cdots$ & $\cdots$ & 1200.56 & 1200.97 & 1203.85 \\
\hline $2 p^{4}\left({ }^{1} S\right) 3 d^{2} D_{5 / 2}$ & $\cdots$ & $\cdots$ & 1206.23 & 1206.70 & $\ldots$ \\
\hline $2 p^{4}\left({ }^{1} S\right) 3 d^{2} D_{3 / 2}$ & $\cdots$ & $\cdots$ & 1208.25 & 1208.72 & $\cdots$ \\
\hline $2 s^{2} 2 p^{2}\left({ }^{3} P\right) 4 s{ }^{4} P_{3 / 2}$ & $\cdots$ & $\cdots$ & 1209.38 & 1209.78 & 1212.48 \\
\hline $2 s^{2} 2 p^{2}\left({ }^{3} P\right) 4 s^{2} P_{1 / 2}$ & $\cdots$ & $\cdots$ & 1210.39 & 1210.80 & 1213.48 \\
\hline $2 s^{2} 2 p^{2}\left({ }^{3} P\right) 4 p \quad{ }^{4} D_{1 / 2}$ & $\cdots$ & $\cdots$ & 1210.98 & 1211.41 & 1214.30 \\
\hline $2 s^{2} 2 p^{2}\left({ }^{3} P\right) 4 p{ }^{4} P_{3 / 2}$ & $\cdots$ & $\cdots$ & 1213.51 & 1213.90 & 1216.63 \\
\hline $2 s^{2} 2 p^{2}\left({ }^{3} P\right) 4 s \quad{ }^{4} P_{5 / 2}$ & $\cdots$ & $\cdots$ & 1214.63 & 1215.06 & 1218.04 \\
\hline $2 s^{2} 2 p^{2}\left({ }^{3} P\right) 4 s^{2} P_{3 / 2}$ & $\cdots$ & $\cdots$ & 1215.83 & 1216.26 & 1219.23 \\
\hline $2 s^{2} 2 p^{2}\left({ }^{3} P\right) 4 p{ }^{2} S_{1 / 2}$ & $\cdots$ & $\cdots$ & 1219.55 & 1220.02 & 1222.74 \\
\hline $2 s^{2} 2 p^{2}\left({ }^{3} P\right) 4 p \quad{ }^{4} D_{3 / 2}$ & $\cdots$ & $\cdots$ & 1221.05 & 1221.45 & 1224.15 \\
\hline $2 s^{2} 2 p^{2}\left({ }^{3} P\right) 4 p{ }^{4} D_{5 / 2}$ & $\cdots$ & $\cdots$ & 1221.67 & 1222.05 & 1224.60 \\
\hline $2 s^{2} 2 p^{2}\left({ }^{3} P\right) 4 p{ }^{4} P_{1 / 2}$ & $\cdots$ & $\cdots$ & 1222.66 & 1223.07 & 1225.67 \\
\hline $2 s^{2} 2 p^{2}\left({ }^{3} P\right) 4 p{ }^{2} D_{3 / 2}$ & $\cdots$ & $\cdots$ & 1223.38 & 1223.77 & 1226.35 \\
\hline $2 s^{2} 2 p^{2}\left({ }^{3} P\right) 4 d{ }^{4} F_{3 / 2}$ & $\cdots$ & $\cdots$ & 1224.08 & 1224.47 & 1227.31 \\
\hline $2 s^{2} 2 p^{2}\left({ }^{3} P\right) 4 p{ }^{4} P_{5 / 2}$ & $\cdots$ & $\cdots$ & 1225.48 & 1225.88 & 1228.89 \\
\hline $2 s^{2} 2 p^{2}\left({ }^{3} P\right) 4 d{ }^{4} P_{5 / 2}$ & 1225.0 & $\cdots$ & 1225.50 & 1225.90 & 1228.77 \\
\hline $2 s^{2} 2 p^{2}\left({ }^{3} P\right) 4 p{ }^{4} D_{7 / 2}$ & $\ldots$ & $\cdots$ & 1226.73 & 1227.15 & 1229.97 \\
\hline $2 s^{2} 2 p^{2}\left({ }^{3} P\right) 4 p{ }^{4} S_{3 / 2}$ & $\cdots$ & $\cdots$ & 1227.63 & 1228.01 & 1230.81 \\
\hline $2 s^{2} 2 p^{2}\left({ }^{3} P\right) 4 p{ }^{2} P_{3 / 2}$ & $\cdots$ & $\ldots$ & 1228.45 & 1228.87 & 1231.74 \\
\hline
\end{tabular}


Table 3

(Continued)

\begin{tabular}{|c|c|c|c|c|c|}
\hline \multirow[b]{2}{*}{ Level } & \multicolumn{5}{|c|}{ Energy (eV) } \\
\hline & $\mathrm{NIST}^{\mathrm{a}}$ & CHIANTI $^{\mathrm{b}}$ & $\mathrm{MBPT}^{\mathrm{c}}$ & $\mathrm{MCDHF} / \mathrm{RCI}^{\mathrm{d}}$ & $\mathrm{AS}^{\mathrm{e}}$ \\
\hline $2 s^{2} 2 p^{2}\left({ }^{3} P\right) 4 p^{2} D_{5 / 2}$ & $\cdots$ & $\cdots$ & 1229.50 & 1229.89 & 1232.72 \\
\hline $2 s^{2} 2 p^{2}\left({ }^{3} P\right) 4 p{ }^{2} P_{1 / 2}$ & $\cdots$ & $\cdots$ & 1229.80 & 1230.31 & 1233.06 \\
\hline $2 s^{2} 2 p^{2}\left({ }^{1} D\right) 4 s^{2} D_{5 / 2}$ & $\cdots$ & $\cdots$ & 1230.61 & 1231.11 & 1233.86 \\
\hline $2 s^{2} 2 p^{2}\left({ }^{1} D\right) 4 s^{2} D_{3 / 2}$ & $\cdots$ & $\cdots$ & 1231.02 & 1231.52 & 1234.24 \\
\hline $2 s^{2} 2 p^{2}\left({ }^{3} P\right) 4 f{ }^{4} G_{5 / 2}$ & $\cdots$ & $\cdots$ & 1231.66 & 1232.04 & 1243.56 \\
\hline $2 s^{2} 2 p^{2}\left({ }^{3} P\right) 4 f{ }^{2} G_{7 / 2}$ & $\cdots$ & $\cdots$ & 1231.86 & 1232.24 & 1244.09 \\
\hline $2 s^{2} 2 p^{2}\left({ }^{3} P\right) 4 d{ }^{2} P_{3 / 2}$ & $\cdots$ & $\cdots$ & 1233.07 & 1233.48 & 1236.13 \\
\hline $2 s^{2} 2 p^{2}\left({ }^{3} P\right) 4 d{ }^{4} F_{7 / 2}$ & $\cdots$ & $\cdots$ & 1233.35 & 1233.72 & 1236.43 \\
\hline $2 s^{2} 2 p^{2}\left({ }^{3} P\right) 4 d{ }^{4} D_{1 / 2}$ & $\cdots$ & $\cdots$ & 1233.45 & 1233.80 & 1236.41 \\
\hline $2 s^{2} 2 p^{2}\left({ }^{3} P\right) 4 d{ }^{4} F_{5 / 2}$ & 1232.65 & $\cdots$ & 1233.82 & 1234.22 & 1236.93 \\
\hline $2 s^{2} 2 p^{2}\left({ }^{3} P\right) 4 d{ }^{4} D_{3 / 2}$ & $\ldots$ & $\ldots$ & 1235.31 & 1235.70 & 1238.41 \\
\hline $2 s^{2} 2 p^{2}\left({ }^{3} P\right) 4 d{ }^{2} F_{5 / 2}$ & 1235.38 & $\cdots$ & 1235.46 & 1235.87 & 1238.64 \\
\hline $2 s^{2} 2 p^{2}\left({ }^{3} P\right) 4 d{ }^{4} D_{7 / 2}$ & $\ldots$ & $\cdots$ & 1238.09 & 1238.48 & 1241.45 \\
\hline $2 s^{2} 2 p^{2}\left({ }^{3} P\right) 4 d{ }^{4} F_{9 / 2}$ & $\cdots$ & $\cdots$ & 1238.27 & 1238.68 & 1241.66 \\
\hline $2 s^{2} 2 p^{2}\left({ }^{3} P\right) 4 d{ }^{4} D_{5 / 2}$ & 1238.85 & 1240.09 & 1239.40 & 1239.79 & 1242.70 \\
\hline $2 s^{2} 2 p^{2}\left({ }^{3} P\right) 4 d{ }^{4} P_{3 / 2}$ & 1240.96 & 1240.09 & 1240.02 & 1240.43 & 1243.30 \\
\hline $2 s^{2} 2 p^{2}\left({ }^{3} P\right) 4 d{ }^{4} P_{1 / 2}$ & 1240.96 & 1240.09 & 1240.33 & 1240.77 & 1243.64 \\
\hline $2 s^{2} 2 p^{2}\left({ }^{3} P\right) 4 f^{2} D_{5 / 2}$ & $\ldots$ & $\ldots$ & 1240.50 & 1240.88 & 1234.94 \\
\hline $2 s^{2} 2 p^{2}\left({ }^{3} P\right) 4 f{ }^{4} D_{7 / 2}$ & $\ldots$ & $\ldots$ & 1240.66 & 1241.04 & 1243.76 \\
\hline $2 s^{2} 2 p^{2}\left({ }^{3} P\right) 4 d{ }^{2} P_{1 / 2}$ & $\cdots$ & $\cdots$ & 1240.85 & 1241.33 & 1244.13 \\
\hline $2 s^{2} 2 p^{2}\left({ }^{3} P\right) 4 f^{2} G_{7 / 2}$ & $\cdots$ & $\cdots$ & 1240.94 & 1241.33 & 1244.09 \\
\hline $2 s^{2} 2 p^{2}\left({ }^{3} P\right) 4 f{ }^{4} G_{9 / 2}$ & $\cdots$ & $\cdots$ & 1240.95 & 1241.33 & 1244.07 \\
\hline $2 s^{2} 2 p^{2}\left({ }^{3} P\right) 4 f{ }^{4} F_{3 / 2}$ & $\cdots$ & $\cdots$ & 1241.14 & 1241.50 & 1244.17 \\
\hline $2 s^{2} 2 p^{2}\left({ }^{3} P\right) 4 f{ }^{4} D_{5 / 2}$ & $\cdots$ & $\cdots$ & 1241.40 & 1241.77 & 1244.51 \\
\hline $2 s^{2} 2 p^{2}\left({ }^{3} P\right) 4 d{ }^{2} D_{5 / 2}$ & 1242.20 & $\cdots$ & 1241.52 & 1241.93 & 1244.98 \\
\hline $2 s^{2} 2 p^{2}\left({ }^{3} P\right) 4 d{ }^{2} D_{3 / 2}$ & 1245.17 & $\cdots$ & 1241.59 & 1242.03 & 1245.00 \\
\hline $2 s^{2} 2 p^{2}\left({ }^{3} P\right) 4 d{ }^{2} F_{7 / 2}$ & 1242.20 & $\cdots$ & 1241.80 & 1242.20 & 1245.23 \\
\hline $2 s^{2} 2 p^{2}\left({ }^{1} D\right) 4 p{ }^{2} F_{5 / 2}$ & $\ldots$ & $\cdots$ & 1242.33 & 1242.80 & 1245.45 \\
\hline $2 s^{2} 2 p^{2}\left({ }^{1} D\right) 4 p{ }^{2} D_{3 / 2}$ & $\cdots$ & $\cdots$ & 1242.64 & 1243.10 & 1245.79 \\
\hline $2 s^{2} 2 p^{2}\left({ }^{1} D\right) 4 p{ }^{2} D_{5 / 2}$ & $\cdots$ & $\cdots$ & 1242.98 & 1243.45 & 1246.15 \\
\hline $2 s^{2} 2 p^{2}\left({ }^{1} D\right) 4 p{ }^{2} F_{7 / 2}$ & $\cdots$ & $\cdots$ & 1242.99 & 1243.43 & 1246.04 \\
\hline $2 s^{2} 2 p^{2}\left({ }^{1} D\right) 4 p{ }^{2} P_{1 / 2}$ & $\cdots$ & $\cdots$ & 1243.70 & 1244.15 & 1246.81 \\
\hline $2 s^{2} 2 p^{2}\left({ }^{3} P\right) 4 f^{2} G_{9 / 2}$ & $\cdots$ & $\cdots$ & 1246.03 & 1246.44 & 1249.44 \\
\hline $2 s^{2} 2 p^{2}\left({ }^{3} P\right) 4 f{ }^{4} G_{11 / 2}$ & $\cdots$ & $\cdots$ & 1246.07 & 1246.48 & 1249.49 \\
\hline $2 s^{2} 2 p^{2}\left({ }^{1} S\right) 4 s^{2} S_{1 / 2}$ & $\cdots$ & $\cdots$ & 1246.21 & 1247.18 & 1248.85 \\
\hline $2 s^{2} 2 p^{2}\left({ }^{3} P\right) 4 f{ }^{4} D_{1 / 2}$ & $\cdots$ & $\cdots$ & 1246.30 & 1246.68 & 1249.57 \\
\hline $2 s^{2} 2 p^{2}\left({ }^{3} P\right) 4 f{ }^{4} F_{7 / 2}$ & $\cdots$ & $\cdots$ & 1246.33 & 1246.71 & 1249.70 \\
\hline $2 s^{2} 2 p^{2}\left({ }^{3} P\right) 4 f{ }^{4} D_{3 / 2}$ & $\cdots$ & $\cdots$ & 1246.35 & 1246.73 & 1249.64 \\
\hline $2 s^{2} 2 p^{2}\left({ }^{3} P\right) 4 f^{4} F_{5 / 2}$ & $\cdots$ & $\cdots$ & 1246.40 & 1246.78 & 1249.73 \\
\hline $2 s^{2} 2 p^{2}\left({ }^{3} P\right) 4 f{ }^{4} F_{9 / 2}$ & $\cdots$ & $\cdots$ & 1246.51 & 1246.91 & 1249.95 \\
\hline $2 s^{2} 2 p^{2}\left({ }^{3} P\right) 4 f^{2} D_{3 / 2}$ & $\cdots$ & $\ldots$ & 1246.54 & 1246.94 & 1249.98 \\
\hline $2 s^{2} 2 p^{2}\left({ }^{3} P\right) 4 f^{2} F_{7 / 2}$ & $\cdots$ & $\cdots$ & 1246.62 & 1247.01 & 1250.05 \\
\hline $2 s^{2} 2 p^{2}\left({ }^{3} P\right) 4 f{ }^{2} F_{5 / 2}$ & $\cdots$ & $\cdots$ & 1246.66 & 1247.05 & 1250.06 \\
\hline $2 s^{2} 2 p^{2}\left({ }^{1} D\right) 4 p{ }^{2} P_{3 / 2}$ & $\cdots$ & $\cdots$ & 1246.77 & 1247.23 & 1249.73 \\
\hline $2 s^{2} 2 p^{2}\left({ }^{1} D\right) 4 d{ }^{2} F_{7 / 2}$ & $\cdots$ & $\cdots$ & 1253.94 & 1254.41 & 1257.18 \\
\hline $2 s^{2} 2 p^{2}\left({ }^{1} D\right) 4 d^{2} G_{9 / 2}$ & $\ldots$ & $\cdots$ & 1254.80 & 1255.23 & 1257.98 \\
\hline $2 s^{2} 2 p^{2}\left({ }^{1} D\right) 4 d^{2} D_{5 / 2}$ & 1257.45 & $\cdots$ & 1255.37 & 1255.85 & 1258.58 \\
\hline $2 s^{2} 2 p^{2}\left({ }^{1} D\right) 4 d{ }^{2} D_{3 / 2}$ & 1256.0 & $\cdots$ & 1255.46 & 1255.92 & 1258.60 \\
\hline $2 s^{2} 2 p^{2}\left({ }^{1} D\right) 4 d{ }^{2} G_{7 / 2}$ & 1257.45 & $\cdots$ & 1255.77 & 1256.21 & 1258.96 \\
\hline $2 s^{2} 2 p^{2}\left({ }^{1} D\right) 4 d{ }^{2} P_{1 / 2}$ & $\ldots$ & $\cdots$ & 1255.85 & 1256.27 & 1258.99 \\
\hline $2 s^{2} 2 p^{2}\left({ }^{1} D\right) 4 d^{2} F_{5 / 2}$ & 1258.32 & $\cdots$ & 1257.43 & 1257.93 & 1260.66 \\
\hline $2 s^{2} 2 p^{2}\left({ }^{1} D\right) 4 d{ }^{2} S_{1 / 2}$ & $\ldots$ & $\cdots$ & 1257.70 & 1258.12 & 1260.81 \\
\hline $2 s^{2} 2 p^{2}\left({ }^{1} D\right) 4 d{ }^{2} P_{3 / 2}$ & 1258.32 & $\cdots$ & 1257.87 & 1258.33 & 1260.97 \\
\hline $2 s^{2} 2 p^{2}\left({ }^{1} S\right) 4 p{ }^{2} P_{1 / 2}$ & $\ldots$ & $\cdots$ & 1258.12 & 1259.02 & 1260.66 \\
\hline $2 s^{2} 2 p^{2}\left({ }^{1} S\right) 4 p{ }^{2} P_{3 / 2}$ & $\cdots$ & $\cdots$ & 1259.03 & 1259.94 & 1261.46 \\
\hline
\end{tabular}


Table 3

(Continued)

\begin{tabular}{|c|c|c|c|c|c|}
\hline \multirow[b]{2}{*}{ Level } & \multicolumn{5}{|c|}{ Energy $(\mathrm{eV})$} \\
\hline & $\mathrm{NIST}^{\mathrm{a}}$ & CHIANTI $^{\mathrm{b}}$ & $\mathrm{MBPT}^{\mathrm{c}}$ & $\mathrm{MCDHF} / \mathrm{RCI}^{\mathrm{d}}$ & $\mathrm{AS}^{\mathrm{e}}$ \\
\hline $2 s^{2} 2 p^{2}\left({ }^{1} D\right) 4 f^{2} G_{7 / 2}$ & $\cdots$ & $\cdots$ & 1261.57 & 1262.02 & 1264.74 \\
\hline $2 s^{2} 2 p^{2}\left({ }^{1} D\right) 4 f^{2} G_{9 / 2}$ & $\cdots$ & $\cdots$ & 1261.58 & 1262.03 & 1264.75 \\
\hline $2 s^{2} 2 p^{2}\left({ }^{1} D\right) 4 f^{2} F_{5 / 2}$ & $\cdots$ & $\cdots$ & 1261.74 & 1262.18 & 1264.87 \\
\hline $2 s^{2} 2 p^{2}\left({ }^{1} D\right) 4 f{ }^{2} F_{7 / 2}$ & $\cdots$ & $\cdots$ & 1261.92 & 1262.37 & 1265.09 \\
\hline $2 s^{2} 2 p^{2}\left({ }^{1} D\right) 4 f{ }^{2} H_{9 / 2}$ & $\cdots$ & $\cdots$ & 1262.11 & 1262.56 & 1265.34 \\
\hline $2 s^{2} 2 p^{2}\left({ }^{1} D\right) 4 f^{2} H_{11 / 2}$ & $\cdots$ & $\cdots$ & 1262.21 & 1262.66 & 1265.45 \\
\hline $2 s^{2} 2 p^{2}\left({ }^{1} D\right) 4 f^{2} D_{3 / 2}$ & $\cdots$ & $\cdots$ & 1262.42 & 1262.83 & 1265.52 \\
\hline $2 s^{2} 2 p^{2}\left({ }^{1} D\right) 4 f^{2} D_{5 / 2}$ & $\cdots$ & $\cdots$ & 1262.65 & 1263.07 & 1265.81 \\
\hline $2 s^{2} 2 p^{2}\left({ }^{1} D\right) 4 f{ }^{2} P_{1 / 2}$ & $\cdots$ & $\cdots$ & 1263.15 & 1263.54 & 1266.26 \\
\hline $2 s^{2} 2 p^{2}\left({ }^{1} D\right) 4 f{ }^{2} P_{3 / 2}$ & $\ldots$ & $\cdots$ & 1263.28 & 1263.68 & 1266.43 \\
\hline $2 s^{2} 2 p^{2}\left({ }^{1} S\right) 4 d^{2} D_{5 / 2}$ & 1275.67 & $\cdots$ & 1271.00 & 1271.88 & 1273.55 \\
\hline $2 s^{2} 2 p^{2}\left({ }^{1} S\right) 4 d^{2} D_{3 / 2}$ & 1273.19 & $\cdots$ & 1271.26 & 1272.15 & 1273.81 \\
\hline $2 s^{2} 2 p^{2}\left({ }^{1} S\right) 4 f^{2} F_{5 / 2}$ & $\ldots$ & $\cdots$ & 1277.50 & 1278.34 & 1279.97 \\
\hline $2 s^{2} 2 p^{2}\left({ }^{1} S\right) 4 f{ }^{2} F_{7 / 2}$ & $\cdots$ & $\cdots$ & 1277.63 & 1278.47 & 1280.12 \\
\hline
\end{tabular}

Notes.

a The observed energies from the NIST ASD (Kramida et al. 2014).

${ }^{b}$ The observed energies from the CHIANTI database (Dere et al. 1997; Landi et al. 2013).

${ }^{c}$ The present MBPT energies.

${ }^{\mathrm{d}}$ The present MCDHF/RCI energies.

${ }^{\mathrm{e}}$ The energies calculated by Witthoeft et al. (2007) using the AS code.

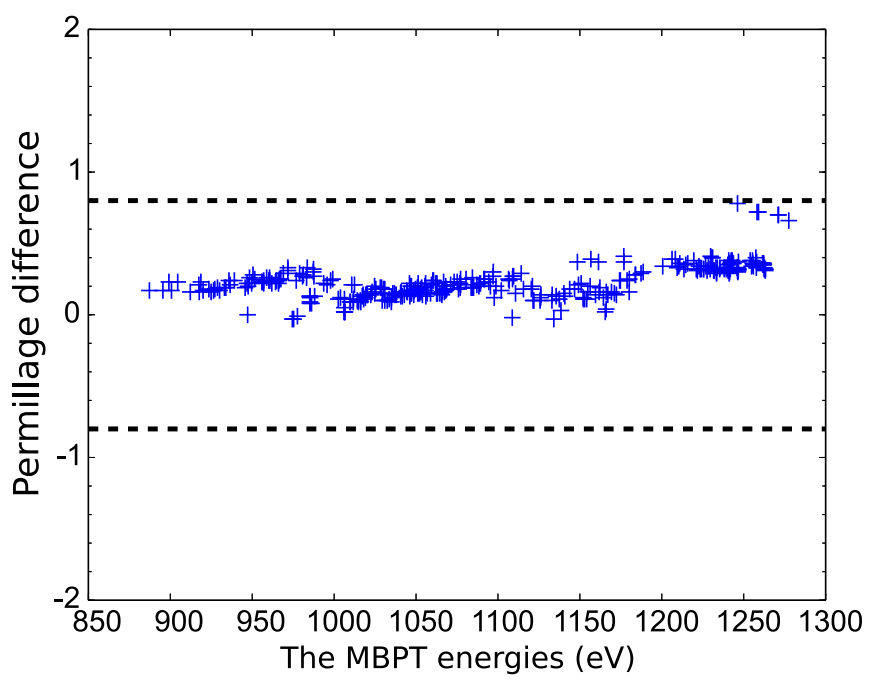

Figure 1. Permillage differences of the MCDHF/RCI values relative to the MBPT energies for the $n=3,4$ levels in Fe xx. Dashed lines indicate differences of $\pm 0.08 \%$.

Furthermore, the identification of these levels becomes problematic in some cases. For example, the $2 s^{2} 2 p^{2}\left({ }^{3} P\right) 3 d{ }^{4} P_{5 / 2}$ $(967.32 \mathrm{eV})$ level (Sugar \& Corliss 1985) from the NIST ASD is observed at a considerably higher energy $(>2.1 \mathrm{eV})$ than from the CHIANTI database and the present MBPT and MCDHF/RCI calculations. The $2 s^{2} 2 p^{2}\left({ }^{3} P\right) 3 d{ }^{2} D_{3 / 2}(974.39 \mathrm{eV})$, $2 s^{2} 2 p^{2}\left({ }^{1} D\right) 3 d^{2} F_{5 / 2}(989.77 \mathrm{eV}), 2 s^{2} 2 p^{2}\left({ }^{3} P\right) 4 d^{2} D_{3 / 2}(1245.17 \mathrm{eV})$, and $2 s^{2} 2 p^{2}\left({ }^{1} S\right) 4 d{ }^{2} D_{5 / 2}(1275.67 \mathrm{eV})$ levels in the NIST ASD are also higher than the present MBPT and MCDHF/RCI calculations by over $2-3 \mathrm{eV}$. The misidentification of these five levels from the NIST ASD cannot be ruled out, as suggested by Radžiūtè et al. (2015). The relative differences between the NIST observations and the MBPT calculations (or the
$\mathrm{MCDHF} / \mathrm{RCI}$ calculations) are within $0.2 \%$ for the remaining $22 n=3$, 4 levels in Fe xx. The agreement with the CHIANTI observed values is better. Deviations of the CHIANTI values relative to the MBPT results (or the MCDHF/RCI results) are less than $0.2 \%$ for 33 levels, except for the $2 s 2 p^{3}\left({ }^{3} S\right) 3 p{ }^{4} P_{5 / 2}$ level. The CHIANTI value is $1056.17 \mathrm{eV}$ for the ${ }^{4} P_{5 / 2}$ level, which is very close to our MBPT and MCDHF/RCI results for the $2 s 2 p^{3}\left({ }^{1} D\right) 3 p^{2} F_{5 / 2}$ level, 1056.83 and $1056.99 \mathrm{eV}$. This indicates that the CHIANTI results should perhaps be designated as the $2 s 2 p^{3}\left({ }^{1} D\right) 3 p^{2} F_{5 / 2}$ level. The mean differences with the CHIANTI values are $0.05 \%$ for both the MBPT and MCDHF/RCI calculations. The other theoretical energies shown in Table 3, i.e., the AS results, differ from the CHIANTI values significantly. The deviations of the AS results from the CHIANTI values are up to $0.42 \%$ for the $2 s^{2} 2 p^{2}\left({ }^{3} P\right) 3 s^{4} P_{5 / 2}$ levels. The mean deviation relative to the CHIANTI values is $0.24 \%$, larger by over one order of magnitude than the present MBPT (MCDHF/RCI) results.

The NIST ASD only includes 108 levels of the total 4472 $n \geqslant 3$ levels in the $13 \mathrm{~N}$-like ions considered here. The relative deviations between the MBPT and NIST values are less than $0.2 \%$ for 85 levels. The remaining 23 states for which the differences are larger than $0.2 \%$ are listed in Table 4. First, we look at the states for which the differences between the MBPT and NIST values exceed $0.5 \%$. The NIST energy $404.004 \mathrm{eV}$ for the $2 s^{2} 2 p^{2}\left({ }^{1} D\right) 3 d^{2} G_{7 / 2}$ level is very close to our MBPT result for the $2 s^{2} 2 p^{2}\left({ }^{1} D\right) 3 d^{2} F_{7 / 2}$ level, $403.552 \mathrm{eV}$, which suggests that it might be mislabeled and should be designated as the ${ }^{2} F_{7 / 2}$ level. Figure 2(a) display the deviations for two representative states $\left(2 s^{2} 2 p^{2}\left({ }^{1} D\right) 3 d d^{2} D_{5 / 2}\right.$ and $\left.2 s^{2} 2 p^{2}\left({ }^{1} S\right) 3 d{ }^{2} D_{5 / 2}\right)$, as well as the differences for the same states but in other N-like ions so as to aid in comparisons. The deviations are $0.39 \%, 0.45 \%$, and $0.65 \%$ for the $2 s^{2} 2 p^{2}\left({ }^{1} D\right) 3 d{ }^{2} D_{5 / 2}$ level in K XIII, Ca XIV, and $\mathrm{V}$ XVII, respectively. Whereas the MBPT results agree 
Table 4

Comparisons of the Levels with Differences Larger than $0.2 \%$ between our MBPT Energies and the Experimental Values of the NIST ASD

\begin{tabular}{|c|c|c|c|c|c|}
\hline \multirow[t]{2}{*}{$Z$} & \multirow[t]{2}{*}{$\mathrm{Key}^{\mathrm{a}}$} & \multirow[t]{2}{*}{ State } & \multicolumn{2}{|c|}{ Energy $(\mathrm{eV})$} & \multirow[t]{2}{*}{ Difference $(\%)$} \\
\hline & & & NIST $^{b}$ & $\mathrm{MBPT}^{\mathrm{c}}$ & \\
\hline 18 & 33 & $2 s^{2} 2 p^{2}\left({ }^{3} P\right) 3 p{ }^{4} S_{3 / 2}$ & 379.27 & 376.264 & 0.79 \\
\hline 18 & 41 & $2 s^{2} 2 p^{2}\left({ }^{1} D\right) 3 p{ }^{2} D_{5 / 2}$ & 387.43 & 385.478 & 0.50 \\
\hline 18 & 42 & $2 s^{2} 2 p^{2}\left({ }^{1} D\right) 3 p{ }^{2} P_{1 / 2}$ & 388.54 & 387.446 & 0.28 \\
\hline 18 & 43 & $2 s^{2} 2 p^{2}\left({ }^{1} D\right) 3 p{ }^{2} P_{3 / 2}$ & 389.62 & 388.648 & 0.25 \\
\hline 18 & 63 & $2 s^{2} 2 p^{2}\left({ }^{3} P\right) 3 d^{2} D_{5 / 2}$ & 400.07 & 399.251 & 0.20 \\
\hline 18 & 67 & $2 s^{2} 2 p^{2}\left({ }^{1} D\right) 3 d{ }^{2} G_{7 / 2}$ & 404.004 & 401.334 & 0.66 \\
\hline 19 & 63 & $2 s^{2} 2 p^{2}\left({ }^{3} P\right) 3 d^{2} D_{5 / 2}$ & 458.5 & 457.275 & 0.27 \\
\hline 19 & 70 & $2 s^{2} 2 p^{2}\left({ }^{1} D\right) 3 d^{2} D_{5 / 2}$ & 463.2 & 461.403 & 0.39 \\
\hline 20 & 63 & $2 s^{2} 2 p^{2}\left({ }^{3} P\right) 3 d^{2} D_{5 / 2}$ & 520.66 & 519.134 & 0.29 \\
\hline 20 & 70 & $2 s^{2} 2 p^{2}\left({ }^{1} D\right) 3 d^{2} D_{5 / 2}$ & 525.94 & 523.578 & 0.45 \\
\hline 21 & 63 & $2 s^{2} 2 p^{2}\left({ }^{3} P\right) 3 d^{2} D_{5 / 2}$ & 586.85 & 584.843 & 0.34 \\
\hline 21 & 83 & $2 s^{2} 2 p^{2}\left({ }^{1} S\right) 3 d^{2} D_{5 / 2}$ & 605.0 & 601.518 & 0.58 \\
\hline 21 & 86 & $2 s^{2} 2 p^{2}\left({ }^{1} S\right) 3 d^{2} D_{3 / 2}$ & 606.03 & 602.287 & 0.62 \\
\hline 22 & 47 & $2 s^{2} 2 p^{2}\left({ }^{3} P\right) 3 d^{2} P_{3 / 2}$ & 643.986 & 642.590 & 0.22 \\
\hline 22 & 62 & $2 s^{2} 2 p^{2}\left({ }^{3} P\right) 3 d^{2} D_{3 / 2}$ & 655.50 & 654.134 & 0.21 \\
\hline 22 & 63 & $2 s^{2} 2 p^{2}\left({ }^{3} P\right) 3 d^{2} D_{5 / 2}$ & 656.286 & 654.415 & 0.29 \\
\hline 23 & 63 & $2 s^{2} 2 p^{2}\left({ }^{3} P\right) 3 d^{2} D_{5 / 2}$ & 731.13 & 727.870 & 0.45 \\
\hline 23 & 70 & $2 s^{2} 2 p^{2}\left({ }^{1} D\right) 3 d^{2} D_{5 / 2}$ & 738.70 & 733.890 & 0.65 \\
\hline 26 & 56 & $2 s^{2} 2 p^{2}\left({ }^{3} P\right) 3 d{ }^{4} P_{5 / 2}$ & 967.32 & 964.894 & 0.25 \\
\hline 26 & 62 & $2 s^{2} 2 p^{2}\left({ }^{3} P\right) 3 d^{2} D_{3 / 2}$ & 974.39 & 971.784 & 0.27 \\
\hline 26 & 80 & $2 s^{2} 2 p^{2}\left({ }^{1} D\right) 3 d^{2} F_{5 / 2}$ & 989.77 & 987.413 & 0.24 \\
\hline 26 & 316 & $2 s^{2} 2 p^{2}\left({ }^{3} P\right) 4 d^{2} D_{3 / 2}$ & 1245.17 & 1241.59 & 0.29 \\
\hline 26 & 356 & $2 s^{2} 2 p^{2}\left({ }^{1} S\right) 4 d^{2} D_{5 / 2}$ & 1275.67 & 1271.00 & 0.37 \\
\hline
\end{tabular}

Notes.

${ }^{\mathrm{a}}$ The index number of the level given in Table 1.

${ }^{\mathrm{b}}$ The NIST recommended energies (Kramida et al. 2014).

${ }^{\mathrm{c}}$ The present MBPT energies.
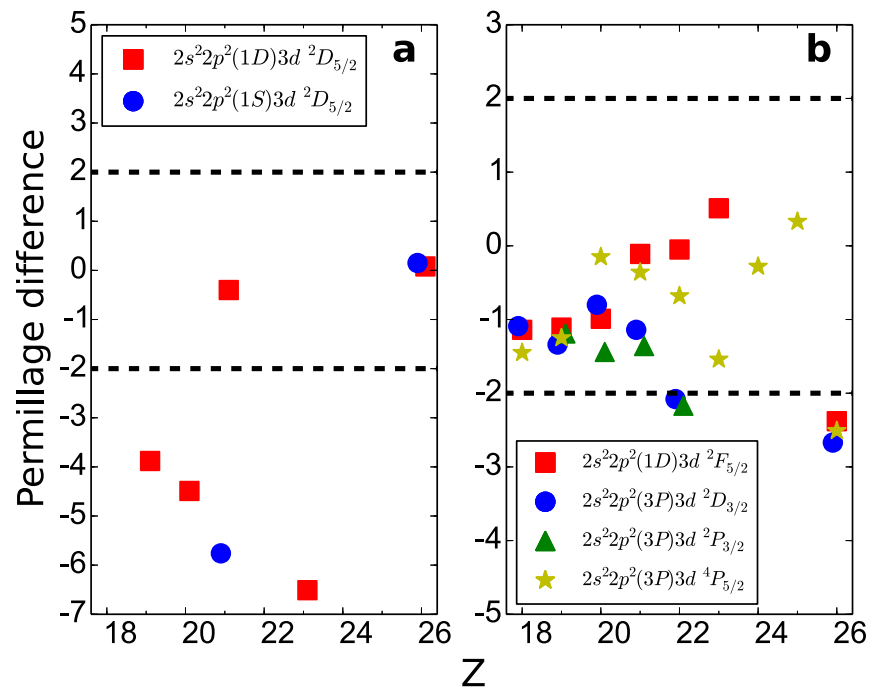

Figure 2. Permillage differences of the present MBPT energies relative to the NIST observations (a) for the $2 s^{2} 2 p^{2}(1 D) 3 d{ }^{2} D_{5 / 2}$ and $2 s^{2} 2 p^{2}(1 S) 3 d{ }^{2} D_{5 / 2}$ levels, and (b) for the $2 s^{2} 2 p^{2}(1 D) 3 d{ }^{2} F_{5 / 2}$ and $2 s^{2} 2 p^{2}(3 P) 3 d{ }^{2} D_{3 / 2}$ and

${ }^{4} P_{5 / 2}$ levels along the sequence.

well with the observations for the same level in Sc xv and Fe xx. In fact, the NIST energy for the $2 s^{2} 2 p^{2}\left({ }^{1} D\right) 3 d{ }^{2} D_{5 / 2}$ level in $\mathrm{KXIII}$ is $463.2 \mathrm{eV}$, and the observed wavelengths $27.53\left(2 s^{2} 2 p^{3}{ }^{2} D_{5 / 2}-2 s^{2} 2 p^{2}\left({ }^{1} D\right) 3 d^{2} D_{5 / 2}\right) \quad$ and $\quad 28.012$

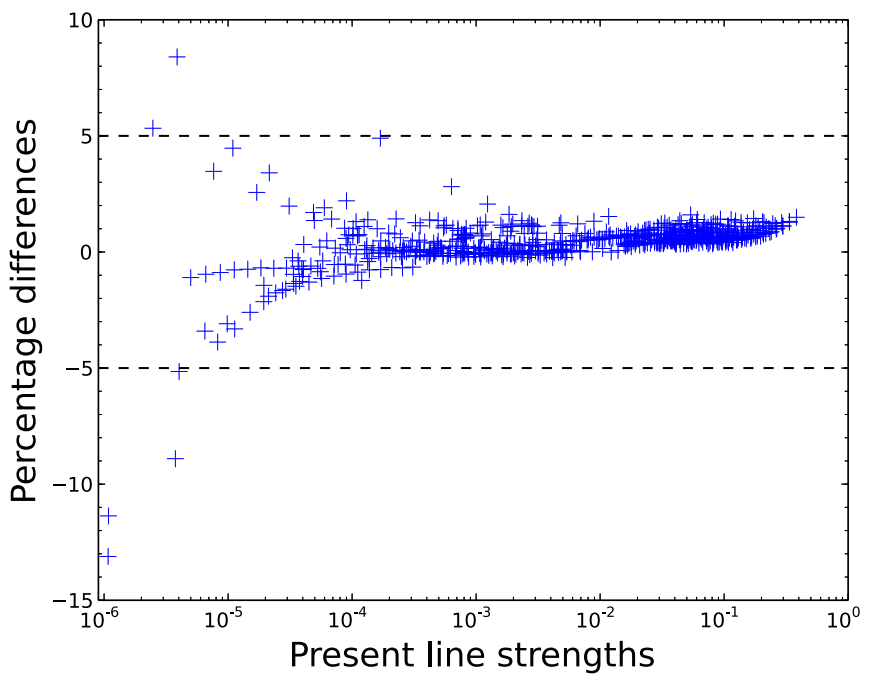

Figure 3. Percentage differences between the present MBPT line strengths and the MCDHF/RCI results for the E1 transitions among the $n=2$ levels. Dashed lines indicate differences of $\pm 5 \%$.

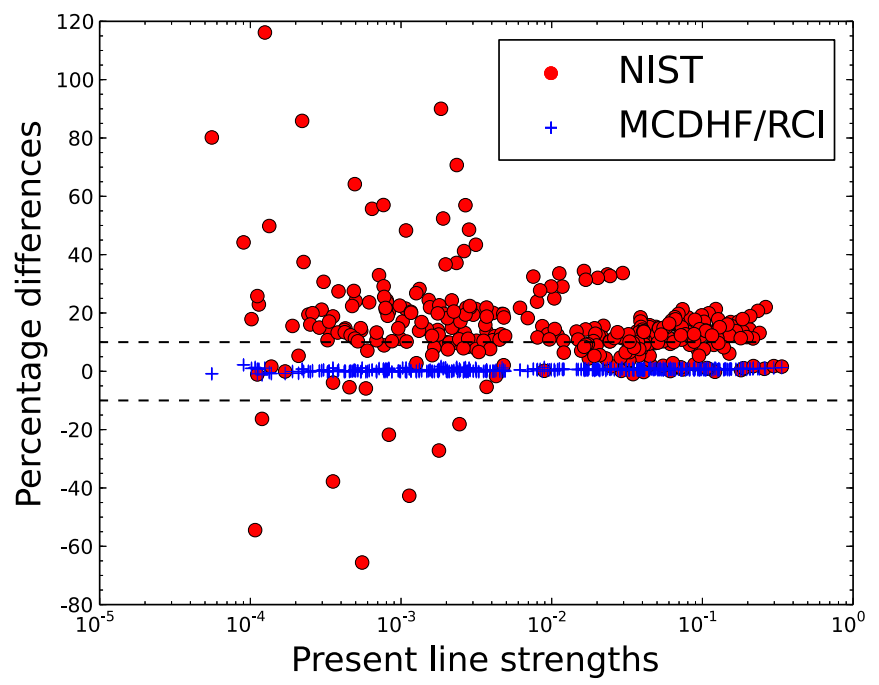

Figure 4. Percentage differences of the NIST and MCDHF/RCI2 line strengths relative to the present MBPT results for the E1 transitions among the $n=2$ levels given by the NIST ASD. Dashed lines indicate differences of $\pm 10 \%$.

$\left(2 s^{2} 2 p^{3}{ }^{2} P_{3 / 2}-2 s^{2} 2 p^{2}\left({ }^{1} D\right) 3 d{ }^{2} D_{5 / 2}\right) \AA$ are used to deduce the energy for $2 s^{2} 2 p^{2}\left({ }^{1} D\right) 3 d^{2} D_{5 / 2}$ with the aid of the known energies of $2 s^{2} 2 p^{3}{ }^{2} D_{5 / 2}$ and ${ }^{2} P_{3 / 2}$ (Fawcett \& Hayes 1975). The MBPT wavelengths, respectively, are 27.656 and $28.142 \AA$ for the above two transitions, which deviate from the observed values (27.53 and $28.012 \mathrm{~A}$ ) up to $0.46 \%$ and $0.47 \%$, but agree well $(0.08 \%$ and $0.15 \%)$ with the more recent experimental values 27.63 and $28.10 \AA$ in the revised identification recommended by the same group (Bromage \& Fawcett 1977). Using the above revised observations, the experimental data for $2 s^{2} 2 p^{3}{ }^{2} D_{5 / 2}$ should be corrected as 461.8 and $462.1 \mathrm{eV}$, respectively, with the aid of the known energies of $2 s^{2} 2 p^{3}{ }^{2} D_{5 / 2}$ and ${ }^{2} P_{3 / 2}$, which agree with our MBPT value of $461.403 \mathrm{eV}$ to within $0.15 \%$. The NIST values of the $2 s^{2} 2 p^{3}{ }^{2} D_{5 / 2}$ level in Ca XIV, and V Xvil are also determined using the observations given by Fawcett \& Hayes (1975). We consider that the observation uncertainty should be relatively large according to similar arguments for K XIII 
Table 5

Comparisons of the Line Strengths with Differences Large than $10 \%$ between our MBPT Results and the NIST Values for Transitions among the $n=2$ Levels

\begin{tabular}{|c|c|c|c|c|c|c|}
\hline \multirow[t]{2}{*}{$Z$} & \multirow[t]{2}{*}{ Transition } & \multicolumn{3}{|c|}{ Line Strengths } & \multicolumn{2}{|c|}{ Difference $(\%)$} \\
\hline & & MBPT & $\mathrm{MCDHF} / \mathrm{RCI} 2$ & NIST & MBPT and MCDHF/RCI2 & MBPT and NIST \\
\hline 21 & $2 s 2 p^{4}{ }^{4} P_{5 / 2}-2 s^{2} 2 p^{3}{ }^{4} S_{3 / 2}$ & $1.429 \mathrm{E}-01$ & $1.441 \mathrm{E}-01$ & $1.600 \mathrm{E}-01$ & 0.1 & 12 \\
\hline 21 & $2 s 2 p^{4}{ }^{4} P_{5 / 2}-2 s^{2} 2 p^{3}{ }^{2} D_{3 / 2}$ & $1.527 \mathrm{E}-03$ & $1.529 \mathrm{E}-03$ & $1.900 \mathrm{E}-03$ & 0.1 & 24 \\
\hline 21 & $2 s 2 p^{4}{ }^{4} P_{5 / 2}-2 s^{2} 2 p^{3}{ }^{2} P_{3 / 2}$ & $7.145 \mathrm{E}-04$ & $7.211 \mathrm{E}-04$ & $9.500 \mathrm{E}-04$ & 0.9 & 33 \\
\hline 21 & $2 s 2 p^{4}{ }^{4} P_{3 / 2}-2 s^{2} 2 p^{3}{ }^{4} S_{3 / 2}$ & $9.674 \mathrm{E}-02$ & $9.757 \mathrm{E}-02$ & $1.120 \mathrm{E}-01$ & 0.9 & 16 \\
\hline 21 & $2 s 2 p^{4}{ }^{4} P_{3 / 2}-2 s^{2} 2 p^{3}{ }^{2} P_{3 / 2}$ & $1.326 \mathrm{E}-03$ & $1.333 \mathrm{E}-03$ & $1.700 \mathrm{E}-03$ & 0.5 & 28 \\
\hline 21 & $2 s 2 p^{4}{ }^{4} P_{1 / 2}-2 s^{2} 2 p^{3}{ }^{4} S_{3 / 2}$ & $4.921 \mathrm{E}-02$ & $4.963 \mathrm{E}-02$ & $5.670 \mathrm{E}-02$ & 0.9 & 15 \\
\hline 21 & $2 s 2 p^{4}{ }^{4} P_{1 / 2}-2 s^{2} 2 p^{3}{ }^{2} P_{1 / 2}$ & $3.323 \mathrm{E}-04$ & $3.326 \mathrm{E}-04$ & $3.800 \mathrm{E}-04$ & 0.1 & 14 \\
\hline 21 & $2 s 2 p^{4}{ }^{2} D_{3 / 2}-2 s^{2} 2 p^{3}{ }^{4} S_{3 / 2}$ & $2.972 \mathrm{E}-04$ & $2.979 \mathrm{E}-04$ & $3.600 \mathrm{E}-04$ & 0.3 & 21 \\
\hline 21 & $2 s 2 p^{4}{ }^{2} D_{3 / 2}-2 s^{2} 2 p^{3}{ }^{2} D_{3 / 2}$ & $1.540 \mathrm{E}-01$ & $1.553 \mathrm{E}-01$ & $1.800 \mathrm{E}-01$ & 0.9 & 17 \\
\hline 21 & $2 s 2 p^{4}{ }^{2} D_{3 / 2}-2 s^{2} 2 p^{3}{ }^{2} D_{5 / 2}$ & $4.680 \mathrm{E}-03$ & $4.734 \mathrm{E}-03$ & $5.600 \mathrm{E}-03$ & 1.2 & 20 \\
\hline 21 & $2 s 2 p^{4}{ }^{2} D_{3 / 2}-2 s^{2} 2 p^{3}{ }^{2} P_{1 / 2}$ & $2.206 \mathrm{E}-02$ & $2.224 \mathrm{E}-02$ & $2.550 \mathrm{E}-02$ & 0.8 & 16 \\
\hline 21 & $2 s 2 p^{4}{ }^{2} D_{3 / 2}-2 s^{2} 2 p^{3}{ }^{2} P_{3 / 2}$ & $1.842 \mathrm{E}-03$ & $1.872 \mathrm{E}-03$ & $3.500 \mathrm{E}-03$ & 1.6 & 90 \\
\hline 21 & $2 s 2 p^{4}{ }^{2} D_{5 / 2}-2 s^{2} 2 p^{3}{ }^{2} D_{5 / 2}$ & $2.055 \mathrm{E}-01$ & $2.072 \mathrm{E}-01$ & $2.350 \mathrm{E}-01$ & 0.9 & 14 \\
\hline 21 & $2 s 2 p^{4}{ }^{2} D_{5 / 2}-2 s^{2} 2 p^{3}{ }^{2} P_{3 / 2}$ & $6.145 \mathrm{E}-02$ & $6.195 \mathrm{E}-02$ & $7.130 \mathrm{E}-02$ & 0.8 & 16 \\
\hline 21 & $2 s 2 p^{4}{ }^{2} S_{1 / 2}-2 s^{2} 2 p^{3}{ }^{4} S_{3 / 2}$ & $3.061 \mathrm{E}-04$ & $3.076 \mathrm{E}-04$ & $4.000 \mathrm{E}-04$ & 0.5 & 31 \\
\hline 21 & $2 s 2 p^{4}{ }^{2} S_{1 / 2}-2 s^{2} 2 p^{3}{ }^{2} P_{3 / 2}$ & $2.342 \mathrm{E}-02$ & $2.364 \mathrm{E}-02$ & $3.120 \mathrm{E}-02$ & 0.9 & 33 \\
\hline 21 & $2 s 2 p^{4}{ }^{2} P_{3 / 2}-2 s^{2} 2 p^{3}{ }^{4} S_{3 / 2}$ & $1.752 \mathrm{E}-03$ & $1.753 \mathrm{E}-03$ & $2.000 \mathrm{E}-03$ & 0.1 & 14 \\
\hline 21 & $2 s 2 p^{4}{ }^{2} P_{3 / 2}-2 s^{2} 2 p^{3}{ }^{2} D_{3 / 2}$ & $4.465 \mathrm{E}-02$ & $4.502 \mathrm{E}-02$ & $5.170 \mathrm{E}-02$ & 0.8 & 16 \\
\hline 21 & $2 s 2 p^{4}{ }^{2} P_{3 / 2}-2 s^{2} 2 p^{3}{ }^{2} D_{5 / 2}$ & $2.395 \mathrm{E}-01$ & $2.416 \mathrm{E}-01$ & $2.710 \mathrm{E}-01$ & 0.9 & 13 \\
\hline 21 & $2 s 2 p^{4}{ }^{2} P_{3 / 2}-2 s^{2} 2 p^{3}{ }^{2} P_{1 / 2}$ & $2.169 \mathrm{E}-02$ & $2.182 \mathrm{E}-02$ & $2.420 \mathrm{E}-02$ & 0.6 & 12 \\
\hline 21 & $2 s 2 p^{4}{ }^{2} P_{1 / 2}-2 s^{2} 2 p^{3}{ }^{4} S_{3 / 2}$ & $1.139 \mathrm{E}-04$ & $1.147 \mathrm{E}-04$ & $1.400 \mathrm{E}-04$ & 0.7 & 23 \\
\hline 21 & $2 s 2 p^{4}{ }^{2} P_{1 / 2}-2 s^{2} 2 p^{3}{ }^{2} D_{3 / 2}$ & $5.269 \mathrm{E}-02$ & $5.320 \mathrm{E}-02$ & $5.850 \mathrm{E}-02$ & 1.0 & 11 \\
\hline 21 & $2 s 2 p^{4}{ }^{2} P_{1 / 2}-2 s^{2} 2 p^{3}{ }^{2} P_{1 / 2}$ & $1.040 \mathrm{E}-02$ & $1.046 \mathrm{E}-02$ & $1.300 \mathrm{E}-02$ & 0.6 & 25 \\
\hline 21 & $2 s 2 p^{4}{ }^{2} P_{1 / 2}-2 s^{2} 2 p^{3}{ }^{2} P_{3 / 2}$ & $1.059 \mathrm{E}-01$ & $1.068 \mathrm{E}-01$ & $1.210 \mathrm{E}-01$ & 0.8 & 14 \\
\hline 21 & $2 p^{5}{ }^{2} P_{3 / 2}-2 s 2 p^{4}{ }^{4} P_{5 / 2}$ & $1.485 \mathrm{E}-03$ & $1.484 \mathrm{E}-03$ & $1.700 \mathrm{E}-03$ & 0.1 & 15 \\
\hline 21 & $2 p^{5}{ }^{2} P_{3 / 2}-2 s 2 p^{4}{ }^{4} P_{1 / 2}$ & $1.904 \mathrm{E}-04$ & $1.903 \mathrm{E}-04$ & $2.200 \mathrm{E}-04$ & -0.1 & 16 \\
\hline 21 & $2 p^{5}{ }^{2} P_{3 / 2}-2 s 2 p^{4}{ }^{2} D_{3 / 2}$ & $3.907 \mathrm{E}-02$ & $3.936 \mathrm{E}-02$ & $4.600 \mathrm{E}-02$ & 0.7 & 18 \\
\hline 21 & $2 p^{5}{ }^{2} P_{3 / 2}-2 s 2 p^{4}{ }^{2} D_{5 / 2}$ & $1.735 \mathrm{E}-01$ & $1.748 \mathrm{E}-01$ & $2.030 \mathrm{E}-01$ & 0.8 & 17 \\
\hline 21 & $2 p^{5}{ }^{2} P_{3 / 2}-2 s 2 p^{4}{ }^{2} P_{3 / 2}$ & $2.631 \mathrm{E}-01$ & $2.657 \mathrm{E}-01$ & $3.210 \mathrm{E}-01$ & 1.0 & 22 \\
\hline 21 & $2 p^{5}{ }^{2} P_{3 / 2}-2 s 2 p^{4}{ }^{2} P_{1 / 2}$ & $2.962 \mathrm{E}-02$ & $2.993 \mathrm{E}-02$ & $3.960 \mathrm{E}-02$ & 1.0 & 34 \\
\hline 21 & $2 p^{5}{ }^{2} P_{1 / 2}-2 s 2 p^{4}{ }^{4} P_{1 / 2}$ & $2.428 \mathrm{E}-04$ & $2.428 \mathrm{E}-04$ & $2.900 \mathrm{E}-04$ & 0.1 & 19 \\
\hline 21 & $2 p^{5}{ }^{2} P_{1 / 2}-2 s 2 p^{4}{ }^{2} D_{3 / 2}$ & $8.001 \mathrm{E}-02$ & $8.068 \mathrm{E}-02$ & $9.480 \mathrm{E}-02$ & 0.8 & 19 \\
\hline 21 & $2 p^{5}{ }^{2} P_{1 / 2}-2 s 2 p^{4}{ }^{2} P_{3 / 2}$ & $7.380 \mathrm{E}-02$ & 7.447E-02 & $8.950 \mathrm{E}-02$ & 0.9 & 21 \\
\hline 21 & $2 p^{5}{ }^{2} P_{1 / 2}-2 s 2 p^{4}{ }^{2} P_{1 / 2}$ & $1.228 \mathrm{E}-01$ & $1.239 \mathrm{E}-01$ & $1.490 \mathrm{E}-01$ & 0.9 & 21 \\
\hline 22 & $2 s 2 p^{4}{ }^{4} P_{5 / 2}-2 s^{2} 2 p^{3}{ }^{2} D_{3 / 2}$ & $2.172 \mathrm{E}-03$ & $2.173 \mathrm{E}-03$ & $2.700 \mathrm{E}-03$ & 0.1 & 24 \\
\hline 22 & $2 s 2 p^{4}{ }^{4} P_{5 / 2}-2 s^{2} 2 p^{3}{ }^{2} P_{3 / 2}$ & $7.666 \mathrm{E}-04$ & $7.724 \mathrm{E}-04$ & $9.900 \mathrm{E}-04$ & 0.8 & 29 \\
\hline 22 & $2 s 2 p^{4}{ }^{4} P_{3 / 2}-2 s^{2} 2 p^{3}{ }^{4} S_{3 / 2}$ & $8.708 \mathrm{E}-02$ & $8.776 \mathrm{E}-02$ & $9.920 \mathrm{E}-02$ & 0.8 & 14 \\
\hline 22 & $2 s 2 p^{4}{ }^{4} P_{3 / 2}-2 s^{2} 2 p^{3}{ }^{2} P_{3 / 2}$ & $1.558 \mathrm{E}-03$ & $1.565 \mathrm{E}-03$ & $1.900 \mathrm{E}-03$ & 0.4 & 22 \\
\hline 22 & $2 s 2 p^{4}{ }^{4} P_{1 / 2}-2 s^{2} 2 p^{3}{ }^{4} S_{3 / 2}$ & $4.447 \mathrm{E}-02$ & $4.480 \mathrm{E}-02$ & $5.120 \mathrm{E}-02$ & 0.7 & 15 \\
\hline 22 & $2 s 2 p^{4}{ }^{4} P_{1 / 2}-2 s^{2} 2 p^{3}{ }^{2} D_{3 / 2}$ & $2.585 \mathrm{E}-04$ & $2.590 \mathrm{E}-04$ & $3.100 \mathrm{E}-04$ & 0.2 & 20 \\
\hline 22 & $2 s 2 p^{4}{ }^{4} P_{1 / 2}-2 s^{2} 2 p^{3}{ }^{2} P_{1 / 2}$ & $4.272 \mathrm{E}-04$ & $4.271 \mathrm{E}-04$ & $4.900 \mathrm{E}-04$ & 0.1 & 15 \\
\hline 22 & $2 s 2 p^{4}{ }^{2} D_{3 / 2}-2 s^{2} 2 p^{3}{ }^{4} S_{3 / 2}$ & $4.996 \mathrm{E}-04$ & $5.002 \mathrm{E}-04$ & $6.200 \mathrm{E}-04$ & 0.1 & 24 \\
\hline 22 & $2 s 2 p^{4}{ }^{2} D_{3 / 2}-2 s^{2} 2 p^{3}{ }^{2} D_{3 / 2}$ & $1.407 \mathrm{E}-01$ & $1.418 \mathrm{E}-01$ & $1.600 \mathrm{E}-01$ & 0.8 & 14 \\
\hline 22 & $2 s 2 p^{4}{ }^{2} D_{3 / 2}-2 s^{2} 2 p^{3}{ }^{2} D_{5 / 2}$ & $3.131 \mathrm{E}-03$ & $3.166 \mathrm{E}-03$ & $3.800 \mathrm{E}-03$ & 1.1 & 21 \\
\hline 22 & $2 s 2 p^{4}{ }^{2} D_{3 / 2}-2 s^{2} 2 p^{3}{ }^{2} P_{1 / 2}$ & $1.926 \mathrm{E}-02$ & $1.940 \mathrm{E}-02$ & $2.210 \mathrm{E}-02$ & 0.7 & 15 \\
\hline 22 & $2 s 2 p^{4}{ }^{2} D_{3 / 2}-2 s^{2} 2 p^{3}{ }^{2} P_{3 / 2}$ & $2.343 \mathrm{E}-03$ & $2.375 \mathrm{E}-03$ & $4.000 \mathrm{E}-03$ & 1.4 & 71 \\
\hline 22 & $2 s 2 p^{4}{ }^{2} D_{5 / 2}-2 s^{2} 2 p^{3}{ }^{2} D_{5 / 2}$ & $1.849 \mathrm{E}-01$ & $1.863 \mathrm{E}-01$ & $2.100 \mathrm{E}-01$ & 0.8 & 14 \\
\hline 22 & $2 s 2 p^{4}{ }^{2} D_{5 / 2}-2 s^{2} 2 p^{3}{ }^{2} P_{3 / 2}$ & $5.615 \mathrm{E}-02$ & $5.655 \mathrm{E}-02$ & $6.430 \mathrm{E}-02$ & 0.7 & 15 \\
\hline 22 & $2 s 2 p^{4}{ }^{2} S_{1 / 2}-2 s^{2} 2 p^{3}{ }^{4} S_{3 / 2}$ & $3.846 \mathrm{E}-04$ & $3.863 \mathrm{E}-04$ & $4.900 \mathrm{E}-04$ & 0.4 & 27 \\
\hline 22 & $2 s 2 p^{4}{ }^{2} S_{1 / 2}-2 s^{2} 2 p^{3}{ }^{2} P_{1 / 2}$ & $5.655 \mathrm{E}-02$ & $5.696 \mathrm{E}-02$ & $6.300 \mathrm{E}-02$ & 0.7 & 11 \\
\hline 22 & $2 s 2 p^{4}{ }^{2} S_{1 / 2}-2 s^{2} 2 p^{3}{ }^{2} P_{3 / 2}$ & $1.637 \mathrm{E}-02$ & $1.652 \mathrm{E}-02$ & $2.200 \mathrm{E}-02$ & 0.9 & 34 \\
\hline 22 & $2 s 2 p^{4}{ }^{2} P_{3 / 2}-2 s^{2} 2 p^{3}{ }^{4} S_{3 / 2}$ & $2.175 \mathrm{E}-03$ & $2.175 \mathrm{E}-03$ & $2.500 \mathrm{E}-03$ & 0.1 & 15 \\
\hline 22 & $2 s 2 p^{4}{ }^{2} P_{3 / 2}-2 s^{2} 2 p^{3}{ }^{2} D_{3 / 2}$ & $3.948 \mathrm{E}-02$ & $3.980 \mathrm{E}-02$ & $4.490 \mathrm{E}-02$ & 0.8 & 14 \\
\hline 22 & $2 s 2 p^{4}{ }^{2} P_{3 / 2}-2 s^{2} 2 p^{3}{ }^{2} D_{5 / 2}$ & $2.166 \mathrm{E}-01$ & $2.183 \mathrm{E}-01$ & $2.410 \mathrm{E}-01$ & 0.8 & 11 \\
\hline 22 & $2 s 2 p^{4}{ }^{2} P_{3 / 2}-2 s^{2} 2 p^{3}{ }^{2} P_{1 / 2}$ & $2.048 \mathrm{E}-02$ & $2.060 \mathrm{E}-02$ & $2.300 \mathrm{E}-02$ & 0.6 & 12 \\
\hline
\end{tabular}


Table 5

(Continued)

\begin{tabular}{|c|c|c|c|c|c|c|}
\hline \multirow[t]{2}{*}{$Z$} & \multirow[t]{2}{*}{ Transition } & \multicolumn{3}{|c|}{ Line Strengths } & \multicolumn{2}{|c|}{ Difference $(\%)$} \\
\hline & & MBPT & MCDHF/RCI2 & NIST & MBPT and MCDHF/RCI2 & MBPT and NIST \\
\hline 22 & $2 s 2 p^{4}{ }^{2} P_{1 / 2}-2 s^{2} 2 p^{3}{ }^{4} S_{3 / 2}$ & $1.113 \mathrm{E}-04$ & $1.121 \mathrm{E}-04$ & $1.400 \mathrm{E}-04$ & 0.7 & 26 \\
\hline 22 & $2 s 2 p^{4}{ }^{2} P_{1 / 2}-2 s^{2} 2 p^{3}{ }^{2} D_{3 / 2}$ & $4.050 \mathrm{E}-02$ & $4.085 \mathrm{E}-02$ & $4.480 \mathrm{E}-02$ & 0.9 & 11 \\
\hline 22 & $2 s 2 p^{4}{ }^{2} P_{1 / 2}-2 s^{2} 2 p^{3}{ }^{2} P_{1 / 2}$ & $7.992 \mathrm{E}-03$ & $8.034 \mathrm{E}-03$ & $9.900 \mathrm{E}-03$ & 0.5 & 24 \\
\hline 22 & $2 s 2 p^{4}{ }^{2} P_{1 / 2}-2 s^{2} 2 p^{3}{ }^{2} P_{3 / 2}$ & $1.025 \mathrm{E}-01$ & $1.032 \mathrm{E}-01$ & $1.200 \mathrm{E}-01$ & 0.7 & 17 \\
\hline 22 & $2 p^{5}{ }^{2} P_{3 / 2}-2 s 2 p^{4}{ }^{4} P_{5 / 2}$ & $1.776 \mathrm{E}-03$ & $1.775 \mathrm{E}-03$ & $2.000 \mathrm{E}-03$ & -0.1 & 13 \\
\hline 22 & $2 p^{5}{ }^{2} P_{3 / 2}-2 s 2 p^{4}{ }^{4} P_{1 / 2}$ & $2.499 \mathrm{E}-04$ & $2.494 \mathrm{E}-04$ & $2.900 \mathrm{E}-04$ & -0.2 & 16 \\
\hline 22 & $2 p^{5}{ }^{2} P_{3 / 2}-2 s 2 p^{4}{ }^{2} D_{3 / 2}$ & $3.882 \mathrm{E}-02$ & $3.907 \mathrm{E}-02$ & $4.600 \mathrm{E}-02$ & 0.6 & 19 \\
\hline 22 & $2 p^{5}{ }^{2} P_{3 / 2}-2 s 2 p^{4}{ }^{2} D_{5 / 2}$ & $1.558 \mathrm{E}-01$ & $1.569 \mathrm{E}-01$ & $1.800 \mathrm{E}-01$ & 0.7 & 16 \\
\hline 22 & $2 p^{5}{ }^{2} P_{3 / 2}-2 s 2 p^{4}{ }^{2} S_{1 / 2}$ & $4.620 \mathrm{E}-02$ & $4.654 \mathrm{E}-02$ & $5.100 \mathrm{E}-02$ & 0.7 & 10 \\
\hline 22 & $2 p^{5}{ }^{2} P_{3 / 2}-2 s 2 p^{4}{ }^{2} P_{3 / 2}$ & $2.336 \mathrm{E}-01$ & $2.356 \mathrm{E}-01$ & $2.820 \mathrm{E}-01$ & 0.9 & 21 \\
\hline 22 & $2 p^{5}{ }^{2} P_{3 / 2}-2 s 2 p^{4}{ }^{2} P_{1 / 2}$ & $2.442 \mathrm{E}-02$ & $2.466 \mathrm{E}-02$ & $3.240 \mathrm{E}-02$ & 1.0 & 33 \\
\hline 22 & $2 p^{5}{ }^{2} P_{1 / 2}-2 s 2 p^{4}{ }^{4} P_{1 / 2}$ & $2.870 \mathrm{E}-04$ & $2.874 \mathrm{E}-04$ & $3.300 \mathrm{E}-04$ & 0.1 & 15 \\
\hline 22 & $2 p^{5}{ }^{2} P_{1 / 2}-2 s 2 p^{4}{ }^{2} D_{3 / 2}$ & $6.925 \mathrm{E}-02$ & $6.978 \mathrm{E}-02$ & $8.090 \mathrm{E}-02$ & 0.8 & 17 \\
\hline 22 & $2 p^{5}{ }^{2} P_{1 / 2}-2 s 2 p^{4}{ }^{2} P_{3 / 2}$ & $6.936 \mathrm{E}-02$ & $6.990 \mathrm{E}-02$ & $8.300 \mathrm{E}-02$ & 0.8 & 20 \\
\hline 22 & $2 p^{5}{ }^{2} P_{1 / 2}-2 s 2 p^{4}{ }^{2} P_{1 / 2}$ & $1.101 \mathrm{E}-01$ & $1.110 \mathrm{E}-01$ & $1.320 \mathrm{E}-01$ & 0.9 & 20 \\
\hline 23 & $2 s 2 p^{4}{ }^{4} P_{5 / 2}-2 s^{2} 2 p^{3}{ }^{4} S_{3 / 2}$ & $1.145 \mathrm{E}-01$ & $1.153 \mathrm{E}-01$ & $1.300 \mathrm{E}-01$ & 0.7 & 14 \\
\hline 23 & $2 s 2 p^{4}{ }^{4} P_{5 / 2}-2 s^{2} 2 p^{3}{ }^{2} D_{3 / 2}$ & $3.015 \mathrm{E}-03$ & $3.016 \mathrm{E}-03$ & $3.600 \mathrm{E}-03$ & 0.1 & 19 \\
\hline 23 & $2 s 2 p^{4}{ }^{4} P_{5 / 2}-2 s^{2} 2 p^{3}{ }^{2} P_{3 / 2}$ & $8.041 \mathrm{E}-04$ & $8.101 \mathrm{E}-04$ & $1.000 \mathrm{E}-03$ & 0.7 & 24 \\
\hline 23 & $2 s 2 p^{4}{ }^{4} P_{3 / 2}-2 s^{2} 2 p^{3}{ }^{4} S_{3 / 2}$ & $7.874 \mathrm{E}-02$ & $7.928 \mathrm{E}-02$ & $8.950 \mathrm{E}-02$ & 0.7 & 14 \\
\hline 23 & $2 s 2 p^{4}{ }^{4} P_{3 / 2}-2 s^{2} 2 p^{3}{ }^{2} D_{3 / 2}$ & $1.249 \mathrm{E}-04$ & $1.263 \mathrm{E}-04$ & $2.700 \mathrm{E}-04$ & 1.1 & 116 \\
\hline 23 & $2 s 2 p^{4}{ }^{4} P_{3 / 2}-2 s^{2} 2 p^{3}{ }^{2} P_{3 / 2}$ & $1.794 \mathrm{E}-03$ & $1.801 \mathrm{E}-03$ & $2.200 \mathrm{E}-03$ & 0.4 & 23 \\
\hline 23 & $2 s 2 p^{4}{ }^{4} P_{1 / 2}-2 s^{2} 2 p^{3}{ }^{4} S_{3 / 2}$ & $4.036 \mathrm{E}-02$ & $4.063 \mathrm{E}-02$ & $4.580 \mathrm{E}-02$ & 0.7 & 14 \\
\hline 23 & $2 s 2 p^{4}{ }^{4} P_{1 / 2}-2 s^{2} 2 p^{3}{ }^{2} D_{3 / 2}$ & $3.535 \mathrm{E}-04$ & $3.538 \mathrm{E}-04$ & $4.200 \mathrm{E}-04$ & 0.1 & 19 \\
\hline 23 & $2 s 2 p^{4}{ }^{4} P_{1 / 2}-2 s^{2} 2 p^{3}{ }^{2} P_{1 / 2}$ & $5.441 \mathrm{E}-04$ & $5.438 \mathrm{E}-04$ & $6.200 \mathrm{E}-04$ & -0.1 & 14 \\
\hline 23 & $2 s 2 p^{4}{ }^{2} D_{3 / 2}-2 s^{2} 2 p^{3}{ }^{4} S_{3 / 2}$ & $8.098 \mathrm{E}-04$ & $8.094 \mathrm{E}-04$ & $1.000 \mathrm{E}-03$ & -0.1 & 24 \\
\hline 23 & $2 s 2 p^{4}{ }^{2} D_{3 / 2}-2 s^{2} 2 p^{3}{ }^{2} D_{3 / 2}$ & $1.292 \mathrm{E}-01$ & $1.301 \mathrm{E}-01$ & $1.500 \mathrm{E}-01$ & 0.7 & 16 \\
\hline 23 & $2 s 2 p^{4}{ }^{2} D_{3 / 2}-2 s^{2} 2 p^{3}{ }^{2} D_{5 / 2}$ & $1.921 \mathrm{E}-03$ & $1.942 \mathrm{E}-03$ & $2.300 \mathrm{E}-03$ & 1.1 & 20 \\
\hline 23 & $2 s 2 p^{4}{ }^{2} D_{3 / 2}-2 s^{2} 2 p^{3}{ }^{2} P_{1 / 2}$ & $1.679 \mathrm{E}-02$ & $1.691 \mathrm{E}-02$ & $1.920 \mathrm{E}-02$ & 0.7 & 14 \\
\hline 23 & $2 s 2 p^{4}{ }^{2} D_{3 / 2}-2 s^{2} 2 p^{3}{ }^{2} P_{3 / 2}$ & $2.676 \mathrm{E}-03$ & $2.709 \mathrm{E}-03$ & $4.200 \mathrm{E}-03$ & 1.2 & 57 \\
\hline 23 & $2 s 2 p^{4}{ }^{2} D_{5 / 2}-2 s^{2} 2 p^{3}{ }^{2} D_{5 / 2}$ & $1.670 \mathrm{E}-01$ & $1.681 \mathrm{E}-01$ & $1.900 \mathrm{E}-01$ & 0.7 & 14 \\
\hline 23 & $2 s 2 p^{4}{ }^{2} D_{5 / 2}-2 s^{2} 2 p^{3}{ }^{2} P_{3 / 2}$ & $5.142 \mathrm{E}-02$ & $5.175 \mathrm{E}-02$ & $5.900 \mathrm{E}-02$ & 0.7 & 15 \\
\hline 23 & $2 s 2 p^{4}{ }^{2} S_{1 / 2}-2 s^{2} 2 p^{3}{ }^{4} S_{3 / 2}$ & $4.861 \mathrm{E}-04$ & $4.875 \mathrm{E}-04$ & $6.200 \mathrm{E}-04$ & 0.3 & 28 \\
\hline 23 & $2 s 2 p^{4}{ }^{2} S_{1 / 2}-2 s^{2} 2 p^{3}{ }^{2} P_{1 / 2}$ & $5.225 \mathrm{E}-02$ & $5.258 \mathrm{E}-02$ & $5.800 \mathrm{E}-02$ & 0.6 & 11 \\
\hline 23 & $2 s 2 p^{4}{ }^{2} S_{1 / 2}-2 s^{2} 2 p^{3}{ }^{2} P_{3 / 2}$ & $1.123 \mathrm{E}-02$ & $1.133 \mathrm{E}-02$ & $1.500 \mathrm{E}-02$ & 0.9 & 34 \\
\hline 23 & $2 s 2 p^{4}{ }^{2} P_{3 / 2}-2 s^{2} 2 p^{3}{ }^{4} S_{3 / 2}$ & $2.652 \mathrm{E}-03$ & $2.653 \mathrm{E}-03$ & $3.000 \mathrm{E}-03$ & 0.1 & 13 \\
\hline 23 & $2 s 2 p^{4}{ }^{2} P_{3 / 2}-2 s^{2} 2 p^{3}{ }^{2} D_{3 / 2}$ & $3.432 \mathrm{E}-02$ & $3.458 \mathrm{E}-02$ & $3.860 \mathrm{E}-02$ & 0.8 & 13 \\
\hline 23 & $2 s 2 p^{4}{ }^{2} P_{3 / 2}-2 s^{2} 2 p^{3}{ }^{2} D_{5 / 2}$ & $1.969 \mathrm{E}-01$ & $1.982 \mathrm{E}-01$ & $2.200 \mathrm{E}-01$ & 0.7 & 12 \\
\hline 23 & $2 s 2 p^{4}{ }^{2} P_{3 / 2}-2 s^{2} 2 p^{3}{ }^{2} P_{1 / 2}$ & $1.949 \mathrm{E}-02$ & $1.958 \mathrm{E}-02$ & $2.200 \mathrm{E}-02$ & 0.5 & 13 \\
\hline 23 & $2 s 2 p^{4}{ }^{2} P_{1 / 2}-2 s^{2} 2 p^{3}{ }^{4} S_{3 / 2}$ & $1.018 \mathrm{E}-04$ & $1.028 \mathrm{E}-04$ & $1.200 \mathrm{E}-04$ & 1.0 & 18 \\
\hline 23 & $2 s 2 p^{4}{ }^{2} P_{1 / 2}-2 s^{2} 2 p^{3}{ }^{2} D_{3 / 2}$ & $3.122 \mathrm{E}-02$ & $3.146 \mathrm{E}-02$ & $3.460 \mathrm{E}-02$ & 0.8 & 11 \\
\hline 23 & $2 s 2 p^{4}{ }^{2} P_{1 / 2}-2 s^{2} 2 p^{3}{ }^{2} P_{1 / 2}$ & $6.159 \mathrm{E}-03$ & $6.188 \mathrm{E}-03$ & $7.500 \mathrm{E}-03$ & 0.5 & 22 \\
\hline 23 & $2 s 2 p^{4}{ }^{2} P_{1 / 2}-2 s^{2} 2 p^{3}{ }^{2} P_{3 / 2}$ & $9.809 \mathrm{E}-02$ & $9.874 \mathrm{E}-02$ & $1.100 \mathrm{E}-01$ & 0.7 & 12 \\
\hline 23 & $2 p^{5}{ }^{2} P_{3 / 2}-2 s 2 p^{4}{ }^{4} P_{3 / 2}$ & $9.900 \mathrm{E}-04$ & $9.890 \mathrm{E}-04$ & $1.100 \mathrm{E}-03$ & -0.1 & 11 \\
\hline 23 & $2 p^{5}{ }^{2} P_{3 / 2}-2 s 2 p^{4}{ }^{4} P_{1 / 2}$ & $3.253 \mathrm{E}-04$ & $3.246 \mathrm{E}-04$ & $3.600 \mathrm{E}-04$ & -0.2 & 11 \\
\hline 23 & $2 p^{5}{ }^{2} P_{3 / 2}-2 s 2 p^{4}{ }^{2} D_{3 / 2}$ & $3.887 \mathrm{E}-02$ & $3.909 \mathrm{E}-02$ & $4.550 \mathrm{E}-02$ & 0.6 & 17 \\
\hline 23 & $2 p^{5}{ }^{2} P_{3 / 2}-2 s 2 p^{4}{ }^{2} D_{5 / 2}$ & $1.406 \mathrm{E}-01$ & $1.415 \mathrm{E}-01$ & $1.600 \mathrm{E}-01$ & 0.6 & 14 \\
\hline 23 & $2 p^{5}{ }^{2} P_{3 / 2}-2 s 2 p^{4}{ }^{2} P_{3 / 2}$ & $2.077 \mathrm{E}-01$ & $2.093 \mathrm{E}-01$ & $2.470 \mathrm{E}-01$ & 0.8 & 19 \\
\hline 23 & $2 p^{5}{ }^{2} P_{3 / 2}-2 s 2 p^{4}{ }^{2} P_{1 / 2}$ & $2.022 \mathrm{E}-02$ & $2.040 \mathrm{E}-02$ & $2.670 \mathrm{E}-02$ & 0.9 & 32 \\
\hline 23 & $2 p^{5}{ }^{2} P_{1 / 2}-2 s 2 p^{4}{ }^{4} P_{1 / 2}$ & $3.332 \mathrm{E}-04$ & $3.335 \mathrm{E}-04$ & $3.900 \mathrm{E}-04$ & 0.1 & 17 \\
\hline 23 & $2 p^{5}{ }^{2} P_{1 / 2}-2 s 2 p^{4}{ }^{2} D_{3 / 2}$ & $5.986 \mathrm{E}-02$ & $6.025 \mathrm{E}-02$ & $6.940 \mathrm{E}-02$ & 0.7 & 16 \\
\hline 23 & $2 p^{5}{ }^{2} P_{1 / 2}-2 s 2 p^{4}{ }^{2} P_{3 / 2}$ & $6.563 \mathrm{E}-02$ & $6.609 \mathrm{E}-02$ & $7.780 \mathrm{E}-02$ & 0.7 & 19 \\
\hline 23 & $2 p^{5}{ }^{2} P_{1 / 2}-2 s 2 p^{4}{ }^{2} P_{1 / 2}$ & $9.902 \mathrm{E}-02$ & $9.976 \mathrm{E}-02$ & $1.180 \mathrm{E}-01$ & 0.8 & 19 \\
\hline 24 & $2 s 2 p^{4}{ }^{4} P_{5 / 2}-2 s^{2} 2 p^{3}{ }^{4} S_{3 / 2}$ & $1.026 \mathrm{E}-01$ & $1.033 \mathrm{E}-01$ & $1.200 \mathrm{E}-01$ & 0.7 & 17 \\
\hline 24 & $2 s 2 p^{4}{ }^{4} P_{5 / 2}-2 s^{2} 2 p^{3}{ }^{2} D_{3 / 2}$ & $4.083 \mathrm{E}-03$ & $4.086 \mathrm{E}-03$ & $4.900 \mathrm{E}-03$ & 0.1 & 20 \\
\hline 24 & $2 s 2 p^{4}{ }^{4} P_{5} / 2-2 s^{2} 2 p^{3}{ }^{2} P_{3 / 2}$ & $8.274 \mathrm{E}-04$ & $8.334 \mathrm{E}-04$ & $1.000 \mathrm{E}-03$ & 0.7 & 21 \\
\hline
\end{tabular}


Table 5

(Continued)

\begin{tabular}{|c|c|c|c|c|c|c|}
\hline \multirow[t]{2}{*}{$Z$} & \multirow[t]{2}{*}{ Transition } & \multicolumn{3}{|c|}{ Line Strengths } & \multicolumn{2}{|c|}{ Difference $(\%)$} \\
\hline & & MBPT & MCDHF/RCI2 & NIST & MBPT and MCDHF/RCI2 & MBPT and NIST \\
\hline 24 & $2 s 2 p^{4}{ }^{4} P_{3 / 2}-2 s^{2} 2 p^{3}{ }^{4} S_{3 / 2}$ & $7.146 \mathrm{E}-02$ & $7.191 \mathrm{E}-02$ & $8.070 \mathrm{E}-02$ & 0.6 & 13 \\
\hline 24 & $2 s 2 p^{4}{ }^{4} P_{3 / 2}-2 s^{2} 2 p^{3}{ }^{2} D_{3 / 2}$ & $2.206 \mathrm{E}-04$ & $2.223 \mathrm{E}-04$ & $4.100 \mathrm{E}-04$ & 0.8 & 86 \\
\hline 24 & $2 s 2 p^{4}{ }^{4} P_{3 / 2}-2 s^{2} 2 p^{3}{ }^{2} P_{3 / 2}$ & $2.030 \mathrm{E}-03$ & $2.037 \mathrm{E}-03$ & $2.400 \mathrm{E}-03$ & 0.4 & 18 \\
\hline 24 & $2 s 2 p^{4}{ }^{4} P_{1 / 2}-2 s^{2} 2 p^{3}{ }^{4} S_{3 / 2}$ & $3.677 \mathrm{E}-02$ & $3.699 \mathrm{E}-02$ & $4.180 \mathrm{E}-02$ & 0.6 & 14 \\
\hline 24 & $2 s 2 p^{4}{ }^{4} P_{1 / 2}-2 s^{2} 2 p^{3}{ }^{2} D_{3 / 2}$ & $4.739 \mathrm{E}-04$ & $4.740 \mathrm{E}-04$ & $5.800 \mathrm{E}-04$ & 0.1 & 22 \\
\hline 24 & $2 s 2 p^{4}{ }^{4} P_{1 / 2}-2 s^{2} 2 p^{3}{ }^{2} P_{1 / 2}$ & $6.869 \mathrm{E}-04$ & $6.873 \mathrm{E}-04$ & $7.600 \mathrm{E}-04$ & 0.1 & 11 \\
\hline 24 & $2 s 2 p^{4}{ }^{2} D_{3 / 2}-2 s^{2} 2 p^{3}{ }^{4} S_{3 / 2}$ & $1.262 \mathrm{E}-03$ & $1.262 \mathrm{E}-03$ & $1.600 \mathrm{E}-03$ & 0.1 & 27 \\
\hline 24 & $2 s 2 p^{4}{ }^{2} D_{3 / 2}-2 s^{2} 2 p^{3}{ }^{2} D_{5 / 2}$ & $1.025 \mathrm{E}-03$ & $1.037 \mathrm{E}-03$ & $1.200 \mathrm{E}-03$ & 1.1 & 17 \\
\hline 24 & $2 s 2 p^{4}{ }^{2} D_{3 / 2}-2 s^{2} 2 p^{3}{ }^{2} P_{1 / 2}$ & $1.461 \mathrm{E}-02$ & $1.470 \mathrm{E}-02$ & $1.660 \mathrm{E}-02$ & 0.6 & 14 \\
\hline 24 & $2 s 2 p^{4}{ }^{2} D_{3 / 2}-2 s^{2} 2 p^{3}{ }^{2} P_{3 / 2}$ & $2.827 \mathrm{E}-03$ & $2.859 \mathrm{E}-03$ & $4.200 \mathrm{E}-03$ & 1.1 & 49 \\
\hline 24 & $2 s 2 p^{4}{ }^{2} D_{5 / 2}-2 s^{2} 2 p^{3}{ }^{2} D_{5 / 2}$ & $1.514 \mathrm{E}-01$ & $1.524 \mathrm{E}-01$ & $1.700 \mathrm{E}-01$ & 0.7 & 12 \\
\hline 24 & $2 s 2 p^{4}{ }^{2} D_{5 / 2}-2 s^{2} 2 p^{3}{ }^{2} P_{3 / 2}$ & $4.722 \mathrm{E}-02$ & $4.750 \mathrm{E}-02$ & $5.300 \mathrm{E}-02$ & 0.6 & 12 \\
\hline 24 & $2 s 2 p^{4}{ }^{2} S_{1 / 2}-2 s^{2} 2 p^{3}{ }^{4} S_{3 / 2}$ & $6.147 \mathrm{E}-04$ & $6.161 \mathrm{E}-04$ & $7.600 \mathrm{E}-04$ & 0.2 & 24 \\
\hline 24 & $2 s 2 p^{4}{ }^{2} S_{1 / 2}-2 s^{2} 2 p^{3}{ }^{2} P_{1 / 2}$ & $4.827 \mathrm{E}-02$ & $4.857 \mathrm{E}-02$ & $5.400 \mathrm{E}-02$ & 0.6 & 12 \\
\hline 24 & $2 s 2 p^{4}{ }^{2} S_{1 / 2}-2 s^{2} 2 p^{3}{ }^{2} P_{3 / 2}$ & $7.549 \mathrm{E}-03$ & $7.609 \mathrm{E}-03$ & $1.000 \mathrm{E}-02$ & 0.8 & 33 \\
\hline 24 & $2 s 2 p^{4}{ }^{2} P_{3 / 2}-2 s^{2} 2 p^{3}{ }^{4} S_{3 / 2}$ & $3.168 \mathrm{E}-03$ & $3.169 \mathrm{E}-03$ & $3.500 \mathrm{E}-03$ & 0.1 & 11 \\
\hline 24 & $2 s 2 p^{4}{ }^{2} P_{3 / 2}-2 s^{2} 2 p^{3}{ }^{2} D_{3 / 2}$ & $2.926 \mathrm{E}-02$ & $2.948 \mathrm{E}-02$ & $3.260 \mathrm{E}-02$ & 0.8 & 11 \\
\hline 24 & $2 s 2 p^{4}{ }^{2} P_{3 / 2}-2 s^{2} 2 p^{3}{ }^{2} D_{5 / 2}$ & $1.796 \mathrm{E}-01$ & $1.808 \mathrm{E}-01$ & $2.000 \mathrm{E}-01$ & 0.7 & 11 \\
\hline 24 & $2 s 2 p^{4}{ }^{2} P_{1 / 2}-2 s^{2} 2 p^{3}{ }^{2} D_{3 / 2}$ & $2.421 \mathrm{E}-02$ & $2.439 \mathrm{E}-02$ & $2.670 \mathrm{E}-02$ & 0.7 & 10 \\
\hline 24 & $2 s 2 p^{4}{ }^{2} P_{1 / 2}-2 s^{2} 2 p^{3}{ }^{2} P_{1 / 2}$ & $4.765 \mathrm{E}-03$ & $4.780 \mathrm{E}-03$ & $5.700 \mathrm{E}-03$ & 0.3 & 20 \\
\hline 24 & $2 p^{5}{ }^{2} P_{3 / 2}-2 s 2 p^{4}{ }^{4} P_{5 / 2}$ & $2.433 \mathrm{E}-03$ & $2.432 \mathrm{E}-03$ & $2.700 \mathrm{E}-03$ & -0.1 & 11 \\
\hline 24 & $2 p^{5}{ }^{2} P_{3 / 2}-2 s 2 p^{4}{ }^{4} P_{1 / 2}$ & $4.204 \mathrm{E}-04$ & 4.198E-04 & $4.800 \mathrm{E}-04$ & -0.2 & 14 \\
\hline 24 & $2 p^{5}{ }^{2} P_{3 / 2}-2 s 2 p^{4}{ }^{2} D_{3 / 2}$ & $3.915 \mathrm{E}-02$ & $3.936 \mathrm{E}-02$ & $4.510 \mathrm{E}-02$ & 0.5 & 15 \\
\hline 24 & $2 p^{5}{ }^{2} P_{3 / 2}-2 s 2 p^{4}{ }^{2} D_{5 / 2}$ & $1.273 \mathrm{E}-01$ & $1.280 \mathrm{E}-01$ & $1.500 \mathrm{E}-01$ & 0.6 & 18 \\
\hline 24 & $2 p^{5}{ }^{2} P_{3 / 2}-2 s 2 p^{4}{ }^{2} S_{1 / 2}$ & $4.156 \mathrm{E}-02$ & $4.182 \mathrm{E}-02$ & $4.600 \mathrm{E}-02$ & 0.6 & 11 \\
\hline 24 & $2 p^{5}{ }^{2} P_{3 / 2}-2 s 2 p^{4}{ }^{2} P_{3 / 2}$ & $1.849 \mathrm{E}-01$ & $1.862 \mathrm{E}-01$ & $2.180 \mathrm{E}-01$ & 0.7 & 18 \\
\hline 24 & $2 p^{5}{ }^{2} P_{3 / 2}-2 s 2 p^{4}{ }^{2} P_{1 / 2}$ & $1.682 \mathrm{E}-02$ & $1.695 \mathrm{E}-02$ & $2.210 \mathrm{E}-02$ & 0.8 & 31 \\
\hline 24 & $2 p^{5}{ }^{2} P_{1 / 2}-2 s 2 p^{4}{ }^{4} P_{1 / 2}$ & $3.796 \mathrm{E}-04$ & $3.796 \mathrm{E}-04$ & $4.300 \mathrm{E}-04$ & 0.1 & 13 \\
\hline 24 & $2 p^{5}{ }^{2} P_{1 / 2}-2 s 2 p^{4}{ }^{2} D_{3 / 2}$ & $5.160 \mathrm{E}-02$ & $5.194 \mathrm{E}-02$ & $5.920 \mathrm{E}-02$ & 0.7 & 15 \\
\hline 24 & $2 p^{5}{ }^{2} P_{1 / 2}-2 s 2 p^{4}{ }^{2} P_{3 / 2}$ & $6.246 \mathrm{E}-02$ & $6.286 \mathrm{E}-02$ & $7.330 \mathrm{E}-02$ & 0.6 & 17 \\
\hline 24 & $2 p^{5}{ }^{2} P_{1 / 2}-2 s 2 p^{4}{ }^{2} P_{1 / 2}$ & $8.925 \mathrm{E}-02$ & $8.986 \mathrm{E}-02$ & $1.050 \mathrm{E}-01$ & 0.7 & 18 \\
\hline 25 & $2 s 2 p^{4}{ }^{2} S_{1 / 2}-2 s^{2} 2 p^{3}{ }^{4} S_{3 / 2}$ & $7.729 \mathrm{E}-04$ & $7.741 \mathrm{E}-04$ & $9.700 \mathrm{E}-04$ & 0.2 & 26 \\
\hline 25 & $2 s 2 p^{4}{ }^{2} P_{3 / 2}-2 s^{2} 2 p^{3}{ }^{4} S_{3 / 2}$ & $3.695 \mathrm{E}-03$ & $3.698 \mathrm{E}-03$ & $4.200 \mathrm{E}-03$ & 0.1 & 14 \\
\hline 25 & $2 s 2 p^{4}{ }^{2} P_{3 / 2}-2 s^{2} 2 p^{3}{ }^{2} D_{3 / 2}$ & $2.440 \mathrm{E}-02$ & $2.457 \mathrm{E}-02$ & $2.690 \mathrm{E}-02$ & 0.7 & 10 \\
\hline 25 & $2 s 2 p^{4}{ }^{2} P_{1 / 2}-2 s^{2} 2 p^{3}{ }^{2} D_{3 / 2}$ & $1.894 \mathrm{E}-02$ & $1.907 \mathrm{E}-02$ & $2.090 \mathrm{E}-02$ & 0.7 & 10 \\
\hline 25 & $2 s 2 p^{4}{ }^{2} P_{1 / 2}-2 s^{2} 2 p^{3}{ }^{2} P_{1 / 2}$ & $3.693 \mathrm{E}-03$ & $3.705 \mathrm{E}-03$ & $4.500 \mathrm{E}-03$ & 0.3 & 22 \\
\hline 25 & $2 p^{5}{ }^{2} P_{3 / 2}-2 s 2 p^{4}{ }^{4} P_{5 / 2}$ & $2.789 \mathrm{E}-03$ & $2.787 \mathrm{E}-03$ & $3.100 \mathrm{E}-03$ & -0.1 & 11 \\
\hline 25 & $2 p^{5}{ }^{2} P_{3 / 2}-2 s 2 p^{4}{ }^{4} P_{1 / 2}$ & $5.401 \mathrm{E}-04$ & $5.391 \mathrm{E}-04$ & $6.200 \mathrm{E}-04$ & -0.2 & 15 \\
\hline 25 & $2 p^{5}{ }^{2} P_{1 / 2}-2 s 2 p^{4}{ }^{4} P_{1 / 2}$ & $4.233 \mathrm{E}-04$ & 4.237E-04 & $4.800 \mathrm{E}-04$ & 0.1 & 13 \\
\hline 26 & $2 s 2 p^{4}{ }^{4} P_{5 / 2}-2 s^{2} 2 p^{3}{ }^{2} D_{3 / 2}$ & $6.935 \mathrm{E}-03$ & $6.936 \mathrm{E}-03$ & $8.200 \mathrm{E}-03$ & 0.1 & 18 \\
\hline 26 & $2 s 2 p^{4}{ }^{4} P_{5 / 2}-2 s^{2} 2 p^{3}{ }^{2} D_{5 / 2}$ & $3.624 \mathrm{E}-03$ & $3.626 \mathrm{E}-03$ & $4.200 \mathrm{E}-03$ & 0.1 & 16 \\
\hline 26 & $2 s 2 p^{4}{ }^{4} P_{5 / 2}-2 s^{2} 2 p^{3}{ }^{2} P_{3 / 2}$ & $8.312 \mathrm{E}-04$ & $8.365 \mathrm{E}-04$ & $1.000 \mathrm{E}-03$ & 0.6 & 20 \\
\hline 26 & $2 s 2 p^{4}{ }^{4} P_{3 / 2}-2 s^{2} 2 p^{3}{ }^{4} S_{3 / 2}$ & $5.958 \mathrm{E}-02$ & $5.988 \mathrm{E}-02$ & $6.640 \mathrm{E}-02$ & 0.5 & 11 \\
\hline 26 & $2 s 2 p^{4}{ }^{4} P_{3 / 2}-2 s^{2} 2 p^{3}{ }^{2} D_{3 / 2}$ & $4.934 \mathrm{E}-04$ & 4.957E-04 & $8.100 \mathrm{E}-04$ & 0.5 & 64 \\
\hline 26 & $2 s 2 p^{4}{ }^{4} P_{3 / 2}-2 s^{2} 2 p^{3}{ }^{2} P_{3 / 2}$ & $2.477 \mathrm{E}-03$ & $2.484 \mathrm{E}-03$ & $2.900 \mathrm{E}-03$ & 0.3 & 17 \\
\hline 26 & $2 s 2 p^{4}{ }^{4} P_{1 / 2}-2 s^{2} 2 p^{3}{ }^{4} S_{3 / 2}$ & $3.080 \mathrm{E}-02$ & $3.095 \mathrm{E}-02$ & $3.450 \mathrm{E}-02$ & 0.5 & 12 \\
\hline 26 & $2 s 2 p^{4}{ }^{4} P_{1 / 2}-2 s^{2} 2 p^{3}{ }^{2} D_{3 / 2}$ & $7.929 \mathrm{E}-04$ & $7.925 \mathrm{E}-04$ & $9.600 \mathrm{E}-04$ & -0.1 & 21 \\
\hline 26 & $2 s 2 p^{4}{ }^{4} P_{1 / 2}-2 s^{2} 2 p^{3}{ }^{2} P_{1 / 2}$ & $1.070 \mathrm{E}-03$ & $1.069 \mathrm{E}-03$ & $1.300 \mathrm{E}-03$ & -0.1 & 22 \\
\hline 26 & $2 s 2 p^{4}{ }^{2} D_{3 / 2}-2 s^{2} 2 p^{3}{ }^{4} S_{3 / 2}$ & $2.710 \mathrm{E}-03$ & $2.707 \mathrm{E}-03$ & $3.300 \mathrm{E}-03$ & -0.1 & 22 \\
\hline 26 & $2 s 2 p^{4}{ }^{2} D_{3 / 2}-2 s^{2} 2 p^{3}{ }^{2} D_{5 / 2}$ & $9.015 \mathrm{E}-05$ & $9.214 \mathrm{E}-05$ & $1.300 \mathrm{E}-04$ & 2.2 & 44 \\
\hline 26 & $2 s 2 p^{4}{ }^{2} D_{3 / 2}-2 s^{2} 2 p^{3}{ }^{2} P_{1 / 2}$ & $1.094 \mathrm{E}-02$ & $1.100 \mathrm{E}-02$ & $1.230 \mathrm{E}-02$ & 0.6 & 12 \\
\hline 26 & $2 s 2 p^{4}{ }^{2} D_{3 / 2}-2 s^{2} 2 p^{3}{ }^{2} P_{3 / 2}$ & $2.620 \mathrm{E}-03$ & $2.649 \mathrm{E}-03$ & $3.700 \mathrm{E}-03$ & 1.1 & 41 \\
\hline 26 & $2 s 2 p^{4}{ }^{2} D_{5 / 2}-2 s^{2} 2 p^{3}{ }^{2} D_{3 / 2}$ & $5.550 \mathrm{E}-05$ & $5.503 \mathrm{E}-05$ & $1.000 \mathrm{E}-04$ & -0.9 & 80 \\
\hline 26 & $2 s 2 p^{4}{ }^{2} D_{5 / 2}-2 s^{2} 2 p^{3}{ }^{2} D_{5 / 2}$ & $1.257 \mathrm{E}-01$ & $1.264 \mathrm{E}-01$ & $1.400 \mathrm{E}-01$ & 0.5 & 11 \\
\hline 26 & $2 s 2 p^{4}{ }^{2} D_{5 / 2}-2 s^{2} 2 p^{3}{ }^{2} P_{3 / 2}$ & $4.019 \mathrm{E}-02$ & $4.039 \mathrm{E}-02$ & $4.500 \mathrm{E}-02$ & 0.5 & 12 \\
\hline
\end{tabular}


Table 5

(Continued)

\begin{tabular}{|c|c|c|c|c|c|c|}
\hline \multirow[t]{2}{*}{$Z$} & \multirow[t]{2}{*}{ Transition } & \multicolumn{3}{|c|}{ Line Strengths } & \multicolumn{2}{|c|}{ Difference $(\%)$} \\
\hline & & MBPT & MCDHF/RCI2 & NIST & MBPT and MCDHF/RCI2 & MBPT and NIST \\
\hline 26 & $2 s 2 p^{4}{ }^{2} S_{1 / 2}-2 s^{2} 2 p^{3}{ }^{4} S_{3 / 2}$ & $9.587 \mathrm{E}-04$ & $9.602 \mathrm{E}-04$ & $1.100 \mathrm{E}-03$ & 0.2 & 15 \\
\hline 26 & $2 s 2 p^{4}{ }^{2} S_{1 / 2}-2 s^{2} 2 p^{3}{ }^{2} P_{3 / 2}$ & $3.138 \mathrm{E}-03$ & $3.163 \mathrm{E}-03$ & $4.500 \mathrm{E}-03$ & 0.8 & 43 \\
\hline 26 & $2 s 2 p^{4}{ }^{2} P_{3 / 2}-2 s^{2} 2 p^{3}{ }^{4} S_{3 / 2}$ & $4.195 \mathrm{E}-03$ & 4.197E-03 & $4.700 \mathrm{E}-03$ & 0.1 & 12 \\
\hline 26 & $2 s 2 p^{4}{ }^{2} P_{1 / 2}-2 s^{2} 2 p^{3}{ }^{2} D_{3 / 2}$ & $1.497 \mathrm{E}-02$ & $1.506 \mathrm{E}-02$ & $1.660 \mathrm{E}-02$ & 0.6 & 11 \\
\hline 26 & $2 s 2 p^{4}{ }^{2} P_{1 / 2}-2 s^{2} 2 p^{3}{ }^{2} P_{1 / 2}$ & $2.873 \mathrm{E}-03$ & $2.882 \mathrm{E}-03$ & $3.500 \mathrm{E}-03$ & 0.3 & 22 \\
\hline 26 & $2 p^{5}{ }^{2} P_{3 / 2}-2 s 2 p^{4}{ }^{4} P_{1 / 2}$ & $6.885 \mathrm{E}-04$ & $6.870 \mathrm{E}-04$ & $7.800 \mathrm{E}-04$ & -0.2 & 13 \\
\hline 26 & $2 p^{5}{ }^{2} P_{3 / 2}-2 s 2 p^{4}{ }^{2} D_{3 / 2}$ & $4.008 \mathrm{E}-02$ & $4.025 \mathrm{E}-02$ & $4.580 \mathrm{E}-02$ & 0.4 & 14 \\
\hline 26 & $2 p^{5}{ }^{2} P_{3 / 2}-2 s 2 p^{4}{ }^{2} D_{5 / 2}$ & $1.053 \mathrm{E}-01$ & $1.058 \mathrm{E}-01$ & $1.200 \mathrm{E}-01$ & 0.5 & 14 \\
\hline 26 & $2 p^{5}{ }^{2} P_{3 / 2}-2 s 2 p^{4}{ }^{2} S_{1 / 2}$ & $3.709 \mathrm{E}-02$ & $3.728 \mathrm{E}-02$ & $4.100 \mathrm{E}-02$ & 0.5 & 11 \\
\hline 26 & $2 p^{5}{ }^{2} P_{3 / 2}-2 s 2 p^{4}{ }^{2} P_{3 / 2}$ & $1.465 \mathrm{E}-01$ & $1.474 \mathrm{E}-01$ & $1.700 \mathrm{E}-01$ & 0.6 & 16 \\
\hline 26 & $2 p^{5}{ }^{2} P_{3 / 2}-2 s 2 p^{4}{ }^{2} P_{1 / 2}$ & $1.178 \mathrm{E}-02$ & $1.186 \mathrm{E}-02$ & $1.520 \mathrm{E}-02$ & 0.7 & 29 \\
\hline 26 & $2 p^{5}{ }^{2} P_{1 / 2}-2 s 2 p^{4}{ }^{4} P_{1 / 2}$ & $4.628 \mathrm{E}-04$ & $4.631 \mathrm{E}-04$ & $5.200 \mathrm{E}-04$ & 0.1 & 12 \\
\hline 26 & $2 p^{5}{ }^{2} P_{1 / 2}-2 s 2 p^{4}{ }^{2} D_{3 / 2}$ & $3.794 \mathrm{E}-02$ & $3.813 \mathrm{E}-02$ & $4.300 \mathrm{E}-02$ & 0.5 & 13 \\
\hline 26 & $2 p^{5}{ }^{2} P_{1 / 2}-2 s 2 p^{4}{ }^{2} P_{3 / 2}$ & $5.737 \mathrm{E}-02$ & $5.766 \mathrm{E}-02$ & $6.600 \mathrm{E}-02$ & 0.5 & 15 \\
\hline 26 & $2 p^{5}{ }^{2} P_{1 / 2}-2 s 2 p^{4}{ }^{2} P_{1 / 2}$ & $7.299 \mathrm{E}-02$ & $7.341 \mathrm{E}-02$ & $8.400 \mathrm{E}-02$ & 0.6 & 15 \\
\hline 27 & $2 s 2 p^{4}{ }^{4} P_{5 / 2}-2 s^{2} 2 p^{3}{ }^{4} S_{3 / 2}$ & $7.280 \mathrm{E}-02$ & $7.325 \mathrm{E}-02$ & $8.070 \mathrm{E}-02$ & 0.6 & 11 \\
\hline 27 & $2 s 2 p^{4}{ }^{4} P_{5 / 2}-2 s^{2} 2 p^{3}{ }^{2} D_{3 / 2}$ & $8.660 \mathrm{E}-03$ & $8.661 \mathrm{E}-03$ & $1.000 \mathrm{E}-02$ & 0.1 & 16 \\
\hline 27 & $2 s 2 p^{4}{ }^{4} P_{5 / 2}-2 s^{2} 2 p^{3}{ }^{2} D_{5 / 2}$ & $4.067 \mathrm{E}-03$ & $4.068 \mathrm{E}-03$ & $4.500 \mathrm{E}-03$ & 0.1 & 11 \\
\hline 27 & $2 s 2 p^{4}{ }^{4} P_{5 / 2}-2 s^{2} 2 p^{3}{ }^{2} P_{3 / 2}$ & $8.149 \mathrm{E}-04$ & $8.198 \mathrm{E}-04$ & $9.700 \mathrm{E}-04$ & 0.6 & 19 \\
\hline 27 & $2 s 2 p^{4}{ }^{4} P_{3 / 2}-2 s^{2} 2 p^{3}{ }^{4} S_{3 / 2}$ & $5.476 \mathrm{E}-02$ & $5.503 \mathrm{E}-02$ & $6.040 \mathrm{E}-02$ & 0.5 & 10 \\
\hline 27 & $2 s 2 p^{4}{ }^{4} P_{3 / 2}-2 s^{2} 2 p^{3}{ }^{2} D_{3 / 2}$ & $6.422 \mathrm{E}-04$ & $6.452 \mathrm{E}-04$ & $1.000 \mathrm{E}-03$ & 0.5 & 56 \\
\hline 27 & $2 s 2 p^{4}{ }^{4} P_{3 / 2}-2 s^{2} 2 p^{3}{ }^{2} P_{3 / 2}$ & $2.679 \mathrm{E}-03$ & $2.687 \mathrm{E}-03$ & $3.200 \mathrm{E}-03$ & 0.3 & 19 \\
\hline 27 & $2 s 2 p^{4}{ }^{4} P_{1 / 2}-2 s^{2} 2 p^{3}{ }^{4} S_{3 / 2}$ & $2.828 \mathrm{E}-02$ & $2.842 \mathrm{E}-02$ & $3.160 \mathrm{E}-02$ & 0.5 & 12 \\
\hline 27 & $2 s 2 p^{4}{ }^{4} P_{1 / 2}-2 s^{2} 2 p^{3}{ }^{2} D_{3 / 2}$ & $9.795 \mathrm{E}-04$ & $9.792 \mathrm{E}-04$ & $1.200 \mathrm{E}-03$ & 0.1 & 23 \\
\hline 27 & $2 s 2 p^{4}{ }^{4} P_{1 / 2}-2 s^{2} 2 p^{3}{ }^{2} P_{1 / 2}$ & $1.317 \mathrm{E}-03$ & $1.316 \mathrm{E}-03$ & $1.500 \mathrm{E}-03$ & -0.1 & 14 \\
\hline 27 & $2 s 2 p^{4}{ }^{2} D_{3 / 2}-2 s^{2} 2 p^{3}{ }^{4} S_{3 / 2}$ & $3.705 \mathrm{E}-03$ & $3.702 \mathrm{E}-03$ & $4.400 \mathrm{E}-03$ & -0.1 & 19 \\
\hline 27 & $2 s 2 p^{4}{ }^{2} D_{3 / 2}-2 s^{2} 2 p^{3}{ }^{2} P_{1 / 2}$ & $9.408 \mathrm{E}-03$ & $9.457 \mathrm{E}-03$ & $1.060 \mathrm{E}-02$ & 0.5 & 13 \\
\hline 27 & $2 s 2 p^{4}{ }^{2} D_{3 / 2}-2 s^{2} 2 p^{3}{ }^{2} P_{3 / 2}$ & $2.333 \mathrm{E}-03$ & $2.359 \mathrm{E}-03$ & $3.200 \mathrm{E}-03$ & 1.1 & 37 \\
\hline 27 & $2 s 2 p^{4}{ }^{2} D_{5 / 2}-2 s^{2} 2 p^{3}{ }^{2} D_{3 / 2}$ & $1.335 \mathrm{E}-04$ & $1.329 \mathrm{E}-04$ & $2.000 \mathrm{E}-04$ & -0.4 & 50 \\
\hline 27 & $2 s 2 p^{4}{ }^{2} D_{5 / 2}-2 s^{2} 2 p^{3}{ }^{2} D_{5 / 2}$ & $1.149 \mathrm{E}-01$ & $1.156 \mathrm{E}-01$ & $1.300 \mathrm{E}-01$ & 0.6 & 13 \\
\hline 27 & $2 s 2 p^{4}{ }^{2} D_{5 / 2}-2 s^{2} 2 p^{3}{ }^{2} P_{3 / 2}$ & $3.725 \mathrm{E}-02$ & $3.742 \mathrm{E}-02$ & $4.100 \mathrm{E}-02$ & 0.5 & 10 \\
\hline 27 & $2 s 2 p^{4}{ }^{2} S_{1 / 2}-2 s^{2} 2 p^{3}{ }^{4} S_{3 / 2}$ & $1.163 \mathrm{E}-03$ & $1.164 \mathrm{E}-03$ & $1.400 \mathrm{E}-03$ & 0.1 & 20 \\
\hline 27 & $2 s 2 p^{4}{ }^{2} S_{1 / 2}-2 s^{2} 2 p^{3}{ }^{2} P_{3 / 2}$ & $1.903 \mathrm{E}-03$ & $1.920 \mathrm{E}-03$ & $2.900 \mathrm{E}-03$ & 0.9 & 52 \\
\hline 27 & $2 s 2 p^{4}{ }^{2} P_{3 / 2}-2 s^{2} 2 p^{3}{ }^{4} S_{3 / 2}$ & $4.615 \mathrm{E}-03$ & $4.618 \mathrm{E}-03$ & $5.200 \mathrm{E}-03$ & 0.1 & 13 \\
\hline 27 & $2 s 2 p^{4}{ }^{2} P_{1 / 2}-2 s^{2} 2 p^{3}{ }^{2} D_{3 / 2}$ & $1.195 \mathrm{E}-02$ & $1.202 \mathrm{E}-02$ & $1.320 \mathrm{E}-02$ & 0.6 & 11 \\
\hline 27 & $2 s 2 p^{4}{ }^{2} P_{1 / 2}-2 s^{2} 2 p^{3}{ }^{2} P_{1 / 2}$ & $2.241 \mathrm{E}-03$ & $2.247 \mathrm{E}-03$ & $2.700 \mathrm{E}-03$ & 0.3 & 21 \\
\hline 27 & $2 s 2 p^{4}{ }^{2} P_{1 / 2}-2 s^{2} 2 p^{3}{ }^{2} P_{3 / 2}$ & $7.721 \mathrm{E}-02$ & $7.758 \mathrm{E}-02$ & $8.700 \mathrm{E}-02$ & 0.5 & 13 \\
\hline 27 & $2 p^{5}{ }^{2} P_{3 / 2}-2 s 2 p^{4}{ }^{4} P_{5 / 2}$ & $3.531 \mathrm{E}-03$ & $3.530 \mathrm{E}-03$ & $3.900 \mathrm{E}-03$ & 0.1 & 11 \\
\hline 27 & $2 p^{5}{ }^{2} P_{3 / 2}-2 s 2 p^{4}{ }^{4} P_{1 / 2}$ & $8.703 \mathrm{E}-04$ & $8.684 \mathrm{E}-04$ & $9.600 \mathrm{E}-04$ & -0.2 & 10 \\
\hline 27 & $2 p^{5}{ }^{2} P_{3 / 2}-2 s 2 p^{4}{ }^{2} D_{3 / 2}$ & $4.054 \mathrm{E}-02$ & $4.071 \mathrm{E}-02$ & $4.610 \mathrm{E}-02$ & 0.4 & 14 \\
\hline 27 & $2 p^{5}{ }^{2} P_{3 / 2}-2 s 2 p^{4}{ }^{2} D_{5 / 2}$ & $9.614 \mathrm{E}-02$ & $9.655 \mathrm{E}-02$ & $1.100 \mathrm{E}-01$ & 0.4 & 14 \\
\hline 27 & $2 p^{5}{ }^{2} P_{3 / 2}-2 s 2 p^{4}{ }^{2} P_{3 / 2}$ & $1.303 \mathrm{E}-01$ & $1.311 \mathrm{E}-01$ & $1.500 \mathrm{E}-01$ & 0.6 & 15 \\
\hline 27 & $2 p^{5}{ }^{2} P_{3 / 2}-2 s 2 p^{4}{ }^{2} P_{1 / 2}$ & $9.916 \mathrm{E}-03$ & $9.973 \mathrm{E}-03$ & $1.280 \mathrm{E}-02$ & 0.6 & 29 \\
\hline 27 & $2 p^{5}{ }^{2} P_{1 / 2}-2 s 2 p^{4}{ }^{4} P_{1 / 2}$ & $4.945 \mathrm{E}-04$ & $4.954 \mathrm{E}-04$ & $5.500 \mathrm{E}-04$ & 0.2 & 11 \\
\hline 27 & $2 p^{5}{ }^{2} P_{1 / 2}-2 s 2 p^{4}{ }^{2} D_{3 / 2}$ & $3.230 \mathrm{E}-02$ & $3.246 \mathrm{E}-02$ & $3.640 \mathrm{E}-02$ & 0.5 & 13 \\
\hline 27 & $2 p^{5}{ }^{2} P_{1 / 2}-2 s 2 p^{4}{ }^{2} P_{3 / 2}$ & $5.525 \mathrm{E}-02$ & $5.550 \mathrm{E}-02$ & $6.350 \mathrm{E}-02$ & 0.5 & 15 \\
\hline 27 & $2 p^{5}{ }^{2} P_{1 / 2}-2 s 2 p^{4}{ }^{2} P_{1 / 2}$ & $6.621 \mathrm{E}-02$ & $6.657 \mathrm{E}-02$ & $7.800 \mathrm{E}-02$ & 0.5 & 18 \\
\hline 28 & $2 s 2 p^{4}{ }^{4} P_{5 / 2}-2 s^{2} 2 p^{3}{ }^{4} S_{3 / 2}$ & $6.443 \mathrm{E}-02$ & $6.486 \mathrm{E}-02$ & $7.090 \mathrm{E}-02$ & 0.7 & 10 \\
\hline 28 & $2 s 2 p^{4}{ }^{4} P_{5 / 2}-2 s^{2} 2 p^{3}{ }^{2} D_{3 / 2}$ & $1.048 \mathrm{E}-02$ & $1.050 \mathrm{E}-02$ & $1.200 \mathrm{E}-02$ & 0.2 & 15 \\
\hline 28 & $2 s 2 p^{4}{ }^{4} P_{5 / 2}-2 s^{2} 2 p^{3}{ }^{2} D_{5 / 2}$ & $4.510 \mathrm{E}-03$ & $4.515 \mathrm{E}-03$ & $5.000 \mathrm{E}-03$ & 0.1 & 11 \\
\hline 28 & $2 s 2 p^{4}{ }^{4} P_{5 / 2}-2 s^{2} 2 p^{3}{ }^{2} P_{3 / 2}$ & $7.887 \mathrm{E}-04$ & $7.944 \mathrm{E}-04$ & $9.600 \mathrm{E}-04$ & 0.7 & 22 \\
\hline 28 & $2 s 2 p^{4}{ }^{4} P_{3 / 2}-2 s^{2} 2 p^{3}{ }^{2} D_{3 / 2}$ & $7.643 \mathrm{E}-04$ & $7.699 \mathrm{E}-04$ & $1.200 \mathrm{E}-03$ & 0.7 & 57 \\
\hline 28 & $2 s 2 p^{4}{ }^{4} P_{3 / 2}-2 s^{2} 2 p^{3}{ }^{2} P_{3 / 2}$ & $2.860 \mathrm{E}-03$ & $2.872 \mathrm{E}-03$ & $3.500 \mathrm{E}-03$ & 0.4 & 22 \\
\hline 28 & $2 s 2 p^{4}{ }^{4} P_{1 / 2}-2 s^{2} 2 p^{3}{ }^{4} S_{3 / 2}$ & $2.603 \mathrm{E}-02$ & $2.617 \mathrm{E}-02$ & $2.900 \mathrm{E}-02$ & 0.5 & 11 \\
\hline 28 & $2 s 2 p^{4}{ }^{4} P_{1 / 2}-2 s^{2} 2 p^{3}{ }^{2} D_{3 / 2}$ & $1.166 \mathrm{E}-03$ & $1.167 \mathrm{E}-03$ & $1.400 \mathrm{E}-03$ & 0.1 & 20 \\
\hline
\end{tabular}


Table 5

(Continued)

\begin{tabular}{|c|c|c|c|c|c|c|}
\hline \multirow[t]{2}{*}{$Z$} & \multirow[t]{2}{*}{ Transition } & \multicolumn{3}{|c|}{ Line Strengths } & \multicolumn{2}{|c|}{ Difference $(\%)$} \\
\hline & & MBPT & MCDHF/RCI2 & NIST & MBPT and MCDHF/RCI2 & MBPT and NIST \\
\hline 28 & $2 s 2 p^{4}{ }^{4} P_{1 / 2}-2 s^{2} 2 p^{3}{ }^{2} P_{1 / 2}$ & $1.605 \mathrm{E}-03$ & $1.605 \mathrm{E}-03$ & $1.800 \mathrm{E}-03$ & 0.1 & 12 \\
\hline 28 & $2 s 2 p^{4}{ }^{2} D_{3 / 2}-2 s^{2} 2 p^{3}{ }^{4} S_{3 / 2}$ & $4.812 \mathrm{E}-03$ & $4.812 \mathrm{E}-03$ & $5.700 \mathrm{E}-03$ & 0.1 & 19 \\
\hline 28 & $2 s 2 p^{4}{ }^{2} D_{3 / 2}-2 s^{2} 2 p^{3}{ }^{2} D_{3 / 2}$ & $8.805 \mathrm{E}-02$ & $8.850 \mathrm{E}-02$ & $9.700 \mathrm{E}-02$ & 0.5 & 10 \\
\hline 28 & $2 s 2 p^{4}{ }^{2} D_{3 / 2}-2 s^{2} 2 p^{3}{ }^{2} P_{1 / 2}$ & $8.045 \mathrm{E}-03$ & $8.093 \mathrm{E}-03$ & $8.980 \mathrm{E}-03$ & 0.6 & 12 \\
\hline 28 & $2 s 2 p^{4}{ }^{2} D_{3 / 2}-2 s^{2} 2 p^{3}{ }^{2} P_{3 / 2}$ & $1.976 \mathrm{E}-03$ & $2.000 \mathrm{E}-03$ & $2.700 \mathrm{E}-03$ & 1.2 & 37 \\
\hline 28 & $2 s 2 p^{4}{ }^{2} D_{5 / 2}-2 s^{2} 2 p^{3}{ }^{2} D_{3 / 2}$ & $2.255 \mathrm{E}-04$ & $2.254 \mathrm{E}-04$ & $3.100 \mathrm{E}-04$ & -0.1 & 38 \\
\hline 28 & $2 s 2 p^{4}{ }^{2} D_{5 / 2}-2 s^{2} 2 p^{3}{ }^{2} D_{5 / 2}$ & $1.054 \mathrm{E}-01$ & $1.060 \mathrm{E}-01$ & $1.200 \mathrm{E}-01$ & 0.6 & 14 \\
\hline 28 & $2 s 2 p^{4}{ }^{2} S_{1 / 2}-2 s^{2} 2 p^{3}{ }^{4} S_{3 / 2}$ & $1.369 \mathrm{E}-03$ & $1.371 \mathrm{E}-03$ & $1.600 \mathrm{E}-03$ & 0.1 & 17 \\
\hline 28 & $2 s 2 p^{4}{ }^{2} S_{1 / 2}-2 s^{2} 2 p^{3}{ }^{2} P_{3 / 2}$ & $1.079 \mathrm{E}-03$ & $1.091 \mathrm{E}-03$ & $1.600 \mathrm{E}-03$ & 1.2 & 48 \\
\hline 28 & $2 s 2 p^{4}{ }^{2} P_{3 / 2}-2 s^{2} 2 p^{3}{ }^{4} S_{3 / 2}$ & $4.906 \mathrm{E}-03$ & $4.910 \mathrm{E}-03$ & $5.500 \mathrm{E}-03$ & 0.1 & 12 \\
\hline 28 & $2 s 2 p^{4}{ }^{2} P_{1 / 2}-2 s^{2} 2 p^{3}{ }^{2} D_{3 / 2}$ & $9.645 \mathrm{E}-03$ & $9.696 \mathrm{E}-03$ & $1.070 \mathrm{E}-02$ & 0.5 & 11 \\
\hline 28 & $2 s 2 p^{4}{ }^{2} P_{1 / 2}-2 s^{2} 2 p^{3}{ }^{2} P_{1 / 2}$ & $1.752 \mathrm{E}-03$ & $1.757 \mathrm{E}-03$ & $2.100 \mathrm{E}-03$ & 0.3 & 20 \\
\hline 28 & $2 s 2 p^{4}{ }^{2} P_{1 / 2}-2 s^{2} 2 p^{3}{ }^{2} P_{3 / 2}$ & $7.210 \mathrm{E}-02$ & $7.244 \mathrm{E}-02$ & $8.100 \mathrm{E}-02$ & 0.5 & 12 \\
\hline 28 & $2 p^{5}{ }^{2} P_{3 / 2}-2 s 2 p^{4}{ }^{4} P_{1 / 2}$ & $1.089 \mathrm{E}-03$ & $1.087 \mathrm{E}-03$ & $1.200 \mathrm{E}-03$ & -0.2 & 10 \\
\hline 28 & $2 p^{5}{ }^{2} P_{3 / 2}-2 s 2 p^{4}{ }^{2} D_{3 / 2}$ & 4.087E-02 & $4.105 \mathrm{E}-02$ & $4.640 \mathrm{E}-02$ & 0.4 & 14 \\
\hline 28 & $2 p^{5}{ }^{2} P_{3 / 2}-2 s 2 p^{4}{ }^{2} D_{5 / 2}$ & $8.799 \mathrm{E}-02$ & $8.841 \mathrm{E}-02$ & $9.920 \mathrm{E}-02$ & 0.5 & 13 \\
\hline 28 & $2 p^{5}{ }^{2} P_{3 / 2}-2 s 2 p^{4}{ }^{2} S_{1 / 2}$ & $3.286 \mathrm{E}-02$ & $3.304 \mathrm{E}-02$ & $3.620 \mathrm{E}-02$ & 0.5 & 10 \\
\hline 28 & $2 p^{5}{ }^{2} P_{3 / 2}-2 s 2 p^{4}{ }^{2} P_{3 / 2}$ & $1.158 \mathrm{E}-01$ & $1.165 \mathrm{E}-01$ & $1.300 \mathrm{E}-01$ & 0.6 & 12 \\
\hline 28 & $2 p^{5}{ }^{2} P_{3 / 2}-2 s 2 p^{4}{ }^{2} P_{1 / 2}$ & $8.376 \mathrm{E}-03$ & $8.429 \mathrm{E}-03$ & $1.070 \mathrm{E}-02$ & 0.6 & 28 \\
\hline 28 & $2 p^{5}{ }^{2} P_{1 / 2}-2 s 2 p^{4}{ }^{4} P_{1 / 2}$ & $5.168 \mathrm{E}-04$ & $5.177 \mathrm{E}-04$ & $5.700 \mathrm{E}-04$ & 0.2 & 10 \\
\hline 28 & $2 p^{5}{ }^{2} P_{1 / 2}-2 s 2 p^{4}{ }^{2} D_{3 / 2}$ & $2.734 \mathrm{E}-02$ & $2.749 \mathrm{E}-02$ & $3.100 \mathrm{E}-02$ & 0.6 & 13 \\
\hline 28 & $2 p^{5}{ }^{2} P_{1 / 2}-2 s 2 p^{4}{ }^{2} P_{3 / 2}$ & $5.330 \mathrm{E}-02$ & $5.357 \mathrm{E}-02$ & $6.000 \mathrm{E}-02$ & 0.5 & 13 \\
\hline 28 & $2 p^{5}{ }^{2} P_{1 / 2}-2 s 2 p^{4}{ }^{2} P_{1 / 2}$ & $6.016 \mathrm{E}-02$ & $6.050 \mathrm{E}-02$ & $7.000 \mathrm{E}-02$ & 0.6 & 16 \\
\hline
\end{tabular}

Notes.

The MCDHF/RCI2 results are also listed for comparison.

used above. Furthermore, our MBPT energies of the $2 s^{2} 2 p^{2}\left({ }^{1} D\right) 3 d^{2} D_{5 / 2}$ level in eight ions (from $\mathrm{K}$ XII to Fe $\mathrm{xx}$ ) agree well (within $0.1 \%$ ) with the calculated values recommended by Bromage \& Fawcett (1977). Thus, we can state with confidence that the observation uncertainty for the $2 s^{2} 2 p^{2}\left({ }^{1} D\right) 3 d^{2} D_{5 / 2}$ level in $\mathrm{K}$ XIII, Ca XIV, and V XVII in the NIST ASD exceeds the "uncertainty" of the MBPT calculations. As also shown in Figure 2(a), the NIST and MBPT values agree within $0.01 \%$ for the same level in Fexx, but the NIST compiled energy of $605.0 \mathrm{eV}$ for the $2 s^{2} 2 p^{2}\left({ }^{1} S\right) 3 d{ }^{2} D_{5 / 2}$ state in $\mathrm{Sc} \mathrm{XV}$ is $0.58 \%$ higher than the MBPT values. This is quite strange because the unified treatment is adopted for each ion in the present MBPT calculations, which implies that the calculated results of Sc XV may only be slightly less accurate than those of Fe xx because of more important effects of the electron correlation in the relatively lower- $Z$ system in principle (Wang et al. 2015). In addition, Sugar \& Corliss (1985) said that the $2 s^{2} 2 p^{2}\left({ }^{1} S\right) 3 d{ }^{2} D_{5 / 2}$ state in Sc Xv was from the interpretation by Fawcett \& Hayes (1975) and Bromage \& Fawcett (1977). We look over the above two papers, but do not find the measurement regarding the $2 s^{2} 2 p^{2}\left({ }^{1} S\right) 3 d{ }^{2} D_{5 / 2}$ state. Therefore, the NIST value for the $2 s^{2} 2 p^{2}\left({ }^{1} S\right) 3 d^{2} D_{5 / 2}$ level in $\mathrm{Sc} X V$ may not be determined by the measurement, and we argue that the uncertainty might be large for this level.

In Table 4, there are 17 levels for which the differences between the MBPT and NIST values are in the range of $0.2 \%$ $0.5 \%$. In Figure 2(b) we show the comparison of some representative cases. In order to discuss the Z-dependent behavior, Figure 2(b) also displays the energy deviations $(<0.2 \%)$ for levels in other ions along the sequence. The NIST and MBPT values agree within $0.2 \%$ for most levels, and large differences happen at the higher- $Z$ end $\left(2 s^{2} 2 p^{2}\left({ }^{1} D\right) 3 d{ }^{2} F_{5 / 2}\right.$ and $2 s^{2} 2 p^{2}\left({ }^{3} P\right) 3 d{ }^{2} D_{3 / 2}$ and $\left.{ }^{4} P_{5 / 2}\right)$ and/or in the middle of the isoelectric sequence $\left(2 s^{2} 2 p^{2}\left({ }^{3} P\right) 3 d{ }^{2} D_{3 / 2}\right.$ and $\left.{ }^{2} P_{3 / 2}\right)$. Theoretically, this is not reasonable because the electron correlation effects are usually more significant for lower-Z ions. Furthermore, the present MBPT and MCDHF/RCI results agree well within $0.05 \%$ for the $2 s^{2} 2 p^{2}\left({ }^{1} D\right) 3 d{ }^{2} F_{5 / 2}$ and $2 s^{2} 2 p^{2}\left({ }^{3} P\right) 3 d{ }^{2} D_{3 / 2}$ and ${ }^{4} P_{5 / 2}$ levels in Fe $\mathrm{xx}$. Therefore, we consider that the large deviations for the $23 n=3,4$ levels listed in Table 4 should be mainly caused by relatively large observation uncertainty.

\subsection{Radiative Rates}

In Figure 3, we compare the present MBPT line strengths ( $S$ values) with the MCDHF/RCI2 results (Rynkun et al. 2014) for all of $637 \mathrm{E} 1$ transitions among the $n=2$ levels in N-like ions with $18 \leqslant Z \leqslant 30$. The transitions for which the $S$ values $<10^{-6}$ are not displayed in Figure 3, because there are only five transitions in this range. For most of the transitions (except for six relatively weak transitions with $S$ values $<10^{-5}$ ), the agreement of the two sets of results is within $5 \%$, which is highly satisfactory. The differences of two data sets result from different electron correlation effects considered in the calculations. Weak transitions are generally very sensitive to the electron correlation effects considered in the calculations, and 
Table 6

Comparisons of the MCDHF/RCI Line Strengths and the NIST Values Relative to the Present MBPT Results for Transitions Involving the $n=3,4$ Levels

\begin{tabular}{|c|c|c|c|c|c|c|}
\hline \multirow[t]{2}{*}{$Z$} & \multirow[t]{2}{*}{ Transition } & \multicolumn{3}{|c|}{ Line Strengths } & \multicolumn{2}{|c|}{ Difference $(\%)$} \\
\hline & & MBPT & $\mathrm{MCDHF} / \mathrm{RCI}$ & NIST & $\mathrm{MBPT}$ and $\mathrm{MCDHF} / \mathrm{RCI}$ & MBPT and NIST \\
\hline 26 & $2 s^{2} 2 p^{2}\left({ }^{3} P\right) 3 d{ }^{4} P_{3 / 2}-2 s^{2} 2 p^{3}{ }^{4} S_{3 / 2}$ & $8.230 \mathrm{E}-02$ & $8.25 \mathrm{E}-02$ & $8.70 \mathrm{E}-02$ & 0.2 & 6 \\
\hline 26 & $2 s^{2} 2 p^{2}\left({ }^{3} P\right) 3 d{ }^{4} P_{3 / 2}-2 s^{2} 2 p^{3}{ }^{2} D_{5 / 2}$ & $3.902 \mathrm{E}-03$ & $3.92 \mathrm{E}-03$ & $3.60 \mathrm{E}-03$ & 0.6 & -8 \\
\hline 26 & $2 s^{2} 2 p^{2}\left({ }^{3} P\right) 3 d^{2} D_{3 / 2}-2 s^{2} 2 p^{3}{ }^{4} S_{3 / 2}$ & $9.373 \mathrm{E}-04$ & $9.62 \mathrm{E}-04$ & $8.50 \mathrm{E}-04$ & 2.6 & -9 \\
\hline 26 & $2 s^{2} 2 p^{2}\left({ }^{3} P\right) 3 d^{2} D_{3 / 2}-2 s^{2} 2 p^{3}{ }^{2} D_{5 / 2}$ & $4.479 \mathrm{E}-03$ & $4.51 \mathrm{E}-03$ & $4.80 \mathrm{E}-03$ & 0.7 & 7 \\
\hline 26 & $2 s^{2} 2 p^{2}\left({ }^{3} P\right) 3 d^{2} D_{3 / 2}-2 s^{2} 2 p^{3}{ }^{2} P_{1 / 2}$ & $4.412 \mathrm{E}-02$ & 4.43E-02 & $4.00 \mathrm{E}-02$ & 0.4 & -9 \\
\hline 26 & $2 s^{2} 2 p^{2}\left({ }^{3} P\right) 3 d^{2} D_{3 / 2}-2 s^{2} 2 p^{3}{ }^{2} P_{3 / 2}$ & $5.593 \mathrm{E}-03$ & $5.58 \mathrm{E}-03$ & $5.50 \mathrm{E}-03$ & -0.2 & -2 \\
\hline 26 & $2 s^{2} 2 p^{2}\left({ }^{3} P\right) 3 d^{2} D_{5 / 2}-2 s^{2} 2 p^{3}{ }^{4} S_{3 / 2}$ & $7.721 \mathrm{E}-03$ & $7.89 \mathrm{E}-03$ & $6.80 \mathrm{E}-03$ & 2.2 & -12 \\
\hline 26 & $2 s^{2} 2 p^{2}\left({ }^{3} P\right) 3 d^{2} D_{5 / 2}-2 s^{2} 2 p^{3}{ }^{2} D_{3 / 2}$ & $1.082 \mathrm{E}-01$ & $1.09 \mathrm{E}-01$ & $1.00 \mathrm{E}-01$ & 0.6 & -8 \\
\hline 26 & $2 s^{2} 2 p^{2}\left({ }^{3} P\right) 3 d^{2} D_{5 / 2}-2 s^{2} 2 p^{3}{ }^{2} D_{5 / 2}$ & $3.125 \mathrm{E}-02$ & $3.15 \mathrm{E}-02$ & $3.40 \mathrm{E}-02$ & 0.7 & 9 \\
\hline 26 & $2 s^{2} 2 p^{2}\left({ }^{3} P\right) 3 d^{2} D_{5 / 2}-2 s^{2} 2 p^{3}{ }^{2} P_{3 / 2}$ & $1.611 \mathrm{E}-03$ & $1.61 \mathrm{E}-03$ & $1.10 \mathrm{E}-03$ & -0.2 & -32 \\
\hline 26 & $2 s^{2} 2 p^{2}\left({ }^{1} D\right) 3 d^{2} D_{3 / 2}-2 s^{2} 2 p^{3}{ }^{4} S_{3 / 2}$ & $8.106 \mathrm{E}-04$ & $8.29 \mathrm{E}-04$ & $5.20 \mathrm{E}-04$ & 2.2 & -36 \\
\hline 26 & $2 s^{2} 2 p^{2}\left({ }^{1} D\right) 3 d^{2} D_{3 / 2}-2 s^{2} 2 p^{3}{ }^{2} D_{3 / 2}$ & $4.761 \mathrm{E}-02$ & 4.77E-02 & $4.60 \mathrm{E}-02$ & 0.3 & -3 \\
\hline 26 & $2 s^{2} 2 p^{2}\left({ }^{1} D\right) 3 d^{2} D_{3 / 2}-2 s^{2} 2 p^{3}{ }^{2} D_{5 / 2}$ & $1.188 \mathrm{E}-02$ & $1.19 \mathrm{E}-02$ & $1.10 \mathrm{E}-02$ & 0.3 & -7 \\
\hline 26 & $2 s^{2} 2 p^{2}\left({ }^{1} D\right) 3 d^{2} D_{3 / 2}-2 s^{2} 2 p^{3}{ }^{2} P_{1 / 2}$ & $1.155 \mathrm{E}-02$ & $1.16 \mathrm{E}-02$ & $1.30 \mathrm{E}-02$ & 0.3 & 13 \\
\hline 26 & $2 s^{2} 2 p^{2}\left({ }^{1} D\right) 3 d^{2} D_{3 / 2}-2 s^{2} 2 p^{3}{ }^{2} P_{3 / 2}$ & $1.868 \mathrm{E}-03$ & $1.86 \mathrm{E}-03$ & $1.90 \mathrm{E}-03$ & -0.5 & 2 \\
\hline 26 & $2 s^{2} 2 p^{2}\left({ }^{1} D\right) 3 d^{2} D_{5 / 2}-2 s^{2} 2 p^{3}{ }^{4} S_{3 / 2}$ & $8.639 \mathrm{E}-04$ & $8.45 \mathrm{E}-04$ & $7.20 \mathrm{E}-03$ & -2.2 & 733 \\
\hline 26 & $2 s^{2} 2 p^{2}\left({ }^{1} D\right) 3 d^{2} D_{5 / 2}-2 s^{2} 2 p^{3}{ }^{2} D_{3 / 2}$ & $5.639 \mathrm{E}-02$ & $5.69 \mathrm{E}-02$ & $6.90 \mathrm{E}-02$ & 0.9 & 22 \\
\hline 26 & $\left.2 s^{2} 2 p^{2}{ }^{1} D\right) 3 d^{2} D_{5 / 2}-2 s^{2} 2 p^{3}{ }^{2} D_{5 / 2}$ & $6.775 \mathrm{E}-02$ & $6.78 \mathrm{E}-02$ & $6.10 \mathrm{E}-02$ & 0.1 & -10 \\
\hline 26 & $2 s^{2} 2 p^{2}\left({ }^{1} D\right) 3 d^{2} D_{5 / 2}-2 s^{2} 2 p^{3}{ }^{2} P_{3 / 2}$ & $6.201 \mathrm{E}-03$ & $6.33 \mathrm{E}-03$ & $1.08 \mathrm{E}-03$ & 2.0 & -83 \\
\hline 26 & $2 s^{2} 2 p^{2}\left({ }^{1} D\right) 3 d^{2} P_{3 / 2}-2 s^{2} 2 p^{3}{ }^{4} S_{3 / 2}$ & $5.602 \mathrm{E}-04$ & $5.70 \mathrm{E}-04$ & $4.70 \mathrm{E}-04$ & 1.8 & -16 \\
\hline 26 & $2 s^{2} 2 p^{2}\left({ }^{1} D\right) 3 d^{2} P_{3 / 2}-2 s^{2} 2 p^{3}{ }^{2} D_{3 / 2}$ & $1.188 \mathrm{E}-03$ & $1.19 \mathrm{E}-03$ & $1.40 \mathrm{E}-03$ & -0.1 & 18 \\
\hline 26 & $2 s^{2} 2 p^{2}\left({ }^{1} D\right) 3 d^{2} P_{3 / 2}-2 s^{2} 2 p^{3}{ }^{2} D_{5 / 2}$ & $6.278 \mathrm{E}-03$ & $6.34 \mathrm{E}-03$ & $6.70 \mathrm{E}-03$ & 1.0 & 7 \\
\hline 26 & $2 s^{2} 2 p^{2}\left({ }^{1} D\right) 3 d^{2} P_{3 / 2}-2 s^{2} 2 p^{3}{ }^{2} P_{1 / 2}$ & $6.113 \mathrm{E}-03$ & $6.16 \mathrm{E}-03$ & $7.30 \mathrm{E}-03$ & 0.8 & 19 \\
\hline 26 & $2 s^{2} 2 p^{2}\left({ }^{1} D\right) 3 d^{2} P_{3 / 2}-2 s^{2} 2 p^{3}{ }^{2} P_{3 / 2}$ & $6.458 \mathrm{E}-02$ & $6.49 \mathrm{E}-02$ & $6.20 \mathrm{E}-02$ & 0.6 & -4 \\
\hline 26 & $2 s^{2} 2 p^{2}\left({ }^{1} S\right) 3 d^{2} D_{5 / 2}-2 s^{2} 2 p^{3}{ }^{2} D_{5 / 2}$ & $4.953 \mathrm{E}-03$ & $5.11 \mathrm{E}-03$ & $6.10 \mathrm{E}-03$ & 3.1 & 23 \\
\hline 26 & $2 s^{2} 2 p^{2}\left({ }^{1} S\right) 3 d^{2} D_{5 / 2}-2 s^{2} 2 p^{3}{ }^{2} P_{3 / 2}$ & $7.838 \mathrm{E}-02$ & $7.93 \mathrm{E}-02$ & $9.00 \mathrm{E}-02$ & 1.2 & 15 \\
\hline
\end{tabular}

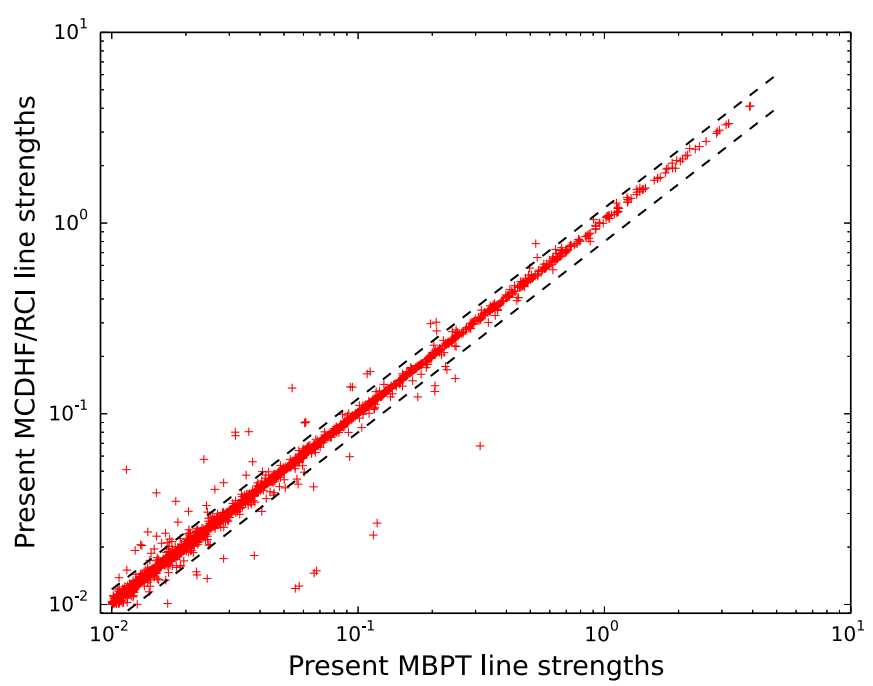

Figure 5. Comparison of the present MBPT line strengths with the MCDHF/ RCI results for the strong E1 transitions involving the $n=3,4$ levels in Fe xx. Dashed lines indicate differences of $\pm 20 \%$.

sometimes are even sensitive to the high-order relativistic effects that might be necessary to describe the coupling conditions very accurately.

The NIST ASD lists the $S$ values for 337 out of the total 637 transitions among the $n=2$ complex. Figure 4 compares the present MBPT $S$ values with those included in the NIST ASD. The NIST values differ from the MBPT results by over $10 \%$ for
$74 \%$ out of the $337 \mathrm{E} 1$ transitions. Even for many very strong transitions with $S$ values $\geqslant 10^{-2}$, the differences are also larger than $10 \%$. Table 5 lists all the E1 transitions for which the deviations between the NIST and MBPT $S$ values exceed $10 \%$. We notice that these transitions belong to the ions with 21-28, and the source of the NIST data is from Cheng et al. (1979), which may be out of date. In their calculations, the MCDHF technique was used to calculate energy levels and wavefunctions for the $n=2$ levels. Only the configurations within the $n=2$ complex were included to account for electron correlations and intermediate coupling. As shown in Figure 4 and Table 5, there is a good agreement (within $2 \%$ ) between the present MBPT $S$ values and those from Rynkun et al. (2014). The present MBPT calculations, as well as the MCDHF/RCI2 results, should be more accurate and reliable than those values recommended by the NIST ASD.

Of the large number of the E1 transitions involving the higher excited levels of the $n=3,4$ complexes in the 13 N-like ions, the NIST ASD only lists the $S$ values for 26 onephoton-one-electron transitions in Fe xx. These NIST values are included in Table 6, as well as the present MBPT and $\mathrm{MCDHF} / \mathrm{RCI}$ results. Even for the one electron transitions, the differences of the NIST values relative to the MBPT results (or the MCDHF/RCI results) are over 20\% (up to a factor of 7 for $2 s^{2} 2 p^{2}\left({ }^{1} D\right) 3 d^{2} D_{5 / 2} \rightarrow 2 s^{2} 2 p^{3}{ }^{4} S_{3 / 2}$ for which $\Delta S=1$ and $\Delta L=2$ ) in six cases. As seen from Table 6, the agreement between the present MBPT and MCDHF/RCI $S$ values is satisfactory, within $4 \%$ for all 26 E1 transitions. To further assess the accuracy of the present transitions' properties, in 
Table 7

Comparisons of the MCDHF/RCI2 Line Strengths and the NIST Values Relative to the Present MBPT Results for the M1 and E2 Transitions among the $n=2$ Levels

\begin{tabular}{|c|c|c|c|c|c|c|c|}
\hline \multirow[t]{2}{*}{$Z$} & \multirow[t]{2}{*}{ Transition } & \multirow[t]{2}{*}{ Type } & \multicolumn{3}{|c|}{ Line Strengths } & \multicolumn{2}{|c|}{ Difference $(\%)$} \\
\hline & & & MBPT & $\mathrm{MCDHF} / \mathrm{RCI} 2$ & NIST & MBPT and MCDHF/RCI2 & MBPT and NIST \\
\hline 19 & $2 s^{2} 2 p^{3}{ }^{2} D_{3 / 2}-2 s^{2} 2 p^{3}{ }^{4} S_{3 / 2}$ & M1 & $3.312 \mathrm{E}-02$ & $3.303 \mathrm{E}-02$ & $3.190 \mathrm{E}-02$ & -0.3 & -4 \\
\hline 19 & $2 s^{2} 2 p^{3}{ }^{2} P_{1 / 2}-2 s^{2} 2 p^{3}{ }^{4} S_{3 / 2}$ & M1 & $1.642 \mathrm{E}-02$ & $1.641 \mathrm{E}-02$ & $1.600 \mathrm{E}-02$ & -0.1 & -3 \\
\hline 19 & $2 s^{2} 2 p^{3}{ }^{2} P_{3 / 2}-2 s^{2} 2 p^{3}{ }^{4} S_{3 / 2}$ & M1 & $5.796 \mathrm{E}-02$ & $5.816 \mathrm{E}-02$ & $5.680 \mathrm{E}-02$ & 0.3 & -2 \\
\hline 21 & $2 s^{2} 2 p^{3}{ }^{2} D_{3 / 2}-2 s^{2} 2 p^{3}{ }^{4} S_{3 / 2}$ & M1 & $1.048 \mathrm{E}-01$ & $1.045 \mathrm{E}-01$ & $1.186 \mathrm{E}-01$ & -0.3 & 13 \\
\hline 21 & $2 s^{2} 2 p^{3}{ }^{2} D_{5 / 2}-2 s^{2} 2 p^{3}{ }^{2} D_{3 / 2}$ & M1 & $2.055 \mathrm{E}+00$ & $2.064 \mathrm{E}+00$ & $2.020 \mathrm{E}+00$ & 0.5 & -2 \\
\hline 21 & $2 s^{2} 2 p^{3}{ }^{2} D_{5 / 2}-2 s^{2} 2 p^{3}{ }^{2} D_{3 / 2}$ & E2 & $3.768 \mathrm{E}-03$ & $\ldots$ & $4.500 \mathrm{E}-03$ & $\cdots$ & 19 \\
\hline 21 & $2 s^{2} 2 p^{3}{ }^{2} P_{1 / 2}-2 s^{2} 2 p^{3}{ }^{4} S_{3 / 2}$ & M1 & $3.253 \mathrm{E}-02$ & $3.250 \mathrm{E}-02$ & $3.522 \mathrm{E}-02$ & -0.1 & 8 \\
\hline 21 & $2 s^{2} 2 p^{3}{ }^{2} P_{1 / 2}-2 s^{2} 2 p^{3}{ }^{2} D_{3 / 2}$ & M1 & $1.722 \mathrm{E}-01$ & $1.731 \mathrm{E}-01$ & $1.857 \mathrm{E}-01$ & 0.5 & 8 \\
\hline 21 & $2 s^{2} 2 p^{3}{ }^{2} P_{1 / 2}-2 s^{2} 2 p^{3}{ }^{2} D_{3 / 2}$ & $\mathrm{E} 2$ & $1.102 \mathrm{E}-02$ & $1.109 \mathrm{E}-02$ & $1.100 \mathrm{E}-02$ & 0.6 & 0 \\
\hline 21 & $2 s^{2} 2 p^{3}{ }^{2} P_{1 / 2}-2 s^{2} 2 p^{3}{ }^{2} D_{5 / 2}$ & E2 & $8.440 \mathrm{E}-03$ & $\ldots$ & $8.700 \mathrm{E}-03$ & $\cdots$ & 3 \\
\hline 21 & $2 s^{2} 2 p^{3}{ }^{2} P_{3 / 2}-2 s^{2} 2 p^{3}{ }^{4} S_{3 / 2}$ & M1 & $8.954 \mathrm{E}-02$ & $8.978 \mathrm{E}-02$ & $9.390 \mathrm{E}-02$ & 0.3 & 5 \\
\hline 21 & $2 s^{2} 2 p^{3}{ }^{2} P_{3 / 2}-2 s^{2} 2 p^{3}{ }^{2} D_{3 / 2}$ & M1 & $5.492 \mathrm{E}-01$ & $5.509 \mathrm{E}-01$ & $6.049 \mathrm{E}-01$ & 0.3 & 10 \\
\hline 21 & $2 s^{2} 2 p^{3}{ }^{2} P_{3 / 2}-2 s^{2} 2 p^{3}{ }^{2} D_{3 / 2}$ & $\mathrm{E} 2$ & $6.318 \mathrm{E}-03$ & $6.353 \mathrm{E}-03$ & $6.000 \mathrm{E}-03$ & 0.6 & -5 \\
\hline 21 & $2 s^{2} 2 p^{3}{ }^{2} P_{3 / 2}-2 s^{2} 2 p^{3}{ }^{2} D_{5 / 2}$ & M1 & $3.280 \mathrm{E}-01$ & $3.299 \mathrm{E}-01$ & $3.680 \mathrm{E}-01$ & 0.6 & 12 \\
\hline 21 & $2 s^{2} 2 p^{3}{ }^{2} P_{3 / 2}-2 s^{2} 2 p^{3}{ }^{2} D_{5 / 2}$ & E2 & $2.459 \mathrm{E}-02$ & $2.478 \mathrm{E}-02$ & $2.400 \mathrm{E}-02$ & 0.8 & -2 \\
\hline 21 & $2 s^{2} 2 p^{3}{ }^{2} P_{3 / 2}-2 s^{2} 2 p^{3}{ }^{2} P_{1 / 2}$ & M1 & $1.119 \mathrm{E}+00$ & $1.125 \mathrm{E}+00$ & $1.100 \mathrm{E}+00$ & 0.5 & -2 \\
\hline 21 & $2 s^{2} 2 p^{3}{ }^{2} P_{3 / 2}-2 s^{2} 2 p^{3}{ }^{2} P_{1 / 2}$ & E2 & $1.519 \mathrm{E}-03$ & $\ldots$ & $1.800 \mathrm{E}-03$ & $\ldots$ & 19 \\
\hline 21 & $2 p^{5}{ }^{2} P_{1 / 2}-2 p^{5}{ }^{2} P_{3 / 2}$ & M1 & $1.319 \mathrm{E}+00$ & $1.330 \mathrm{E}+00$ & $1.386 \mathrm{E}+00$ & 0.9 & 25 \\
\hline 21 & $2 p^{5}{ }^{2} P_{1 / 2}-2 p^{5}{ }^{2} P_{3 / 2}$ & $\mathrm{E} 2$ & $6.929 \mathrm{E}-03$ & $\ldots$ & $7.900 \mathrm{E}-03$ & $\cdots$ & 14 \\
\hline 22 & $2 s^{2} 2 p^{3}{ }^{2} D_{3 / 2}-2 s^{2} 2 p^{3}{ }^{4} S_{3 / 2}$ & M1 & $1.741 \mathrm{E}-01$ & $1.735 \mathrm{E}-01$ & $1.900 \mathrm{E}-01$ & -0.3 & 9 \\
\hline 22 & $2 s^{2} 2 p^{3}{ }^{2} D_{5 / 2}-2 s^{2} 2 p^{3}{ }^{2} D_{3 / 2}$ & M1 & $1.997 \mathrm{E}+00$ & $2.007 \mathrm{E}+00$ & $1.970 \mathrm{E}+00$ & 0.5 & -1 \\
\hline 22 & $2 s^{2} 2 p^{3}{ }^{2} D_{5 / 2}-2 s^{2} 2 p^{3}{ }^{2} D_{3 / 2}$ & $\mathrm{E} 2$ & $3.453 \mathrm{E}-03$ & $\ldots$ & $3.900 \mathrm{E}-03$ & $\ldots$ & 13 \\
\hline 22 & $2 s^{2} 2 p^{3}{ }^{2} P_{1 / 2}-2 s^{2} 2 p^{3}{ }^{4} S_{3 / 2}$ & M1 & $4.456 \mathrm{E}-02$ & $4.451 \mathrm{E}-02$ & $4.700 \mathrm{E}-02$ & -0.1 & 5 \\
\hline 22 & $2 s^{2} 2 p^{3}{ }^{2} P_{1 / 2}-2 s^{2} 2 p^{3}{ }^{2} D_{3 / 2}$ & M1 & $1.967 \mathrm{E}-01$ & $1.976 \mathrm{E}-01$ & $2.200 \mathrm{E}-01$ & 0.5 & 12 \\
\hline 22 & $2 s^{2} 2 p^{3}{ }^{2} P_{1 / 2}-2 s^{2} 2 p^{3}{ }^{2} D_{3 / 2}$ & E2 & $8.595 \mathrm{E}-03$ & $8.648 \mathrm{E}-03$ & $8.400 \mathrm{E}-03$ & 0.6 & -2 \\
\hline 22 & $2 s^{2} 2 p^{3}{ }^{2} P_{1 / 2}-2 s^{2} 2 p^{3}{ }^{2} D_{5 / 2}$ & E2 & $6.777 \mathrm{E}-03$ & $\ldots$ & $6.900 \mathrm{E}-03$ & $\cdots$ & 2 \\
\hline 22 & $2 s^{2} 2 p^{3}{ }^{2} P_{3 / 2}-2 s^{2} 2 p^{3}{ }^{4} S_{3 / 2}$ & M1 & $1.046 \mathrm{E}-01$ & $1.049 \mathrm{E}-01$ & $1.100 \mathrm{E}-01$ & 0.3 & 5 \\
\hline 22 & $2 s^{2} 2 p^{3}{ }^{2} P_{3 / 2}-2 s^{2} 2 p^{3}{ }^{2} D_{3 / 2}$ & M1 & $6.426 \mathrm{E}-01$ & $6.441 \mathrm{E}-01$ & $7.000 \mathrm{E}-01$ & 0.2 & 9 \\
\hline 22 & $2 s^{2} 2 p^{3}{ }^{2} P_{3 / 2}-2 s^{2} 2 p^{3}{ }^{2} D_{3 / 2}$ & $\mathrm{E} 2$ & $4.418 \mathrm{E}-03$ & $4.438 \mathrm{E}-03$ & $4.300 \mathrm{E}-03$ & 0.5 & -3 \\
\hline 22 & $2 s^{2} 2 p^{3}{ }^{2} P_{3 / 2}-2 s^{2} 2 p^{3}{ }^{2} D_{5 / 2}$ & M1 & $3.833 \mathrm{E}-01$ & $3.852 \mathrm{E}-01$ & $4.300 \mathrm{E}-01$ & 0.5 & 12 \\
\hline 22 & $2 s^{2} 2 p^{3}{ }^{2} P_{3 / 2}-2 s^{2} 2 p^{3}{ }^{2} D_{5 / 2}$ & $\mathrm{E} 2$ & $1.907 \mathrm{E}-02$ & $1.919 \mathrm{E}-02$ & $2.000 \mathrm{E}-02$ & 0.6 & 5 \\
\hline 22 & $2 s^{2} 2 p^{3}{ }^{2} P_{3 / 2}-2 s^{2} 2 p^{3}{ }^{2} P_{1 / 2}$ & M1 & $1.083 \mathrm{E}+00$ & $1.088 \mathrm{E}+00$ & $1.100 \mathrm{E}+00$ & 0.4 & 2 \\
\hline 22 & $2 s^{2} 2 p^{3}{ }^{2} P_{3 / 2}-2 s^{2} 2 p^{3}{ }^{2} P_{1 / 2}$ & $\mathrm{E} 2$ & $1.447 \mathrm{E}-03$ & $\ldots$ & $1.700 \mathrm{E}-03$ & $\cdots$ & 18 \\
\hline 22 & $2 s^{1} 2 p^{4}{ }^{4} P_{3 / 2}-2 s^{1} 2 p^{4}{ }^{4} P_{5 / 2}$ & M1 & $3.558 \mathrm{E}+00$ & $3.572 \mathrm{E}+00$ & $3.600 \mathrm{E}+00$ & 0.4 & 1 \\
\hline 22 & $2 s^{1} 2 p^{4}{ }^{4} P_{1 / 2}-2 s^{1} 2 p^{4}{ }^{4} P_{5 / 2}$ & E2 & $5.176 \mathrm{E}-03$ & $\ldots$ & $5.500 \mathrm{E}-03$ & $\cdots$ & 6 \\
\hline 22 & $2 s^{1} 2 p^{4}{ }^{4} P_{1 / 2}-2 s^{1} 2 p^{4}{ }^{4} P_{3 / 2}$ & M1 & $3.246 \mathrm{E}+00$ & $3.259 \mathrm{E}+00$ & $3.260 \mathrm{E}+00$ & 0.4 & 0 \\
\hline 22 & $2 s^{1} 2 p^{4}{ }^{2} D_{3 / 2}-2 s^{1} 2 p^{4}{ }^{4} P_{3 / 2}$ & M1 & $4.358 \mathrm{E}-02$ & $4.318 \mathrm{E}-02$ & $3.700 \mathrm{E}-02$ & -0.9 & -15 \\
\hline 22 & $2 s^{1} 2 p^{4}{ }^{2} D_{3 / 2}-2 s^{1} 2 p^{4}{ }^{4} P_{1 / 2}$ & M1 & $1.188 \mathrm{E}-02$ & $1.178 \mathrm{E}-02$ & $8.700 \mathrm{E}-03$ & -0.9 & -27 \\
\hline 22 & $2 s^{1} 2 p^{4}{ }^{2} D_{5 / 2}-2 s^{1} 2 p^{4}{ }^{4} P_{5 / 2}$ & M1 & $9.246 \mathrm{E}-02$ & $9.180 \mathrm{E}-02$ & $8.800 \mathrm{E}-02$ & -0.7 & -5 \\
\hline 22 & $2 s^{1} 2 p^{4}{ }^{2} D_{5 / 2}-2 s^{1} 2 p^{4}{ }^{4} P_{3 / 2}$ & M1 & $1.341 \mathrm{E}-02$ & $1.336 \mathrm{E}-02$ & $1.300 \mathrm{E}-02$ & -0.4 & -3 \\
\hline 22 & $2 s^{1} 2 p^{4}{ }^{2} D_{5 / 2}-2 s^{1} 2 p^{4}{ }^{2} D_{3 / 2}$ & M1 & $2.345 \mathrm{E}+00$ & $\ldots$ & $2.400 \mathrm{E}+00$ & $\cdots$ & 2 \\
\hline 22 & $2 s^{1} 2 p^{4}{ }^{2} S_{1 / 2}-2 s^{1} 2 p^{4}{ }^{4} P_{3 / 2}$ & M1 & $4.768 \mathrm{E}-02$ & $4.751 \mathrm{E}-02$ & $4.800 \mathrm{E}-02$ & -0.4 & 1 \\
\hline 22 & $2 s^{1} 2 p^{4}{ }^{2} S_{1 / 2}-2 s^{1} 2 p^{4}{ }^{2} D_{5 / 2}$ & E2 & $1.194 \mathrm{E}-02$ & $1.203 \mathrm{E}-02$ & $1.300 \mathrm{E}-02$ & 0.8 & 9 \\
\hline 22 & $2 s^{1} 2 p^{4}{ }^{2} P_{3 / 2}-2 s^{1} 2 p^{4}{ }^{2} D_{3 / 2}$ & M1 & $7.558 \mathrm{E}-02$ & $7.576 \mathrm{E}-02$ & $7.100 \mathrm{E}-02$ & 0.2 & -6 \\
\hline 22 & $2 s^{1} 2 p^{4}{ }^{2} P_{3 / 2}-2 s^{1} 2 p^{4}{ }^{2} D_{5 / 2}$ & M1 & $3.885 \mathrm{E}-02$ & $3.897 \mathrm{E}-02$ & $3.700 \mathrm{E}-02$ & 0.3 & -5 \\
\hline 22 & $2 s^{1} 2 p^{4}{ }^{2} P_{3 / 2}-2 s^{1} 2 p^{4}{ }^{2} S_{1 / 2}$ & M1 & $1.895 \mathrm{E}-01$ & $1.904 \mathrm{E}-01$ & $1.600 \mathrm{E}-01$ & 0.5 & -16 \\
\hline 22 & $2 s^{1} 2 p^{4}{ }^{2} P_{1 / 2}-2 s^{1} 2 p^{4}{ }^{2} D_{3 / 2}$ & M1 & $2.085 \mathrm{E}-02$ & $2.091 \mathrm{E}-02$ & $2.100 \mathrm{E}-02$ & 0.3 & 1 \\
\hline 22 & $2 s^{1} 2 p^{4}{ }^{2} P_{1 / 2}-2 s^{1} 2 p^{4}{ }^{2} D_{5 / 2}$ & $\mathrm{E} 2$ & $1.800 \mathrm{E}-03$ & $1.810 \mathrm{E}-03$ & $1.800 \mathrm{E}-03$ & 0.6 & 0 \\
\hline 22 & $2 s^{1} 2 p^{4}{ }^{2} P_{1 / 2}-2 s^{1} 2 p^{4}{ }^{2} S_{1 / 2}$ & M1 & $3.441 \mathrm{E}-01$ & $3.452 \mathrm{E}-01$ & $2.800 \mathrm{E}-01$ & 0.3 & -19 \\
\hline 22 & $2 s^{1} 2 p^{4}{ }^{2} P_{1 / 2}-2 s^{1} 2 p^{4}{ }^{2} P_{3 / 2}$ & M1 & $1.111 \mathrm{E}+00$ & $1.118 \mathrm{E}+00$ & $1.200 \mathrm{E}+00$ & 0.6 & 8 \\
\hline 22 & $2 p^{5}{ }^{2} P_{1 / 2}-2 p^{5}{ }^{2} P_{3 / 2}$ & M1 & $1.319 \mathrm{E}+00$ & $1.330 \mathrm{E}+00$ & $1.330 \mathrm{E}+00$ & 0.8 & 1 \\
\hline 22 & $2 p^{5}{ }^{2} P_{1 / 2}-2 p^{5}{ }^{2} P_{3 / 2}$ & $\mathrm{E} 2$ & $5.552 \mathrm{E}-03$ & $\ldots$ & $6.200 \mathrm{E}-03$ & $\ldots$ & 12 \\
\hline 23 & $2 s^{2} 2 p^{3}{ }^{2} D_{3 / 2}-2 s^{2} 2 p^{3}{ }^{4} S_{3 / 2}$ & M1 & $2.772 \mathrm{E}-01$ & $2.763 \mathrm{E}-01$ & $3.000 \mathrm{E}-01$ & -0.3 & 8 \\
\hline 23 & $2 s^{2} 2 p^{3}{ }^{2} D_{5 / 2}-2 s^{2} 2 p^{3}{ }^{4} S_{3 / 2}$ & M1 & $1.227 \mathrm{E}-02$ & $1.222 \mathrm{E}-02$ & $1.200 \mathrm{E}-02$ & -0.4 & -2 \\
\hline 23 & $2 s^{2} 2 p^{3}{ }^{2} D_{5 / 2}-2 s^{2} 2 p^{3}{ }^{2} D_{3 / 2}$ & M1 & $1.941 \mathrm{E}+00$ & $1.949 \mathrm{E}+00$ & $1.900 \mathrm{E}+00$ & 0.4 & -2 \\
\hline
\end{tabular}


Table 7

(Continued)

\begin{tabular}{|c|c|c|c|c|c|c|c|}
\hline \multirow[t]{2}{*}{$Z$} & \multirow[t]{2}{*}{ Transition } & \multirow[t]{2}{*}{ Type } & \multicolumn{3}{|c|}{ Line Strengths } & \multicolumn{2}{|c|}{ Difference $(\%)$} \\
\hline & & & MBPT & $\mathrm{MCDHF} / \mathrm{RCI} 2$ & NIST & MBPT and MCDHF/RCI2 & MBPT and NIST \\
\hline 23 & $2 s^{2} 2 p^{3}{ }^{2} D_{5 / 2}-2 s^{2} 2 p^{3}{ }^{2} D_{3 / 2}$ & E2 & $3.084 \mathrm{E}-03$ & $\ldots$ & $3.400 \mathrm{E}-03$ & $\ldots$ & 10 \\
\hline 23 & $2 s^{2} 2 p^{3}{ }^{2} P_{1 / 2}-2 s^{2} 2 p^{3}{ }^{4} S_{3 / 2}$ & M1 & $5.998 \mathrm{E}-02$ & $5.992 \mathrm{E}-02$ & $6.400 \mathrm{E}-02$ & -0.1 & 7 \\
\hline 23 & $2 s^{2} 2 p^{3}{ }^{2} P_{1 / 2}-2 s^{2} 2 p^{3}{ }^{2} D_{3 / 2}$ & M1 & $2.166 \mathrm{E}-01$ & $2.176 \mathrm{E}-01$ & $2.400 \mathrm{E}-01$ & 0.5 & 11 \\
\hline 23 & $2 s^{2} 2 p^{3}{ }^{2} P_{1 / 2}-2 s^{2} 2 p^{3}{ }^{2} D_{3 / 2}$ & $\mathrm{E} 2$ & $6.780 \mathrm{E}-03$ & $6.819 \mathrm{E}-03$ & $6.800 \mathrm{E}-03$ & 0.6 & 0 \\
\hline 23 & $2 s^{2} 2 p^{3}{ }^{2} P_{1 / 2}-2 s^{2} 2 p^{3}{ }^{2} D_{5 / 2}$ & E2 & $5.504 \mathrm{E}-03$ & $\ldots$ & $5.700 \mathrm{E}-03$ & $\cdots$ & 4 \\
\hline 23 & $2 s^{2} 2 p^{3}{ }^{2} P_{3 / 2}-2 s^{2} 2 p^{3}{ }^{4} S_{3 / 2}$ & M1 & $1.172 \mathrm{E}-01$ & $1.175 \mathrm{E}-01$ & $1.200 \mathrm{E}-01$ & 0.2 & 2 \\
\hline 23 & $2 s^{2} 2 p^{3}{ }^{2} P_{3 / 2}-2 s^{2} 2 p^{3}{ }^{2} D_{3 / 2}$ & M1 & $7.358 \mathrm{E}-01$ & $7.374 \mathrm{E}-01$ & $7.800 \mathrm{E}-01$ & 0.2 & 6 \\
\hline 23 & $2 s^{2} 2 p^{3}{ }^{2} P_{3 / 2}-2 s^{2} 2 p^{3}{ }^{2} D_{3 / 2}$ & E2 & $3.127 \mathrm{E}-03$ & $3.140 \mathrm{E}-03$ & $2.900 \mathrm{E}-03$ & 0.4 & -7 \\
\hline 23 & $2 s^{2} 2 p^{3}{ }^{2} P_{3 / 2}-2 s^{2} 2 p^{3}{ }^{2} D_{5 / 2}$ & M1 & $4.352 \mathrm{E}-01$ & $4.371 \mathrm{E}-01$ & $4.900 \mathrm{E}-01$ & 0.5 & 13 \\
\hline 23 & $2 s^{2} 2 p^{3}{ }^{2} P_{3 / 2}-2 s^{2} 2 p^{3}{ }^{2} D_{5 / 2}$ & E2 & $1.495 \mathrm{E}-02$ & $1.504 \mathrm{E}-02$ & $1.500 \mathrm{E}-02$ & 0.6 & 0 \\
\hline 23 & $2 s^{2} 2 p^{3}{ }^{2} P_{3 / 2}-2 s^{2} 2 p^{3}{ }^{2} P_{1 / 2}$ & M1 & $1.048 \mathrm{E}+00$ & $1.052 \mathrm{E}+00$ & $1.030 \mathrm{E}+00$ & 0.4 & -2 \\
\hline 23 & $2 s^{2} 2 p^{3}{ }^{2} P_{3 / 2}-2 s^{2} 2 p^{3}{ }^{2} P_{1 / 2}$ & E2 & $1.349 \mathrm{E}-03$ & $\ldots$ & $1.500 \mathrm{E}-03$ & $\cdots$ & 11 \\
\hline 23 & $2 p^{5}{ }^{2} P_{1 / 2}-2 p^{5}{ }^{2} P_{3 / 2}$ & M1 & $1.320 \mathrm{E}+00$ & $1.329 \mathrm{E}+00$ & $1.360 \mathrm{E}+00$ & 0.7 & 3 \\
\hline 23 & $2 p^{5}{ }^{2} P_{1 / 2}-2 p^{5}{ }^{2} P_{3 / 2}$ & $\mathrm{E} 2$ & $4.500 \mathrm{E}-03$ & $\ldots$ & $5.000 \mathrm{E}-03$ & $\cdots$ & 11 \\
\hline 24 & $2 s^{2} 2 p^{3}{ }^{2} D_{3 / 2}-2 s^{2} 2 p^{3}{ }^{4} S_{3 / 2}$ & M1 & $4.234 \mathrm{E}-01$ & $4.221 \mathrm{E}-01$ & $4.500 \mathrm{E}-01$ & -0.3 & 6 \\
\hline 24 & $2 s^{2} 2 p^{3}{ }^{2} D_{5 / 2}-2 s^{2} 2 p^{3}{ }^{4} S_{3 / 2}$ & M1 & $2.054 \mathrm{E}-02$ & $2.047 \mathrm{E}-02$ & $2.100 \mathrm{E}-02$ & -0.3 & 2 \\
\hline 24 & $2 s^{2} 2 p^{3}{ }^{2} D_{5 / 2}-2 s^{2} 2 p^{3}{ }^{2} D_{3 / 2}$ & M1 & $1.886 \mathrm{E}+00$ & $1.893 \mathrm{E}+00$ & $1.860 \mathrm{E}+00$ & 0.4 & -1 \\
\hline 24 & $2 s^{2} 2 p^{3}{ }^{2} D_{5 / 2}-2 s^{2} 2 p^{3}{ }^{2} D_{3 / 2}$ & E2 & $2.690 \mathrm{E}-03$ & $\ldots$ & $2.800 \mathrm{E}-03$ & $\cdots$ & 4 \\
\hline 24 & $2 s^{2} 2 p^{3}{ }^{2} P_{1 / 2}-2 s^{2} 2 p^{3}{ }^{4} S_{3 / 2}$ & M1 & $7.940 \mathrm{E}-02$ & 7.927E-02 & $8.300 \mathrm{E}-02$ & -0.2 & 5 \\
\hline 24 & $2 s^{2} 2 p^{3}{ }^{2} P_{1 / 2}-2 s^{2} 2 p^{3}{ }^{2} D_{3 / 2}$ & M1 & $2.306 \mathrm{E}-01$ & $2.315 \mathrm{E}-01$ & $2.500 \mathrm{E}-01$ & 0.4 & 8 \\
\hline 24 & $2 s^{2} 2 p^{3}{ }^{2} P_{1 / 2}-2 s^{2} 2 p^{3}{ }^{2} D_{3 / 2}$ & $\mathrm{E} 2$ & $5.401 \mathrm{E}-03$ & $5.430 \mathrm{E}-03$ & $5.300 \mathrm{E}-03$ & 0.5 & -2 \\
\hline 24 & $2 s^{2} 2 p^{3}{ }^{2} P_{1 / 2}-2 s^{2} 2 p^{3}{ }^{2} D_{5 / 2}$ & E2 & $4.516 \mathrm{E}-03$ & $\ldots$ & $4.600 \mathrm{E}-03$ & $\cdots$ & 2 \\
\hline 24 & $2 s^{2} 2 p^{3}{ }^{2} P_{3 / 2}-2 s^{2} 2 p^{3}{ }^{4} S_{3 / 2}$ & M1 & $1.259 \mathrm{E}-01$ & $1.263 \mathrm{E}-01$ & $1.300 \mathrm{E}-01$ & 0.3 & 3 \\
\hline 24 & $2 s^{2} 2 p^{3}{ }^{2} P_{3 / 2}-2 s^{2} 2 p^{3}{ }^{2} D_{3 / 2}$ & M1 & $8.295 \mathrm{E}-01$ & $8.309 \mathrm{E}-01$ & $8.900 \mathrm{E}-01$ & 0.2 & 7 \\
\hline 24 & $2 s^{2} 2 p^{3}{ }^{2} P_{3 / 2}-2 s^{2} 2 p^{3}{ }^{2} D_{3 / 2}$ & $\mathrm{E} 2$ & $2.247 \mathrm{E}-03$ & $2.256 \mathrm{E}-03$ & $2.100 \mathrm{E}-03$ & 0.4 & -7 \\
\hline 24 & $2 s^{2} 2 p^{3}{ }^{2} P_{3 / 2}-2 s^{2} 2 p^{3}{ }^{2} D_{5 / 2}$ & M1 & $4.825 \mathrm{E}-01$ & $4.844 \mathrm{E}-01$ & $5.200 \mathrm{E}-01$ & 0.4 & 8 \\
\hline 24 & $2 s^{2} 2 p^{3}{ }^{2} P_{3 / 2}-2 s^{2} 2 p^{3}{ }^{2} D_{5 / 2}$ & E2 & $1.185 \mathrm{E}-02$ & $1.192 \mathrm{E}-02$ & $1.200 \mathrm{E}-02$ & 0.6 & 1 \\
\hline 24 & $2 s^{2} 2 p^{3}{ }^{2} P_{3 / 2}-2 s^{2} 2 p^{3}{ }^{2} P_{1 / 2}$ & M1 & $1.015 \mathrm{E}+00$ & $1.018 \mathrm{E}+00$ & $1.000 \mathrm{E}+00$ & 0.3 & -1 \\
\hline 24 & $2 p^{5}{ }^{2} P_{1 / 2}-2 p^{5}{ }^{2} P_{3 / 2}$ & M1 & $1.321 \mathrm{E}+00$ & $1.329 \mathrm{E}+00$ & $1.300 \mathrm{E}+00$ & 0.6 & -2 \\
\hline 24 & $2 p^{5}{ }^{2} P_{1 / 2}-2 p^{5}{ }^{2} P_{3 / 2}$ & E2 & $3.685 \mathrm{E}-03$ & $\ldots$ & $4.000 \mathrm{E}-03$ & $\cdots$ & 9 \\
\hline 26 & $2 s^{2} 2 p^{3}{ }^{2} D_{3 / 2}-2 s^{2} 2 p^{3}{ }^{4} S_{3 / 2}$ & M1 & $8.729 \mathrm{E}-01$ & $8.703 \mathrm{E}-01$ & $8.900 \mathrm{E}-01$ & -0.3 & 2 \\
\hline 26 & $2 s^{2} 2 p^{3}{ }^{2} D_{5 / 2}-2 s^{2} 2 p^{3}{ }^{4} S_{3 / 2}$ & M1 & $5.106 \mathrm{E}-02$ & $5.087 \mathrm{E}-02$ & $5.170 \mathrm{E}-02$ & -0.4 & 1 \\
\hline 26 & $2 s^{2} 2 p^{3}{ }^{2} D_{5 / 2}-2 s^{2} 2 p^{3}{ }^{2} D_{3 / 2}$ & M1 & $1.780 \mathrm{E}+00$ & $1.785 \mathrm{E}+00$ & $1.760 \mathrm{E}+00$ & 0.3 & -1 \\
\hline 26 & $2 s^{2} 2 p^{3}{ }^{2} D_{5 / 2}-2 s^{2} 2 p^{3}{ }^{2} D_{3 / 2}$ & $\mathrm{E} 2$ & $1.909 \mathrm{E}-03$ & $\ldots$ & $1.900 \mathrm{E}-03$ & $\cdots$ & 0 \\
\hline 26 & $2 s^{2} 2 p^{3}{ }^{2} P_{1 / 2}-2 s^{2} 2 p^{3}{ }^{4} S_{3 / 2}$ & M1 & $1.316 \mathrm{E}-01$ & $1.314 \mathrm{E}-01$ & $1.400 \mathrm{E}-01$ & -0.1 & 6 \\
\hline 26 & $2 s^{2} 2 p^{3}{ }^{2} P_{1 / 2}-2 s^{2} 2 p^{3}{ }^{2} D_{3 / 2}$ & M1 & $2.373 \mathrm{E}-01$ & $2.383 \mathrm{E}-01$ & $2.512 \mathrm{E}-01$ & 0.4 & 6 \\
\hline 26 & $2 s^{2} 2 p^{3}{ }^{2} P_{1 / 2}-2 s^{2} 2 p^{3}{ }^{2} D_{3 / 2}$ & E2 & $3.518 \mathrm{E}-03$ & $3.535 \mathrm{E}-03$ & $3.500 \mathrm{E}-03$ & 0.5 & -1 \\
\hline 26 & $2 s^{2} 2 p^{3}{ }^{2} P_{1 / 2}-2 s^{2} 2 p^{3}{ }^{2} D_{5 / 2}$ & E2 & $3.125 \mathrm{E}-03$ & $\ldots$ & $3.200 \mathrm{E}-03$ & $\cdots$ & 2 \\
\hline 26 & $2 s^{2} 2 p^{3}{ }^{2} P_{3 / 2}-2 s^{2} 2 p^{3}{ }^{4} S_{3 / 2}$ & M1 & $1.273 \mathrm{E}-01$ & $1.279 \mathrm{E}-01$ & $1.280 \mathrm{E}-01$ & 0.5 & 1 \\
\hline 26 & $2 s^{2} 2 p^{3}{ }^{2} P_{3 / 2}-2 s^{2} 2 p^{3}{ }^{2} D_{3 / 2}$ & M1 & $1.020 \mathrm{E}+00$ & $1.021 \mathrm{E}+00$ & $1.060 \mathrm{E}+00$ & 0.1 & 4 \\
\hline 26 & $2 s^{2} 2 p^{3}{ }^{2} P_{3 / 2}-2 s^{2} 2 p^{3}{ }^{2} D_{5 / 2}$ & M1 & $5.600 \mathrm{E}-01$ & $5.618 \mathrm{E}-01$ & $5.900 \mathrm{E}-01$ & 0.3 & 5 \\
\hline 26 & $2 s^{2} 2 p^{3}{ }^{2} P_{3 / 2}-2 s^{2} 2 p^{3}{ }^{2} D_{5 / 2}$ & E2 & $7.691 \mathrm{E}-03$ & $7.730 \mathrm{E}-03$ & $7.700 \mathrm{E}-03$ & 0.5 & 0 \\
\hline 26 & $2 s^{2} 2 p^{3}{ }^{2} P_{3 / 2}-2 s^{2} 2 p^{3}{ }^{2} P_{1 / 2}$ & M1 & $9.556 \mathrm{E}-01$ & $9.583 \mathrm{E}-01$ & $9.457 \mathrm{E}-01$ & 0.3 & -1 \\
\hline 26 & $2 p^{5}{ }^{2} P_{1 / 2}-2 p^{5}{ }^{2} P_{3 / 2}$ & M1 & $1.321 \mathrm{E}+00$ & $1.328 \mathrm{E}+00$ & $1.330 \mathrm{E}+00$ & 0.6 & 1 \\
\hline 26 & $2 p^{5}{ }^{2} P_{1 / 2}-2 p^{5}{ }^{2} P_{3 / 2}$ & $\mathrm{E} 2$ & $2.538 \mathrm{E}-03$ & $2.555 \mathrm{E}-03$ & $2.700 \mathrm{E}-03$ & 0.7 & 6 \\
\hline 27 & $2 s^{2} 2 p^{3}{ }^{2} D_{3 / 2}-2 s^{2} 2 p^{3}{ }^{4} S_{3 / 2}$ & M1 & $1.174 \mathrm{E}+00$ & $1.171 \mathrm{E}+00$ & $1.200 \mathrm{E}+00$ & -0.3 & 2 \\
\hline 27 & $2 s^{2} 2 p^{3}{ }^{2} D_{5 / 2}-2 s^{2} 2 p^{3}{ }^{4} S_{3 / 2}$ & M1 & $7.538 \mathrm{E}-02$ & $7.513 \mathrm{E}-02$ & $7.600 \mathrm{E}-02$ & -0.3 & 1 \\
\hline 27 & $2 s^{2} 2 p^{3}{ }^{2} D_{5 / 2}-2 s^{2} 2 p^{3}{ }^{2} D_{3 / 2}$ & M1 & $1.725 \mathrm{E}+00$ & $1.731 \mathrm{E}+00$ & $1.700 \mathrm{E}+00$ & 0.3 & -1 \\
\hline 27 & $2 s^{2} 2 p^{3}{ }^{2} D_{5 / 2}-2 s^{2} 2 p^{3}{ }^{2} D_{3 / 2}$ & $\mathrm{E} 2$ & $1.555 \mathrm{E}-03$ & $\ldots$ & $1.700 \mathrm{E}-03$ & $\ldots$ & 9 \\
\hline 27 & $2 s^{2} 2 p^{3}{ }^{2} P_{1 / 2}-2 s^{2} 2 p^{3}{ }^{4} S_{3 / 2}$ & M1 & $1.643 \mathrm{E}-01$ & $1.641 \mathrm{E}-01$ & $1.700 \mathrm{E}-01$ & -0.1 & 3 \\
\hline 27 & $2 s^{2} 2 p^{3}{ }^{2} P_{1 / 2}-2 s^{2} 2 p^{3}{ }^{2} D_{3 / 2}$ & M1 & $2.300 \mathrm{E}-01$ & $2.310 \mathrm{E}-01$ & $2.400 \mathrm{E}-01$ & 0.4 & 4 \\
\hline 27 & $2 s^{2} 2 p^{3}{ }^{2} P_{1 / 2}-2 s^{2} 2 p^{3}{ }^{2} D_{3 / 2}$ & E2 & $2.868 \mathrm{E}-03$ & $2.881 \mathrm{E}-03$ & $2.900 \mathrm{E}-03$ & 0.4 & 1 \\
\hline 27 & $2 s^{2} 2 p^{3}{ }^{2} P_{1 / 2}-2 s^{2} 2 p^{3}{ }^{2} D_{5 / 2}$ & $\mathrm{E} 2$ & $2.631 \mathrm{E}-03$ & $\ldots$ & $2.700 \mathrm{E}-03$ & $\cdots$ & 3 \\
\hline 27 & $2 s^{2} 2 p^{3}{ }^{2} P_{3 / 2}-2 s^{2} 2 p^{3}{ }^{4} S_{3 / 2}$ & M1 & $1.196 \mathrm{E}-01$ & $1.202 \mathrm{E}-01$ & $1.200 \mathrm{E}-01$ & 0.5 & 0 \\
\hline 27 & $2 s^{2} 2 p^{3}{ }^{2} P_{3 / 2}-2 s^{2} 2 p^{3}{ }^{2} D_{3 / 2}$ & M1 & $1.117 \mathrm{E}+00$ & $1.118 \mathrm{E}+00$ & $1.200 \mathrm{E}+00$ & 0.1 & 7 \\
\hline
\end{tabular}


Table 7

(Continued)

\begin{tabular}{|c|c|c|c|c|c|c|c|}
\hline \multirow[t]{2}{*}{$Z$} & \multirow[t]{2}{*}{ Transition } & \multirow[t]{2}{*}{ Type } & \multicolumn{3}{|c|}{ Line Strengths } & \multicolumn{2}{|c|}{ Difference $(\%)$} \\
\hline & & & MBPT & MCDHF/RCI2 & NIST & MBPT and MCDHF/RCI2 & MBPT and NIST \\
\hline 27 & $2 s^{2} 2 p^{3}{ }^{2} P_{3 / 2}-2 s^{2} 2 p^{3}{ }^{2} D_{5 / 2}$ & M1 & $5.903 \mathrm{E}-01$ & $5.922 \mathrm{E}-01$ & $6.300 \mathrm{E}-01$ & 0.3 & 7 \\
\hline 27 & $2 s^{2} 2 p^{3}{ }^{2} P_{3 / 2}-2 s^{2} 2 p^{3}{ }^{2} D_{5 / 2}$ & E2 & $6.287 \mathrm{E}-03$ & $6.315 \mathrm{E}-03$ & $6.200 \mathrm{E}-03$ & 0.4 & -1 \\
\hline 27 & $2 s^{2} 2 p^{3}{ }^{2} P_{3 / 2}-2 s^{2} 2 p^{3}{ }^{2} P_{1 / 2}$ & M1 & $9.300 \mathrm{E}-01$ & $9.327 \mathrm{E}-01$ & $9.100 \mathrm{E}-01$ & 0.3 & -2 \\
\hline 27 & $2 p^{5}{ }^{2} P_{1 / 2}-2 p^{5}{ }^{2} P_{3 / 2}$ & M1 & $1.321 \mathrm{E}+00$ & $1.328 \mathrm{E}+00$ & $1.330 \mathrm{E}+00$ & 0.5 & 1 \\
\hline 27 & $2 p^{5}{ }^{2} P_{1 / 2}-2 p^{5}{ }^{2} P_{3 / 2}$ & E2 & $2.132 \mathrm{E}-03$ & $2.145 \mathrm{E}-03$ & $2.300 \mathrm{E}-03$ & 0.6 & 8 \\
\hline 28 & $2 s^{2} 2 p^{3}{ }^{2} D_{3 / 2}-2 s^{2} 2 p^{3}{ }^{4} S_{3 / 2}$ & M1 & $1.508 \mathrm{E}+00$ & $1.505 \mathrm{E}+00$ & $1.600 \mathrm{E}+00$ & -0.2 & 6 \\
\hline 28 & $2 s^{2} 2 p^{3}{ }^{2} D_{5 / 2}-2 s^{2} 2 p^{3}{ }^{4} S_{3 / 2}$ & M1 & $1.063 \mathrm{E}-01$ & $1.060 \mathrm{E}-01$ & $1.100 \mathrm{E}-01$ & -0.3 & 3 \\
\hline 28 & $2 s^{2} 2 p^{3}{ }^{2} D_{5 / 2}-2 s^{2} 2 p^{3}{ }^{2} D_{3 / 2}$ & M1 & $1.670 \mathrm{E}+00$ & $1.675 \mathrm{E}+00$ & $1.660 \mathrm{E}+00$ & 0.3 & -1 \\
\hline 28 & $2 s^{2} 2 p^{3}{ }^{2} P_{1 / 2}-2 s^{2} 2 p^{3}{ }^{4} S_{3 / 2}$ & M1 & $2.005 \mathrm{E}-01$ & $2.003 \mathrm{E}-01$ & $2.100 \mathrm{E}-01$ & -0.1 & 5 \\
\hline 28 & $2 s^{2} 2 p^{3}{ }^{2} P_{1 / 2}-2 s^{2} 2 p^{3}{ }^{2} D_{3 / 2}$ & M1 & $2.166 \mathrm{E}-01$ & $2.177 \mathrm{E}-01$ & $2.186 \mathrm{E}-01$ & 0.5 & 1 \\
\hline 28 & $2 s^{2} 2 p^{3}{ }^{2} P_{1 / 2}-2 s^{2} 2 p^{3}{ }^{2} D_{3 / 2}$ & E2 & $2.350 \mathrm{E}-03$ & $2.360 \mathrm{E}-03$ & $2.400 \mathrm{E}-03$ & 0.4 & 2 \\
\hline 28 & $2 s^{2} 2 p^{3}{ }^{2} P_{1 / 2}-2 s^{2} 2 p^{3}{ }^{2} D_{5 / 2}$ & E2 & $2.231 \mathrm{E}-03$ & $\ldots$ & $2.200 \mathrm{E}-03$ & $\cdots$ & -1 \\
\hline 28 & $2 s^{2} 2 p^{3}{ }^{2} P_{3 / 2}-2 s^{2} 2 p^{3}{ }^{4} S_{3 / 2}$ & M1 & $1.074 \mathrm{E}-01$ & $1.080 \mathrm{E}-01$ & $1.100 \mathrm{E}-01$ & 0.6 & 2 \\
\hline 28 & $2 s^{2} 2 p^{3}{ }^{2} P_{3 / 2}-2 s^{2} 2 p^{3}{ }^{2} D_{3 / 2}$ & M1 & $1.215 \mathrm{E}+00$ & $1.216 \mathrm{E}+00$ & $1.200 \mathrm{E}+00$ & 0.1 & -1 \\
\hline 28 & $2 s^{2} 2 p^{3}{ }^{2} P_{3 / 2}-2 s^{2} 2 p^{3}{ }^{2} D_{5 / 2}$ & M1 & $6.155 \mathrm{E}-01$ & $6.174 \mathrm{E}-01$ & $6.400 \mathrm{E}-01$ & 0.3 & 4 \\
\hline 28 & $2 s^{2} 2 p^{3}{ }^{2} P_{3 / 2}-2 s^{2} 2 p^{3}{ }^{2} D_{5 / 2}$ & E2 & $5.186 \mathrm{E}-03$ & $5.209 \mathrm{E}-03$ & $5.200 \mathrm{E}-03$ & 0.5 & 0 \\
\hline 28 & $2 s^{2} 2 p^{3}{ }^{2} P_{3 / 2}-2 s^{2} 2 p^{3}{ }^{2} P_{1 / 2}$ & M1 & $9.069 \mathrm{E}-01$ & $9.092 \mathrm{E}-01$ & $9.120 \mathrm{E}-01$ & 0.3 & 1 \\
\hline 28 & $2 p^{5}{ }^{2} P_{1 / 2}-2 p^{5}{ }^{2} P_{3 / 2}$ & M1 & $1.321 \mathrm{E}+00$ & $1.327 \mathrm{E}+00$ & $1.300 \mathrm{E}+00$ & 0.5 & -2 \\
\hline 28 & $2 p^{5}{ }^{2} P_{1 / 2}-2 p^{5}{ }^{2} P_{3 / 2}$ & E2 & $1.804 \mathrm{E}-03$ & $1.814 \mathrm{E}-03$ & $1.900 \mathrm{E}-03$ & 0.5 & 5 \\
\hline
\end{tabular}

Figure 5 the MCDHF/RCI $S$ values are plotted against the MBPT results for 2307 strong transitions $\left(S\right.$ values $\left.\geqslant 10^{-2}\right)$ in Fexx. For $83 \%$ of these strong transitions, our MBPT and MCDHF/RCI $S$ values agree to within 5\%, while they differ from each other by over $20 \%$ (but no more than a factor of 3.5) for 67 transitions. Many of these transitions are intercombination E1 transitions, for which cancellation effects often decrease the accuracy considerably. Nevertheless, except for those 67 transitions, the average difference (with standard deviation) between our MBPT and MCDHF/RCI $S$ values for the remaining 2240 strong transitions is only $2 \% \pm 4 \%$.

The NIST ASD lists the $S$ values for the total 129 M1 and E2 transitions in the 13 ions considered here, which are all within the $n=2$ states. The NIST values for these 129 transitions are compared with the MBPT results in Table 7 . The MCDHF/RCI2 results are also collected in Table 7 for comparison. The deviations of the NIST $S$ values relative to the present MBPT results are less than $10 \%$ for 109 transitions, and are between $10 \%$ and $30 \%$ for 20 transitions. The largest discrepancy is about $27 \%$ for the $2 s 2 p^{4}{ }^{2} D_{3 / 2} \rightarrow{ }^{4} P_{1 / 2}$ transition in TixvI. The MBPT and MCDHF/RCI2 values agree well $(1 \%)$ for this transition. The MCDHF/RCI2 calculations reported the $S$ values for 107 out of 129 transitions. The MBPT and MCDHF/RCI2 values agree within $2 \%$ for all the transitions. The MBPT and MCDHF/RCI2 calculations are also more accurate and reliable than the NIST values for the M1 and E2 transitions.

\section{SUMMARY}

Using the combined RCI and MBPT approach, we have performed systematic calculations of the energies and radiative transition properties for highly charged N-like ions from Ar XII to $\mathrm{Zn}$ xxiv. A complete and consistent data set of energies, wavelengths, line strengths, oscillator strengths, and transition rates for all possible E1, M1, E2, and M2 transitions among the 359 levels of the $2 s^{2} 2 p^{3}, 2 s 2 p^{4}, 2 p^{5}, 2 s^{2} 2 p^{2} 3 l, 2 s 2 p^{3} 3 l, 2 p^{4} 3 l$, and $2 s^{2} 2 p^{2} 4 l$ configurations, is provided for all 13 ions. By comparing with available observations, the present MCDHF/ RCI values, and other elaborate/systematic theoretical calculations, a high accuracy for the present MBPT results is achieved, i.e., the accuracy of level energies is assessed to be within $0.1 \%$ for most states, and is less than $0.2 \%$ for all states; the accuracy of the line strengths is estimated to be better than 5\% for most transitions among the $n=2$ states, and for a majority of strong transitions in Fe Xx. In view of the fact that our calculations are systematic and consistent, which means the unified treatment thus unified quality of data, we anticipated that the accuracy of the line strengths is within 5\% for a majority of transitions involving the $n \geqslant 3$ levels, especially for the strong transitions. We consider that the observation uncertainty should be large for the $n \geqslant 3$ states included in Table 4, and precise experimental investigations are expected. The elaborate calculations involving higher excited states, especially for the $n=4$ states, are also expected to further assess the accuracy of the existing experimental and theoretical data.

Since more sufficient correlation effects have been taken into account by considering more configurations in both the $N$ and $M$ spaces, the present MBPT energies reveal an improvement in accuracy compared with the elaborate systematic calculations, such as the MCDHF/RCI work (Rynkun et al. 2014) and the MBPT results (Gu 2005a). The present MBPT calculations agree well with the MCDHF/RCI results of Radžiūte et al. (2015), i.e., the mean energy deviation for Fe XXI is $0.015 \%$. Meanwhile, the present calculations have significantly increased the accurate data for nitrogen-like ions in quantity, and may be considered as the benchmark for other calculations. The accuracy of the energy data is high enough to enable the identification and interpretation of observed spectra involving the $n=3,4$ levels, for which the experimental values are largely missing. We expect that the present data sets of high accuracy will be useful for the identification and interpretation 
of observed spectra, and for modeling and diagnosing astrophysical and fusion plasmas.

The authors express our gratitude to Dr. MingFeng $\mathrm{Gu}$ for offering guidance in using his FAC code. We acknowledge support from the National Natural Science Foundation of China (grant No. 21503066, No. 11504421, No. 11105015, No. 11205019, No. 11371218, No. 11274001, and No. 11474034) and the support from the Foundation for the Development of Science and Technology of the Chinese Academy of Engineering Physics (grant No. 2012B0102012). This work is also supported by the NSAF under grant No. 11076009, the Chinese Association of Atomic and Molecular Data, the Chinese National Fusion Project for ITER No. 2015GB117000, and the Swedish research council. One of the authors (K.W.) expresses his gratitude to the support from the visiting researcher program at the Fudan University.

\section{REFERENCES}

Acton, L. W., Bruner, M. E., Brown, W. A., et al. 1985, ApJ, 291, 865 Badnell, N. R. 1986, JPhB, 19, 3827

Becker, S. R., Butler, K., \& Zeippen, C. J. 1989, A\&A, 221, 375

Behar, E., Cottam, J., \& Kahn, S. M. 2001, ApJ, 548, 966

Beiersdorfer, P., Träbert, E., Lepson, J. K., Brickhouse, N. S., \& Golub, L. 2014, ApJ, 788, 25

Bhatia, A. K., Seely, J. F., \& Feldman, U. 1989, ADNDT, 43, 99

Brinkman, A. C., Gunsing, C. J. T., Kaastra, J. S., et al. 2000, ApJL, 530, L111

Bromage, G. E., \& Fawcett, B. C. 1977, MNRAS, 179, 683

Brosius, J. W., Davila, J. M., \& Thomas, R. J. 1998, ApJS, 119, 255

Brown, C. M., Feldman, U., Seely, J. F., Korendyke, C. M., \& Hara, H. 2008, ApJS, 176, 511

Brown, G. V., Beiersdorfer, P., Liedahl, D. A., et al. 2002, ApJS, 140, 589

Chen, H., Gu, M. F., Behar, E., et al. 2007, ApJS, 168, 319

Cheng, K., Kim, Y. K., \& Desclaux, J. 1979, ADNDT, 24, 111

Curdt, W., Brekke, P., Feldman, U., et al. 2001, A\&A, 375, 591

Curdt, W., Landi, E., \& Feldman, U. 2004, A\&A, 427, 1045

Del Zanna, G. 2008, A\&A, 481, L69

Del Zanna, G. 2012, A\&A, 537, A38

Del Zanna, G., \& Andretta, V. 2011, A\&A, 528, A139

Del Zanna, G., \& Woods, T. N. 2013, A\&A, 555, A59

Dere, K. P., Landi, E., Mason, H. E., Monsignori Fossi, B. C., \& Young, P. R. 1997, A\&AS, 125, 149

Dong, F., Wang, F., Zhong, J., Liang, G., \& Zhao, G. 2012, PASJ, 64, 131

Doschek, G. A., \& Cowan, R. D. 1984, ApJS, 56, 67

Doschek, G. A., Feldman, U., \& Cowan, R. D. 1981, ApJ, 245, 315

Doyle, J. G. 1987, A\&A, 173, 408

Dyall, K., Grant, I., Johnson, C., Parpia, F., \& Plummer, E. 1989, CoPhC, 55, 425

Eidelsberg, M., Crifo-Magnant, F., \& Zeippen, C. J. 1981, A\&AS, 43, 455

Eissner, W., Jones, M., \& Nussbaumer, H. 1974, CoPhC, 8, 270

Eissner, W., Landi, E., \& Bhatia, A. K. 2005, ADNDT, 89, 139

Fawcett, B. C., \& Hayes, R. W. 1975, MNRAS, 170, 185

Fawcett, B. C., Phillips, K. J. H., Jordan, C., \& Lemen, J. R. 1987, MNRAS, 225,1013

Feldman, U., Behring, W. E., Curdt, W., et al. 1997, ApJS, 113, 195

Feldman, U., Curdt, W., Landi, E., \& Wilhelm, K. 2000, ApJ, 544, 508

Feldman, U., Doschek, G. A., \& Kreplin, R. W. 1980, ApJ, 238, 365

Feldman, U., Landi, E., \& Curdt, W. 2004, ApJ, 607, 1039

Gaigalas, G., Zalandauskas, T., \& Fritzsche, S. 2004, CoPhC, 157, 239

Godefroid, M., \& Fischer, C. F. 1984, JPhB, 17, 681

Gu, M. F. 2003, ApJ, 582, 1241

Gu, M. F. 2005a, ADNDT, 89, 267
Gu, M. F. 2005b, ApJS, 156, 105

Gu, M. F. 2008, CaJPh, 86, 675

Gu, M. F., Beiersdorfer, P., Brown, G. V., et al. 2007, ApJ, 657, 1172

Gu, M. F., Holczer, T., Behar, E., \& Kahn, S. M. 2006, ApJ, 641, 1227

Ishibashi, K., Dewey, D., Huenemoerder, D. P., \& Testa, P. 2006, ApJL, 644, L117

Jonauskas, V., Bogdanovich, P., Keenan, F. P., et al. 2005, A\&A, 433, 745

Jönsson, P., Gaigalas, G., Bieroń, J., Fischer, C. F., \& Grant, I. P. 2013, $\mathrm{CoPhC}, 184,2197$

Jönsson, P., He, X., Fischer, C. F., \& Grant, I. 2007, CoPhC, 177, 597

Kaastra, J. S., Steenbrugge, K. C., Raassen, A. J. J., et al. 2002, A\&A, 386, 427

Kallman, T. R., \& Palmeri, P. 2007, RvMP, 79, 79

Ko, Y. K., Raymond, J. C., Li, J., et al. 2002, ApJ, 578, 979

Kramida, A., Ralchenko, Yu., Reader, J. \& NIST ASD Team 2014, NIST Atomic Spectra Database (ver. 5.2), [Online] Available: http:// physicsnistgov/asd National Institute of Standards and Technology, Gaithersburg, MD

Landi, E., \& Bhatia, A. K. 2005, ADNDT, 90, 177

Landi, E., Feldman, U., \& Dere, K. P. 2002, ApJS, 139, 281

Landi, E., \& Phillips, K. J. H. 2005, ApJS, 160, 286

Landi, E., \& Phillips, K. J. H. 2006, ApJS, 166, 421

Landi, E., Young, P. R., Dere, K. P., Del Zanna, G., \& Mason, H. E. 2013, ApJ, 763, 86

Lawson, K. D., \& Peacock, N. J. 1984, A\&AS, 58, 475

Lepson, J. K., Beiersdorfer, P., Behar, E., \& Kahn, S. M. 2003, ApJ, 590, 604

Lindgren, I. 1974, JPhB, 7, 2441

Lippmann, S., Finkenthal, M., Huang, L. K., et al. 1987, ApJ, 316, 819

Massacrier, G., \& Artru, M. C. 2012, A\&A, 538, A52

McKenzie, B. J., Grant, I. P., \& Norrington, P. H. 1980a, CoPhC, 21, 233

McKenzie, D. L., Landecker, P. B., Broussard, R. M., et al. 1980b, ApJ, 241, 409

Merkelis, G., Martinson, I., Kisielius, R., \& Vilkas, M. J. 1999, PhyS, 59,122

Merkelis, G., Vilkas, M. J., Kisielius, R., Gaigalas, G., \& Martinson, I. 1997, PhyS, 56, 41

Mewe, R., Raassen, A. J. J., Drake, J. J., et al. 2001, A\&A, 368, 888

Mohan, A., Landi, E., \& Dwivedi, B. N. 2003, ApJ, 582, 1162

Nahar, S. N. 2004, A\&A, 413, 779

Nave, G., Nahar, S., \& Zhao, G. 2015, arXiv:1510.08591

Ness, J.-U., Brickhouse, N. S., Drake, J. J., \& Huenemoerder, D. P. 2003, ApJ, 598, 1277

Parenti, S., Vial, J.-C., \& Lemaire, P. 2005, A\&A, 443, 679

Phillips, K. J. H., Fawcett, B. C., Kent, B. J., et al. 1982, ApJ, 256, 774

Phillips, K. J. H., Lemen, J. R., Cowan, R. D., Doschek, G. A., \& Leibacher, J. W. 1983, ApJ, 265, 1120

Raassen, A. J. J., Mewe, R., Audard, M., et al. 2002, A\&A, 389, 228

Radžiūtė, L., Ekman, J., Jönsson, P., \& Gaigalas, G. 2015, A\&A, 582, A61

Rynkun, P., Jönsson, P., Gaigalas, G., \& Froese Fischer, C. 2014, ADNDT, 100,315

Safronova, M. S., Johnson, W. R., \& Safronova, U. I. 1996, PhRvA, 53, 4036

Seely, J. F., Feldman, U., \& Safronova, U. I. 1986, ApJ, 304, 838

Shestov, S. V., Bozhenkov, S. A., Zhitnik, I. A., et al. 2008, ApL, 34, 33

Si, R., Guo, X., Yan, J., et al. 2015a, JQSRT, 163, 7

Si, R., Guo, X. L., Yan, J., et al. 2015b, JPhB, 48, 175004

Sugar, J., \& Corliss, C. 1985, JPCRD, 14, 1

Tachiev, G. I., \& Froese Fischer, C. 2002, A\&A, 385, 716

Träbert, E., Beiersdorfer, P., Brickhouse, N. S., \& Golub, L. 2014a, ApJS, 215, 6

Träbert, E., Beiersdorfer, P., Brickhouse, N. S., \& Golub, L. 2014b, ApJS, 211, 14

Vilkas, M. J., Ishikawa, Y., \& Koc, K. 1999, PhRvA, 60, 2808

Wang, K., Guo, X. L., Liu, H. T., et al. 2015, ApJS, 218, 16

Wang, K., Li, D. F., Liu, H. T., et al. 2014, ApJS, 215, 26

Warren, H. P., Feldman, U., \& Brown, C. M. 2008, ApJ, 685, 1277

Witthoeft, M. C., Del Zanna, G., \& Badnell, N. R. 2007, A\&A, 466, 763 